\title{
THE TOTAL SYNTHESIS OF GIBBERELLIC ACID:
}

\section{THE HYDROFLUORENE ROUTE}

\author{
A THESIS \\ PRESENTED FOR THE DEGREE OF \\ DOCTOR OF PHILOSOPHY
}

in the

AUSTRALIAN NATIONAL UNIVERSITY

by

RUDOLF URECH

Research School of Chemistry

CANBERRA, A.C.T. 


\section{CONTENTS}

DECLARATION

Page

ACKNOWLEDGEMENTS

SUMMARY

INTRODUCTION

RESULTS AND DISCUSSION

CHAPTER 1 Preparation of hydrofluorenone 103

CHAPTER 2 Preparation of hydrophenanthrenones

$\underline{106 / 124}$ and tetracyclic 139

CHAPTER 3

3.1 Preliminary considerations

3.2 The total synthesis of gibberellic acid

3. 3 Addendum

EXPERIMENTAL

General Topics

General Procedures

Notes on Nomenclature

CHAPTER 1

CHAPTER 2

CHAPTER 3

REFERENCES 
(i)

\section{DECLARATION}

This thesis contains no material previously submitted for a degree in any other University, and to the best of my knowledge and belief, contains no material previously published or written by another person, except where due reference is made in the text.

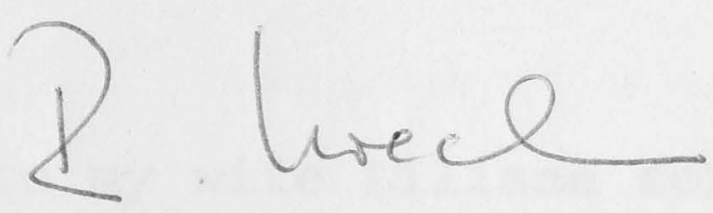

Rudolf Urech 


\section{ACKNOWLEDGEMENTS}

I would like to thank Dr. L.N. Mander for his stimulating advice and guidance during his supervision of this work.

I am also grateful to Ailsa L. Cossey for technical assistance, to my colleagues Drs. Luigi Lombardo, Graeme Potter, John V. Turner and Michael Woolias for their help in the preparation of the manuscript, and to Mrs. J.A. Mahon for typing this thesis.

The award of an Australian National University Ph.D. Scholarship is gratefully acknowledged.

Special thanks are due to my wife Liliane for drawing the chemical structures and her invaluable support throughout the course of this work. 


\section{SUMMARY}

In this thesis a total synthesis of gibberellic acid via an $\mathrm{ABC}+\mathrm{D}$ approach is described.

In Chapter 1, an efficient preparation of hydrofluorenone 103 is presented. Lithium-ammonia reduction of 2,5-dimethoxybenzojc acid produces the dianion 75 which is alkylated with benzyl bromide 90 to give acid 102 . Cyclisation of 102 leads to the intermediate 103 , suitably functionalised for elaboration into a gibberellin structure.

Chapter 2 contains a description of an equally short synthesis of the similarly substituted hydrophenanthrenones $106 / 124$. This synthesis also proceeds through a reductive alkylation/cyclisation procedure. Attachment of the D-ring to $106 / 124$ and subsequent reductive methylation of the aromatic pro-A-ring gives the tetracyclic 139, another potential intermediate in a gibberellin synthesis.

Chapter 3 describes the total synthesis of gibberellic acid 2 from the hydrofluorenones $\underline{71 / 145}$. These compounds are initially converted into the gibbane 161 into which the B-ring carboxyl group is then introduced. Subsequent hydrogenation establishes the correct stereochemistry in the C/D-portion of the gibberellin precursor 165. Finally, elaboration of benzenoid A-ring, including reductive methylation and bromo lactonisation, gives the norgibberellin 194 and thereby gibberellic acid. 
INTRODUCTION 
Gibberellins are a group of tetracyclic diterpenoids which, like auxins and cytokinins, form a class of important plant growth hormones. ${ }^{1,2}$ The primary role of gibberellins is still obscure ${ }^{3}$ but their profound effects, in stimulating cell elongation and cell division for example, have long been recognised. ${ }^{1}$ Thus, they have been exploited in agriculture to increase the size of seedless grapes, to stimulate the growth of sugarcane, to offset frost damage, and to break dormancy periods. ${ }^{1,3}$ For these purposes, the most widely used gibberellin is gibberellic acid, GA, which is produced industrially by fermentation using the fungus Gibberezla fujikuroi.

More than fifty gibberellins have so far been isolated from both green plants and fungi. 2,4 Their structures are based on the diterpenoid ent-gibberellane skeleton 1,5
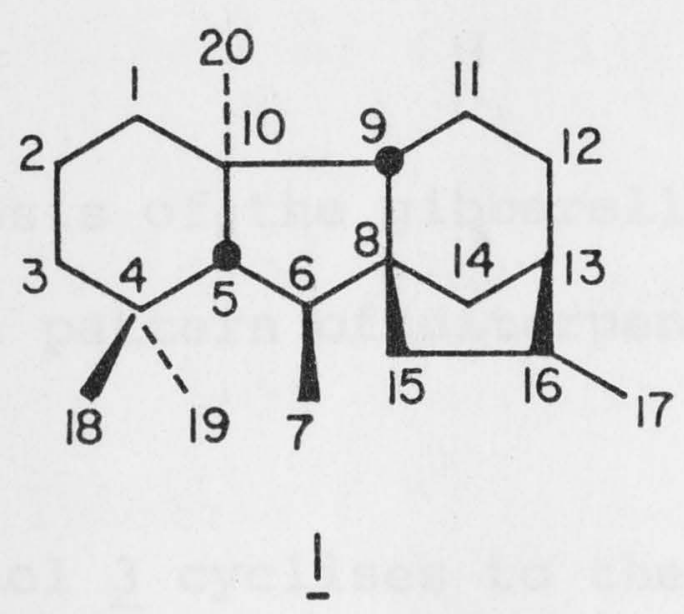

and are further divided into $C_{20}$ and $C_{19}$ gibberellins. The exciting exploration of the gibberellin chemistry started about eighty years ago in Japan, when the disease "baka-nae" attracted the attention of scientists. ${ }^{6}$ This disease caused rice seedlings to grow too quickly, to dwindle, and subsequently to die. An active cell-free 
extract was obtained in $1926^{7}$ from Gibberelza fujikuroi, the fungus which had infected the rice plants. Twelve years later a crystalline substance, named gibberellin A, was isolated, ${ }^{8}$ which in 1955 was shown to consist of three components: gibberellin $\mathrm{A}_{1}, \mathrm{~A}_{2}$ and $\mathrm{A}_{3} \cdot{ }^{9}$ Cross and coworkers determined the planar structure of $\mathrm{GA}_{3}$ in 1959,10 but placed the hydrogen at $\mathrm{C} 9$ incorrectly on the $\alpha$-face. The absolute structure of $\mathrm{GA}_{3} \underline{2}$ was finally established less than twenty years ago by $x$-ray diffraction and circulardichroism studies. 11,12

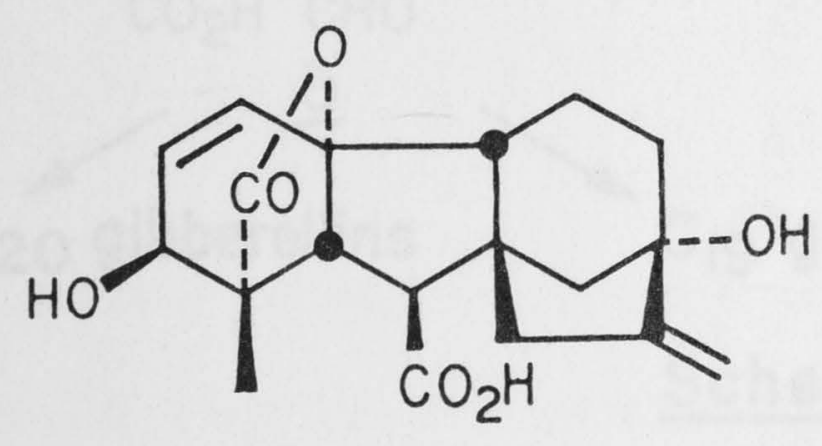

2

\section{$\mathrm{GA}_{3}$, gibberellic acid}

The biosynthesis of the gibberellins was shown to follow the general pattern of diterpenoid synthesis (Scheme 1).13

Geranylgeraniol 3 cyclises to the kaurene $\underline{4}^{14}$ which then undergoes oxidation at the cl9-methyl group to the acid and at $\mathrm{C} 7$ to the $\beta$-alcohol, with subsequent rearrangement to the gibberellane skeleton $\underline{5}^{15}$ the immediate precursor of the $\mathrm{C}_{20}$ gibberellins. Loss of $\mathrm{C} 20$ as carbon dioxide leads to the $\mathrm{C}_{19}$ gibberellins. 16 

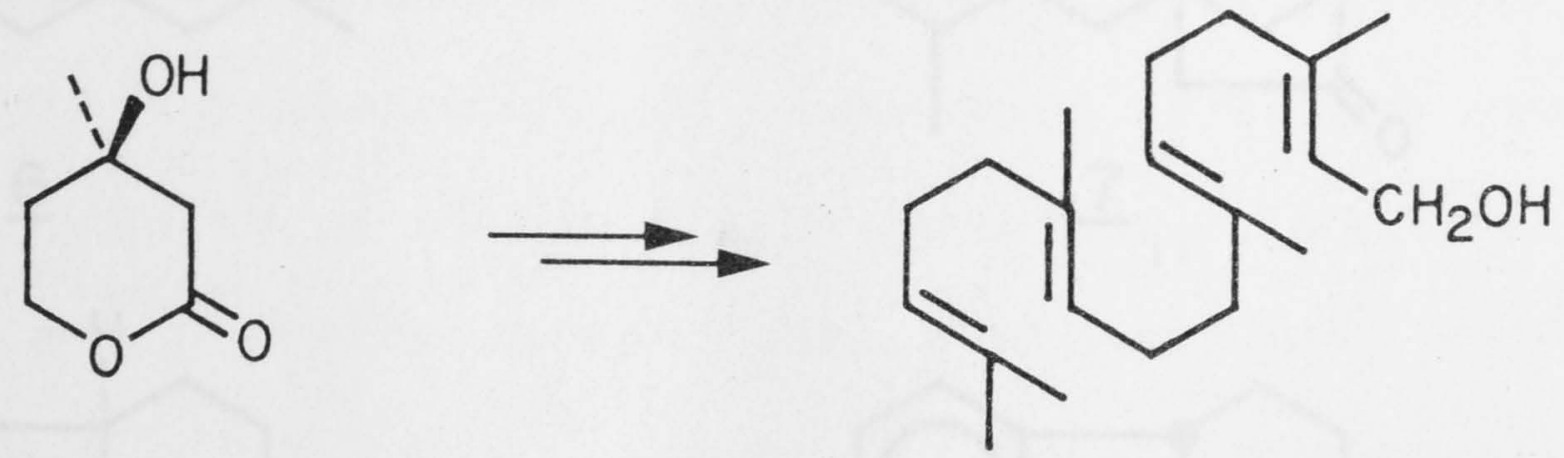

$\underline{3}$
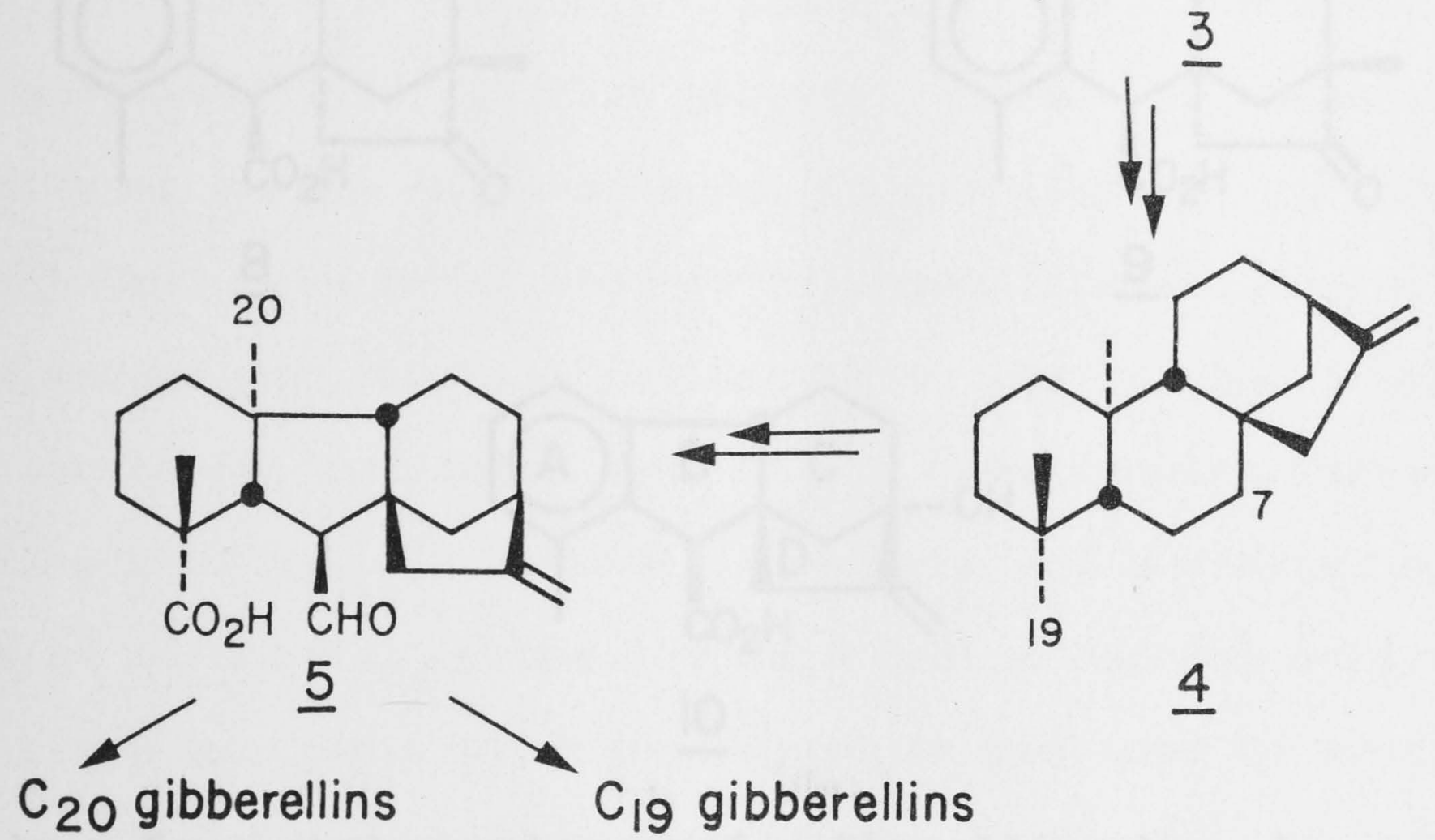

$\mathrm{C}_{19}$ gibberellins

\section{Scheme I}

The versatile biological activity of the gibberellins and the uncertainty about their structure brought about an early interest in the synthesis of gibberellins and their degradation products. 17 The synthesis of the gibberellic acid derivatives, gibberene $6{ }^{18}$ gibberone $\underline{7}^{19}, 20$ gibberic acid $\underline{8}^{21}$ and epigibberic acid $\underline{9}^{22}$ made a very significant contribution towards the structure elucidation of gibberellic acid 2. Groups led by Mori ${ }^{23}$ and House ${ }^{24}$ independently synthesised epiallogibberic acid 10 which was the first compound to possess the $\mathrm{C} / \mathrm{D}$-portion of $\mathrm{GA}_{3} \underline{2}$, the ultimate target of more recent syntheses, including that described in this thesis. 


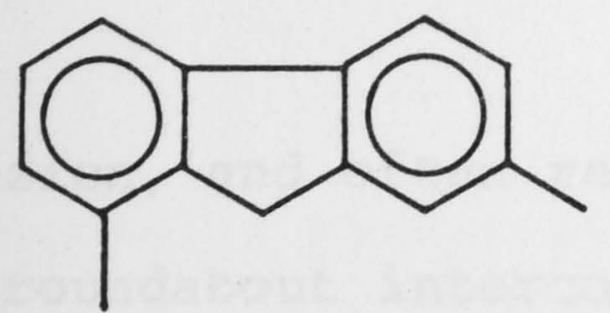

$\underline{6}$

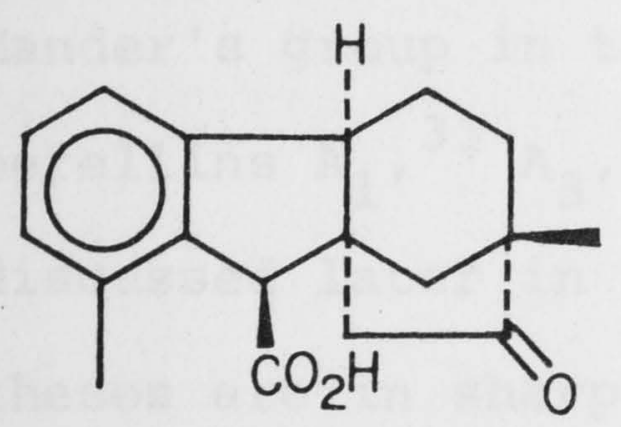

8

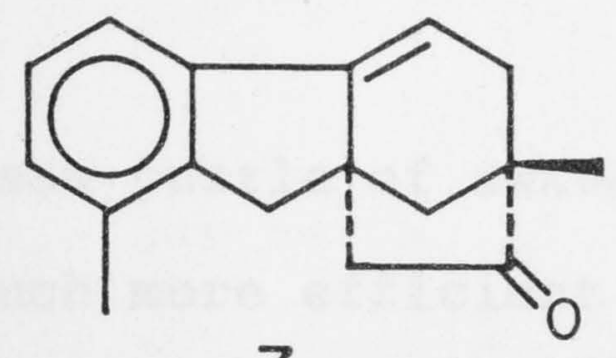

7

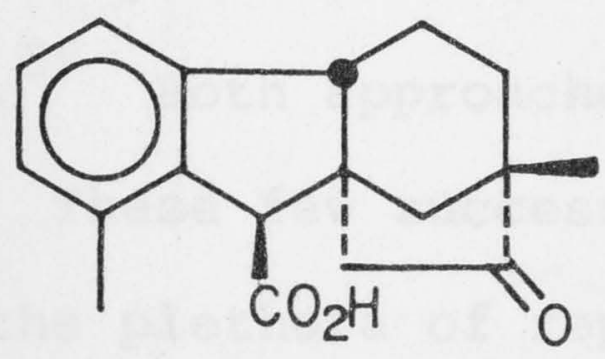

9

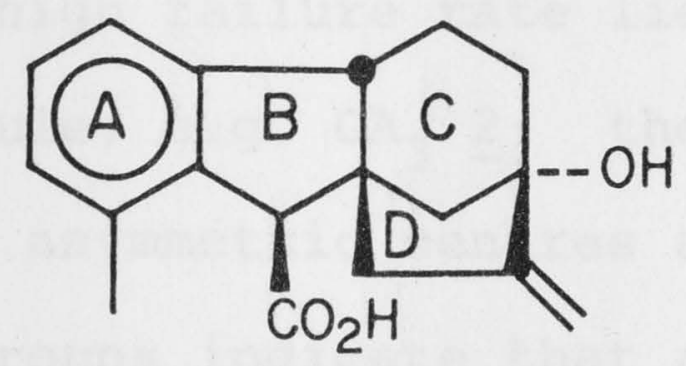

IO

Only a few total syntheses of gibberellins have been achieved so far. The simple $\mathrm{C}_{20}$ gibberellins $\mathrm{GA}_{12}, 25 \mathrm{GA}_{15}, 26,27$ and $\mathrm{GA}_{37} 27$ have been prepared via a hydrophenanthrene nucleus. $\mathrm{GA}_{4} \underline{11}, \mathrm{a}_{19}$ gibberellin,

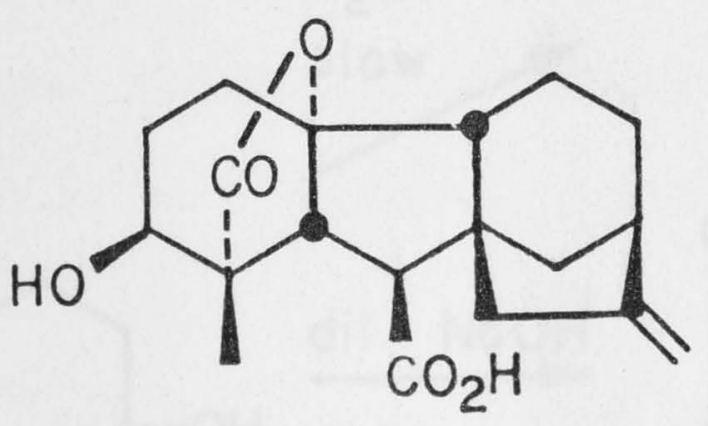

II

was made in over 50 steps by Mori et ar. ${ }^{28}$ and also constitutes a formal synthesis of gibberellins $A_{2}, A_{9}$ and $A_{10}$ since these had been prepared previously from GA $4 \cdot 29-31$ Most of these syntheses could only be completed with the use of relay compounds (except $\mathrm{GA}_{15}{ }^{26}$ ). They consequently lacked 
cohesion, and often resembled a jigsaw puzzle of awkward and roundabout interconversions. Much more efficient routes were taken by corey et $a r$. in their synthesis of $\mathrm{GA}_{3}{ }^{32}$ and by Mander's group in the recent total synthesis of gibberellins $A_{1}, 33 A_{3}, A_{8}, 34$ and $A_{4} \cdot 35$ Both approaches will be discussed later in this chapter. These few successful syntheses are in sharp contrast to the plethora of reports which deal with model studies or incomplete sequences. ${ }^{17}$ The reason for the high failure rate lies in the structure of the target molecule, e.g. $\mathrm{GA}_{3} \underline{2}$ : the complex carbocyclic skeleton with eight asymmetric centres and a cluster of labile functional groups indicate that a careful analysis of possible synthetic processes would be required to synthesise $\mathrm{GA}_{3}$. The most sensitive part of $\mathrm{GA}_{3} \underline{2}$, the A-ring, undergoes facile rearrangement ${ }^{36,37}$ and aromatisation (Scheme 2). 36
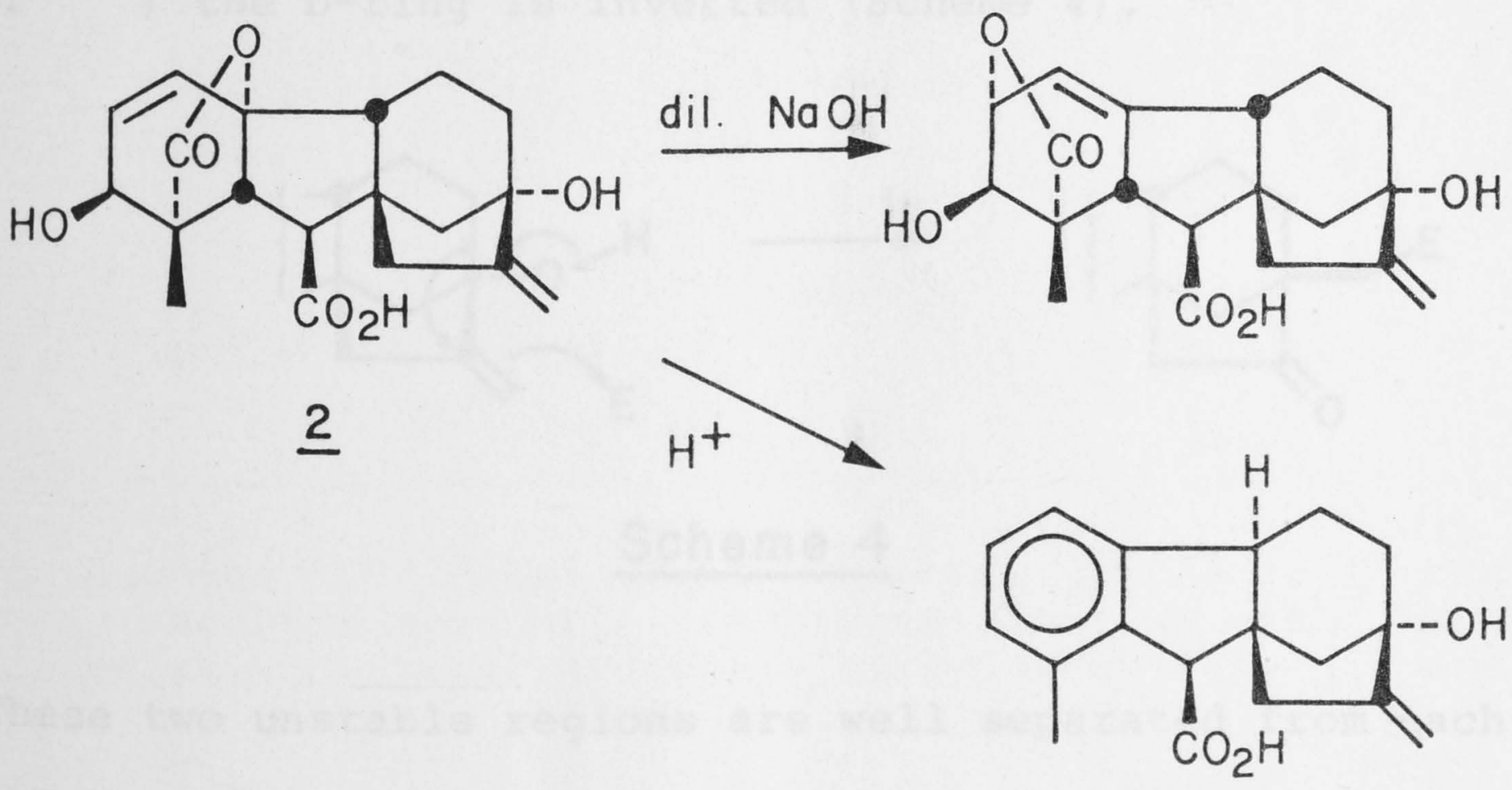
Gibberellins with a saturated A-ring, such as GA $1 \underline{12}$, are prone to sterochemical inversion at $\mathrm{C} 3$ under basic conditions, through a retro-aldol cleavage of the C3-C4 bond, to give the equatorial $\alpha$-alcohol (Scheme 3 ). 36,38

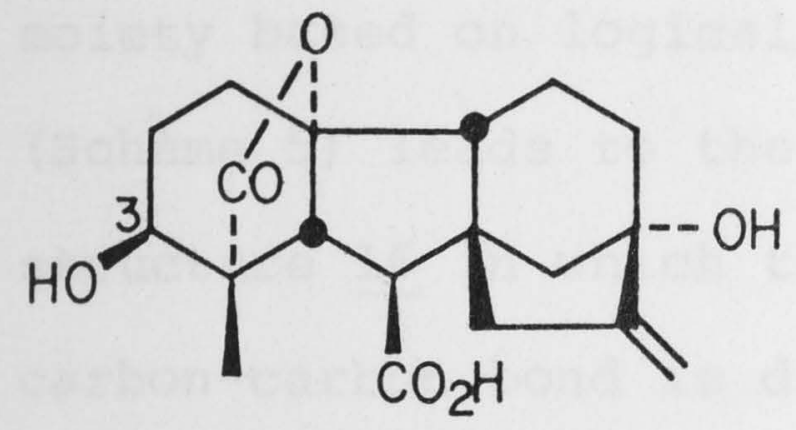

$\underline{12}$

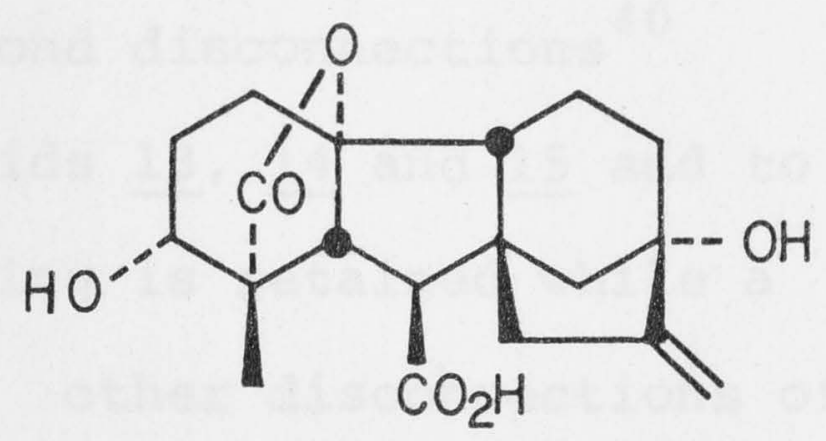

$\mathbb{1}$

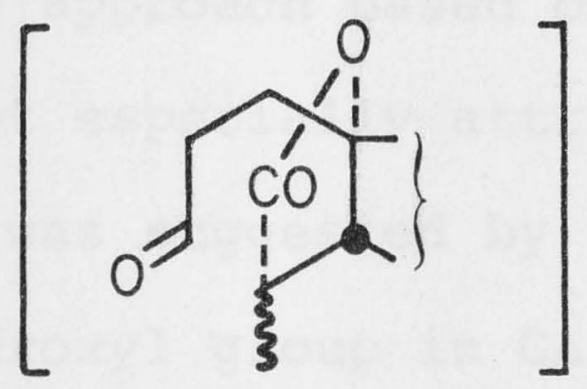

Scheme 3

The C/D-system rearranges less readily, but when treated with electrophilic reagents (warm mineral acias ${ }^{39}$ or $\mathrm{Br}^{+}{ }^{11}$ ) the D-ring is inverted (Scheme 4).
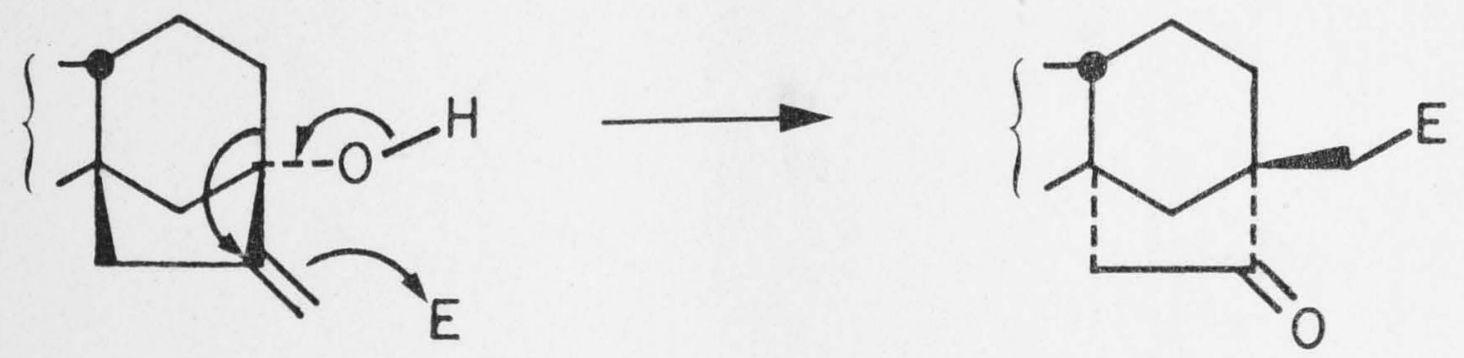

\section{Scheme 4}

These two unstable regions are well separated from each other by the five membered B-ring with a carboxyl group 
attached at C6 in the thermodynamically favoured B-position. Therefore, when planning the synthesis of $\mathrm{GA}_{3}$ it seemed sensible to focus attention on the construction of the Aand $\mathrm{C} / \mathrm{D}$-rings, keeping in mind that they must be connected eventually. Retrosynthetic analysis of the A-ring/lactone moiety based on logical strategic bond disconnections 40 (Scheme 5) leads to the olefinic acids $\underline{13}, \underline{14}$ and $\underline{15}$ and to structure 16 in which the lactone ring is retained while a carbon-carbon bond is disconnected; other disconnections of the latter type do not appear to be worth serious consideration. Similarly, an approach based on the precursor hydroxy acid 17 is not especially attractive.

Disconnection a was suggested by the facile epimerisation of the A-ring hydroxyl group in $\mathrm{GA}_{1} 12 .{ }^{36}$ The feasibility of this approach, which nicely establishes the stereochemistry at $\mathrm{C} 4 *$, was first demonstrated by Dolby and coworkers in their synthesis of the hydrindane model compounds 18 and 19 (Scheme 6$) .41$

* Throughout this thesis, the numbering system of $1^{5}$ has been used for synthetic structures when indicate $\bar{d}$ by an asterisk, to facilitate their correlation with gibberellins. 


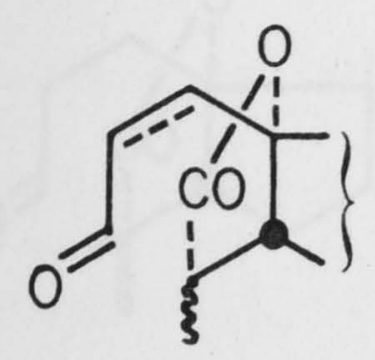<smiles>C[C@@]1(C(=O)O)CCCC2(O)CCCC1(O)CC2</smiles>

16

$h_{a}$

$\sqrt{17}$

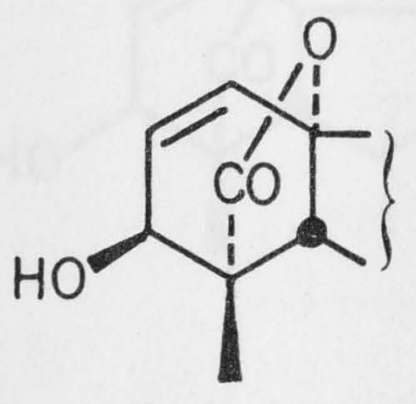

by $\quad \underline{c} \square \quad \underline{d}$

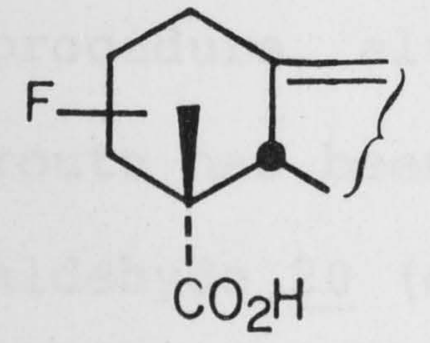

13<smiles>CC12CCCC1=CCC[C@]2(C)C(=O)O</smiles>

14

$\sqrt{7}$<smiles>[R]OC(=C)C(=C)/C=C\C=CC</smiles><smiles>COC1=CCC2=C(CCC2)[C@@]1(C)C(=O)O</smiles>

15<smiles>COc1ccc2c(c1C(=O)O)CC[IH]2</smiles>

Scheme 5 

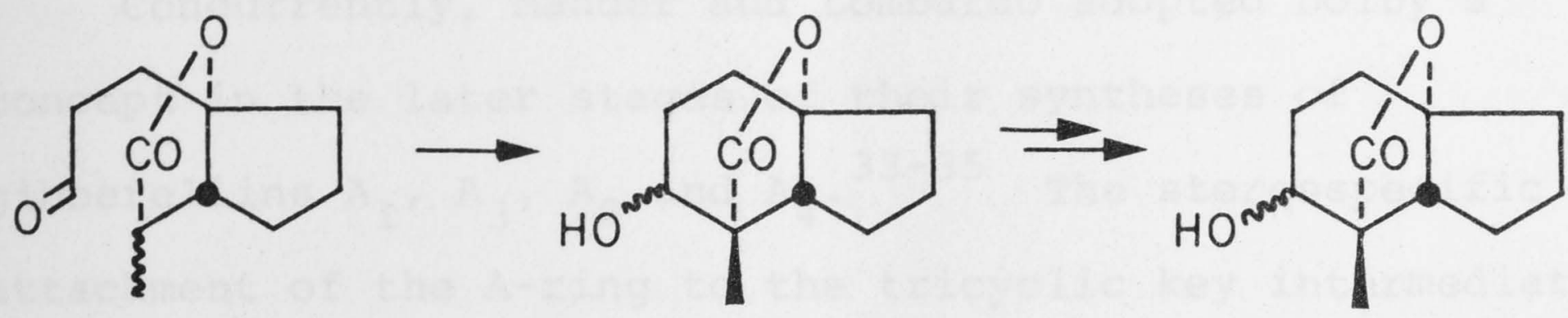

18 a $: \beta=10: 1$

$18 a: \beta=1: 1$
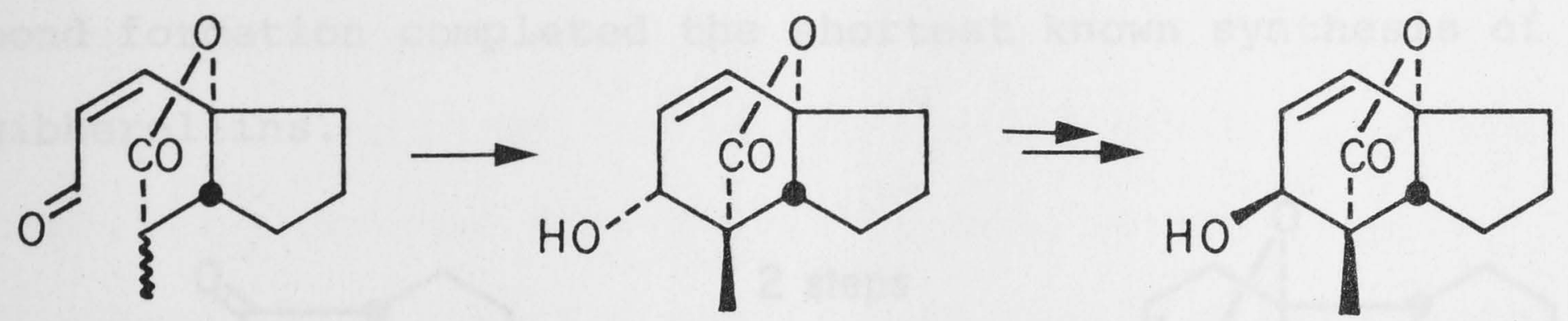

$\underline{19}$

\section{Scheme 6}

The major drawback to this approach was the formation of the

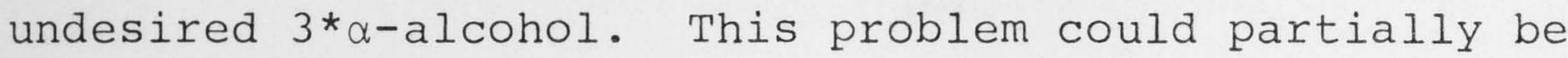
corrected through an oxidation/Meerwein-Ponndorf reduction procedure, although in low yield. A refinement of this route has been published by stork and Singh. ${ }^{42}$ Treatment of aldehyde 20 (derived from gibberellic acid) with a catalytic amount of sodium ethoxide in ethanol at $0^{\circ}$ gave a $1: 3$ mixture of $\alpha$ - and $\beta$-alcohols 21 (Scheme 7).

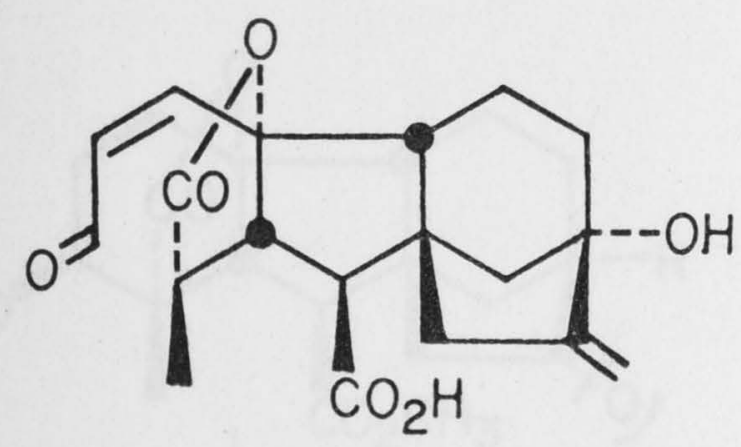

$\underline{20}$

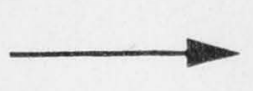

Scheme 7

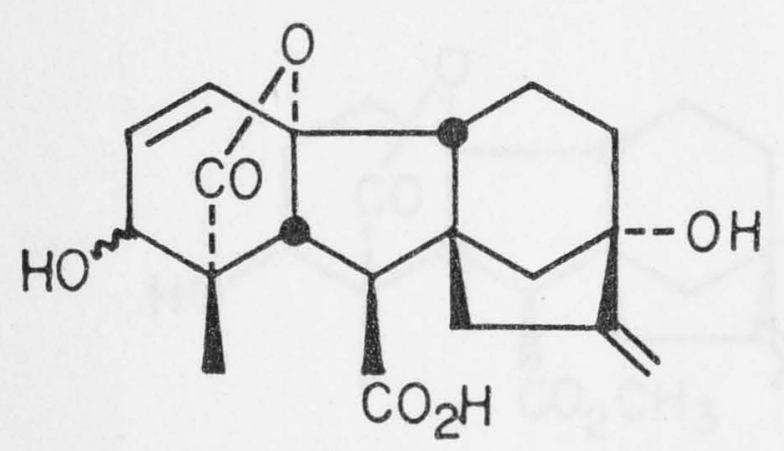

21 
Concurrently, Mander and Lombardo adopted Dolby's concept in the later stages of their syntheses of gibberellins $A_{1}, A_{3}, A_{8}$ and $A_{4} \cdot 33-35$ The stereospecific attachment of the A-ring to the tricyclic key intermediate 22. (Scheme 8) through repeated intramolecular carbon-carbon bond formation completed the shortest known synthesis of gibberellins.

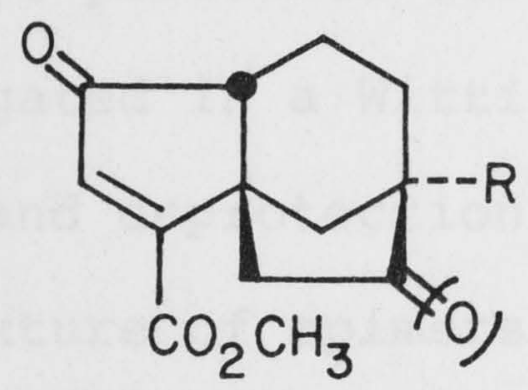

$\underline{22}$
2 słeps

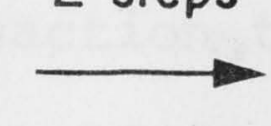

\section{2 steps}

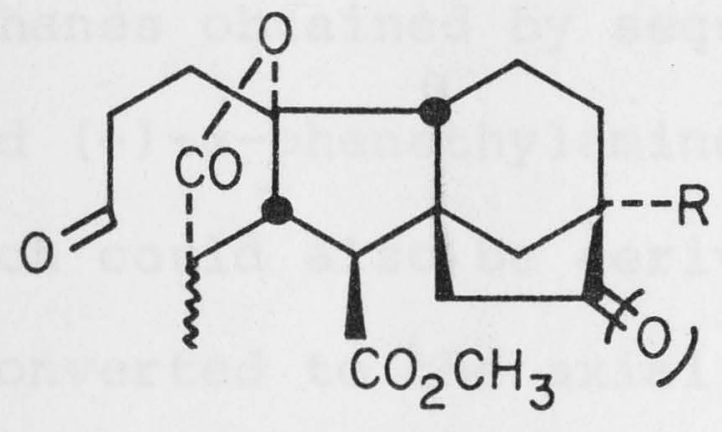

$\underline{23}$
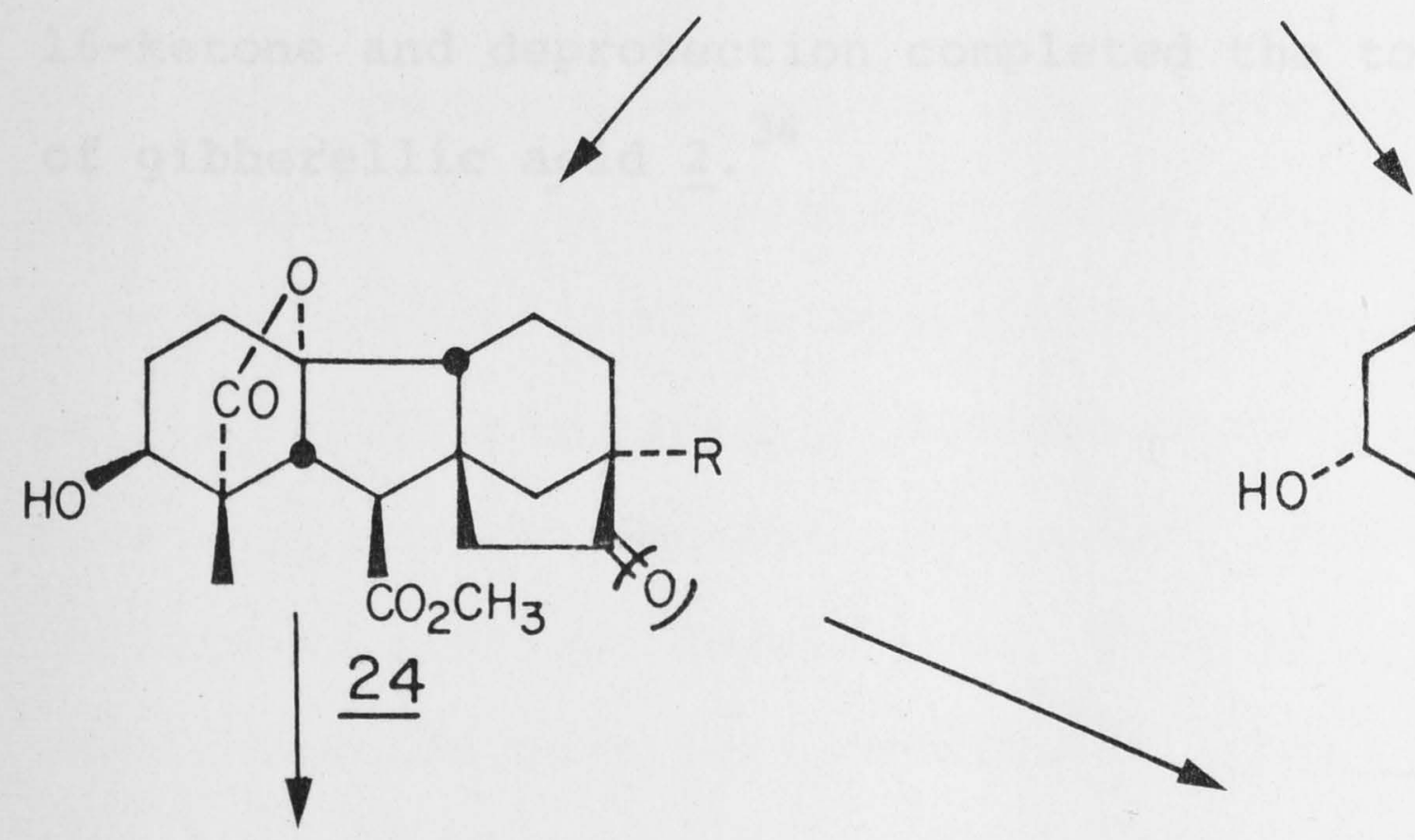

$\mathrm{GA}, \underline{12}(\mathrm{R}=\mathrm{OH})$

$\mathrm{GA}_{4}$ II $(\mathrm{R}=\mathrm{H})$

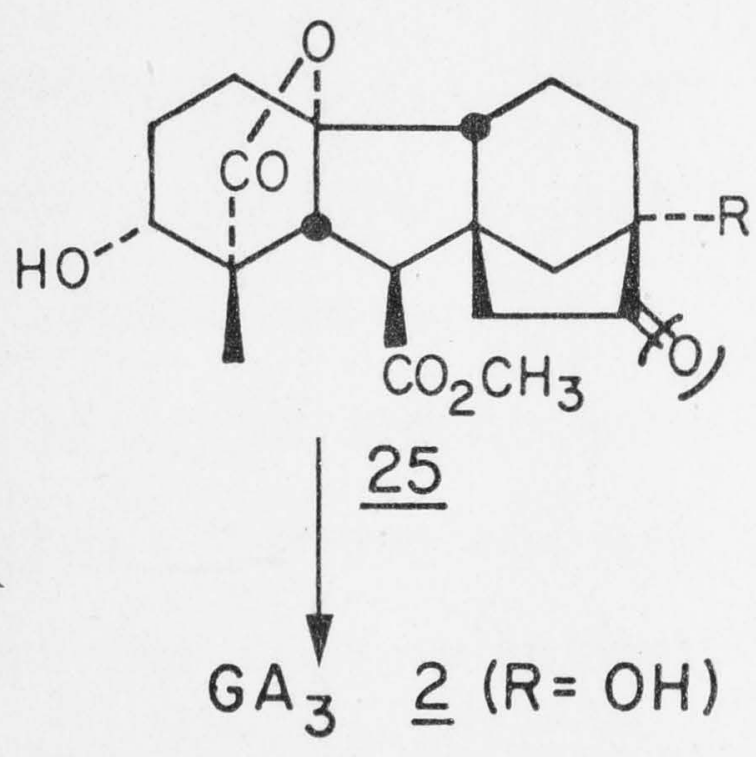

Scheme 8 
The crucial steps in the construction of the A-ring were (i) the stereospecific addition of triallylalane to ketone 22 which resisted addition of a variety of organometallic reagents, (ii) the formation of the $\gamma$-lactone 23 by an intramolecular Michael addition and (iii) a kinetically controlled aldol condensation to give the c $3 *$-epimers 24 and 25 in a ratio of $3: 1 \quad(R=H)$ and $1: 1 \quad(R=O H)$. Suitably hydroxyl-protected derivatives of keto esters 24 were homologated in a wittig reaction to yield, after demethylation and deprotection, $\mathrm{GA}_{1} 12(\mathrm{R}=\mathrm{OH})^{33}$ and $\mathrm{GA}_{4} \underline{11}(\mathrm{R}=\mathrm{H})$. $^{35}$ The mixture of epimers $\underline{24}(\mathrm{R}=\mathrm{OH})$ and $\underline{25}(\mathrm{R}=\mathrm{OH})$ was stereospecifically converted into $\mathrm{GA}_{3} \underline{2}$ as indicated in scheme 9 . The olefin 26 was resolved by chromatography of the diastereomeric urethanes obtained by sequential treatment of 26 with phosgene and $(-)-\alpha$-phenethylamine. ${ }^{32}$ The optically pure olefin 26 , which could also be derived from natural gibberellins, was converted to the axial allylic benzoate 27 via a benzylidene intermediate. Homologation of the 16-ketone and deprotection completed the total synthesis of gibberellic acid $\underline{2}^{34}$ 


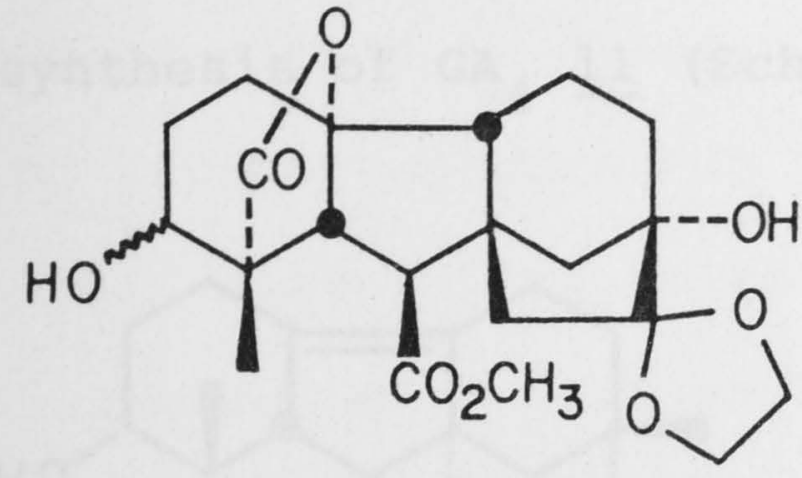

$\underline{24} / \underline{25}$
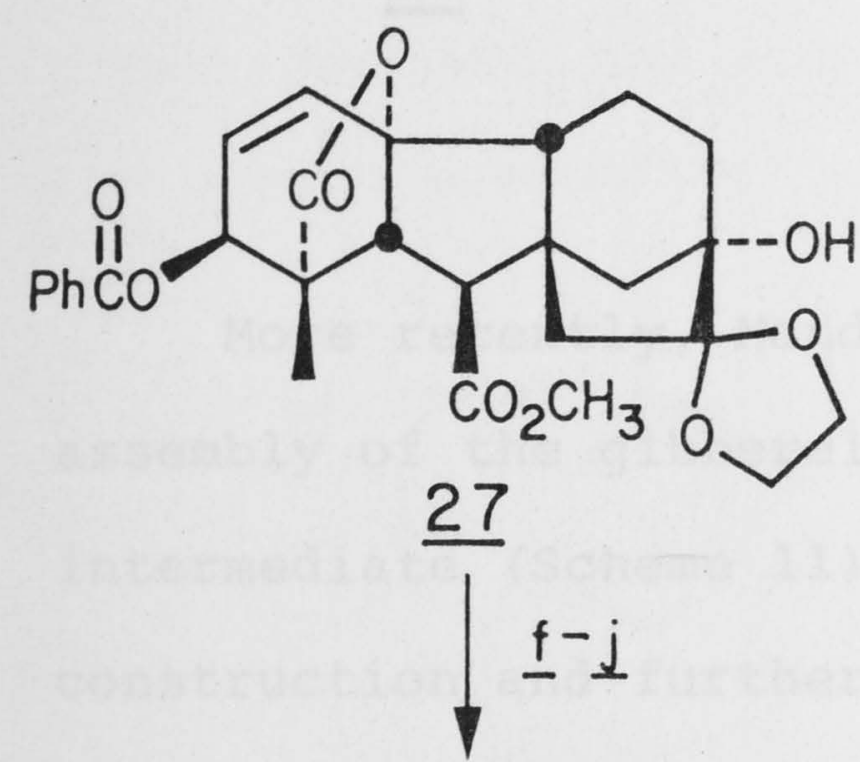

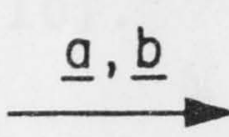

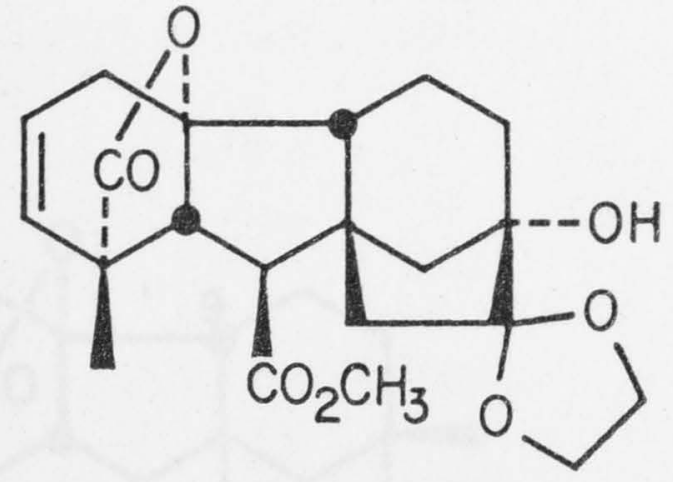

26 $\underline{C}, \underline{d}$
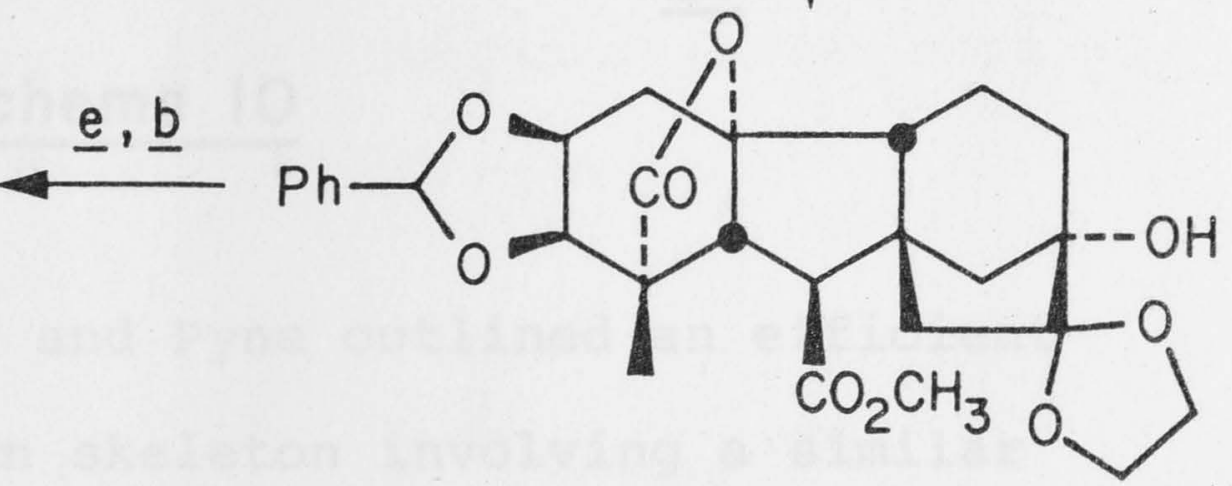

$\mathrm{GA}_{3} \underline{2}$

a $\mathrm{PhSO}_{2} \mathrm{Cl}, \mathrm{py} ; \underline{\mathrm{b}} \mathrm{DBN},(\mathrm{Bu}){ }_{4} \mathrm{~N}^{+} \mathrm{Br}^{-}, \mathrm{DMF} ; \quad \underline{\mathrm{C}} \mathrm{OsO}_{4} ; \underline{\mathrm{d}} \mathrm{PhCHO}$; $\underline{\mathrm{NBS}}$; $\underline{\mathrm{f}} \mathrm{H}^{+} ; \underline{\mathrm{g}} \mathrm{TMSCl} ; \underline{\mathrm{h}} \mathrm{Ph}_{3} \mathrm{P}^{+} \mathrm{CH}_{3} \mathrm{Br}^{-}, \mathrm{KOtBu}$; $\mathrm{K}_{2} \mathrm{CO}_{3} ; \underline{\mathrm{j}} \mathrm{LiSC}_{3} \mathrm{H}_{7}, \mathrm{HMPA}$.

\section{Scheme 9}

All other strategies for the construction of the A-ring have been based on unsaturated acids, which were induced to form the lactone with an appropriate electrophile. Intermediate acids according to disconnection $\underline{b}$ (Scheme 5, p.8) have been used in several approaches. These acids 13, containing a 9*,10* double bond, undergo trans-lactonisation when subjected to acidic conditions. This process ensures the correct relative stereochemistry of the lactone bridge to the proton at $\mathrm{C}^{*}$. A precursor of this type, diester 28 , was converted to the lactone 29 by Mori's group, in their 
synthesis of $\mathrm{GA}_{4} \underline{11}$ (Scheme 10). 28

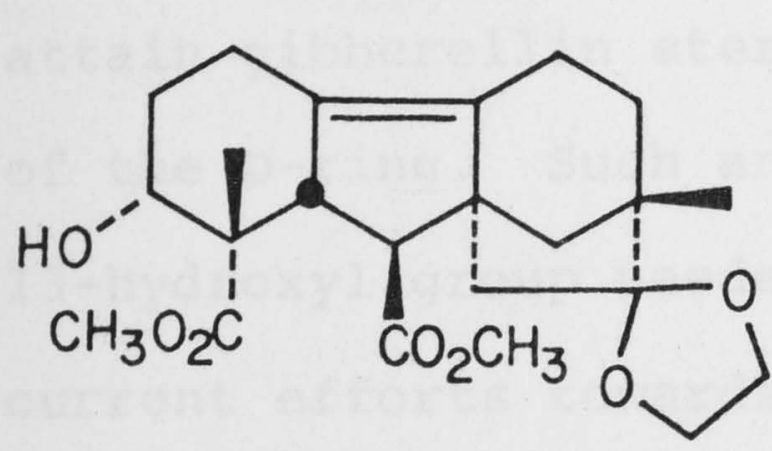

$\underline{28}$

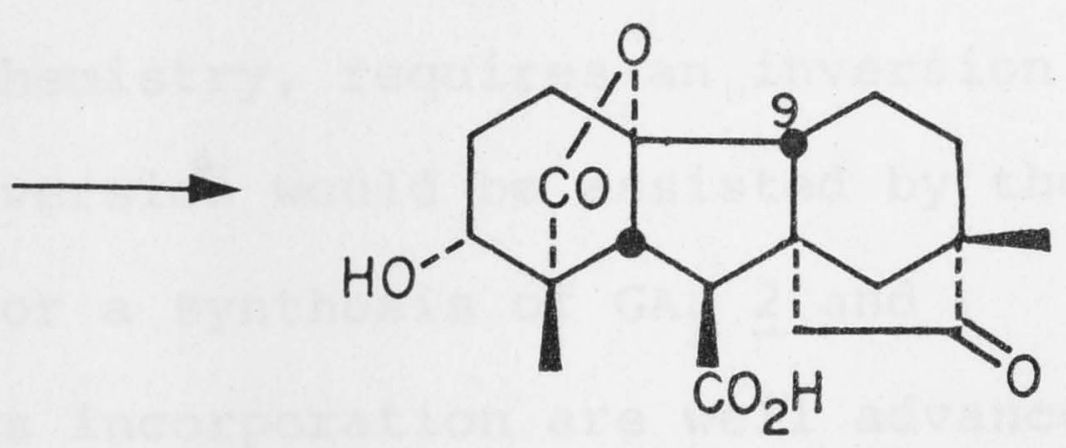

$\underline{29}$

\section{Scheme 10}

More recently, Mander and Pyne outlined an efficient assembly of the gibberellin skeleton involving a similar intermediate (Scheme 11). 43 a-Diazoketone 30, whose construction and further reactions are based on the use of the latent functionalities contained in the anisole synthon,<smiles>COC(=O)C(CCCc1ccc(OC)c2c1CCC(C(=O)C=[W])C2)C(=O)OC</smiles>

$\underline{30}$<smiles>[R]OC1CC23CC1CCC1=C2CCCC(C(=O)O)(C(=O)O)C1CC3O</smiles>

$\underline{31}$

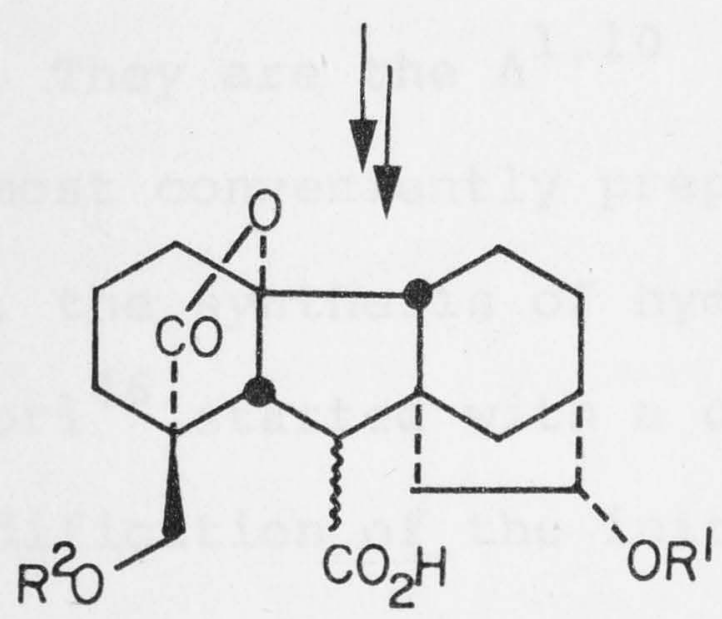

$\underline{32}$ 
was converted to diacid 31. Acid-promoted lactonisation and further elaboration gave acid 32 which, in order to attain gibberellin stereochemistry, requires an inversion of the D-ring. Such an inversion would be assisted by the 13-hydroxyl group needed for a synthesis of $\mathrm{GA}_{3} \underline{2}$ and current efforts towards its incorporation are well advanced. 44 Yet another entry to this type of intermediate, based on a rearrangement and subsequent aldol condensation of acid 33 , has been presented by Monti and Chen (Scheme 12). 45

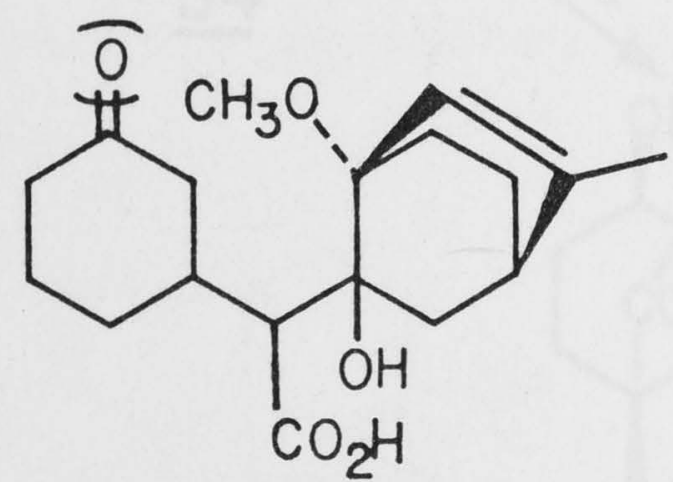

33

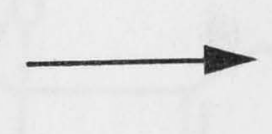

Scheme 12

Evidently, more work is needed to incorporate some of the crucial functionalities, and to assess the stereochemistry at $\mathrm{C} 5$ *

A different class of lactone precursors is suggested by disconnection $\underline{c}($ Scheme $5, \mathrm{p} .8)$. They are the $\Delta^{1,10}$ unsaturated acids 14 , which are most conveniently prepared by a Diels-Alder reaction. Thus, the synthesis of hydrofluorenone 34 by Nakanishi and Hori ${ }^{46}$ started with a cycloaddition to yield, after some modification of the initial adduct, anhydride 35 (Scheme 13). 

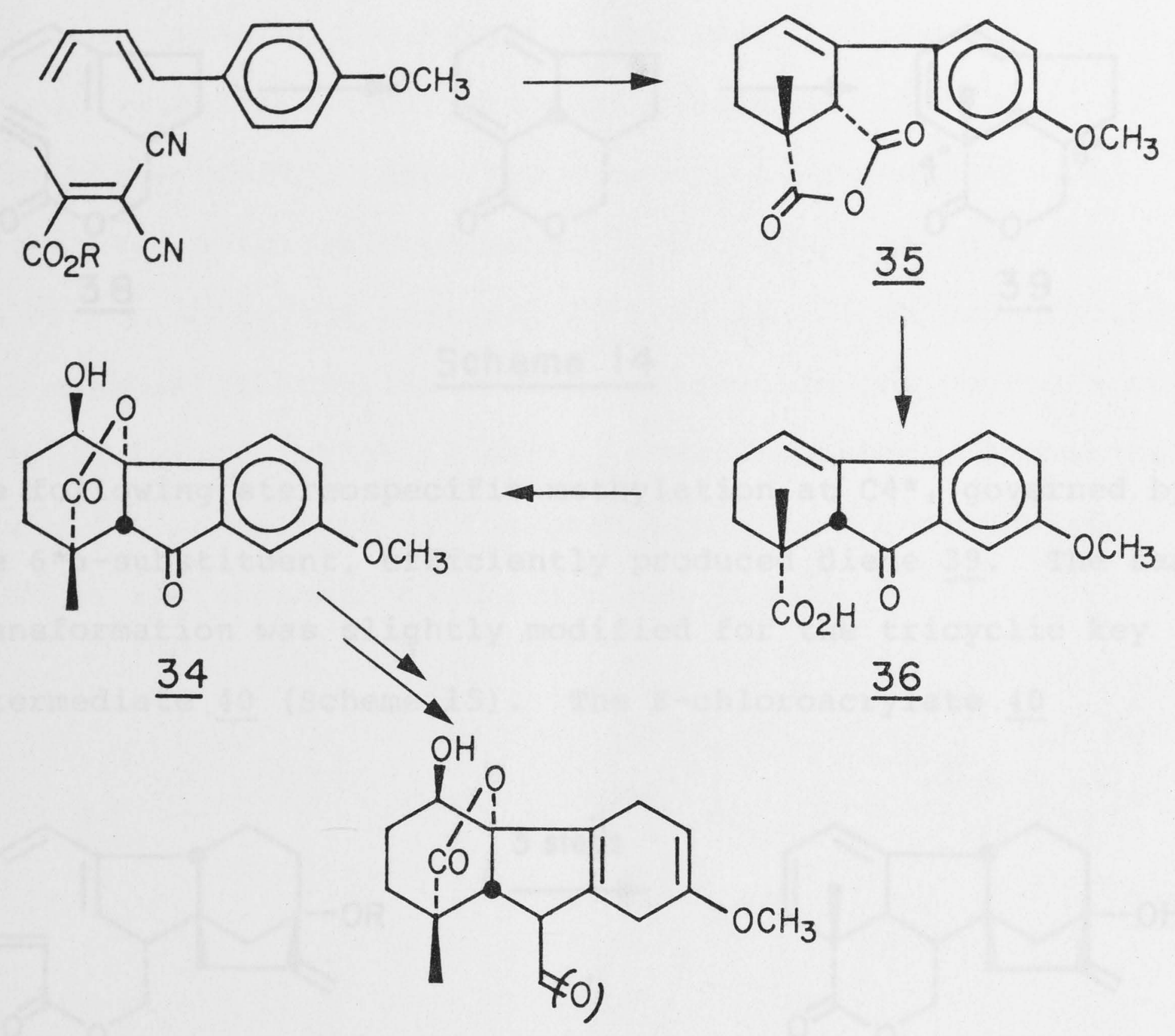

$\underline{35}$

37

\section{Scheme 13}

Keto acid 36 obtained by intramolecular acylation from anhydride 35 , was subjected to peracid to give the hydroxy lactone 34 . Yamada et al. homologated the ketone 34 stereospecifically via an epoxide 47 and reduced the c-ring (after protection of the lactone as its carboxylate salt) with sodium in ammonia to produce, after reclosure, lactone 37.48 The total synthesis of $\mathrm{GA}_{3} 2$ by Corey's group 32 also involved an olefinic acid of this type. The strategy elaborated on a model system was based on an intramolecular Diels-Alder reaction of the acetylenic dienophile 38 (Scheme 14). 49 


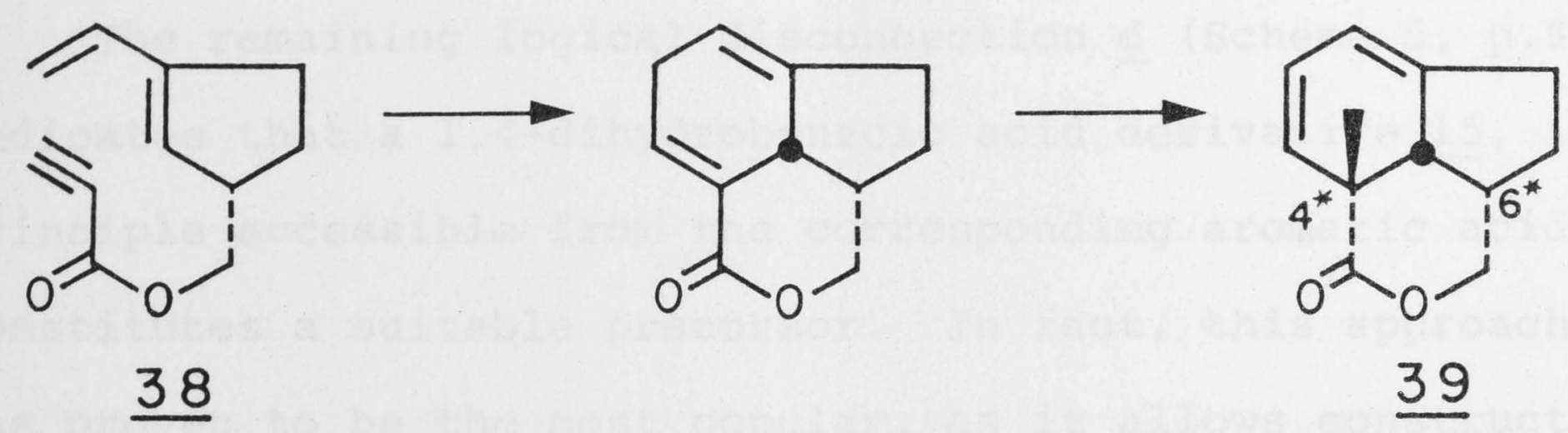

\section{Scheme 14}

The following stereospecific methylation at $\mathrm{C} 4$ *, governed by the $6 * \alpha$-substituent, efficiently produced diene 39 . The same transformation was slightly modified for the tricyclic key intermediate $\underline{40}$ (Scheme 15). The E-chloroacrylate 40

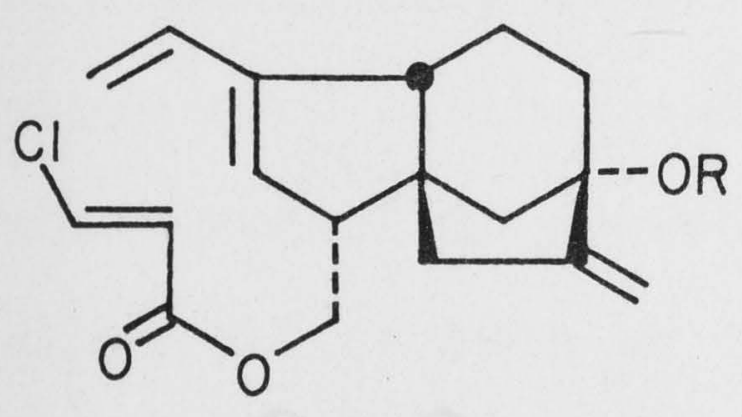

$\underline{40}$

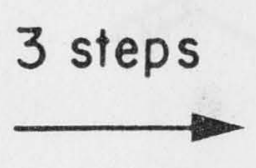

6 steps

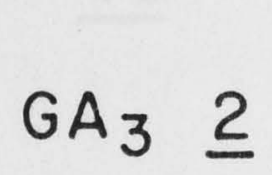

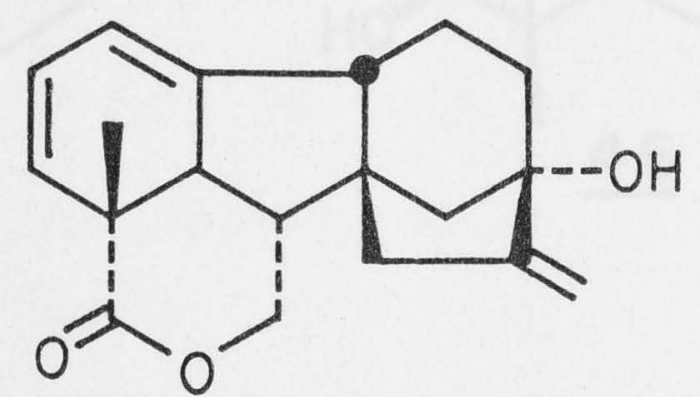

41
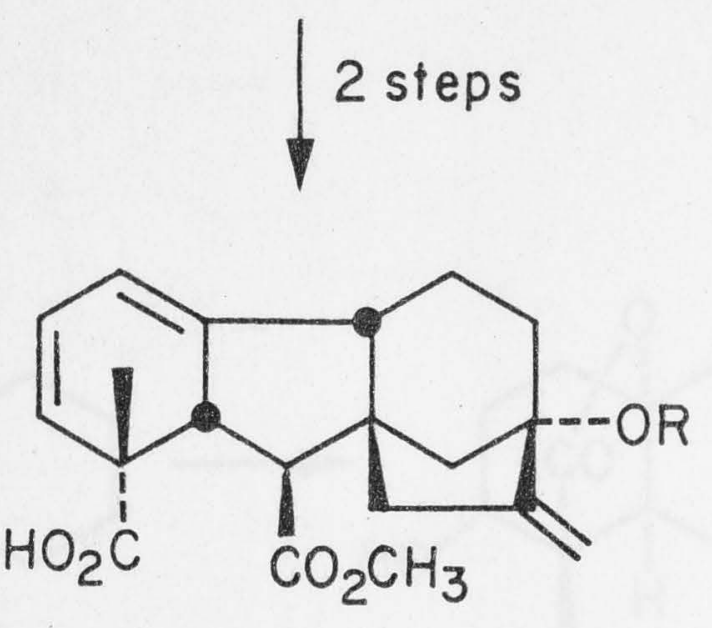

42

Scheme 15

had to be used instead of the propiolate to obtain satisfactory results in the Diels-Alder reaction. Lactone 41 was converted to the acid ester 42 which, through repeated lactonisations, had previously been transformed to $\mathrm{GA}_{3} \cdot 50$ 
The remaining logical disconnection d (Scheme 5, p.8) indicates that a 1,4-dihydrobenzoic acid derivative 15 , in principle accessible from the corresponding aromatic acid, constitutes a suitable precursor. In fact, this approach has proven to be the most popular, as it allows construction of the whole gibberellin carbon skeleton in the presence of a stable A-ring, which is easily modified later. Loewenthal et al. have done most of the pioneering work on the elaboration of the aromatic A-ring (Scheme 16). 51

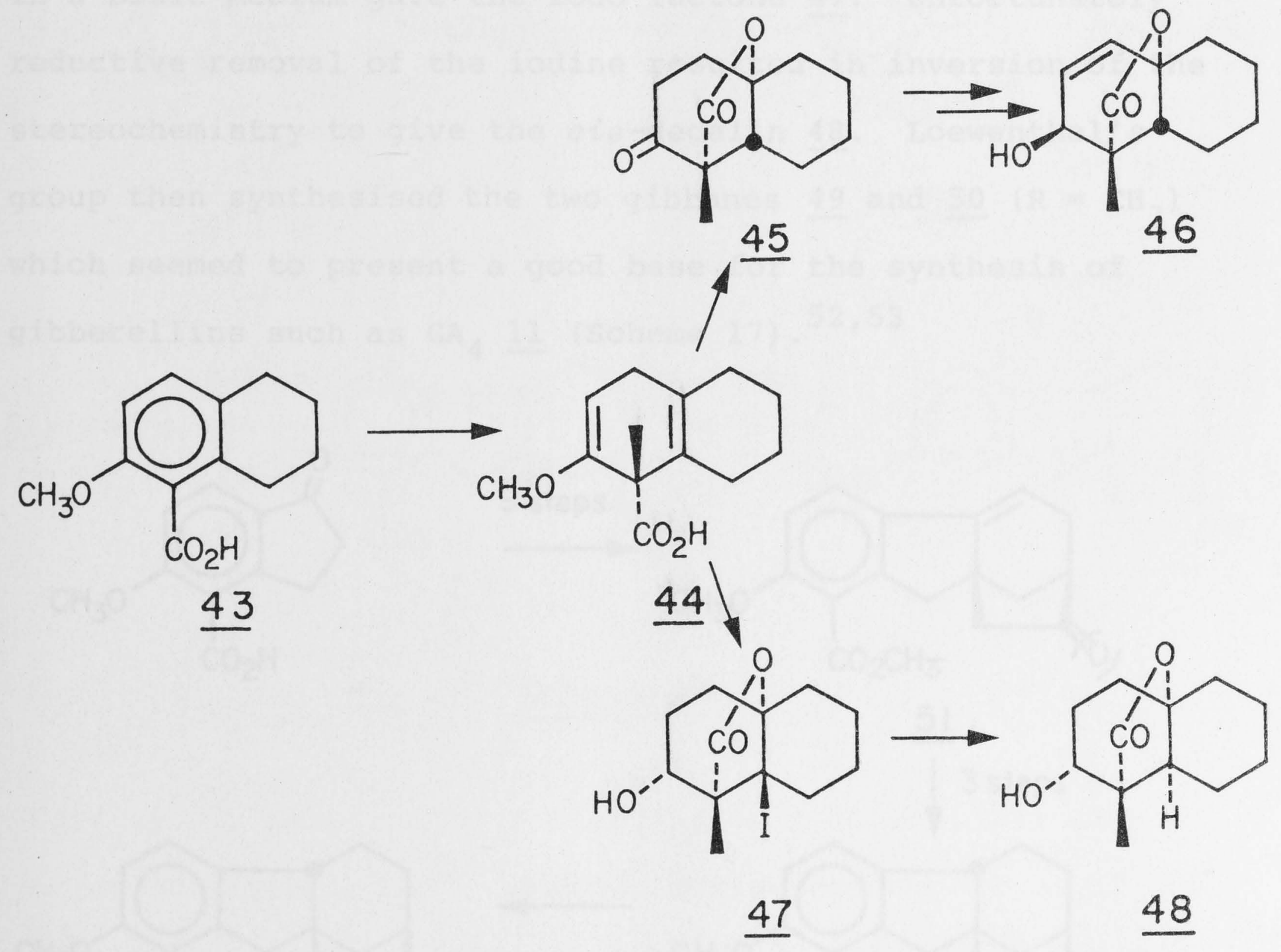

Scheme 16 
Birch reduction of the acid 43 followed by in situ methylation of the resulting dianion, referred to as reductive methylation, afforded the acid $\underline{44}$. Brief treatment of $\underline{44}$ with mineral acid gave keto lactone 45 which was converted to the desired allylic alcohol 46 in low yield. Alternatively, the lactonisation was performed under non-acidic conditions.

Thus, acid $\underline{4} 4$ was methylated, the enol ether hydrolysed, and the resulting ketone reduced with sodium borohydride. Hydrolysis of the ester and subsequent treatment with iodine in a basic medium gave the iodo lactone 47 . Unfortunately reductive removal of the iodine resulted in inversion of the stereochemistry to give the cis-decalin 48 . Loewenthal's group then synthesised the two gibbanes $\underline{49}$ and $\underline{50}\left(\mathrm{R}=\mathrm{CH}_{3}\right)$ which seemed to present a good base for the synthesis of gibberellins such as $\mathrm{GA}_{4} 11$ (Scheme 17). 52,53<smiles>COc1ccc2c(c1C(=O)O)CCC2=O</smiles>
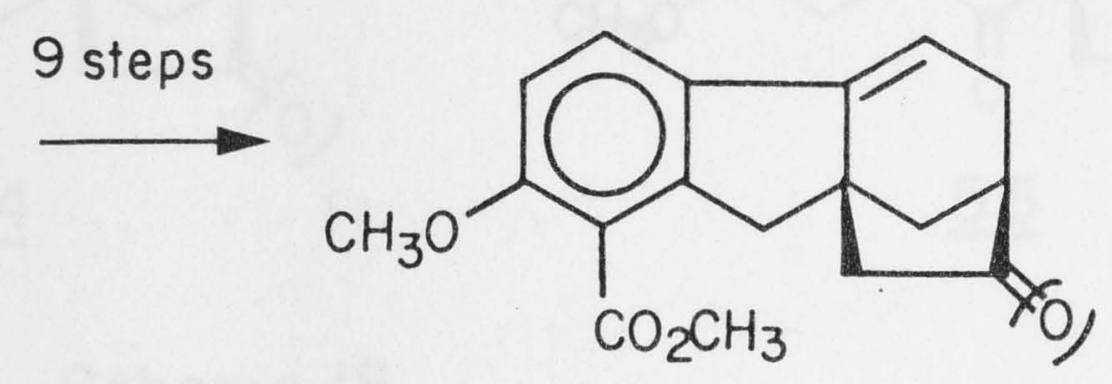

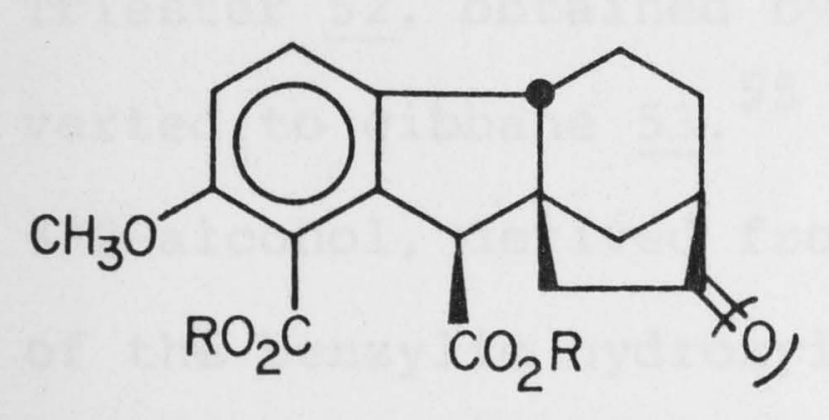

$\underline{50}$
51

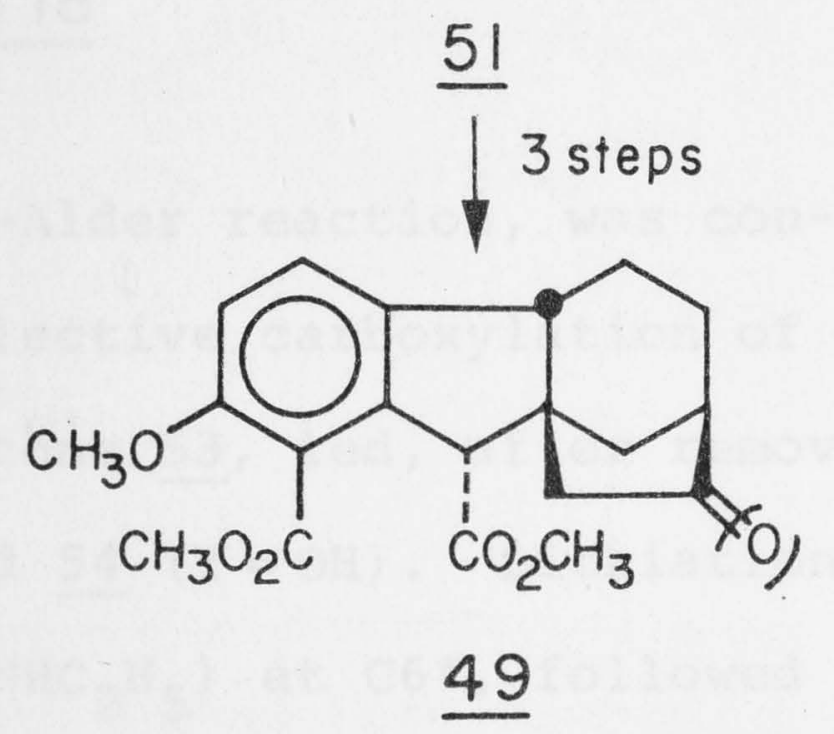


Carboxylation of ester $\underline{51}$ at the benzylic position gave exclusively the $6^{*} \alpha$-carboxylate which controlled the subsequent hydrogenation of the $9 *, 11 *$-double bond to yield diester 49 possessing the cis-fused B/C-ring system. The gibberellinlike $6 * \beta$-carboxylate $\underline{50}\left(\mathrm{R}=\mathrm{CH}_{3}\right)$ was obtained from $\underline{49}$ by an isomerisation under basic conditions. Diacid $\underline{50}(\mathrm{R}=\mathrm{OH})$ had previously been prepared by Baker and Goudie using a completely different approach (Scheme 18). 54

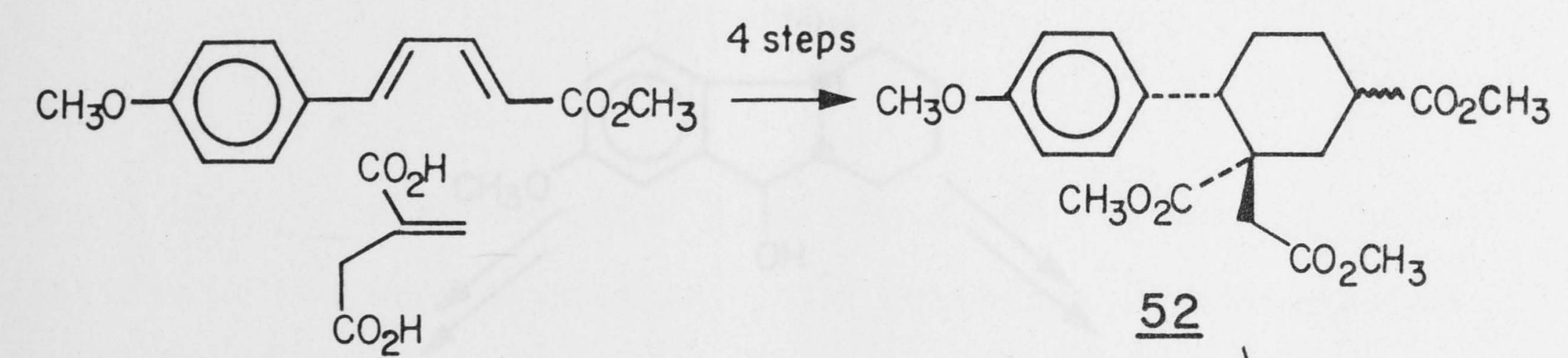

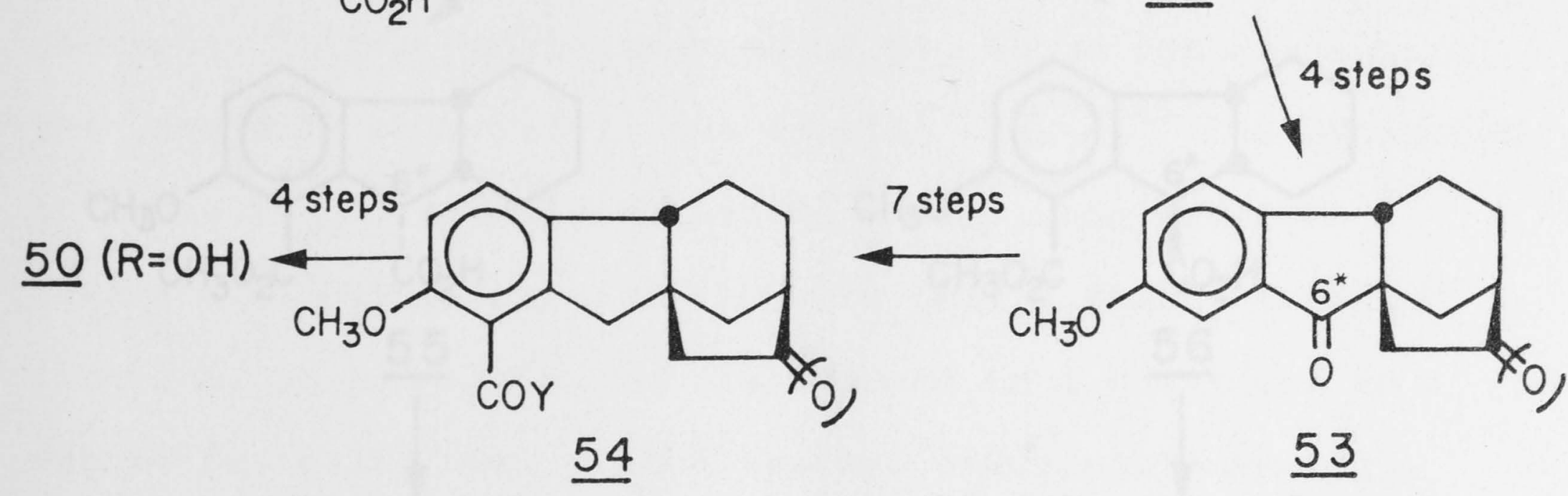

\section{Scheme 18}

Triester 52 , obtained by a Diels-Alder reaction, was converted to gibbane $53 .{ }^{55}$ Regioselective carboxylation of the $6 * \beta$-alcohol, derived from the ketone 53, led, after removal of the benzylic hydroxyl, to acid $\underline{54}(\mathrm{Y}=\mathrm{OH})$. Lithiation of the corresponding amide $\underline{54}\left(\mathrm{Y}=\mathrm{NHC}_{2} \mathrm{H}_{5}\right)$ at $\mathrm{C}^{*}$, followed by carboxylation and hydrolysis of the amide function gave diacid $\underline{50}(\mathrm{R}=\mathrm{OH})$. Both syntheses of the gibbane $\underline{50}$, 
however, seem to be incompatible with an efficient incorporation of the 13-hydroxyl group required for a synthesis of $\mathrm{GA}_{3} \cdot+$

The elaboration of a benzoic acid derivative as a model for the A-ring of gibberellins was also investigated by House and coworkers. They reported that reductive methylation of hydrofluorenones 55 and 56 proceeded exclusively from the side opposite to the $6 *$-carboxyl group (Scheme 19). 56

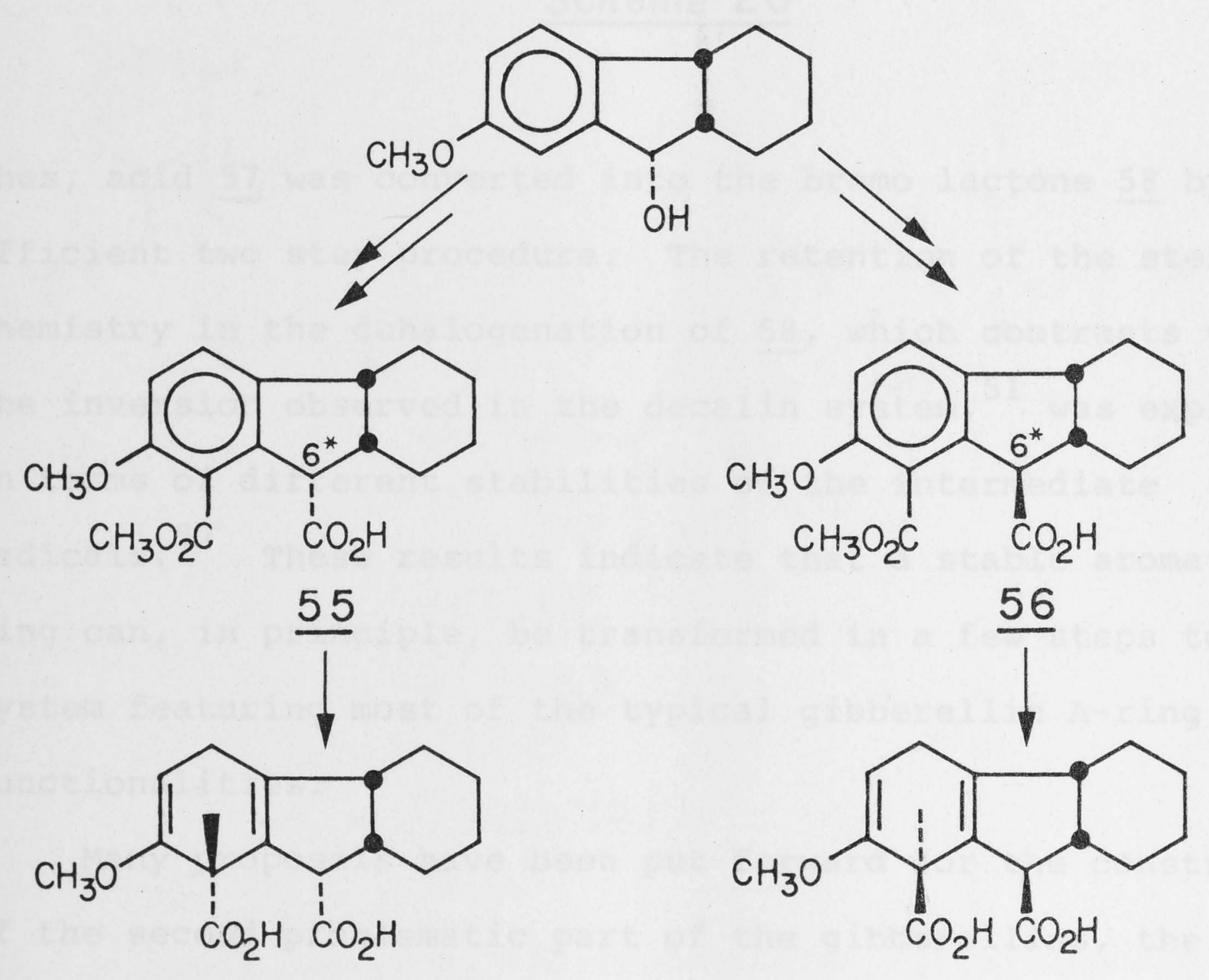

Scheme 19

\footnotetext{
the incorporation of a 13-hydroxyl group into diester 50 could, in principle, be achieved by the method developed by Mori23 which, however, involves a low-yielding nine step sequence.
} 
Moreover, House's group looked at the halolactonisation of a 1,4-dihydrobenzoic acid in an indene system (Scheme 20). 57

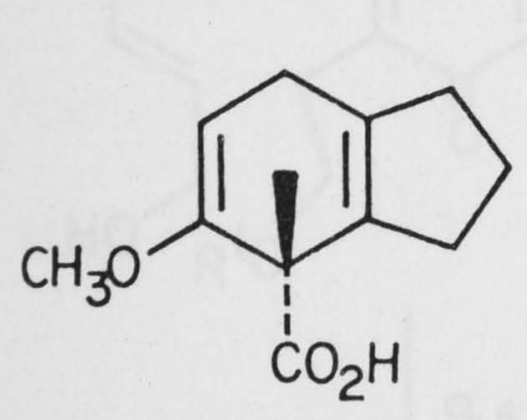

57

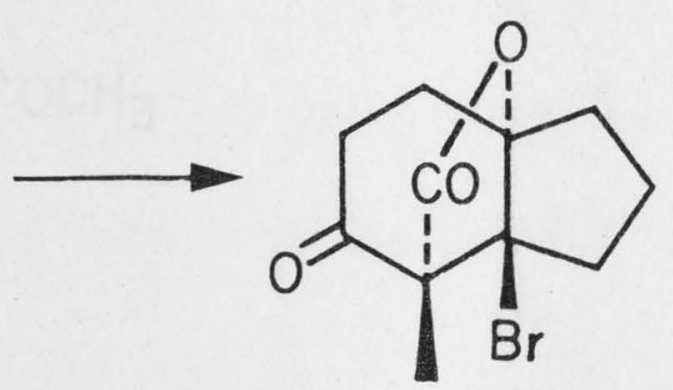

$\underline{58}$

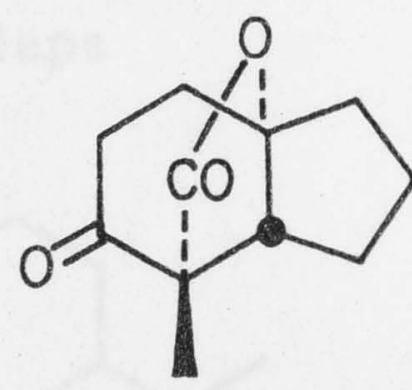

\section{Scheme 20}

Thus, acid $\underline{57}$ was converted into the bromo lactone $\underline{58}$ by an efficient two step procedure. The retention of the stereochemistry in the dehalogenation of 58 , which contrasts with the inversion observed in the decalin system, ${ }^{51}$ was explained in terms of different stabilities of the intermediate radicals. 57 These results indicate that a stable aromatic ring can, in principle, be transformed in a few steps to a system featuring most of the typical gibberellin A-ring functionalities.

Many proposals have been put forward for the construction of the second problematic part of the gibberellins, the bicyclo|3.2.1/octane system. Most of them are presented in Fujita's review ${ }^{17}$ and only the outstanding ones dealing with the construction of the hydroxylated system are discussed here. Corey and coworkers developed two different routes to the key intermediate $\underline{59}$ in their $\mathrm{GA}_{3}$ synthesis (Scheme 21). 32 

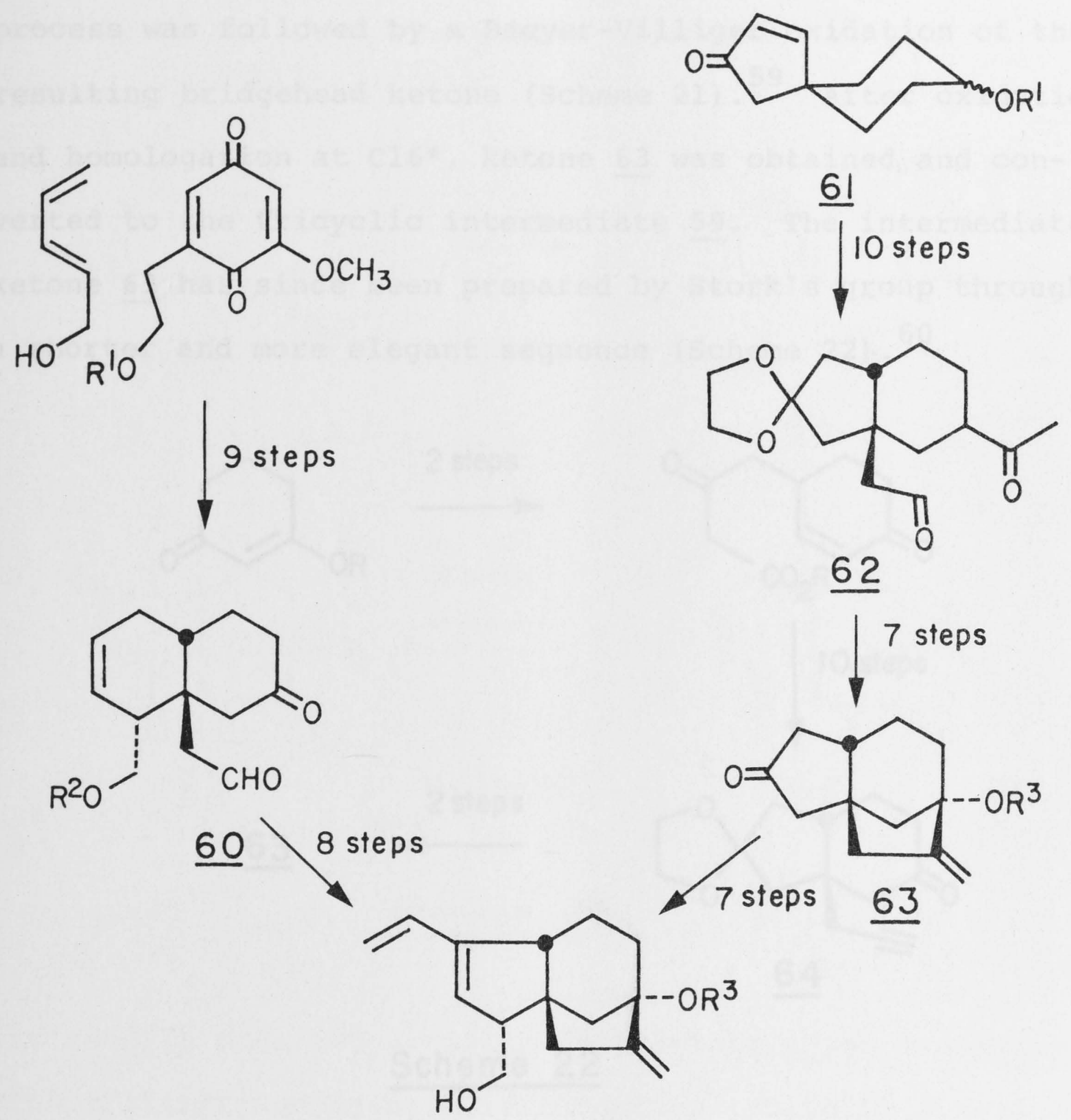

$\underline{59}$

\section{Scheme 21}

In the first approach, they constructed the cis-decalone 60 by a Diels-Alder reaction and a rather lengthy reduction sequence of the initial adduct. A tricky pinacol cyclisation established the D-ring and further elaboration led to the desired key intermediate 59.58 pursuing a totally different strategy, they transformed spiroenone 61 into keto aldehyde 62 . Cyclisation of 62 through an aldol 
process was followed by a Baeyer-Villiger oxidation of the resulting bridgehead ketone (Scheme 21). ${ }^{59}$ After oxidation and homologation at $\mathrm{Cl}^{*}$, ketone 63 was obtained and converted to the tricyclic intermediate 59. The intermediate ketone 63 has since been prepared by stork's group through a shorter and more elegant sequence (Scheme 22). 60
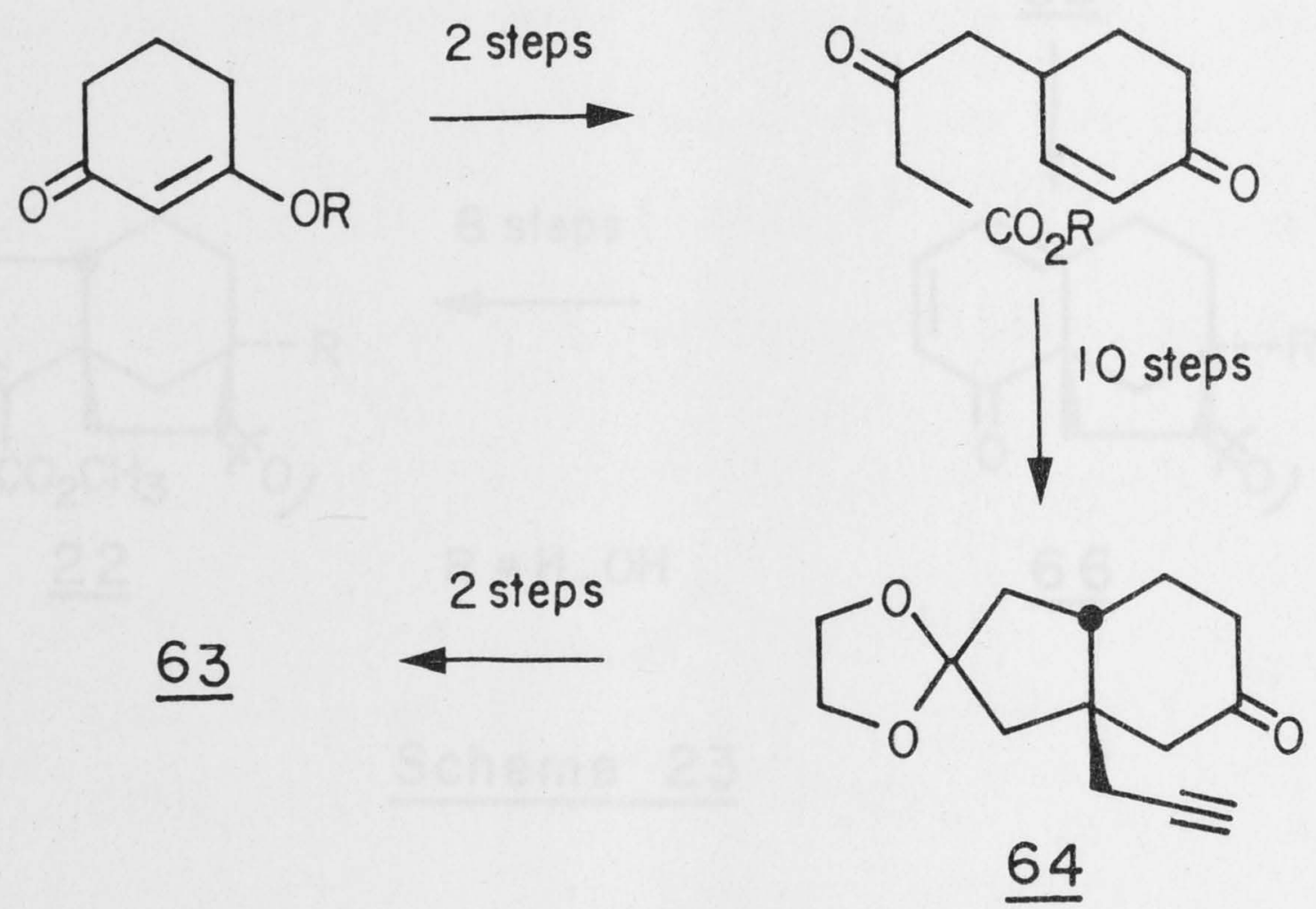

\section{Scheme 22}

The reductive cyclisation of the keto acetylene 64 with potassium in ammonia yields the desired system directly with the correct functionalities in place.

$$
\text { Mander's strategy for the construction of the }
$$

bicyclo|3.2.1/octane system is based on an acid catalysed cyclisation of unsaturated $\alpha$-diazoketones. 61 The approach is adaptable to the synthesis of C/D-rings containing a hydrogen, a methyl or a hydroxyl group at the bridgehead position without any drastic changes to the sequence. 62 Its efficiency has been illustrated in the synthesis of precursors 22 
$(\mathrm{R}=\mathrm{H}, \mathrm{OH})$ for the gibberellins $\mathrm{A}_{1}, \mathrm{~A}_{3}, \mathrm{~A}_{8}$ and $\mathrm{A}_{4}$ (Scheme 23) $\cdot^{33-35}$<smiles>[R]C1([R])CCc2cccc(OC)c2C1</smiles>

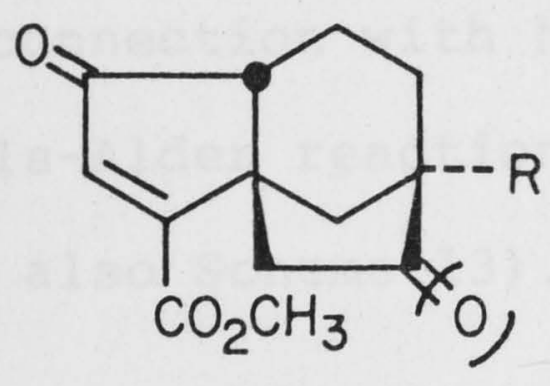

22

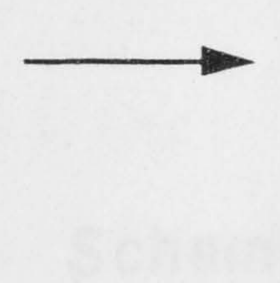

8 steps

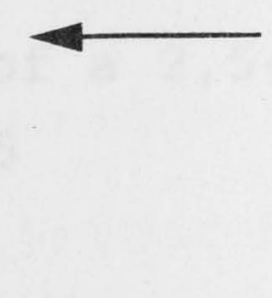

$\mathrm{R}=\mathrm{H}, \mathrm{OH}$

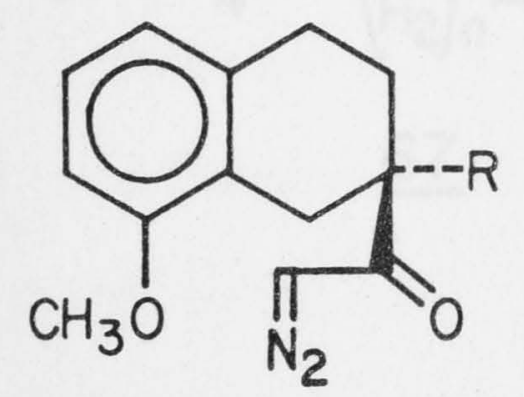

65

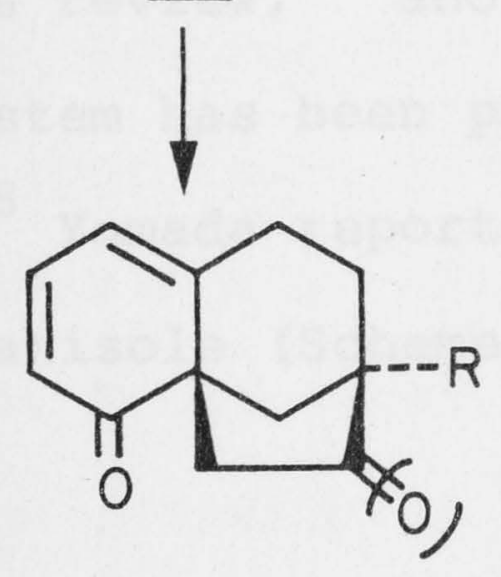

$\underline{66}$

\section{Scheme 23}

The readily prepared aromatic diazoketone 65 , on treatment with trifluoroacetic acid, affords the tricyclic diketone 66 , which is subsequently transformed into the key intermediate 22 (cf. Scheme 8) by a sequence including a photochemically induced Wolff rearrangement. Cyclisation of diazoketones can also be achieved with styrene double bonds acting as nucleophiles. This cyclisation provides a very direct transformation of hydrofluorenones and hydrophenanthrenones into tetracyclic compounds such as $67(n=1,2) \quad($ Scheme 24$) .63,64$ 

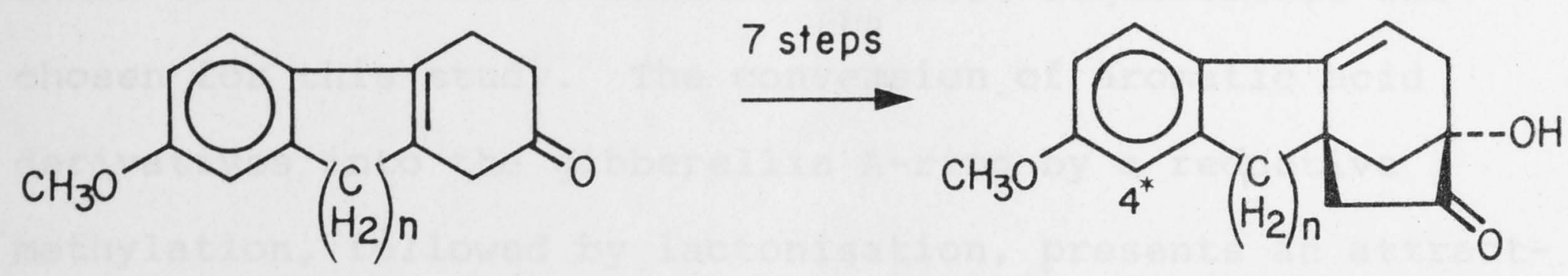

67

\section{Scheme 24}

Since the publication of Fujita's review, ${ }^{17}$ another construction of the |3.2.1|octanol system has been proposed. In connection with his earlier work, ${ }^{48}$ yamada reported a Diels-Alder reaction of a 2,5-dihydroanisole (Scheme 25, see also scheme 13).65

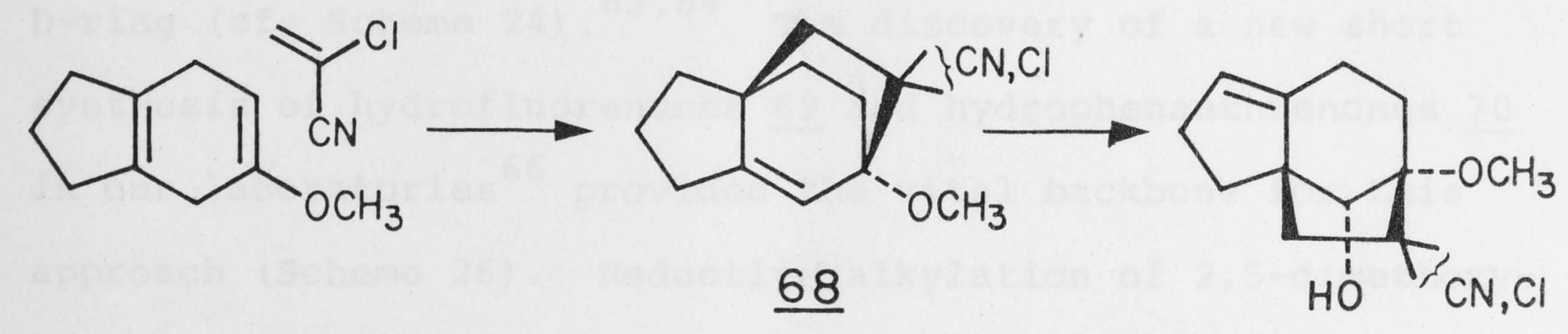

\section{Scheme 25}

Epoxidation of the adduct $\underline{68}$ was followed by a skeletal rearrangement to yield the desired system.

Although only a small slice of the actual research in the field of the gibberellin synthesis has been covered here, several successful approaches did, and may still, emerge from these ideas. They will have to include a short and efficient assembly of the gibberellin skeleton, the incorporation and effective manipulation of the numerous labile functional groups, and the maintenance of stereochemical control throughout the whole sequence. A strategy 
which seemed to meet a maximum of these requirements was chosen for this study. The conversion of aromatic acid derivatives into the gibberellin A-ring by a reductive methylation, followed by lactonisation, presents an attractive route to the gibberellins. These transformations have been performed successfully on model compounds by Loewenthal's group (Scheme 16) 51 and by House et al. (Schemes 19,20).56,57 The precursors required for this transformation, compounds such as 67 , containing an additional carboxyl group at $\mathrm{C} 4$ *, should be accessible from either the corresponding hydrofluorenone $(n=1)$ or hydrophenanthrenone $(n=2)$ using Mander's procedure for the addition of the D-ring (cf. Scheme 24). 63,64 The discovery of a new short synthesis of hydrofluorenones $\underline{69}$ and hydrophenanthrenones 70 in our laboratories ${ }^{6} 6$ provided the vital backbone for this approach (Scheme 26). Reductive alkylation of 2,5-dimethoxybenzoic acid with benzyl- or phenethyl halides, followed by an acid promoted cyclisation gave the hydrofluorenones 69 and hydrophenanthrenones 70 , respectively, in good yields. In view of the planned synthesis, the sequence had to be extended to produce $\mathrm{C} 33^{*}$-oxygenated compounds $\underline{69}$ and/or 70 possessing a 4 *-carboxyl group, to allow further manipulation as outlined above. 


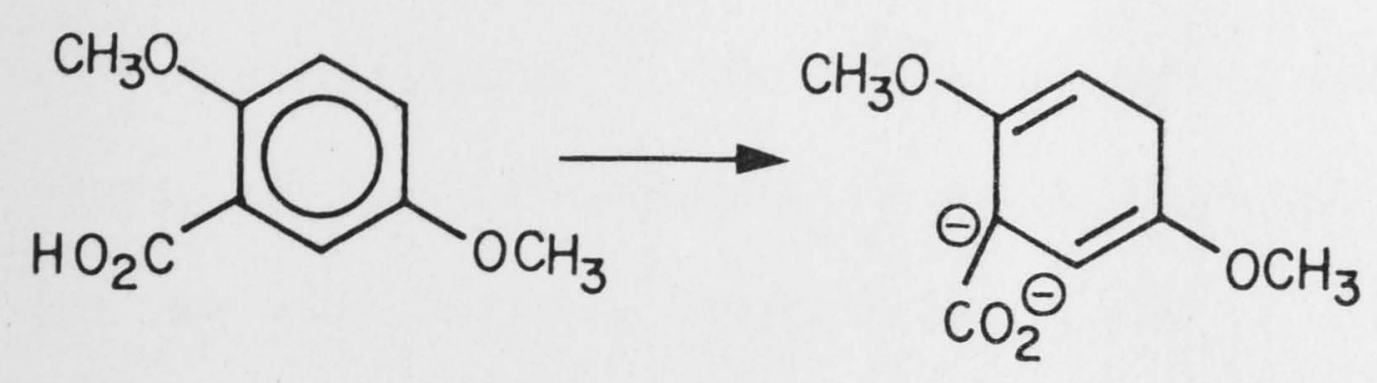

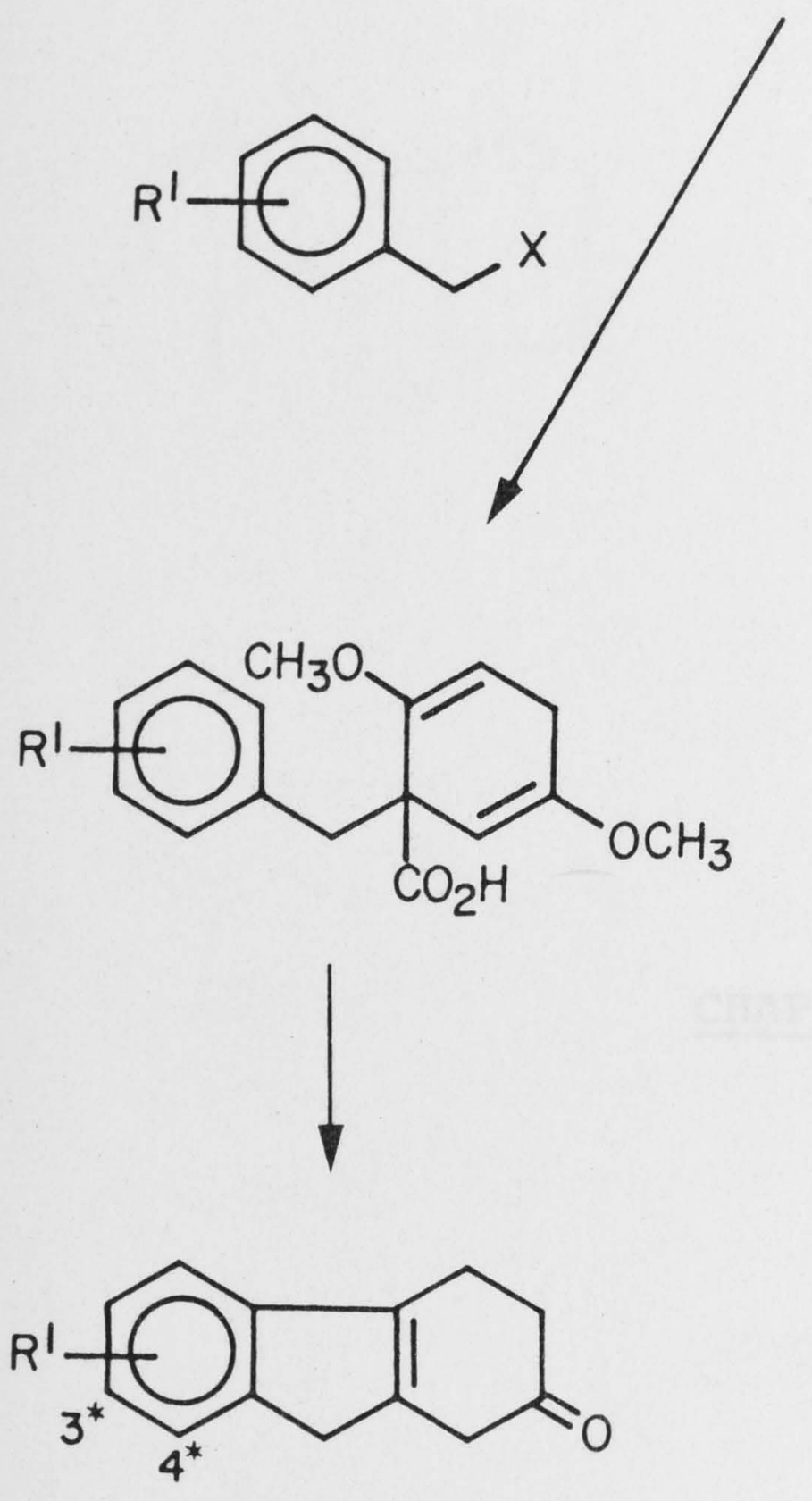

$\underline{69}$
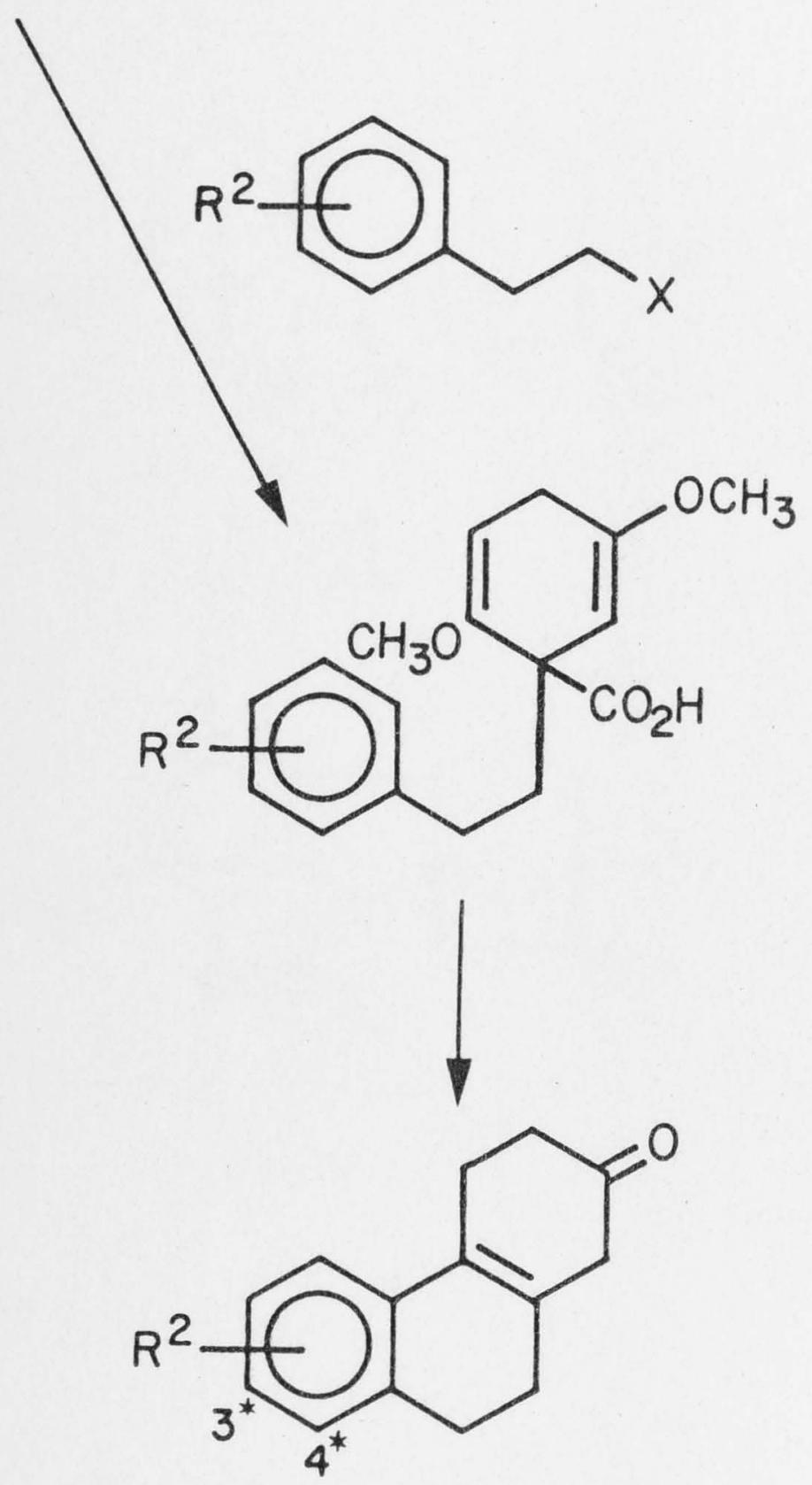

70

Scheme 26

The scope of this new route for the synthesis of hydrofluorenones and hydrophenanthrenones, containing the crucial functional groups, is explored in the first part of this thesis. Elaboration of the resulting intermediates to tetracyclic gibberellin precursors, culminating in the formal total synthesis of the ultimate target, gibberellic acid, is described in the second part. 
CHAPTER 1 
Retrosynthetic analysis as outlined in the introduction leads to the fluorenone 71 as a logical tricyclic precursor for an efficacious synthesis of $\mathrm{GA}_{3} \underline{2}$ (Scheme 27).

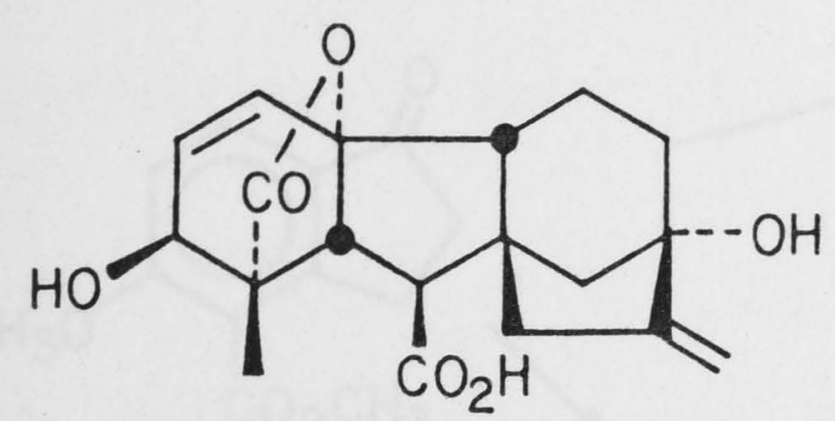

$\underline{2}$<smiles>CCOC(=O)c1c(OC)ccc2c1CC1=C2CCC(=O)C1</smiles>

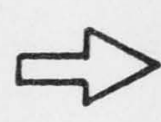<smiles></smiles>

$\sqrt{3}$

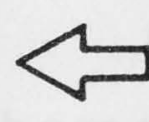

71

Scheme 27

The synthesis of fluorenone 71 through an annulation procedure starting from a suitably substituted $\beta$-indanone ${ }^{67}$ is impractical, since two regioisomers can be obtained. The $\alpha$-indanone $72^{52}$ could in principle be converted into either the fluorenone 71 , using the annulation method developed by Ponaras, ${ }^{68}$ or into its cyanohydrin (the next compound in the planned synthesis) by a sequence involving a Diels-Alder reaction (Scheme 28).63 Both transformations, however, lack the efficiency required in the early stages of such a synthesis, and furthermore, imply the preparation of 
$\alpha$-indanone 72 , available in seven steps. ${ }^{52}$
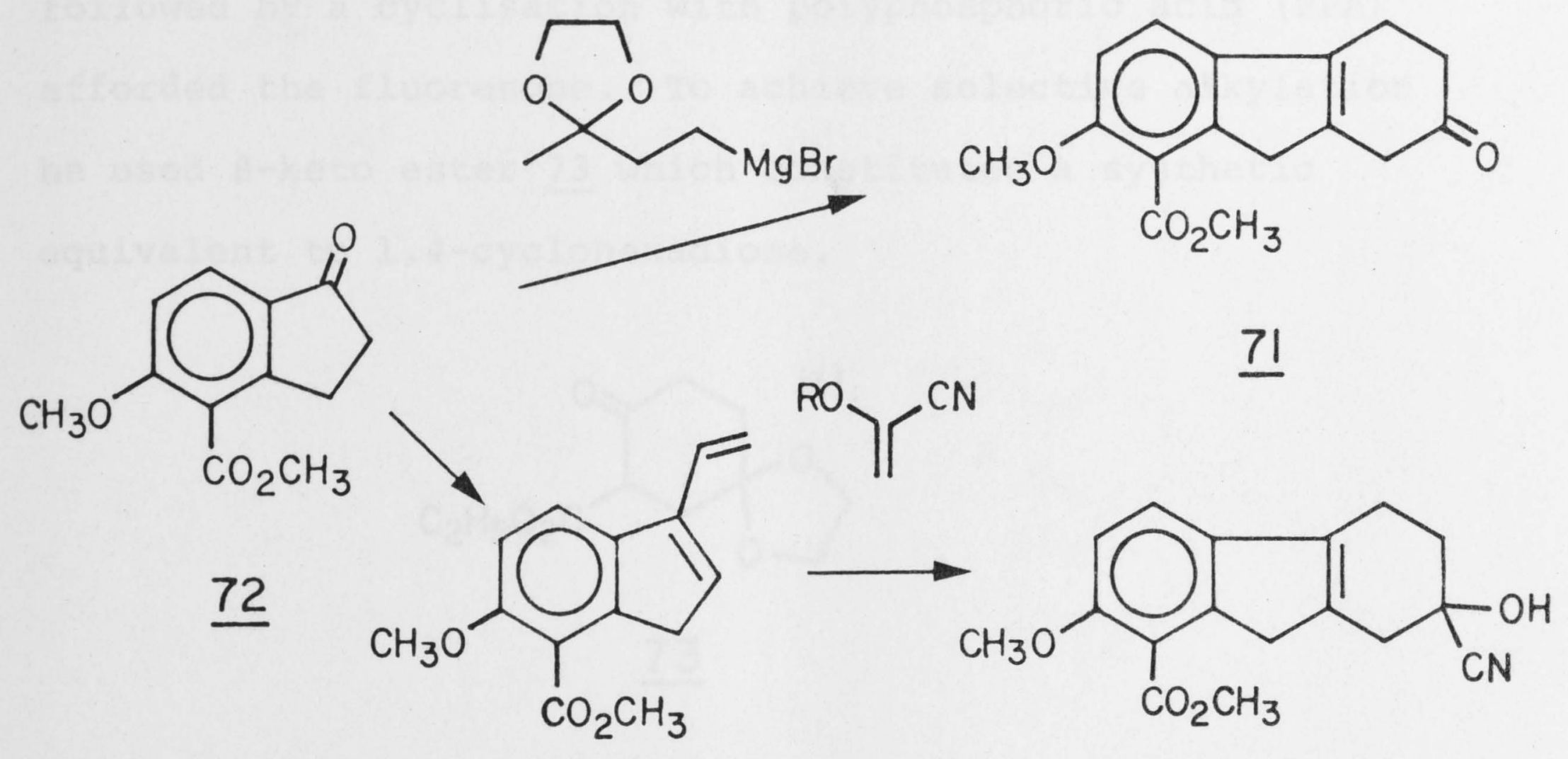

\section{Scheme 28}

An alternative approach originally put forward by Thompson 69 appeared more suitable for this task (Scheme 29).

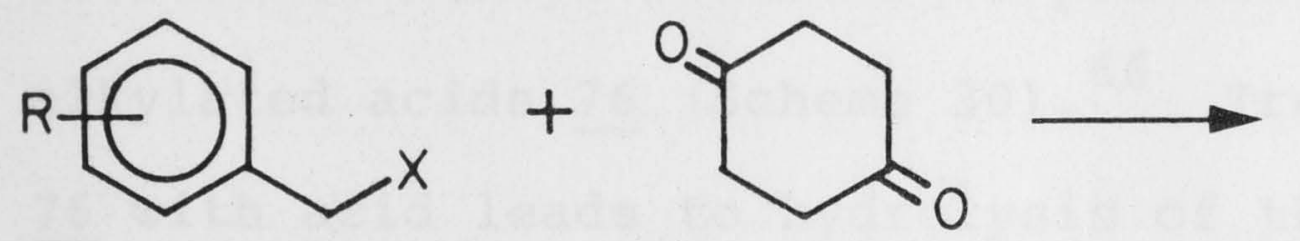<smiles>[R]CCCC(Cc1ccccc1)C1CC(=O)CCC1=O</smiles>
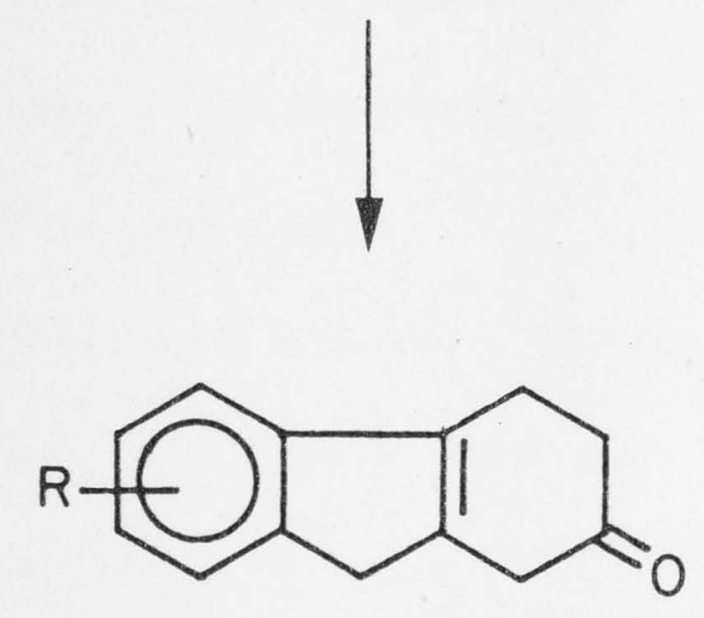

Scheme 29 
Alkylation of 1,4-cyclohexadione with a benzyl halide, followed by a cyclisation with polyphosphoric acid (PPA) afforded the fluorenone. To achieve selective alkylation he used $\beta$-keto ester 73 which constitutes a synthetic equivalent to 1,4-cyclohexadione.
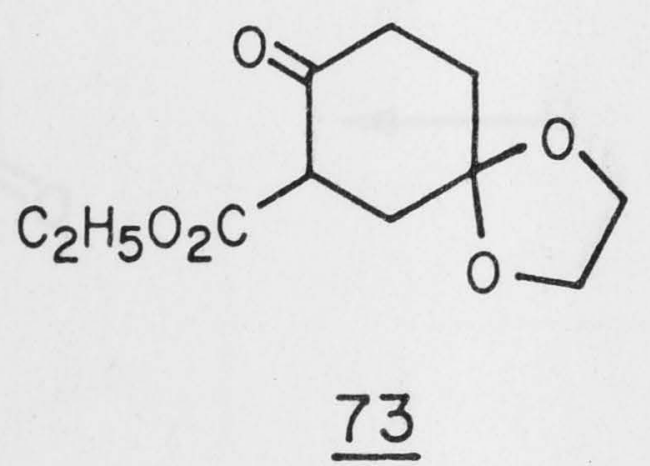

Since the preparation of keto ester $\underline{73}$ requires four steps, 70 it was fortunate that an operational equivalent to 1,4cyclohexadione was found, which is commercially available: reduction of 2,5 -dimethoxybenzoic acid $\underline{74}$ with lithium in ammonia produces dianion 75 , which reacts in situ with alkyl iodides or benzyl bromides to provide high yields of alkylated acids 76 (Scheme 30). 66 Treatment of the products 76 with acid leads to hydrolysis of the enol ethers and decarboxylation ( $\beta$-keto acid) to produce the monoalkylated 1,4-cyclohexadione 77 . 


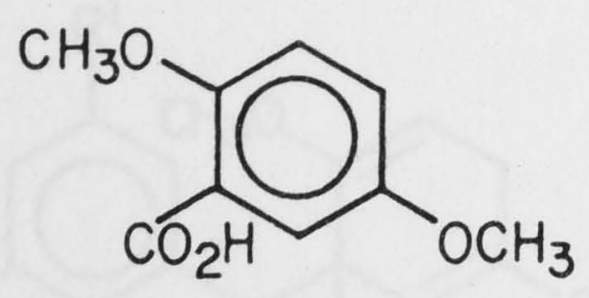

74

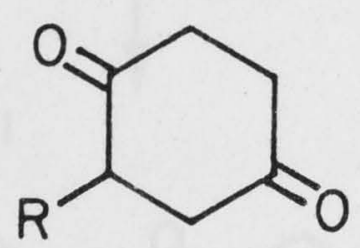

$\underline{77}$

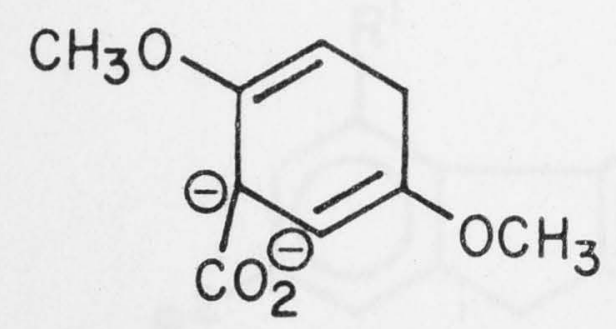

$\underline{75}$

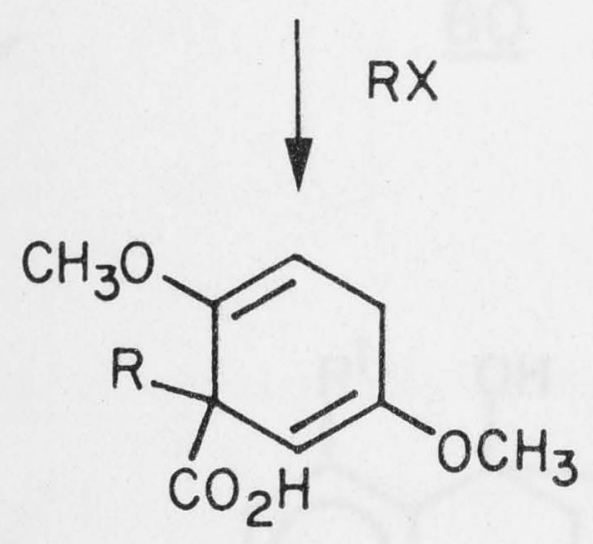

76

\section{Scheme 30}

Acids 78 , obtained from the alkylation of dianion 75 with benzyl bromides, were cyclised directly with mineral acids without isolation of the dione 79 (Scheme 31). ${ }^{66}$ The desired fluorenones 80 were only formed when the aromatic ring contained at least one methoxyl group $\left(\mathrm{R}^{1}=\mathrm{H}, \mathrm{R}^{2}=\mathrm{OCH}_{3}\right.$; $\mathrm{R}^{1}=\mathrm{R}^{2}=\mathrm{OCH}_{3}$ ), whereas the unsubstituted phenyl derivative $\left(\mathrm{R}^{1}=\mathrm{R}^{2}=\mathrm{H}\right)$ gave the bicyclo/3.3.1/nonane 81 through cyclisation onto the alternative ketone (C5). The preference for the formation of the six- rather than the five-membered ring had been observed earlier in similar systems. ${ }^{1,72}$ The cyclisation of $\underline{79}$ to the bicyclo/3.3.1/nonane system, however, was found to be reversible, provided that it contained an electron-rich aromatic ring $\left(\mathrm{R}^{1}=\mathrm{H}, \mathrm{R}^{2}=\mathrm{OCH}_{3} ; \mathrm{R}^{1}=\mathrm{R}^{2}=\mathrm{OCH}_{3}\right) .66$ Reprotonation of the aromatic ring in the bicyclo/3.3.1/nonane 81 led to cleavage of the newly formed bond and thereby regeneration of dione 79 (cf. Scheme 31 ). 
<smiles>[R]c1cc([R])cc(CC2(C(=O)O)C=C(OC)CC=C2OC)c1</smiles>

78

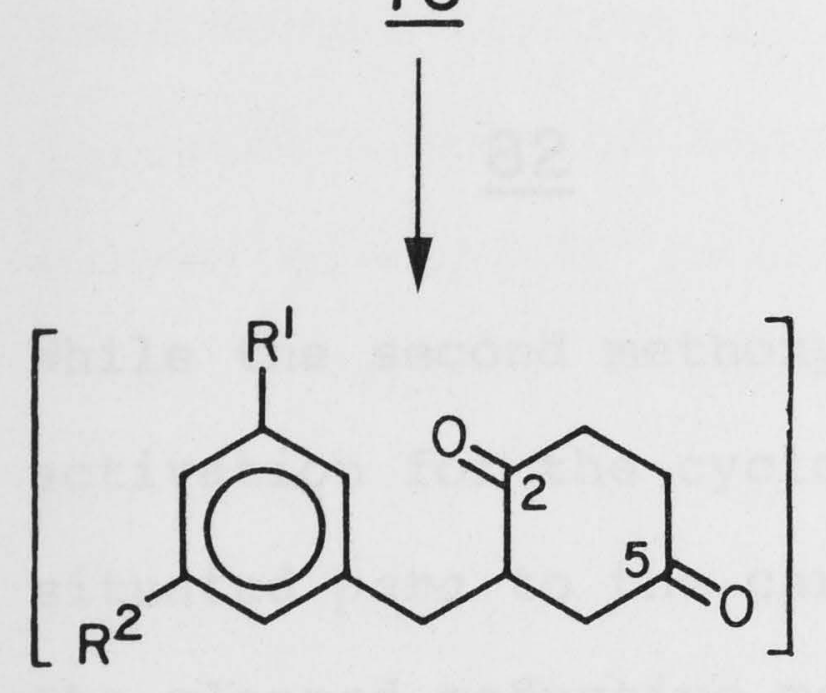

79

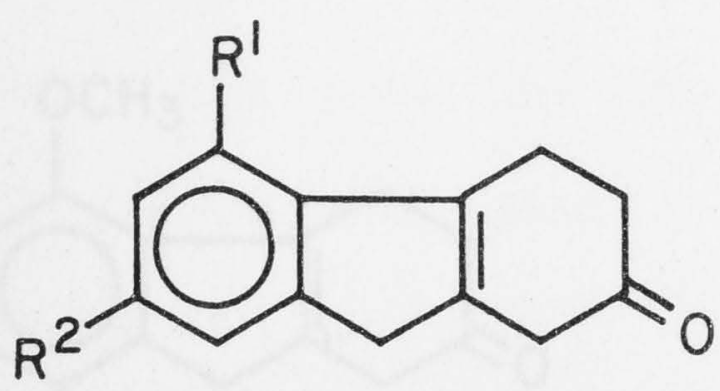

$\underline{80}$

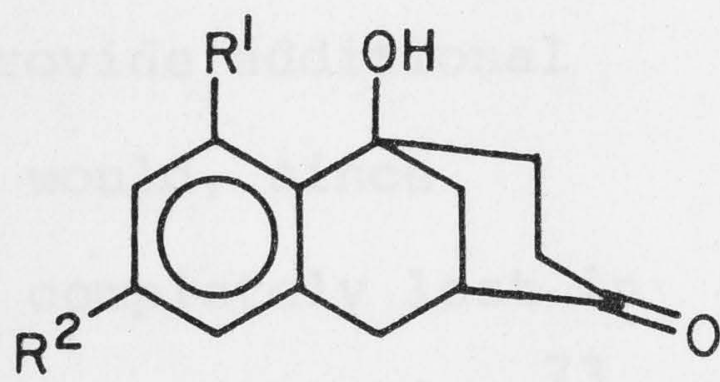

81

\section{Scheme 31}

The rapid dehydration occurring in the fluorenone skeleton, once it has formed, prevents a similar reversal. 66 Therefore it could not be taken for granted that a cyclodehydration leading to the desired fluorenone 71 would take place, since the aromatic ring contains an electron-withdrawing carbomethoxyl group. Hence it seemed advisable to attempt the synthesis of the analogous dimethoxyfluorenone $\underline{82}$ or 83 first. 
<smiles>COc1cc(OC)c2c(c1C(C)=O)CC1=C2CC(=O)CC1</smiles>

82

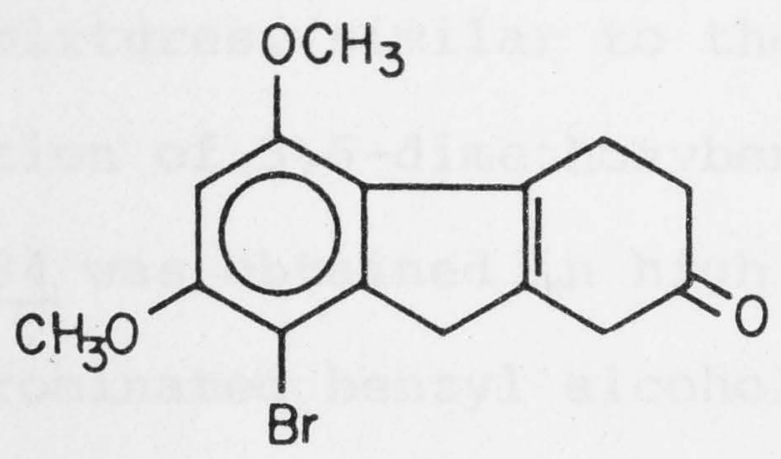

83

While the second methoxyl group would provide additional activation for the cyclodehydration, it would, since situated para to the carboxyl group, be completely lost in the planned reductive methylation of the aromatic ring. 73 The presence of the less electron-withdrawing bromine atom rather than the carboxyl group, in the precursor to 83 should once more enhance the probability of forming the fluorenone instead of the bicyclo/3.3.1/nonane system during the cyclisation. With a short synthesis of the required benzyl bromide 84 at hand, 74 the construction of the hydrofluorenone 83 was initiated first.<smiles>COc1cc(CBr)c(Br)c(OC)c1</smiles>

84

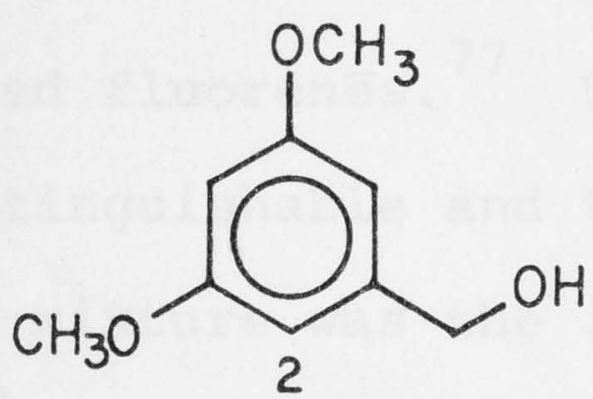

$\underline{85}$

3,5-Dimethoxybenzyl alcohol 85 was brominated selectively at the 2-position with $\mathrm{N}$-bromosuccinimide at low temperature and in the absence of light. ${ }^{74}$ This selectivity stands in contrast to experiments with bromine and the bromine-dioxane 
adduct $^{75}$ which afforded complex mixtures, similar to the one observed in the straight bromination of 3,5-dimethoxybenzyl bromide. 76 The desired bromide 84 was obtained in high yield on treatment of the ring-brominated benzyl alcohol with phosphorqus tribromide. ${ }^{74}$ Alkylation of the dianion 75 with 1.3 equivalents of benzyl bromide 84 in ammonia gave the alkylated acid $\underline{86}$ in good yield (77\%). Cyclodehydration of $\underline{86}$ under a variety of conditions (60-85\% sulfuric acid, PPA) provided dark coloured complex mixtures (analysed by ${ }^{1} \mathrm{H}$ nuclear magnetic resonance (n.m.r.) spectroscopy and thin layer chromatography (t.1.c.)). The cleanest mixture, obtained from the cyclisation in $60 \%$ sulfuric acid at roomtemperature, was chromatographed and the two major fractions were analysed. The first fraction was a $\sim 1: 2$ mixture of hydrofluorenones 83 and 87 , the more polar band contained fluorenols 88 and 89 (Scheme 32). Fluorenols 88 and 90 were easily identified by the low field resonance of $\mathrm{H} 4$ in the ${ }^{{ }^{1}} \mathrm{H}$ n.m.r. spectrum ( $\delta 7.78 \mathrm{ppm})$. The downfield shift of $\mathrm{H} 4$, caused by congestion with the 5-methoxyl substituent, is characteristic of similarly substituted fluorenes. ${ }^{77}$ The ${ }^{1_{H}}$ n.m.r. shifts of 88 and $\underline{89}$ were indistinguishable and the only indication for the presence of a mixture was the integration for $\sim 3.5$ protons over the aromatic region (exclusive of $\mathrm{H} 4$ ). The mass spectra (m.s.) showed intense molecular ions for both compounds 88 (m/z 322/320) and $\underline{89}(\mathrm{~m} / \mathrm{z} 242)$. The fluorenones 83 and 87 showed the expected ${ }^{1} \mathrm{H}$ n.m.r. resonances in the aliphatic region $(\delta 2.56, t, J=8 \mathrm{~Hz}, \mathrm{H} 3$; $3.10, \mathrm{~m}, \mathrm{H} 4 ; 3.76, \mathrm{e}, \mathrm{Hl}, \mathrm{H} 9) .66$ The methoxyl and aromatic 
protons of the two compounds had different shifts and therefore an approximate ratio could be obtained from the integration. The presence of both molecular ions in the mass spectra (m/z $324 / 322(\underline{83}), 244$ (ㄱ) $)$, substantiated the assignments. A rationalisation for the formation of compounds 83, $87-89$ is given in scheme 32. The ring-closure onto the carbon atom bearing the bromine seems to be favoured over the desired cyclisation. The oxidation to the fluorenols 88 and<smiles>COC1=CC(Cc2cc(OC)cc(OC)c2Br)(C(=O)O)C(OC)=CC1</smiles><smiles>COc1cc(OC)c2c3c(sc2c1Br)C(C)CC(=O)C3</smiles><smiles>COc1cc(OC)c2c(c1Br)Cc1cc(O)ccc1-2</smiles>
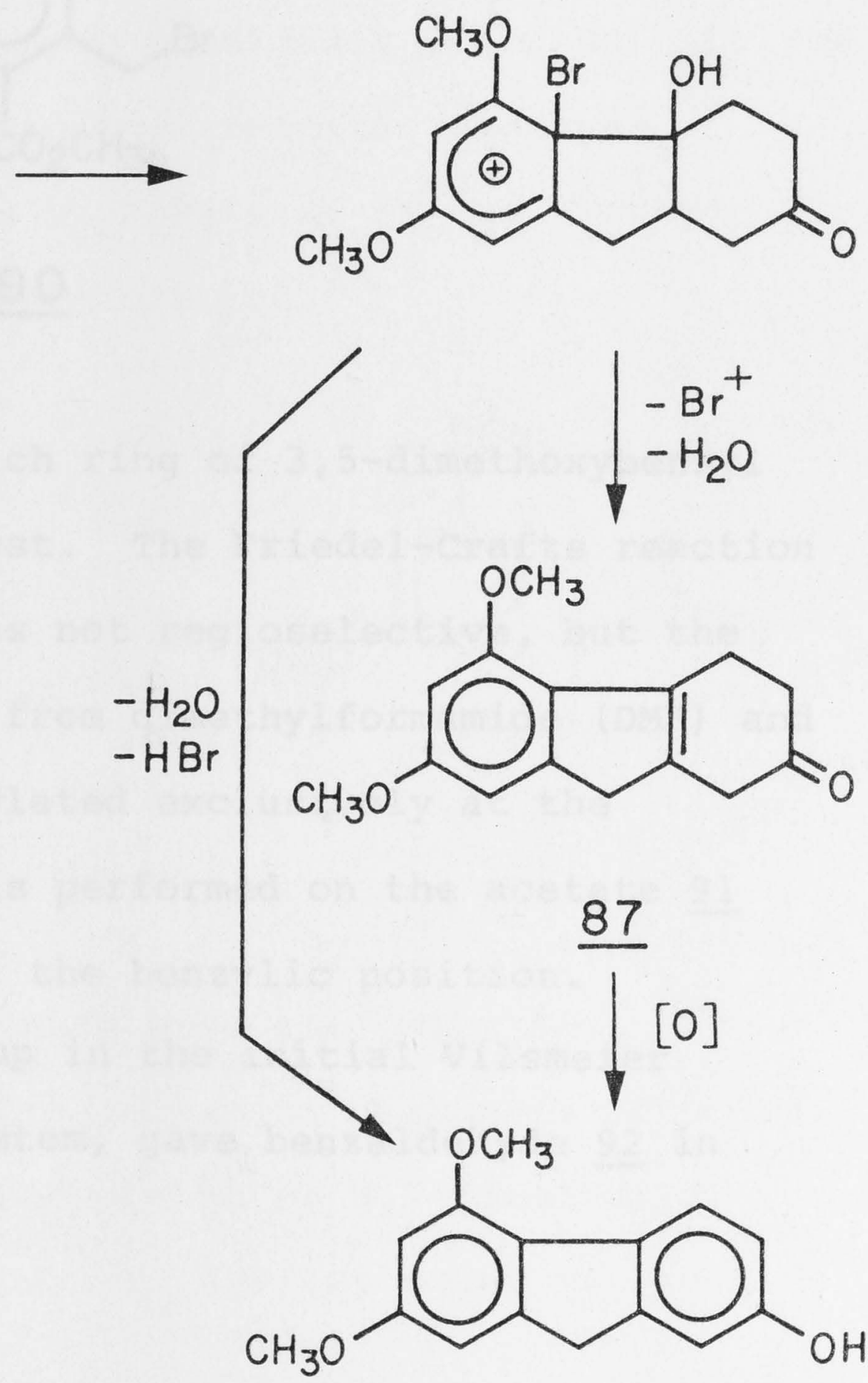
89 could be caused by the liberated bromonium ion or by

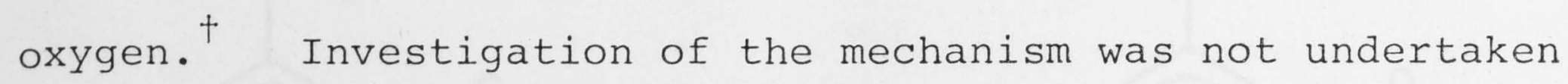
as the precious bromide functionality was lost anyway. Instead, attention was turned towards the synthesis of bromide $\underline{90}$, the alkylating agent needed for the construction of fluorenone 82 .

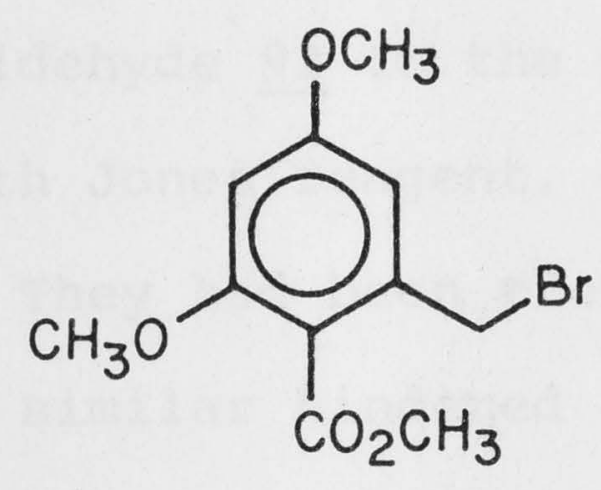

\section{0}

Acylation of the electron-rich ring of 3,5-dimethoxybenzyl alcohol 85 was attempted first. The Friedel-crafts reaction with methyl chloroformate was not regioselective, but the Vilsmeier reagent (obtained from dimethylformamide (DMF) and phosphordus oxychloride) acylated exclusively at the 2-position. The reaction was performed on the acetate 91 to prevent side reactions at the benzylic position. Hydrolysis of the imino group in the initial Vilsmeier product using a buffered system, gave benzaldehyde $\underline{92}$ in almost quantitative yield.

The fluorenones 83 and 87 were also oxidised during isolation and purification. 
<smiles></smiles>

91<smiles></smiles>

92

Oxidation of the aldehyde $\underline{92}$ to the corresponding acid could not be achieved with Jones reagent, even in the presence of cerium(IV) ions. They had been previously added to catalyse the oxidation of a similar hindered aromatic aldehyde. 52 Acid 93 was finally obtained by treatment of the aldehyde 92 with hot aqueous potassium permanganate. $78,+$<smiles>COc1cc(COC(C)=O)c(C(=O)O)c(OC)c1</smiles>

93<smiles>COCc1cc(OC)cc(OC)c1C(C)=O</smiles>

94

Esterification with diazomethane gave the ester 94 . Hydrolysis of the acetate with potassium carbonate afforded a single compound which turned out to be 5,7-dimethoxyphthalide $95^{80}$ and not the desired hydroxy ester 96 .

\footnotetext{
'Today, the oxidising agent of choice would most likely be tetrabutylammonium permanganate. 79
} 
<smiles>COc1cc2c(c(OC)c1)C(=O)OC2</smiles>

95<smiles>COC(=O)c1c(CO)cc(OC)cc1OC</smiles>

96

Selective hydrolysis of the acetyl functionality in 94 with one equivalent of sodium hydroxide gave an identical result. Phthalide 96 was also the only product obtained upon hydrolysis of the acetate of acid 93. This result was rather confusing, since the hydroxy acid 97 was readily isolated from the hydrolysis of the corresponding phthalide (Scheme 33).81
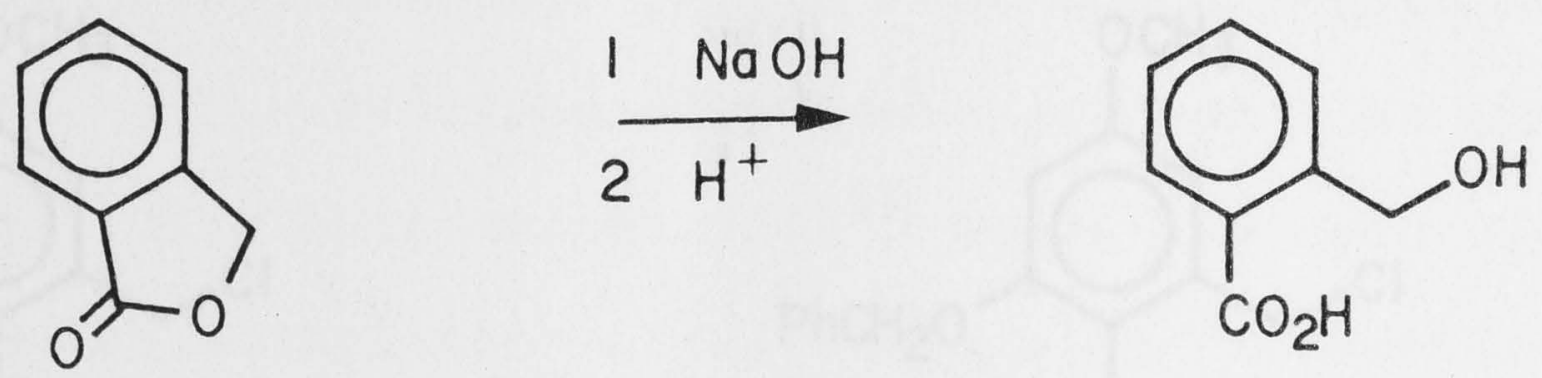

\section{$\underline{97}$}

\section{Scheme 33}

In an attempt to circumvent the cyclisation of the hydroxy ester 96 during the deprotection of the hydroxyl group, 3,5-dimethoxybenzyl alcohol 85 was protected firstly as the chloroacetate and secondly as the benzyl ether, two groups which later could be removed under much milder conditions. ${ }^{82}$ 
No problems were encountered with these two substrates in the Vilsmeier reaction, but neither withstood the harsh oxidising conditions and no distinct products were obtained. Another approach was the $\mathrm{S}_{\mathrm{N}}{ }^{2}$-type opening of 5,7-dimethoxyphthalide 95 with gaseous hydrogen bromide in methanol to give directly the bromo ester 90. It appeared that with high concentrations of hydrogen bromide in methanol the bromo acid was formed instead (t.1.c. analysis), but the reaction reversed to the phthalide $\underline{95}$ as soon as the excessive hydrogen bromide was removed from the solution.

At the same time, work carried out in neighbouring laboratories seemed to indicate a different solution to this problem. Benzyl chloride $98\left(\mathrm{R}=\mathrm{CH}_{2} \mathrm{Ph}\right)$ had been lithiated at $-100^{\circ}$, and subsequent reaction with carbon dioxide gave the corresponding acid $\underline{99}$ in moderate yield. 83<smiles>[R20]c1cc(OC)cc(CCl)c1Br</smiles>

98

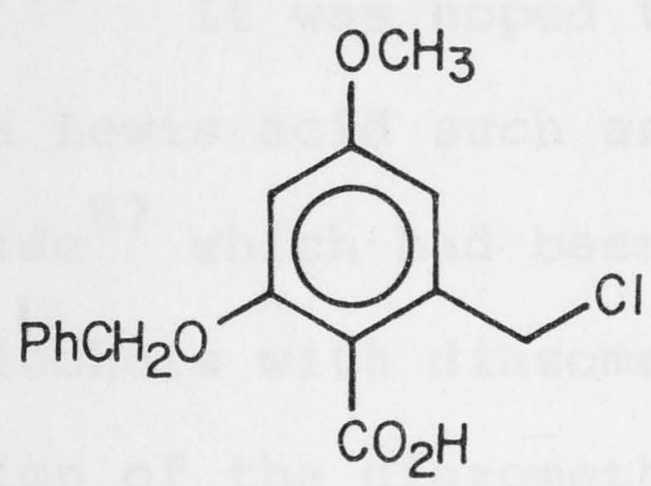

99

Repetition of the sequence with benzyl chloride $98\left(\mathrm{R}=\mathrm{CH}_{3}\right)$ produced only phthalide 95 in spite of the precaution taken during the reaction and work-up.

This series of incidents made it clear that possible interactions between the carboxyl and the benzylic groups had to be eliminated if a successful synthesis of bromo ester 90 
was to be achieved. An approach fulfilling these requirements was found in the bromination ${ }^{80}$ of ortho-toluic ester $\underline{100} .^{84 \dagger}$<smiles>COC(=O)c1c(C)cc(OC)cc1O</smiles>

100

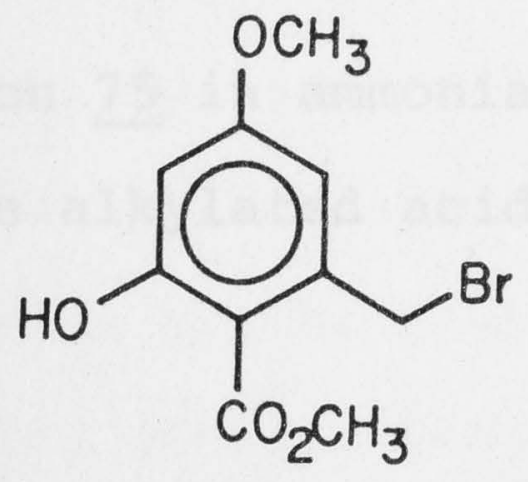

$\underline{101}$

Reaction of this strongly hydrogen-bonded ester (infra red (i.r.) $\nu_{\max } 1650 \mathrm{~cm}^{-1}$ ) with bromine afforded the benzyl bromide 101 in much higher yield than had been reported, 80 when a radical carrier was added. Methylation of o-phenolic esters is known to be a slow process and is often not at all possible with diazomethane. $80,85,86$ It was hoped to solve this problem by the addition of a Lewis acid such as boron trifluoride 86 or aluminium chloride ${ }^{87}$ which had been used to catalyse the methylation of alcohols with diazomethane. Both catalysts led to decomposition of the diazomethane prior to methylation of phenol 10l. Methanol had been found to be a superior catalyst than the Lewis acids in the addition of diazomethane to aldehydes and ketones. 88 Accordingly, the methylation of phenol 101 with five equivalents of diazomethane in 5\% methanol/ether over five days at $2^{\circ}$ gave

The bromination is reported on the ethyl ester, 80 but was performed on the methyl ester in view of future planned conversions. 
about $90 \%$ conversion. The resulting dimethoxybromo ester 90 had to be separated by chromatography from the phenolic starting material, since basic extraction of the latter from the mixture was unsuccessful.

Addition of bromide $\underline{90}$ to dianion $\underline{75}$ in ammonia and tetrahydrofuran (THF) (10:1) gave the alkylated acid 102 in $71 \%$ yield.<smiles>COC1=CC(Cc2cc(OC)cc(OC)c2C(=O)O)(C(=O)O)C(OC)=CC1</smiles>

102

The optimised cyclodehydration of acid 102 with PPA at room temperature afforded a single product in good yield. Unfortunately, it proved to be very unstable and was very difficult to handle. All spectroscopic data $\left({ }^{1} \mathrm{H}\right.$.m.r., i.r., ultra violet (u.v.), m.s.) were in full agreement with the structure 103, a double bond isomer of the expected<smiles>COC(=O)c1c(OC)cc(OC)c2c1CC1=CC(=O)CCC12</smiles>

$\underline{103}$<smiles>COC(=O)c1c(OC)cc(OC)c2c1CC1=C2CC2(CC1)OCCO2</smiles>

$\underline{105}$ 
fluorenone $82 .{ }^{+} \quad$ A confirmation of the structure 103 was obtained by its conversion to the slightly more stable ketal 105. It was fortunate that the formation of the isomeric fluorenone 103 would not affect the progress of the sequence. The addition of hydrogen cyanide to the ketone 103 is expected to proceed in a 1,2-fashion followed or probably preceded by an isomerisation of the double bond into conjugation with the aromatic ring (Scheme 34 ).<smiles>COc1cc(OC)c2c(c1C(C)=O)CC1=CC(=O)CCC12</smiles><smiles>COC(=O)c1c(OC)cc(OC)c2c1CC1=C2CCC(O)(C#N)C1</smiles>

103

Scheme 34

† Another fluorenone, 104 , possessing an $\alpha, \beta$-unsaturated ketone was obtained later. $6 \overline{6}$

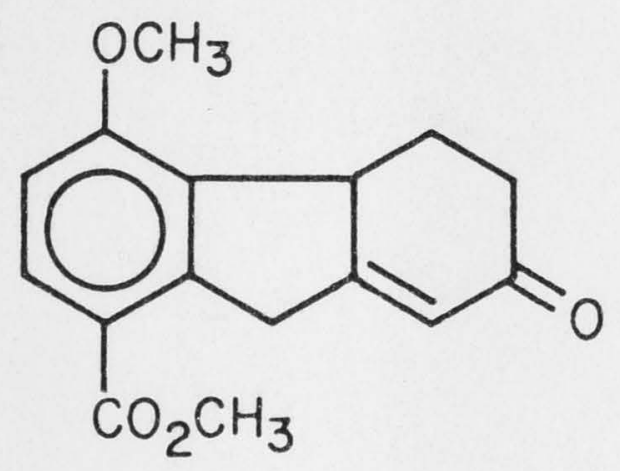

104 
Alternatively, the fluorenone 82 could most likely be isolated from a cautious hydrolysis of ketal 105. The successful preparation of fluorenone 103 substantiated the feasibility of the proposed strategy for the synthesis of gibberellin intermediates. The cyclodehydration to the fluorenone took its course without incident in the presence of the vital carbomethoxyl substituent. The instability of the product, however, reduced the practicability of such an approach which would require large scale preparation of this fluorenone. Therefore it seemed worthwhile to investigate the synthesis of different precursors, with a similar potential for the gibberellin synthesis, before an attempt starting from fluorenone 103 was made. 
CHAPTER 2 
The search for a more stable, readily accessible intermediate which presented the same prospects for the gibberellin synthesis as offered by fluorenones 83 and 103 , led to the possibility of using a hydrophenanthrenone such as 106.

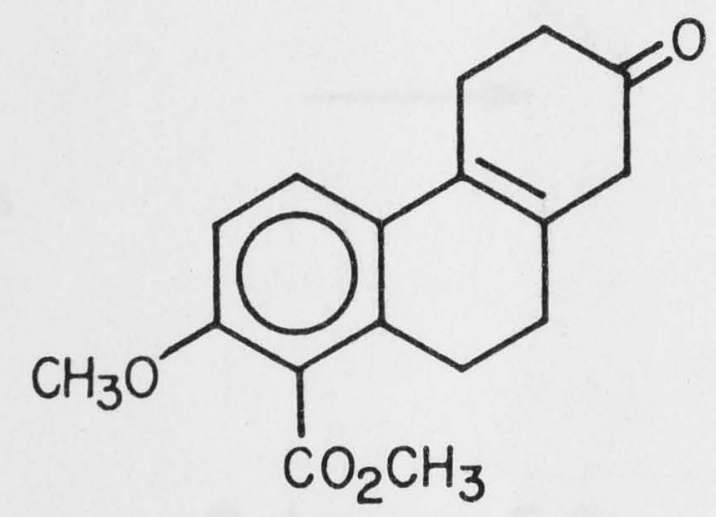

\section{6}

The potential of the hydrophenanthrene nucleus as an intermediate in the gibberellin synthesis is well established (vide supra) and different methods for the required B-ring contraction have already been presented. In our laboratories, a particularly convenient procedure has been devised (Scheme 35)43,89 in which diazoketone 107 was prepared, using a novel direct diazo-group transfer, 90 and subjected to a photochemically induced Wolff rearrangement which effected the ring contraction to give the desired acid 108. ${ }^{43}$

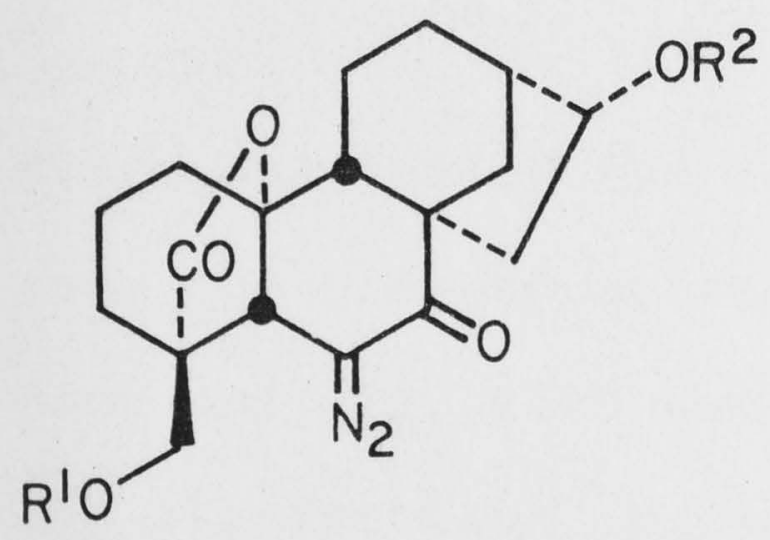

$\underline{107}$

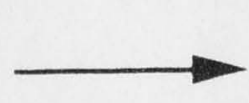

Scheme 35 
An alternative route for this transformation was proposed by Hanson and Galt, 91 and has since been applied successfully in the synthesis of $c_{20}$ gibberellins (Scheme 36).92,93
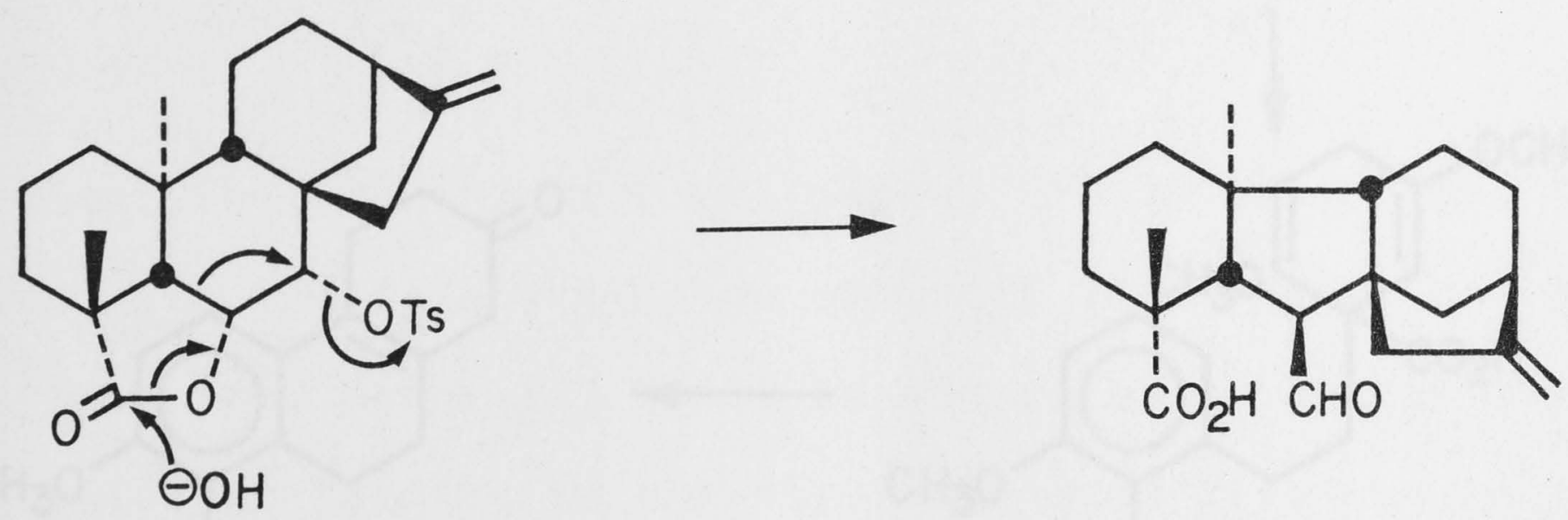

\section{Scheme 36}

Based on the preparation of fluorenone 103 and the successful alkylation of dianion 75 with simple phenethyl iodides, ${ }^{66}$ the synthesis of the initially required hydrophenanthrenone 106 seemed fairly straightforward through alkylation of $\underline{75}$ with phenethyl iodide 109 , then cyclisation of the intermediate acid 110 (Scheme 37). 
<smiles>COC(=O)c1c(CCI)cccc1OC</smiles>

109<smiles>COc1ccc2c(c1C(C)=O)CCC1=C2CCC(=O)C1</smiles>

106<smiles>COC1=CC(OC(=O)[O-])C(OC)=CC1</smiles><smiles>COC1=CC(CCc2cccc(OC)c2C(=O)O)(C(=O)O)C=CC1</smiles>

\section{Scheme 37}

Attachment of the D-ring by an established procedure ${ }^{64}$ then should readily yield the tetracyclic ester 111 .<smiles>[R]O[C@]12CC=C3c4ccc(OC)c(C(C)=O)c4CCC3(CC1=O)C2</smiles>

III

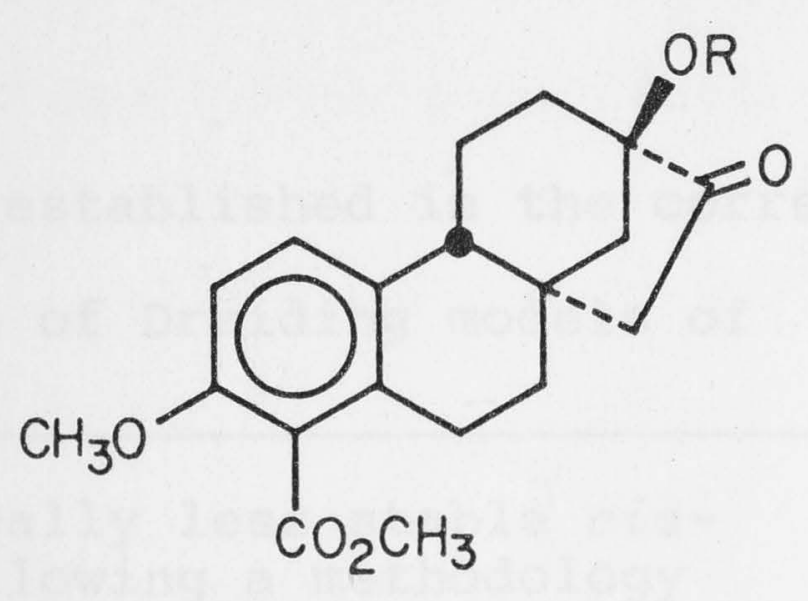

112

Hydrogenation of the double bond in 111 occurs exclusively from the side opposite to the two carbon bridge 94 to give compound 112, with the BC-rings joined in a trans-fashion. The cis-junction, present in all gibberellins, should be obtainable through rearrangement, for example by the acyloin 
isomerisation which occurs readily in these systems: $66,+$
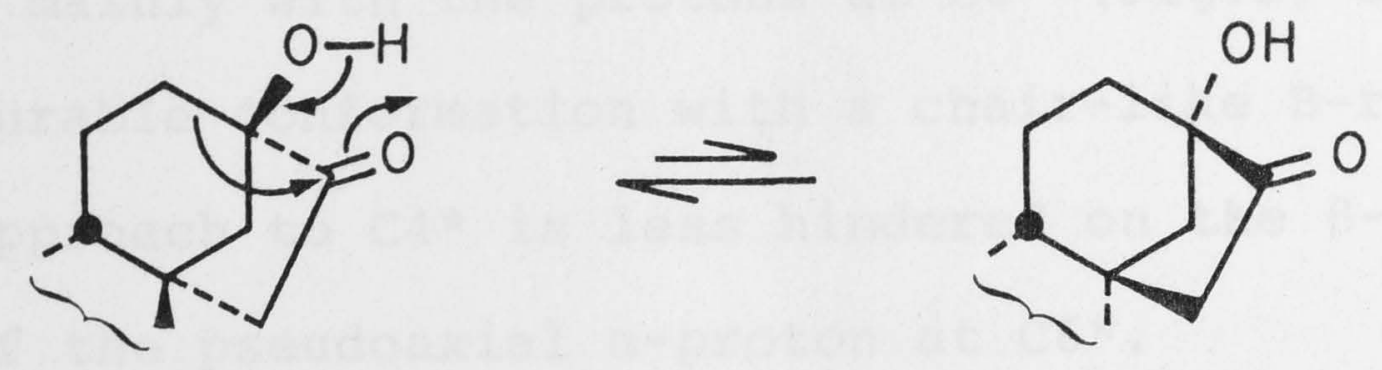

However, before this isomerisation, the intention was to elaborate the A- and B-rings of ester 112. Thus, the acid derived from ester 112 would be subjected to a reductive methylation leading to the alkylated acid 113 .

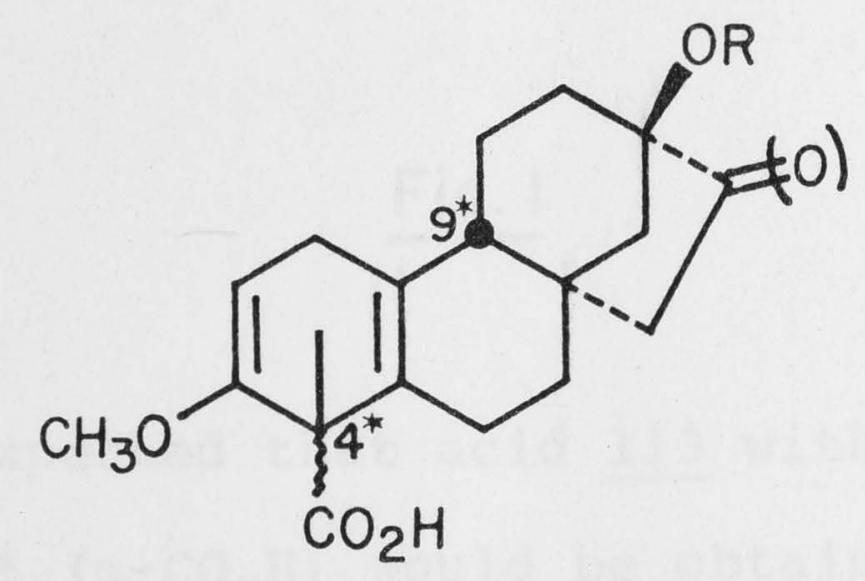

\section{3}

The stereochemistry at $\mathrm{C} 4$ * must be established in the correct relationship to $\mathrm{C}^{*}$. An inspection of Dreiding models of

Isomerisation to the thermodynamically less stable ciscompound should be possible by following a methodology which led to a similar rearrangement of camphor.95
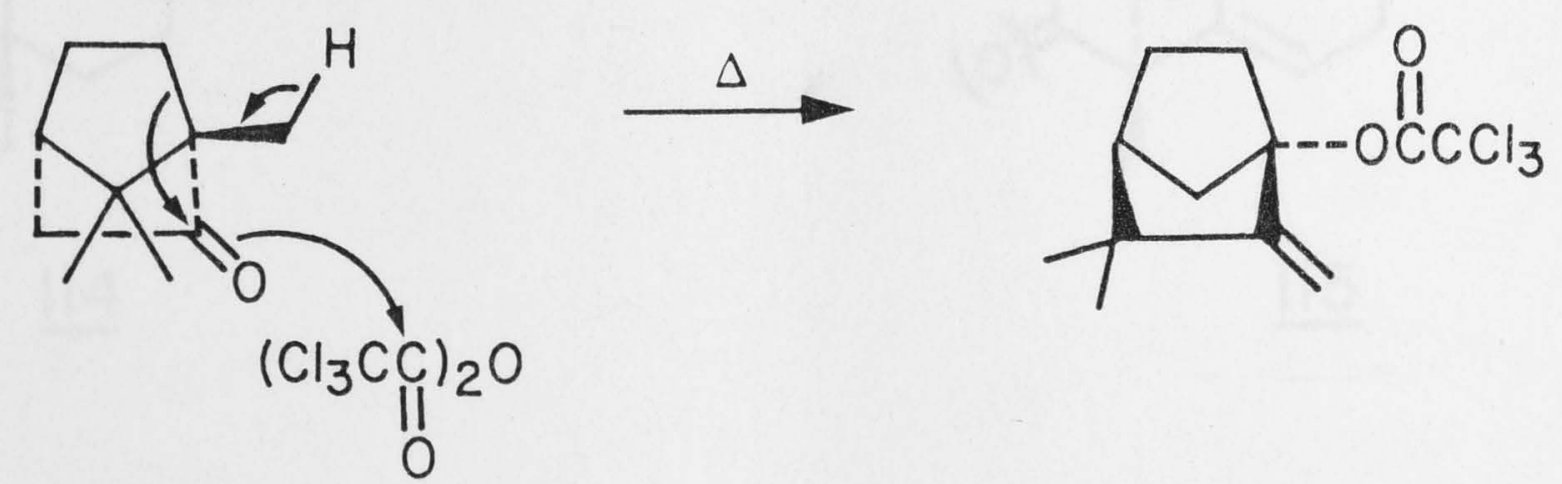

* See footnote p.7 
the anion to be alkylated, revealed that the entering group interacts mainly with the protons at C6* (Fig.1) and, in the most favourable conformation with a chair-like B-ring, "axial" approach to $\mathrm{C} 4$ * is less hindered on the $\beta$-face because of the pseudoaxial $\alpha$-proton at $\mathrm{C} 6$ *
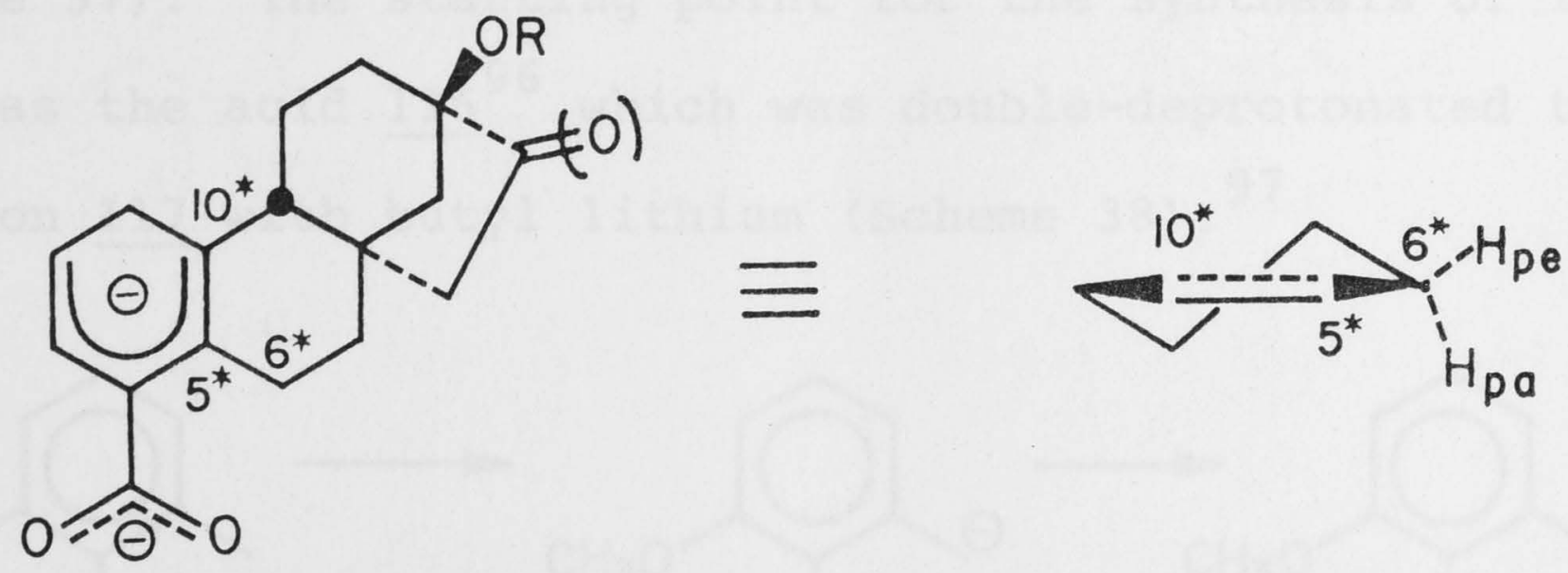

Fig. I

Hence, it was expected that acid 113 with the correct stereochemistry at $\mathrm{C} 4 *\left(\alpha-\mathrm{CO}_{2} \mathrm{H}\right)$ would be obtained as the major product. After hydrolysis of the enol ether and subsequent protection of the resulting oxygen function an iodo lactonisation $^{51}$ would give the lactone 114 .

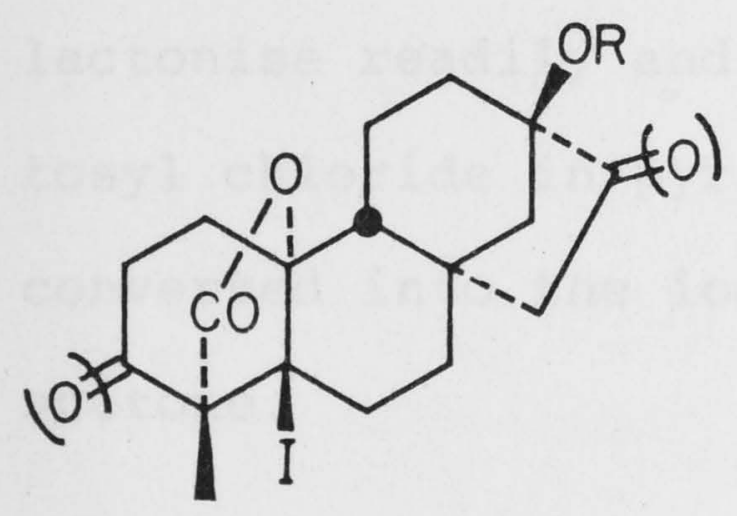

114

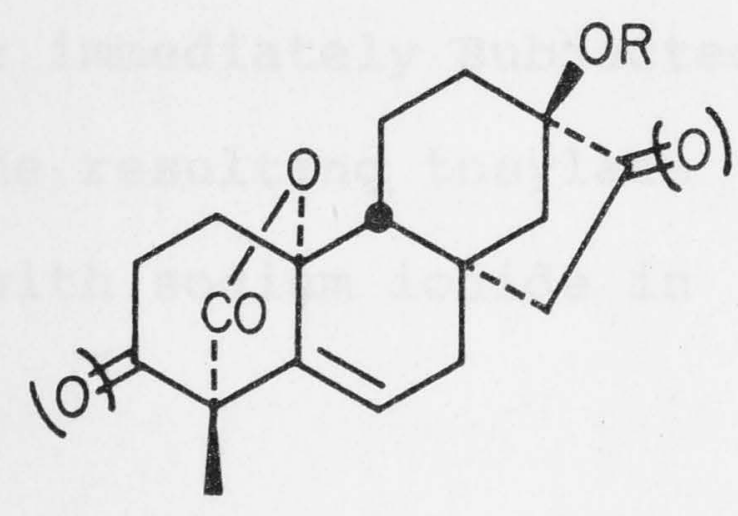

115

\footnotetext{
* See footnote p.7
} 
Elimination of hydrogen iodide would lead to the olefinic lactone 115 which, in turn, enables the functionalisation of the B-ring as required for the ring contraction.

The success of the outlined approach clearly relies on an efficient preparation of the phenethyl iodide 109 (cf. Scheme 37). The starting point for the synthesis of iodide 109 was the acid $116^{96}$ which was double-deprotonated to dianion 117 with butyl lithium (Scheme 38). 97<smiles>COc1cccc(C)c1C(=O)O</smiles>

\section{Scheme 38}

Reaction of dianion 117 with paraformaldehyde afforded the hydroxy acid 118 and thence the methyl ester 119 on treatment with an excess of diazomethane. The ester 119 tended to lactonise readily and was therefore immediately subjected to tosyl chloride in pyridine 98 and the resulting tosylate converted into the iodo ester 109 with sodium iodide in acetone.<smiles>COC(=O)c1c(CCO)cccc1OC</smiles>

119

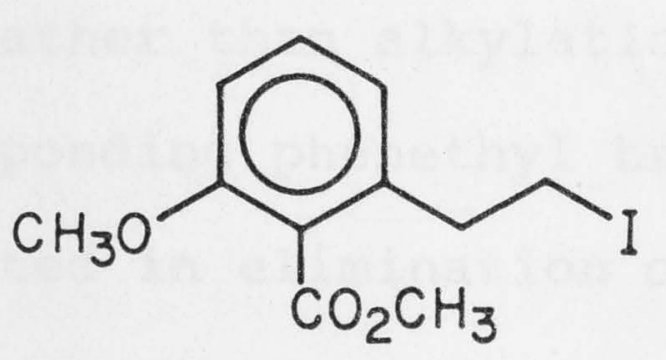

109 
Alkylation of the dianion 75 with phenethyl iodide 109 in ammonia/THF $(10: 1)$ at $-33^{\circ}$ gave the desired alkylated acid 110 in $50 \%$ yield as well as the same amount of dihydro-acid 120 and styrene 121.<smiles>COC1=CC(C(=O)O)C(OC)=CC1</smiles>

120

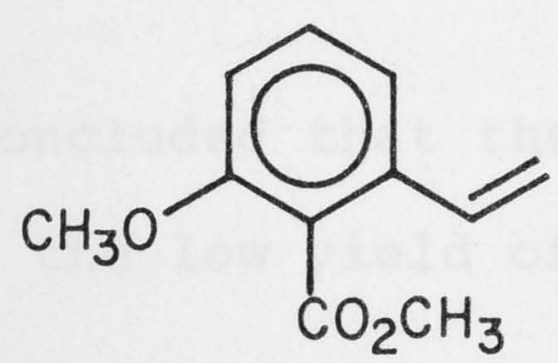

121

The ester group obviously enhances the acidity of the benzylic protons of 109 , so as to make the elimination a competitive process. By changing the reaction conditions it was hoped to discover which species was acting as the base and then to improve the yield. Amide ions, possibly formed from lithium and ammonia, could be excluded since only 2.2 equivalents of metal were added to obtain complete reduction, while the observed elimination accounted for about 0.5 equivalents of base. Alkylation at lower temperature $\left(-78^{\circ}\right)$ or in the absence of ammonia (removed by evaporation prior to the addition of iodide) did not alter the result. The addition of hexamethylphosphoric triamide (HMPA) to the solution of dianion 75 in THF was not tried because this had been found to promote elimination rather than alkylation in similar cases. 99 Use of the corresponding phenethyl bromide 122 instead of the iodide 109 resulted in elimination only. ${ }^{\dagger}$

† Phenethyl tosylates did not react with the dianion 75 in ammonia/THF. 66 


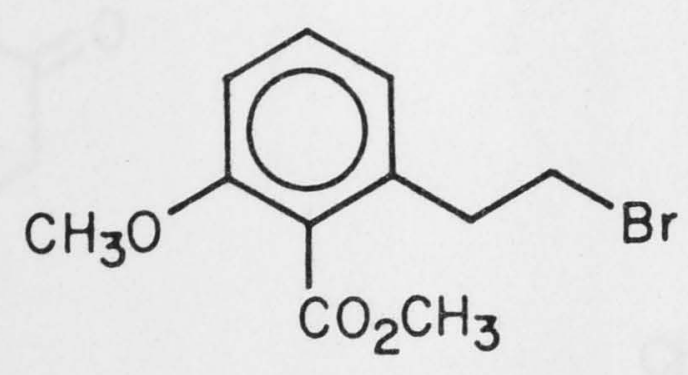

122

Because of these results, it was concluded that the dianion 75 itself was acting as a base and the low yield of acid 110 was accepted in the interim.

The cyclodehydration of acid 110 in $75 \%$ sulfuric acid at room temperature took place as expected, but the angular carboxyl group was partially retained and acid 123 was obtained together with the expected products.

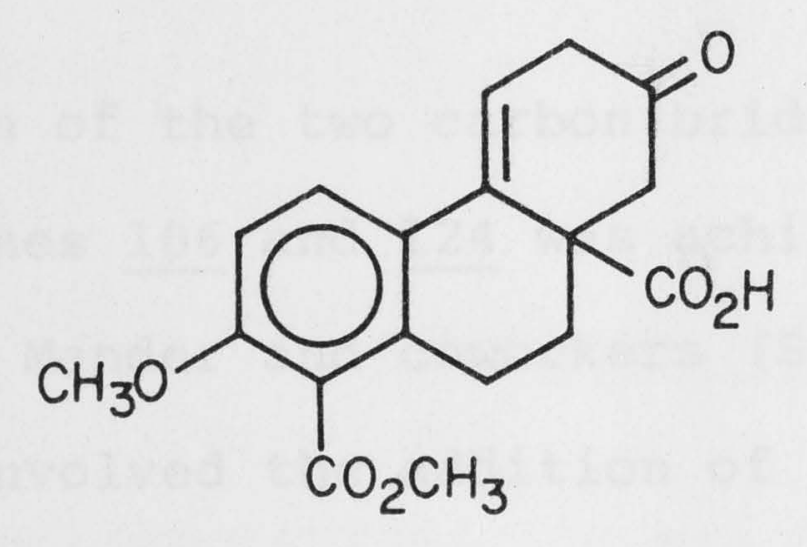

$\underline{123}$

When the temperature was raised $\left(50^{\circ}\right)$ the decarboxylation was completed, but with concomitant hydrolysis of the aromatic ester. Optimal conditions were found with PPA $\left(45^{\circ}, 0.5 \mathrm{hr}\right)$ which gave a 1:2 mixture of the phenanthrenones 106 and $\underline{124}$ in $70 \%$ yield after chromatography. 100 The yield of the crude mixture was much higher $(\approx 90 \%)$ and together with the two phenanthrenones $\underline{106}$ and 124 only a small amount (4\% isolated) of dihydrophenanthrene 125 could be detected (t.1.c. analysis). 
<smiles>COc1ccc2c(c1C(C)=O)CCC1=C2CCC(=O)C1</smiles>

106<smiles>COC(=O)c1c(OC)ccc2c1CCC1=CC(=O)CCC12</smiles>

124<smiles>COc1ccc2c(c1)CCc1c-2ccc(OC)c1C(C)=O</smiles>

125

Addition of the two carbon bridge to the mixture of phenanthrenones $\underline{106}$ and 124 was achieved using the strategy developed by Mander and coworkers (Scheme 39). ${ }^{64}$ The first step involved the addition of an acyl anion equivalent to the keto groups of 106 and $\underline{124}$, both readily enolisable vinylogous $\beta$-tetralones. Under equilibrating conditions cyanide ion, a weak base but powerful nucfelophile, had been found to add effectively to these ketones. 62 
<smiles></smiles>

$\underline{106 / 124}$<smiles>COC(=O)c1c(OC)ccc2c1CCC13CC(=O)[C@@](O)(CC=C21)C3</smiles>

133

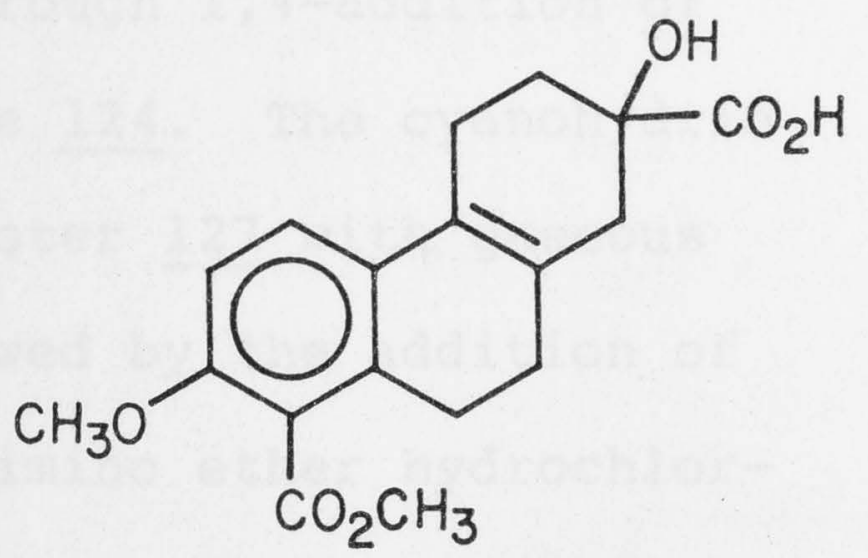

128<smiles>[R]OC1(C(=O)C=[W])CCC2=C(CCc3c2ccc(OC)c3C(=O)OC)C1</smiles>

\section{Scheme 39}

Thus, a single cyanohydrin, 126, was produced on treatment of the crude mixture of phenanthrenones $\underline{106}$ and $\underline{124}$ with sodium cyanide and hydrochloric acid in a two phase system. 62<smiles>COC(=O)c1c(OC)ccc2c1CCC1=C2CCC(O)(C#N)C1</smiles>

126<smiles>COC(=O)c1c(OC)ccc2c1CCC1=C2CCC(O)(C(C)=O)C1</smiles>
127 
No complications were experienced through 1,4-addition of cyanide to the $\alpha, \beta$-unsaturated ketone 124 . The cyanohydrin 126 was converted into the hydroxy ester 127 with gaseous hydrogen chloride in methanol, followed by the addition of water to hydrolyse the intermediate imino ether hydrochloride 101 (50\% overall yield from acid 110). The $\alpha$-hydroxy ester 127 was, in turn, readily hydrolysed under alkaline conditions, to provide the desired acid 128 which was to be converted into the corresponding $\alpha$-diazoketone as indicated in Scheme 39 (p.53). Firstly, the hydroxyl group required protection since it would otherwise intercept the protonated diazoacetyl function prior to the cylisation. 62 In similar cases the dichloroacetyl group had been satisfactory, 102 therefore the hydroxy acid $\underline{128}$ was heated with dichloroacetyl chloride in 1,2-dichloroethane to yield, after hydrolysis of the mixed anhydride, the dichloroacetoxy acid 129.

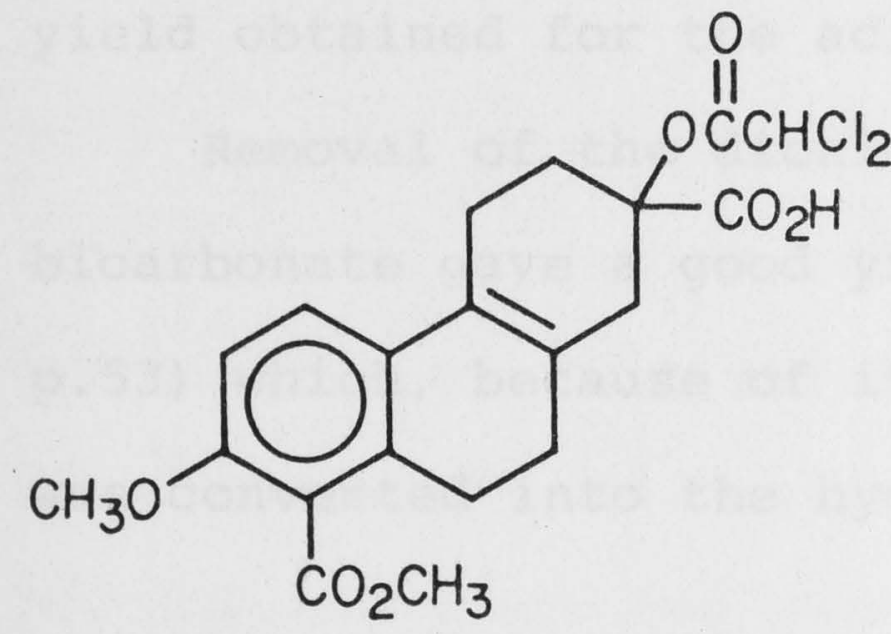

129

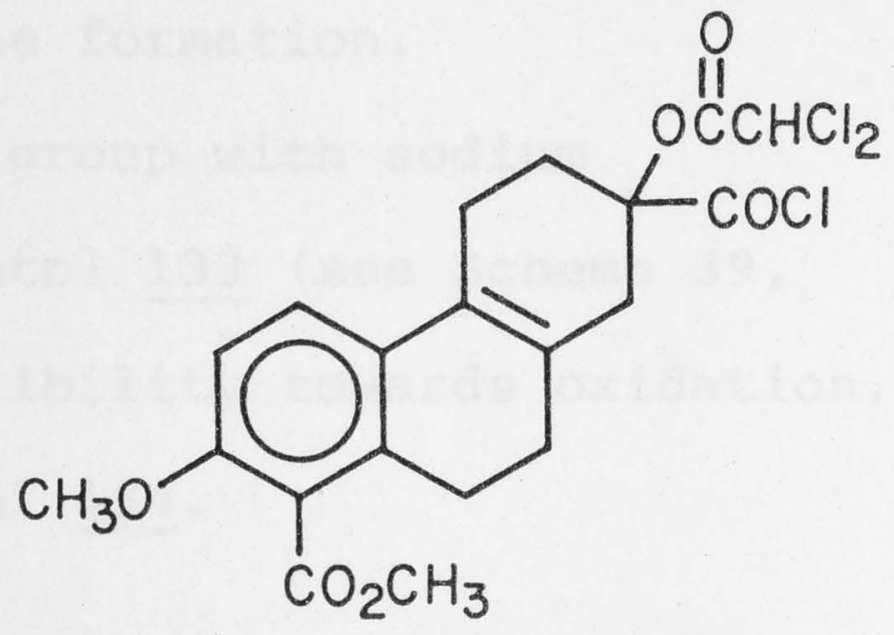

130

The conversion to its acid chloride 130 was poor when the usual procedure - 3 equivalents oxalyl chloride, 1 equivalent pyridine in dichloromethane, $25^{\circ}, 1-2$ days -102 was followed. Replacing the pyridine with a catalytic amount of 
DMF led to a shorter reaction time and an improved yield. The acid chloride 130 was then added to an excess of diazomethane in ether at $-20^{\circ}$ to afford the $\alpha$-diazoketone 131.

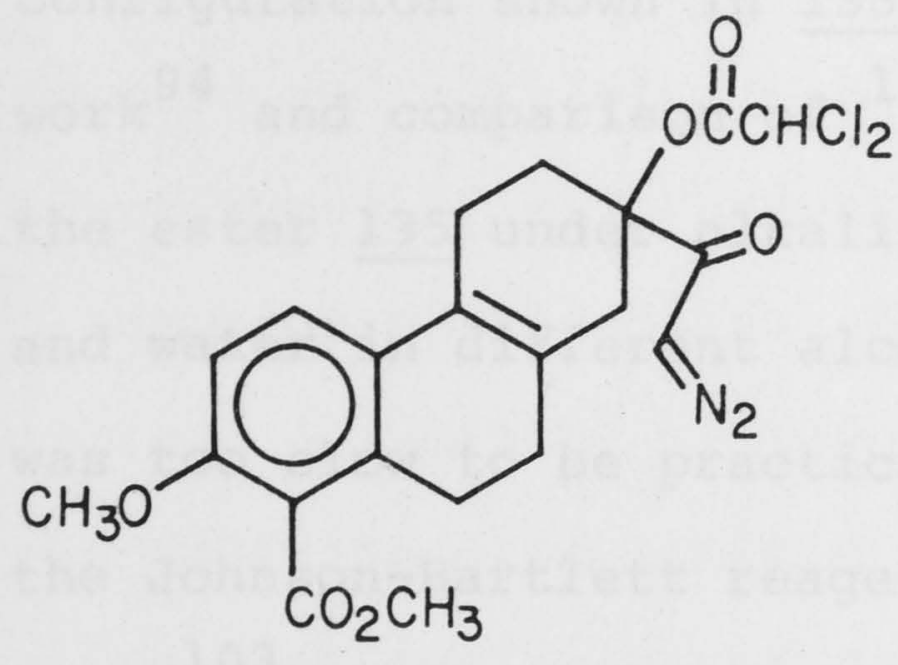

131

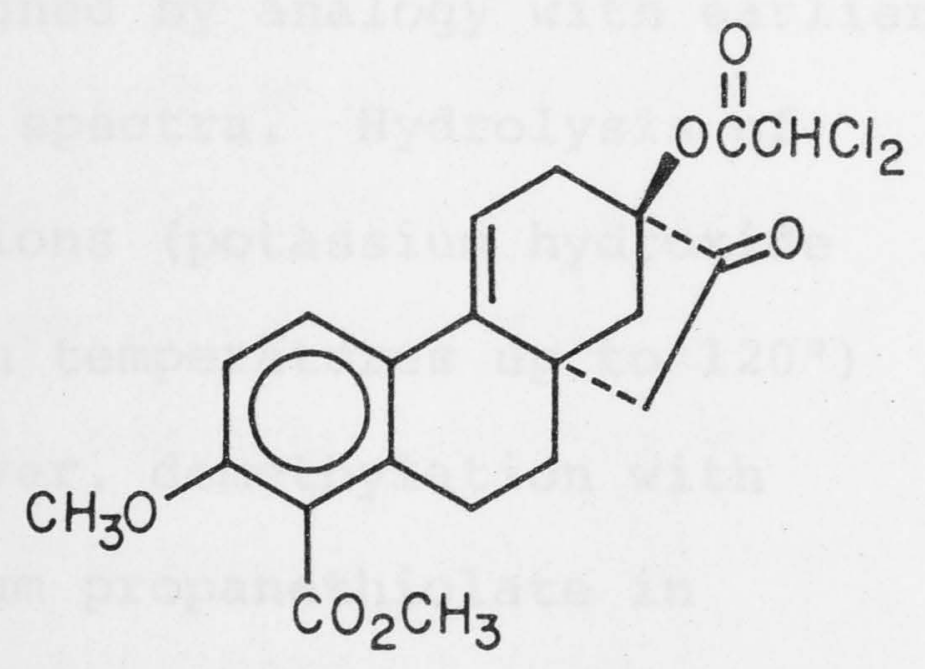

132

Cyclisation of 131 in 1:1 mixture of trifluoroacetic acid and dichloromethane at low temperature 102 furnished the tetracyclic ketone 132 in $56 \%$ yield from the acid 129, after purification by chromatography. The overall yield for the annulation process was disappointing, due mainly to the low yield obtained for the acid chloride formation.

Removal of the dichloroacetyl group with sodium bicarbonate gave a good yield of ketol 133 (see Scheme 39, p.53) which, because of its susceptibility towards oxidation, was converted into the hydroxy ketal 134.<smiles>COC(=O)c1c(OC)ccc2c1CCC13CC4(OCCO4)[C@](O)(CC=C21)C3</smiles>

134<smiles>COC(=O)c1c(OC)ccc2c1CCC13CC(O)(CCC21)C1(C3)OCCO1</smiles>

135 
Catalytic hydrogenation of the olefinic bond gave only one dihydro-isomer, ketal 135 , as indicated by the sharp melting point, t.l.c., ${ }^{1} \mathrm{H}$ and ${ }^{13} \mathrm{C}$ n.m.r. analysis. The transconfiguration shown in 135 was assigned by analogy with earlier work ${ }^{94}$ and comparison of ${ }^{13} \mathrm{C}$ n.m.r. spectra. Hydrolysis of the ester 135 under alkaline conditions (potassium hydroxide and water in different alcohols with temperatures up to $120^{\circ}$ ) was too slow to be practical. However, demethylation with the Johnson-Bartlett reagent (lithium propanethiolate in HMPA) ${ }^{103}$ produced the acid 136 in high yield.

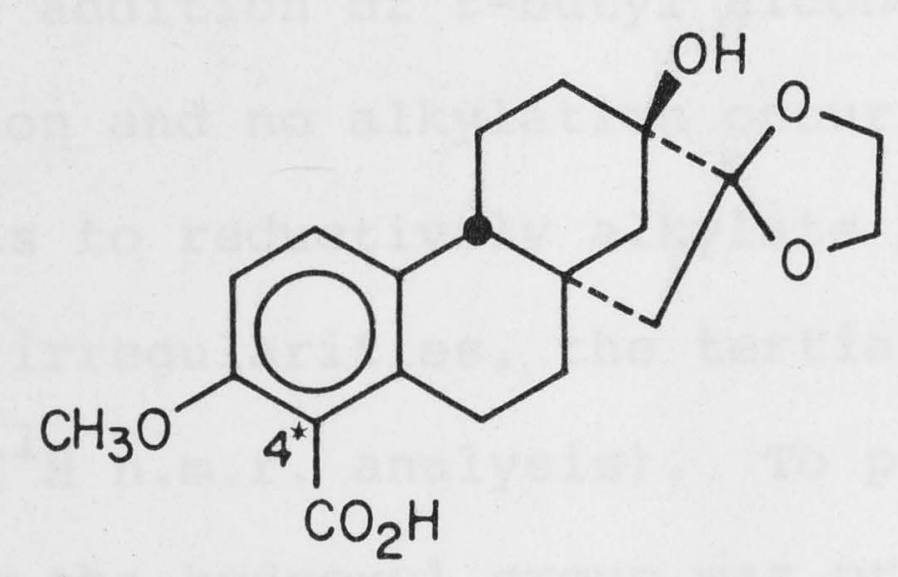

\section{6}

This was the acid required for the introduction of the $\mathrm{C} 4$ *methyl group through a reductive alkylation procedure, a transformation which had already been explored on simple model compounds (vide supra, Schemes 16 and 19). A major problem, however, had been the loss of the ortho-methoxyl substituent during the reductive methylation procedure from the indene 57 and fluorene 56 models, although Loewenthal's group did not report any loss from the naphthoic acid 43 during the same process. 51 In fact, these findings were a significant factor in the decision to approach the gibberellins via a phenanthrene rather than a fluorene nucleus. Since 
then, investigations of related reductive alkylations in our laboratories have largely solved these problems. 104 Thus, o-methoxybenzoic acid, which on direct treatment with lithium in ammonia loses $70 \%$ of the methoxyl group, ${ }^{73}$ could be reduced and alkylated with complete retention of the orthosubstituent by prior neutralisation of the acid with potassium t-butoxide or sodamide. Problems associated with the limited solubility of the metal salts could be improved by the addition of a limited amount of t-butyl alcohol. In the reductive alkylation of 2-methoxy-6-methylbenzoic acid, however, the addition of t-butyl alcohol led to protonation of the dianion and no alkylation occurred. ${ }^{104}$

Attempts to reductively alkylate acid 136 revealed that, among other irregularities, the tertiary hydroxyl group was methylated $\left({ }^{l} \mathrm{H}\right.$ n.m.r. analysis). To prevent this undesired sidereaction the hydroxyl group was protected as the methoxymethyl ether. 105 Thus, treatment of alcohol 135 with chloromethyl methyl ether in the presence of a tertiary amine 106 gave the ether ester 137 which was then demethylated to afford acid 138 .

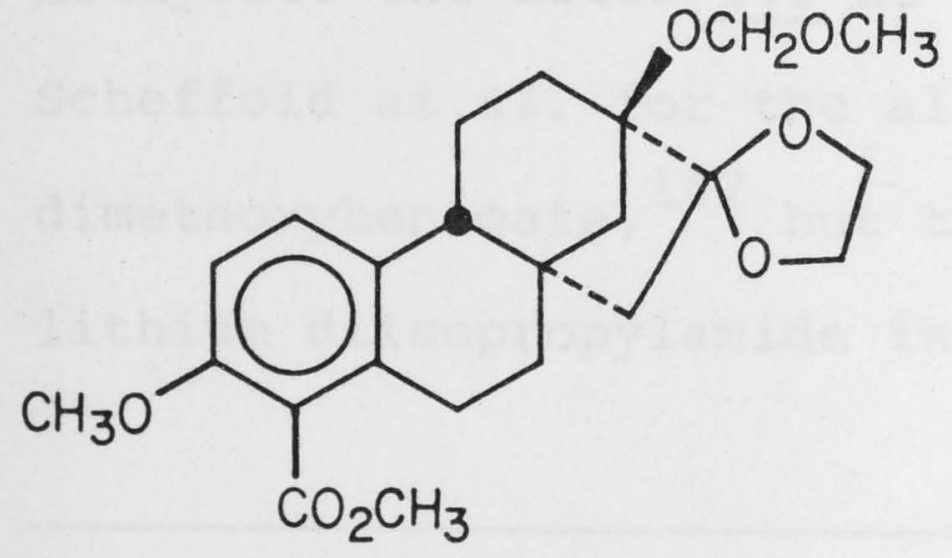

137

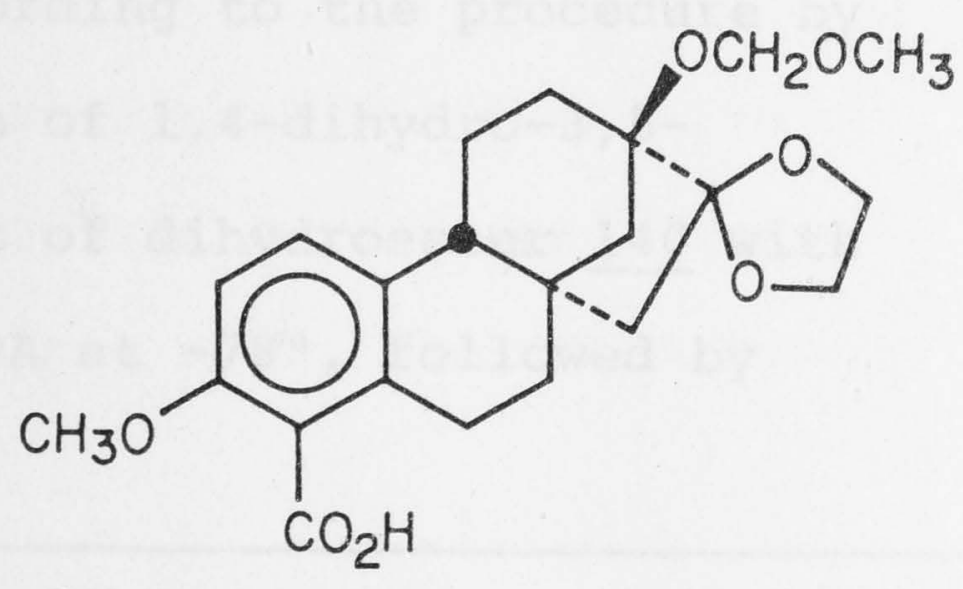

138 
A series of reductive alkylations of acid 138 unveiled some of the mystery surrounding this reaction: the removal of the carboxylic acid proton, prior to the reduction with sodium at $-78^{\circ}$, was essential if the methoxyl group was to be retained. Unfortunately, protonation of the dianion was always competitive with alkylation, so that the desired product, isolated as the methyl ester $139^{\dagger}$ was always accompanied by a considerable amount (30-60\%) of dihydroester $140 .{ }^{\dagger}$

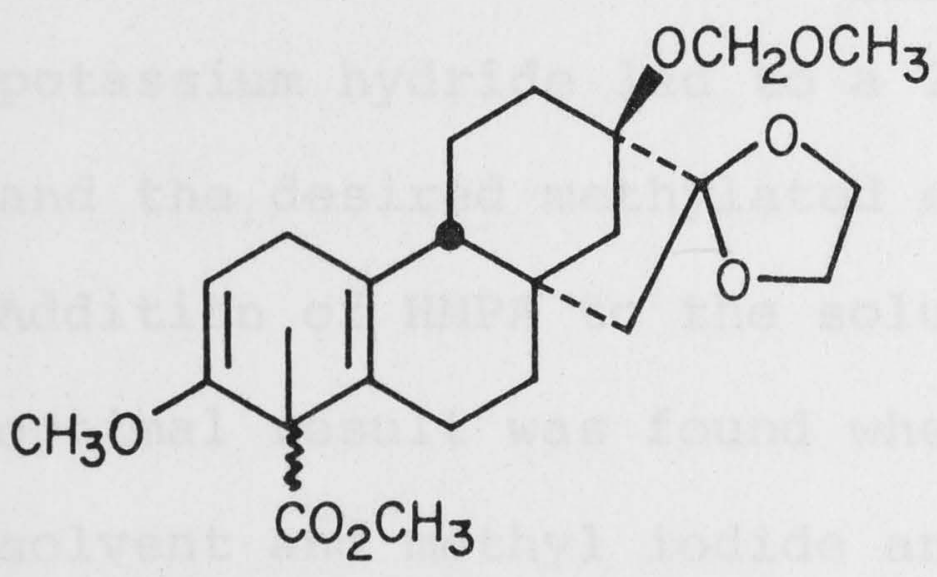

139

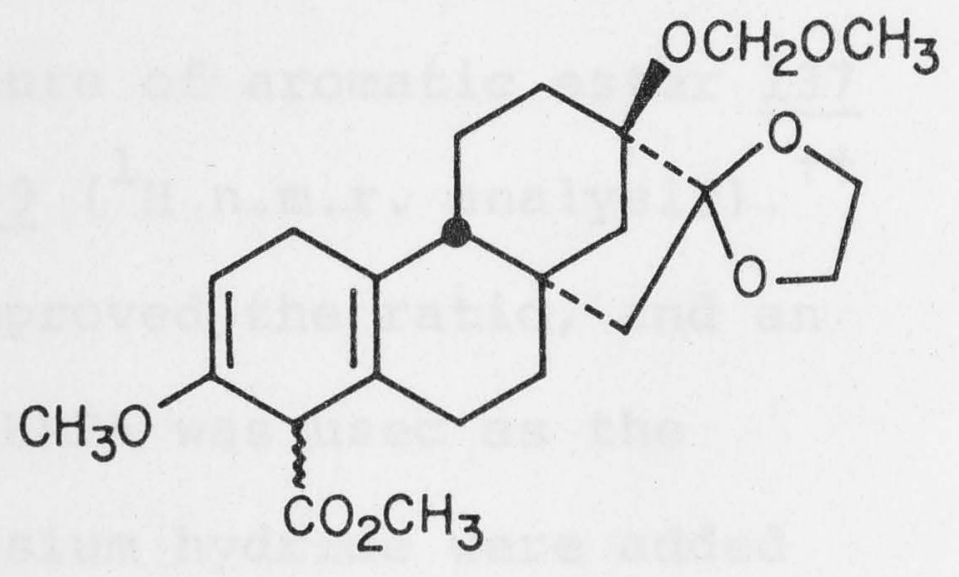

140

Addition of methanol (10 equivalents) prior to the reduction of acid 138 under the conditions described above resulted in exclusive formation of the dihydroester 140 . It was hoped to methylate the ester 140 at $\mathrm{C} 4$ * according to the procedure by Scheffold et al. for the alkylation of 1,4-dihydro-3,5dimethoxybenzoate, 107 but treatment of dihydroester 140 with lithium diisopropylamide in THF/HMPA at $-78^{\circ}$, followed by

\footnotetext{
the reduced acids were converted to the methyl esters (diazomethane) before isolation to prevent the readily occurring oxidative decarboxylation.51
} 
methyl iodide, returned the starting material unchanged. If the temperature was raised during the deprotonation $\left(-40^{\circ}\right.$ and $0^{\circ}$ respectively) increasing amounts of aromatic ester 137 were recovered (40 and $70 \%$ ) together with the starting material, but no methylation was observed. It seemed that the aromatisation occurred before the alkylation could take place. These considerations led to the use of hydride as base, since it could be used in the presence of soft alkylating agents ${ }^{\dagger}$ which would hopefully trap any anion formed. Thus, treatment of ester 140 and methyl iodide in THF with potassium hydride led to a 2:1 mixture of aromatic ester 137 and the desired methylated ester $139\left({ }^{1} \mathrm{H}\right.$ n.m.r. analysis $) .^{+\dagger}$ Addition of HMPA to the solution improved the ratio, and an optimal result was found when neat HMPA was used as the solvent and methyl iodide and potassium hydride were added alternately. In this way about $70 \%$ of methylated ester 139 was obtained together with $30 \%$ of the aromatic ester 137 , but no separation of the two compounds could be achieved. In the ${ }^{1}$ H n.m.r. spectra single resonance peaks for the quakternary methyl and the ester methoxyl group suggested that a single isomer was formed.

At this stage Loewenthal suggested that the reductive alkylation could be performed on aromatic esters, provided the temperature was kept sufficiently low. 109 Accordingly,

† Potassium hydride and diphenyl diselenide had been used together to selenate the $\alpha$-position of a hindered ester. 33,35 ${ }^{+}$The oxidation to the aromatic compound seems to occur through a hydride loss from the anion, since an experiment under rigorous exclusion of oxygen gave the same result. 
ester 137 was reduced with potassium at $-75^{\circ}$ (internal temperature) followed by the addition of methyl iodide. However, alkylation only occurred to an extent of about $60 \%$ and the by-product was again the dihydroester $140 .{ }^{\dagger}$ Another source 110 indicated that the reduction of aromatic esters by Loewenthal's group had been carried out in the presence of a proton source; therefore ester 137 was subjected to the reduction once more and, although this seemed paradoxical, t-butyl alcohol was added prior to the metal addition. With four equivalents of t-butyl alcohol the same result was obtained as when no proton source had been present, but when only one equivalent was added, the required ester 139 was the sole product. In accord with this result, the reductive methylation of the hydroxy ester 135, without any external proton source, resulted in complete methylation at $\mathrm{C} 4$ *. Methylation of the tertiary hydroxyl group was also observed, and could not be prevented, so that the methyl ether 142 was the only isolated product.

${ }^{\dagger}$ A similar puzzling protonation was since observed during the reductive methylation of acid 141.108<smiles>COc1ccc(C)cc1C(=O)O</smiles>

141
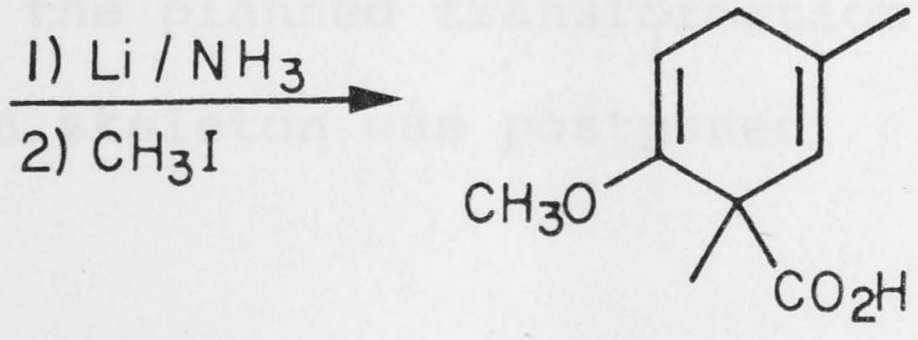

$+$

I<smiles>COC1=CCC(C)=CC1C(=O)O</smiles>

I 


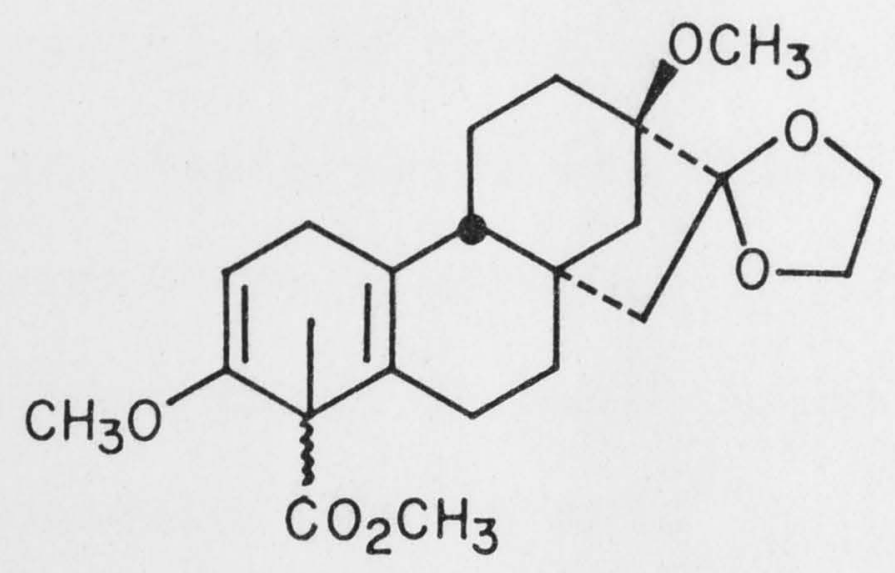

142

${ }^{1} \mathrm{H}$ and ${ }^{13} \mathrm{C}$ n.m.r. analysis again indicated that only one isomer, identical to the one obtained previously, was formed in the reductive methylation of the esters 137 and 135 respectively. The determination of the stereochemistry at C4* by chemical means seemed to require a long synthetic sequence, including the formation of the lactone bridge and the contraction of the B-ring, to allow a comparison with known compounds from the gibberellin series. Therefore attempts were made to establish the structure by single crystal x-ray diffraction. Unfortunately, crystallisations of ester 139 from various solvents and solvent mixtures always produced twinned specimens and no X-ray analysis could be obtained. 111

Due to the structural uncertainty which would have persisted through the entire sequence and in view of the progress achieved on a related subject, described in chapter three, the planned transformation of ester 139 to the gibberellin skeleton was postponed. 
CHAPTER 3

3.1 Preliminary considerations

3.2 The total synthesis of gibberellic acid

3.3 Addendum 
3.1 Concurrently with the execution of the work described in the first two chapters, it was found that the initially envisaged intermediate, fluorenone 71 (cf. Scheme 27) could be obtained in good yield through the reductive alkylation/ cyclisation procedure (Scheme 40). 66<smiles>COC(=O)c1c(CI)cccc1OC</smiles>

143

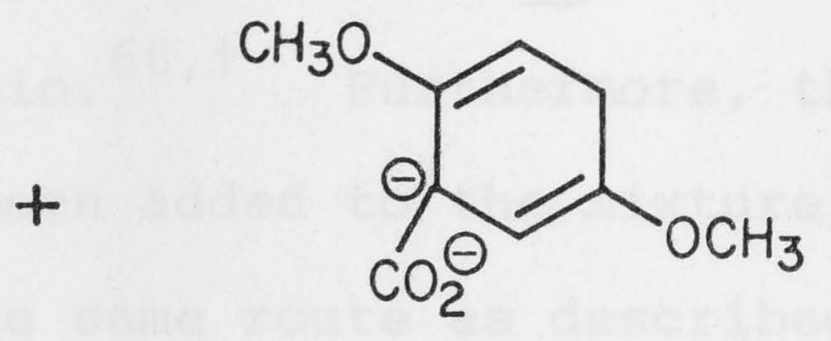

75

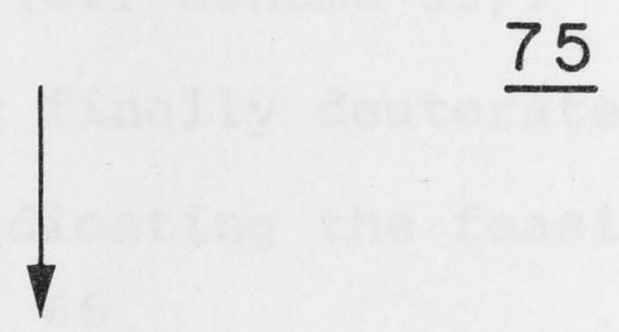<smiles>COC1=CC(Cc2cccc(OC)c2C(=O)O)(C(=O)O)C(OC)=CC1</smiles>

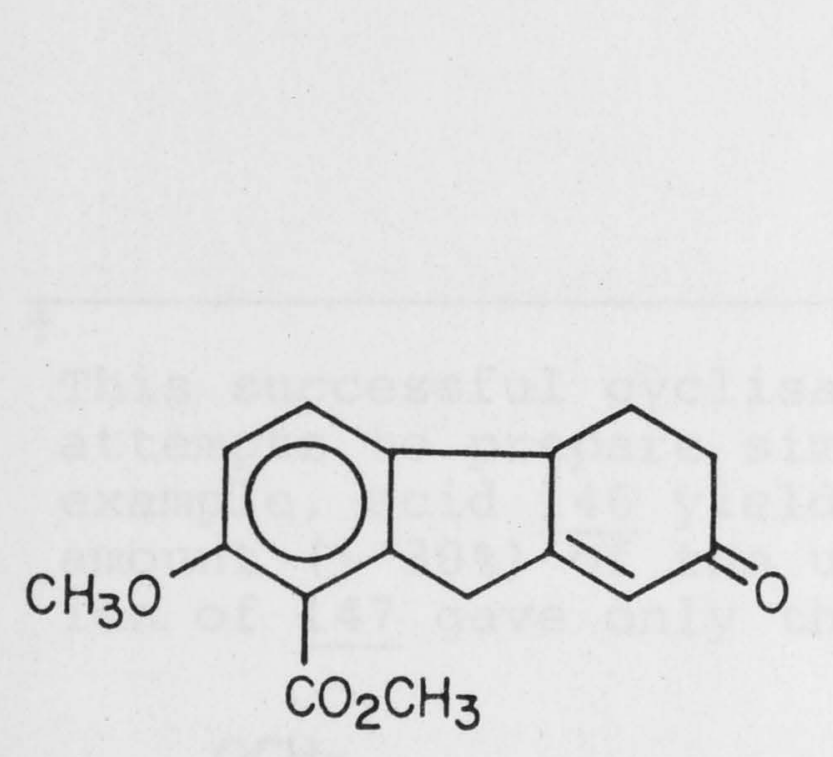

145
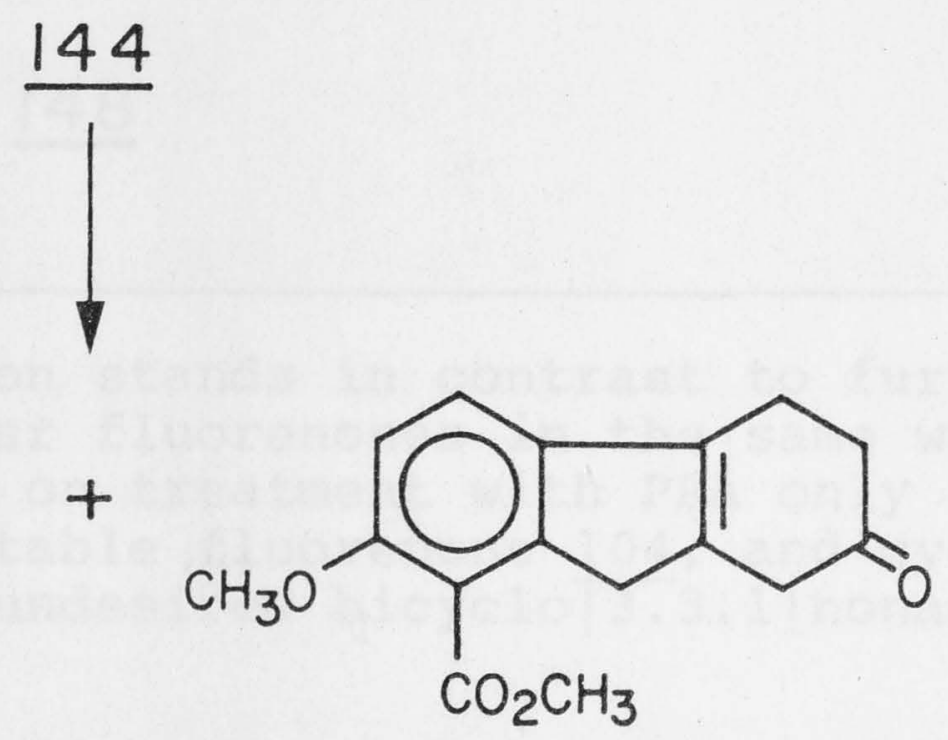

71

Scheme 40 
Thus, alkylation of dianion 75 with benzyl iodide 143 in THF (the ammonia was removed to prevent it from reacting with the iodide) afforded acid $\underline{144}$ in $88 \%$ yield. The acid 144 was cyclised despite the unfavourable electron withdrawing effect of the ester group, using PPA at elevated temperature to furnish the hydrofluorenone $\underline{71}$ and a double bond isomer 145 in a $4: 1$ ratio. $66,+$ Furthermore, the two carbon bridge ( $D$-ring) had been added to the mixture of fluorenones $\underline{71}$ and $\underline{145}$ by the same route as described for the phenanthrenones 106 and 124 (cf. Scheme 39). The resulting tetracyclic compound $\underline{148}$ was finally deuterated at $6^{*}$, via its lithium salt, thereby indicating the feasibility of a carboxylation at this centre. 66

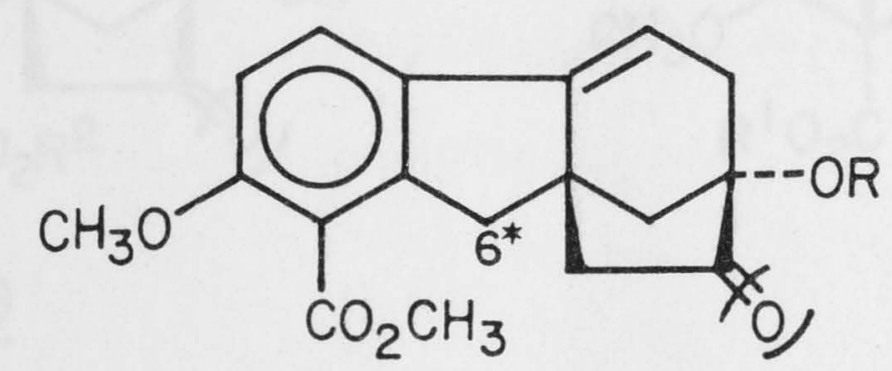

148

This successful cyclisation stands in contrast to further attempts to prepare similar fluorenones in the same way. For example, acid 146 yielded on treatment with PPA only a small amount ( $\sim 30 \%)$ of the unstable fluorenone 104, and cyclisation of 147 gave only the undesired bicyclo 3.3 .1 nonane.66<smiles>COC(=O)c1ccc(OC)cc1CC1(C(=O)O)C=C(OC)CC=C1OC</smiles><smiles>COC1=CC(Cc2ccc(OC)c(OC)c2C(C)=O)(C(=O)[O-])C(OC)=CC1</smiles> 
At the time, the sequence suffered from low yields in several crucial steps. Nevertheless, this sequence seemed, in principle, to provide a direct entry to the synthesis of the gibberellin molecule: the carboxylation of gibbane 148 , by analogy to Loewenthal's work (cf. Scheme 17), 53 was expected to give exclusively the $6 * \alpha$-acid which would direct the hydrogenation to the opposite face, resulting in compound 149, possessing the desired cis-B/C-ring junction (Scheme 41).

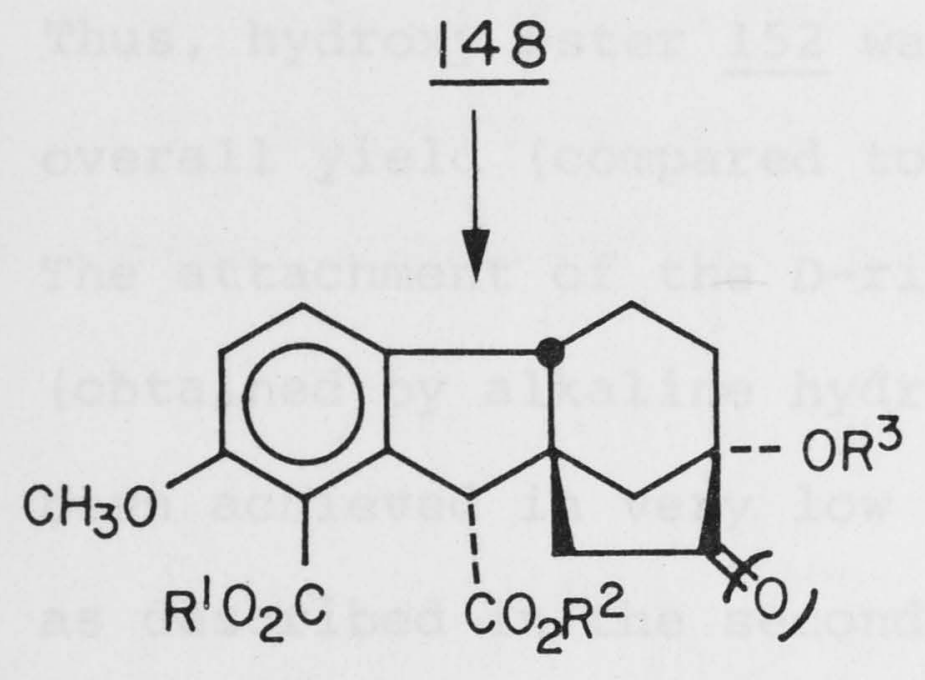

149

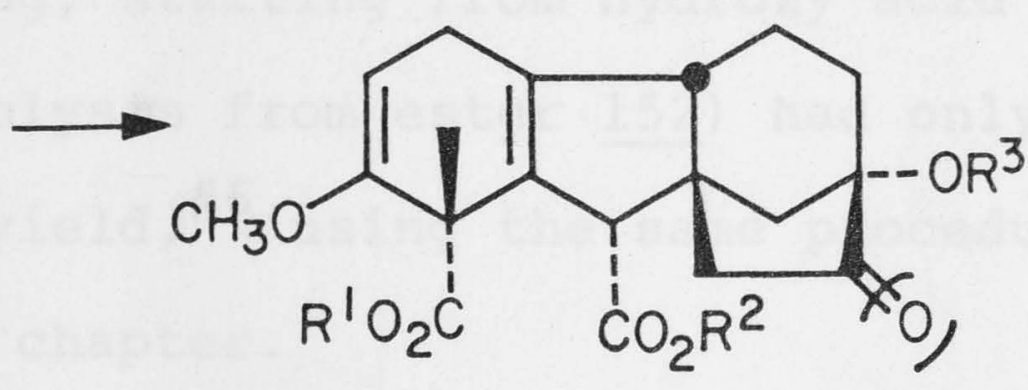

150

\section{Scheme 41}

Reductive methylation of the acid $\underline{149}\left(\mathrm{R}^{1}=\mathrm{H}\right)$, or possibly the ester $149\left(\mathrm{R}^{1}=\mathrm{CH}_{3}\right)$, on the less hindered side would lead to compound 150 , as had been shown by House and coworkers on the model compounds $\underline{55}$ and $\underline{56} \cdot{ }^{56}$ With the gibberellin skeleton assembled and the stereochemistry ascertained, it is formally just a matter of refunctionalisation to reach the gibberellins.

3.2 The improvement of yields in the synthesis of tetracyclic compound 148 was seen as a vital preliminary to 
the subsequent stages. It was achieved by omitting the purification of the rather labile intermediates, hydrofluorenones $\underline{71}$ and $\underline{145}$ and cyanohydrin $\underline{151}$.<smiles>COc1ccc2c(c1C(C)=O)CC1=C2CCC(O)(C#N)C1</smiles>

$\underline{|5|}$

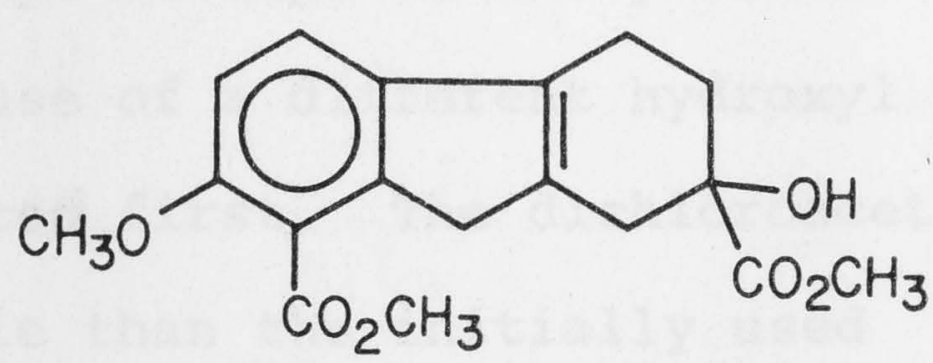

152

Thus, hydroxy ester 152 was obtained from the acid 144 in $50 \%$ overall yield (compared to the reported yield of $32 \% 66$ ). The attachment of the D-ring, starting from hydroxy acid 153 (obtained by alkaline hydrolysis from ester 152) had only been achieved in very low yield, ${ }^{6}$ using the same procedure as described in the second chapter.<smiles>COC(=O)c1c(OC)ccc2c1CC1=C2CCC(O)(C(=O)O)C1</smiles>

$\underline{153}$

Since most of the decomposition of material occurred during the hydrolysis of the cyano group (methanol saturated with gaseous hydrogen chloridel01), a recently developed alternative hydrolysis of cyanohydrins to $\alpha$-hydroxy acids may provide a better solution, i.e., in a related substrate, protection of the hydroxyl group as a methoxymethyl ether, followed by alkaline hydrolysis of the cyano group gave, after acidification, a good yield of the hydroxy acid.l04 
The blame for the low yield had to be put once more on the acid chloride formation (oxalyl chloride, DMF catalytic, dichloromethane, $25^{\circ}, 16 \mathrm{hr}$ ) which caused extensive decomposition of material. In an attempt to improve the yield of the annulation procedure, the use of a different hydroxyl protecting group was investigated first. The dichloroacetate group, although much more stable than the initially used trichloro- and trifluoroacetates, ${ }^{62,102}$ was still a fairly labile group which, for example, did not withstand prolonged contact with silica gel. The use of acetate can be ruled out, as it had been shown to intercept the protonated diazoketone, thereby competing with its cyclisation (Scheme 42). 94<smiles>COc1ccc2c(c1)CCC1=C2CCC(OC(C)=O)(C(=O)C[18O])C1</smiles>

\section{Scheme 42}

Therefore, the obvious choice was the monochloroacetate, assuming that the -I effect of a single chlorine atom would be sufficient to prevent the acyl group from reacting with 
the protonated diazoacetyl function. The greater stability of the chloroacetate, relative to the di- and trichloroacetyl residues, should enable a thorough purification of the resulting tetracyclic compound by chromatography. Hence, the hydroxy acid 153 was heated with chloroacetic anhydride in 1,2-dichloroethane to give the chloroacetoxy acid 154 in $90 \%$ yield.

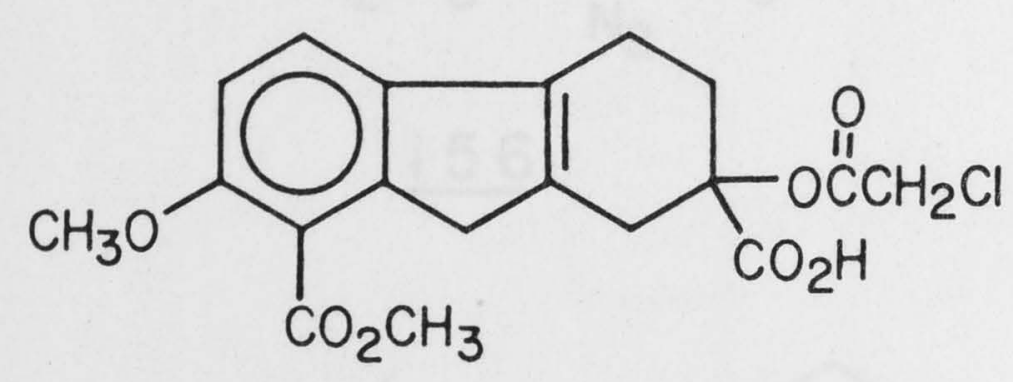

154

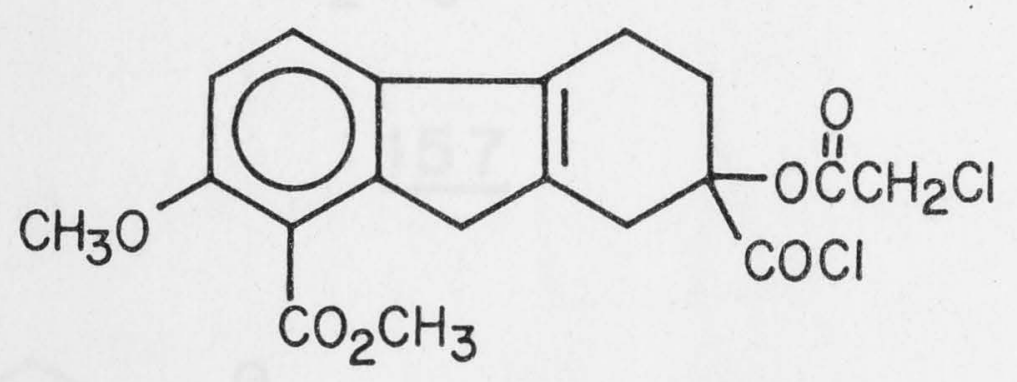

155

The progress of the subsequent acid chloride formation from acid 154 was monitored very carefully in order to trace the difficulties. It became evident, that the reaction could be made to proceed much more quickly than had been indicated by the earlier studies. 66,102 The formation of the acid chloride 155 was complete after a few hours (t.1.c. and i.r. analysis) provided a repetitive addition of catalytic amounts of DMF was made. The resulting crude acid chloride 155 , which had been freed from residual hydrogen chloride, was added to an excess of ethereal diazomethane at $-20^{\circ}$ to give the a-diazoketone 156 which was cyclised in a mixture of trifluoroacetic acid and dichloromethane at $-20^{\circ}$ to give the gibbane 157. None of the trifluoroacetoxymethyl derivative 158 could be detected, indicating that the chloroacetyl functionality did not compete with the styrene double bond 
for the protonated $\alpha$-diazoketone. In fact, the cyclised product 157 could be isolated in $71 \%$ overall yield from the acid 154, corresponding to a doubling of the previously reported yield. 66

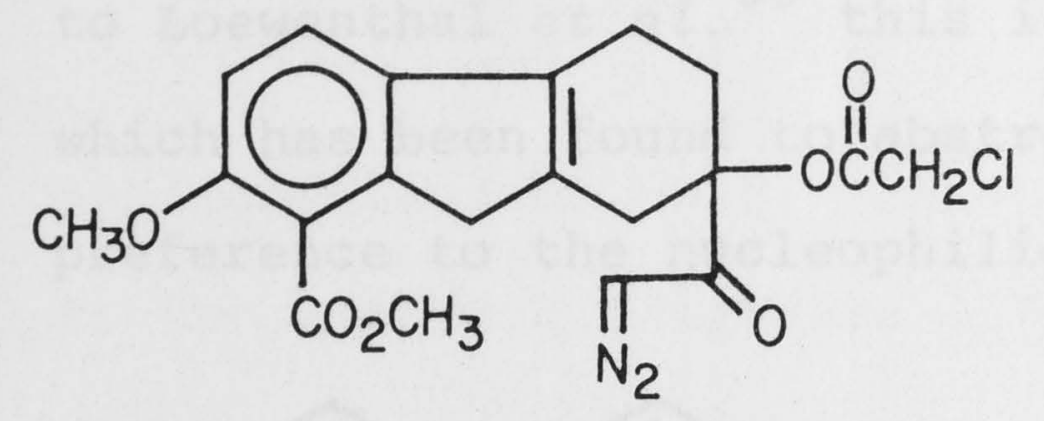

156

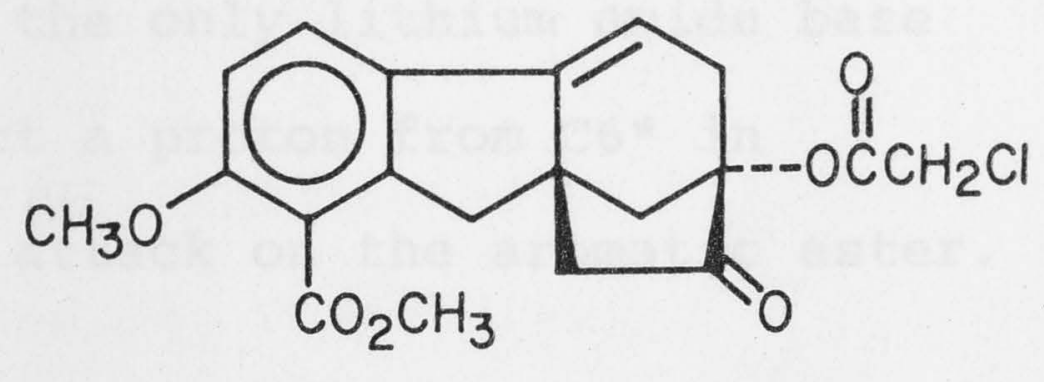

157<smiles>COC(=O)c1c(OC)ccc2c1CC1=C2CCC(OC(=O)CCl)(C(=O)CC(=O)OC(F)(F)F)C1</smiles>

\section{8}

The chloroacetyl group was then removed from 157 by treatment with potassium carbonate and the resulting ketol 159 transformed to the hydroxy ketal 160 by the standard method.

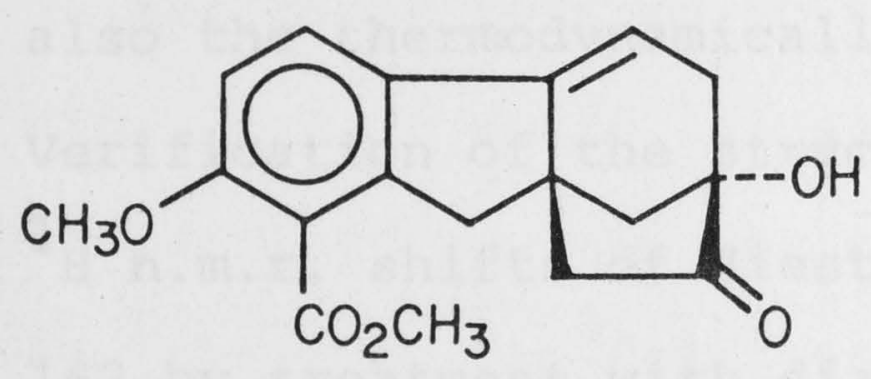

159

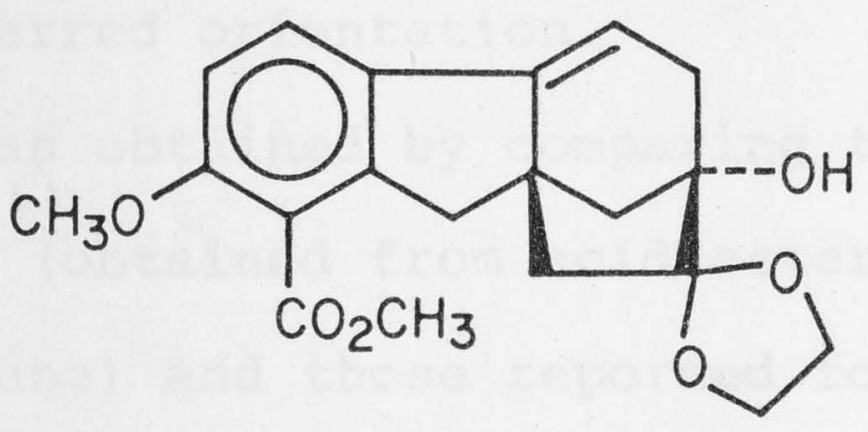

160

The lithiation at $\mathrm{C} 6$ * had been found to be unsuccessful on the compound 160 , possessing the $13 *$-hydroxyl group, so 
that it was necessary to protect the hydroxyl group as its methoxymethyl ether. 66 Deprotonation of the resulting ester 161 at $C 6$ * was achieved in THF in the presence of HMPA with lithium $N-t$-butyl-N-cyclohexylamide. According to Loewenthal et al. ${ }^{53}$ this is the only lithium amide base which has been found to abstract a proton from C6* in preference to the nucleophilic attack on the aromatic ester.

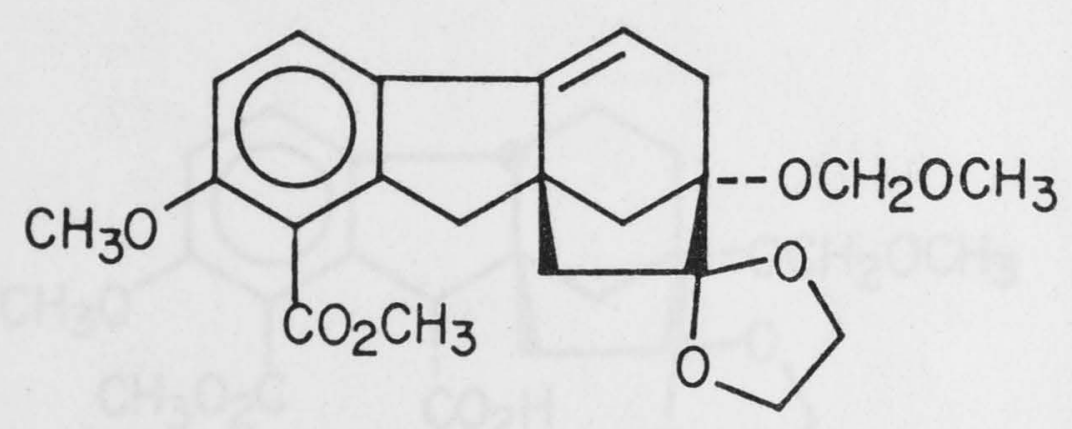

161

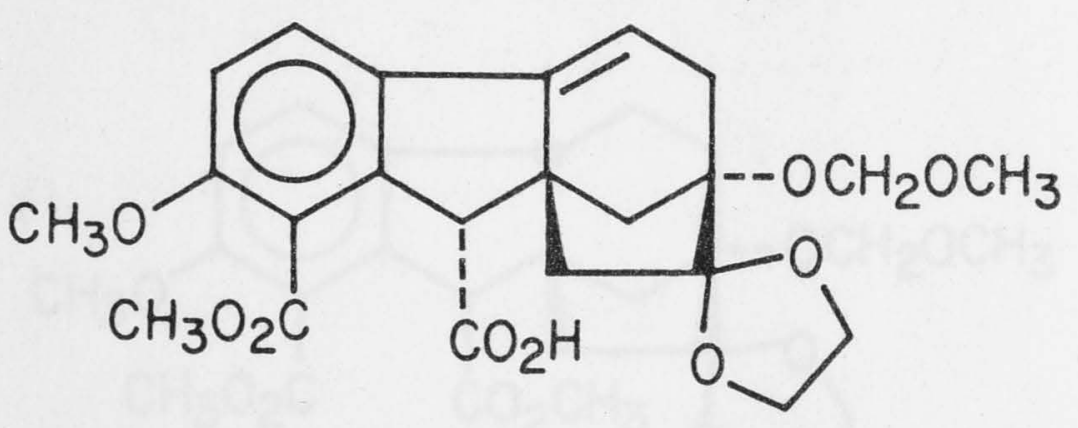

162

The intense purple solution of the lithiated ester 161 was transferred onto a large excess of carbon dioxide in ether at $-78^{\circ}$. After the usual work-up, an acidic product was obtained ( $84 \%$ yield) which, from its physical data, seemed to be a single compound. In accord with Loewenthal's work, 53 it was tentatively assigned structure 162 with the carboxyl group incorporated at $\mathrm{C}^{*}$ * in the a-configuration, which is also the thermodynamically preferred orientation.

Verification of the structure was obtained by comparing the ${ }^{1} \mathrm{H}$ n.m.r. shifts of diester 163 (obtained from acid ester 162 by treatment with diazomethane) and those reported for diester 164.53 The corresponding methoxyl groups, the vinylic (HIl*) and benzylic (H6*) protons in compounds $\underline{163}$ and $\underline{164}$ had almost identical chemical shifts. 


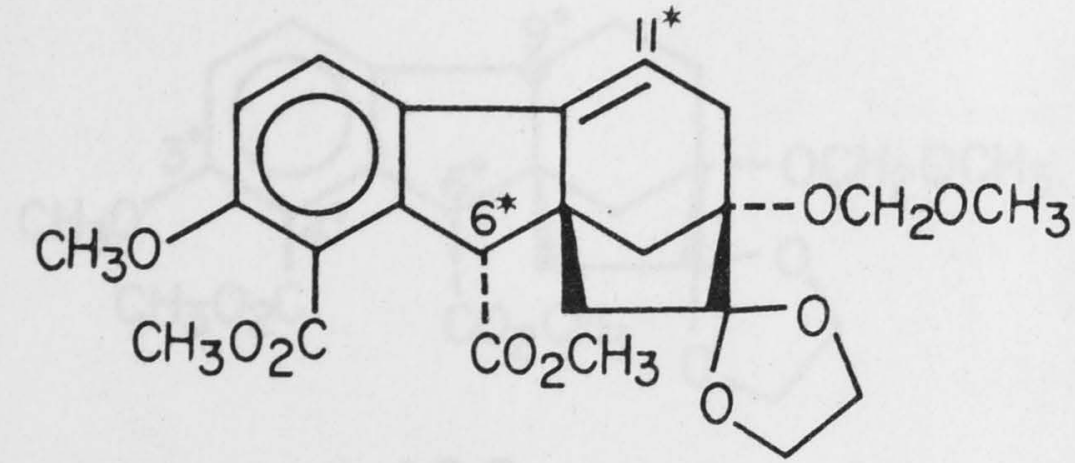

163

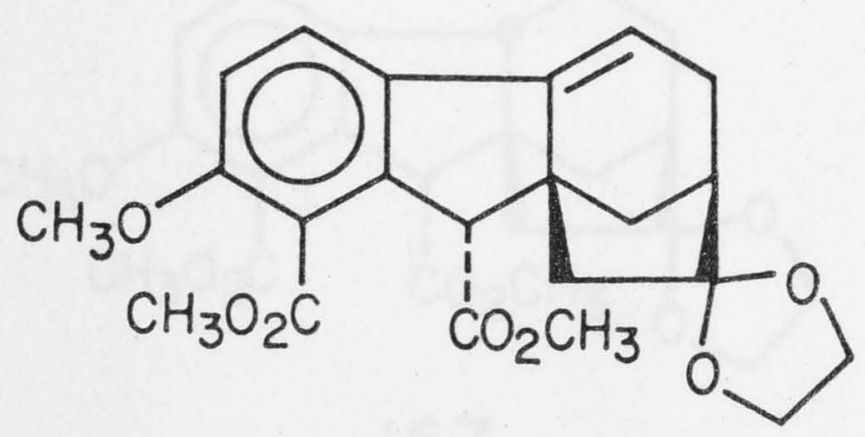

164

Hydrogenation of both, the acid 162 and the ester 163 , led to the single cis-isomers $\underline{165}$ and $\underline{166}$ respectively.

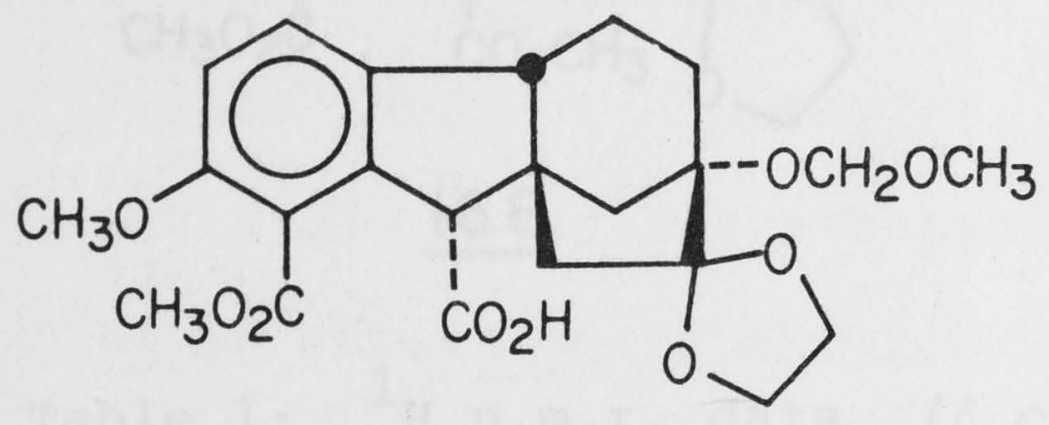

165

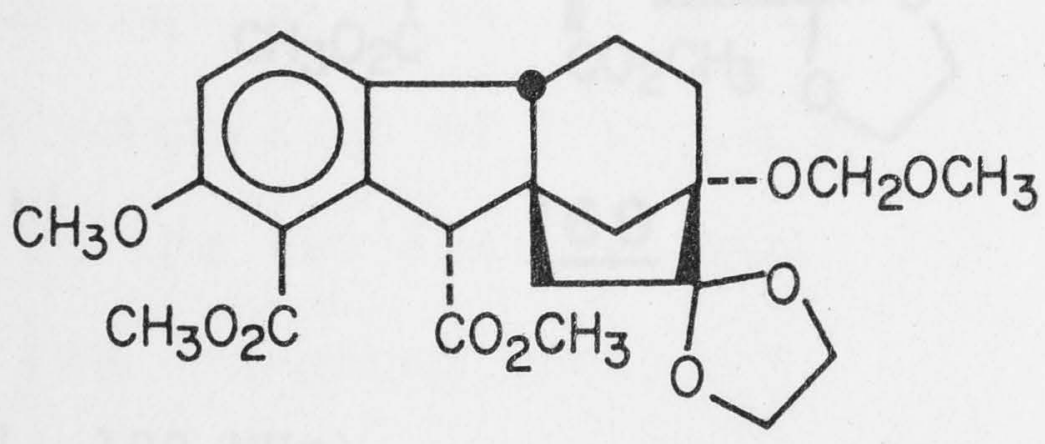

166

The acid $\underline{165}$ could be transformed into ester 166 with diazomethane, thereby establishing that hydrogenation had given the same relative stereochemistry at C9*. The cis-relationship of the B/C-rings in ester 166 was deduced from the analogies in the ${ }^{I_{H}}$ n.m.r. spectra of $\underline{166}$ and $\underline{167}^{53}$ (table 1 ). The proton at $\mathrm{C} 9 *$ in 167 is clearly located on the opposite side to the B-ring ester group, since otherwise it would lie in the deshielding region of the carboxyl group, and therefore resonate at lower field, as was observed for diesters 168 and 169 . 


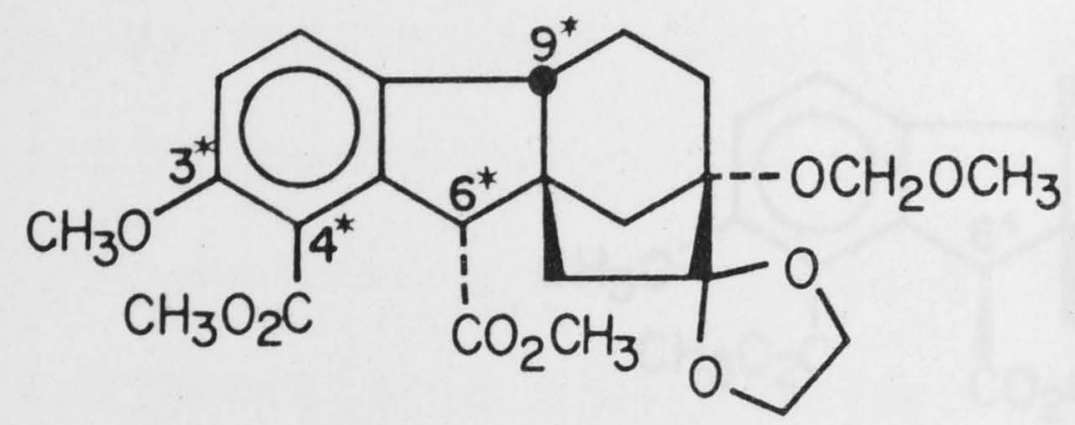

166

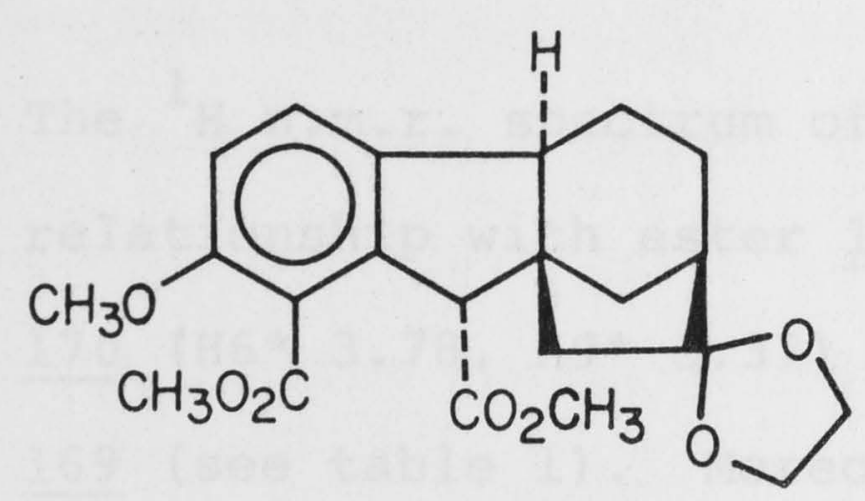

168

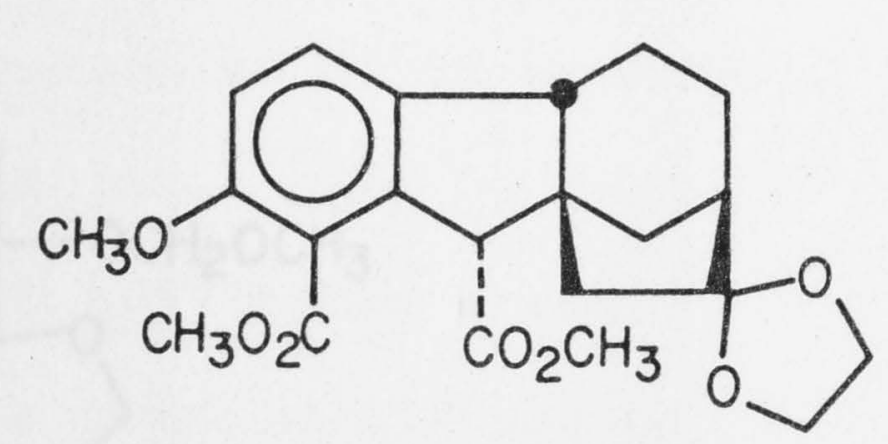

167

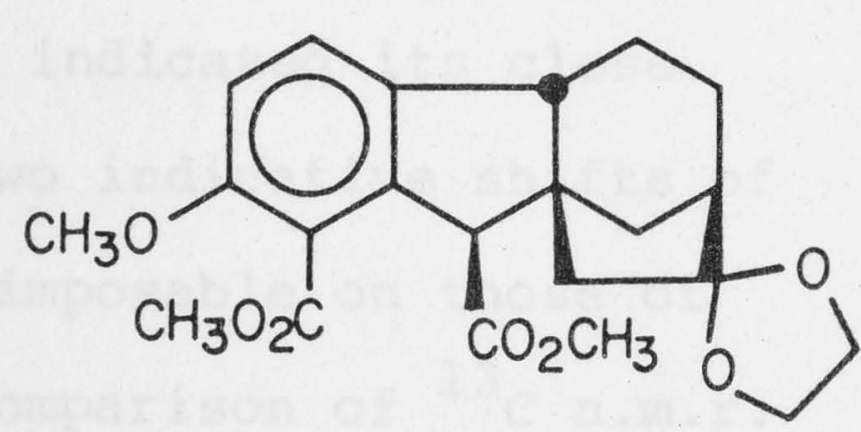

169

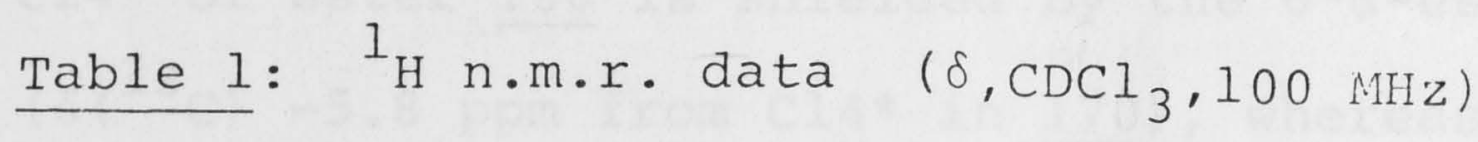

Compound $\quad 3 *-\mathrm{OCH}_{3} \quad 4 *-\mathrm{CO}_{2} \mathrm{CH}_{3} \quad 6 *-\mathrm{CO}_{2} \mathrm{CH}_{3} \quad \mathrm{H} 6$ * $\mathrm{H}$ *

\begin{tabular}{llllll}
$\frac{166}{167}$ & 3.81 & 3.72 & 3.67 & 4.10 & 2.94 \\
$\underline{168}$ & 3.82 & 3.77 & 3.69 & 4.28 & 3.00 \\
$\underline{169}$ & 3.80 & 3.80 & 3.66 & 3.75 & 3.22 \\
\hline
\end{tabular}

Nevertheless, chemical evidence for the proposed structure 166 was sought. The $\beta$-configuration of the 6 *-carboxylate is known to be thermodynamically favoured in similar compounds possessing the B/C-rings fused in a cisfashion. 53,112 Epimerisation of diester 166 with sodium methoxide in methanol gave a 2:1 mixture of $\beta$-ester 170 and starting material, which could be separated by chromatography. 


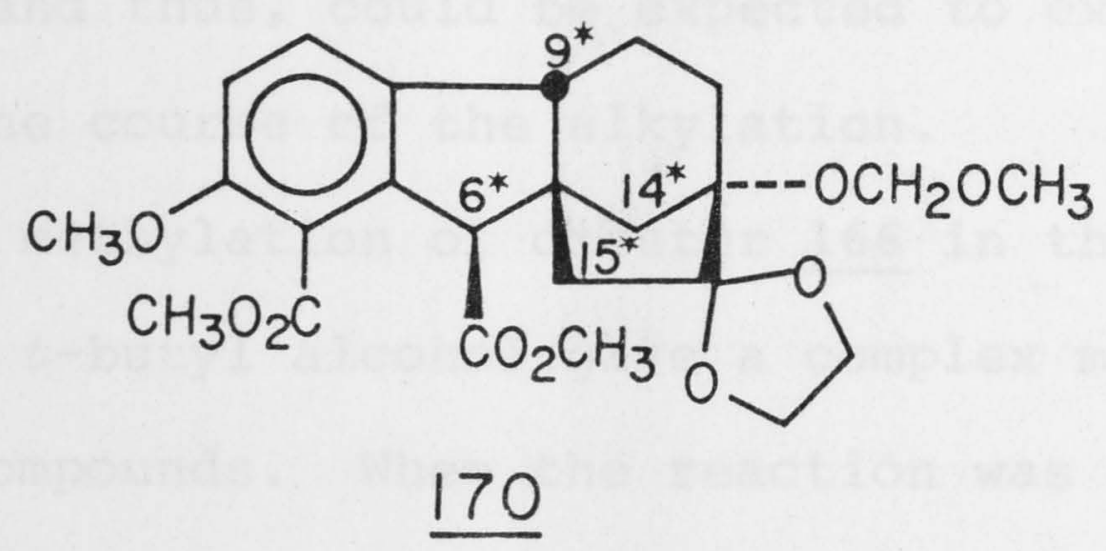

The ${ }^{1}$ H n.m.r. spectrum of ester 170 indicated its close relationship with ester 169: the two indicative shifts of 170 (H6*3.78, H9*3.37) were superimposable on those of 169 (see table 1). Moreover, the comparison of ${ }^{13} \mathrm{C}$ n.m.r. spectra of 166 at $\underline{170}$ substantiated the two assignments. C14* of ester 166 is shielded by the $6 * \alpha$-ester group $\left(\delta\left({ }^{13} \mathrm{C}\right)-5.8 \mathrm{ppm}\right.$ from $\mathrm{Cl} 4$ * in 170$)$, whereas $\mathrm{C} 15$ * of 170 is shifted upfield by 2.2 ppm. 89

In accord with the reports from House et al. ${ }^{56}$ the initially obtained isomer 166 was expected to lead to the correct stereochemistry at pro-c4 in the reductive methylation procedure (cf. Scheme 19). In sharp contradiction however, Loewenthal had later concluded that the introduction of the methyl group into all isomers he had investigated (probably 167-169), occurred exclusively from the side opposite to the two carbon bridge (D-ring), irrespective of the disposition of the carboxyl group at C6*.109,113 The basis of these findings has not been revealed 109 and the conclusions are difficult to rationalise. Examination of molecular models did not reveal any notable change to the environment of $\mathrm{C} 4$, whether the D-ring was present or not. The 6 *-carboxyl group, on the other hand, is reasonably 
close to $\mathrm{C} 4{ }^{*}$, and thus, could be expected to exert a major influence on the course of the alkylation.

Reductive methylation of diester $\underline{166}$ in the presence and absence of t-butyl alcohol gave a complex mixture of ring-reduced compounds. When the reaction was carried out on the ester acid 165 , however, a single $\alpha$-methylated ester acid was obtained in excellent yield ( $84 \%$ ). Its gross structure, 171, could readily be derived from spectroscopic data but the relative chirality of C4 was not clear.

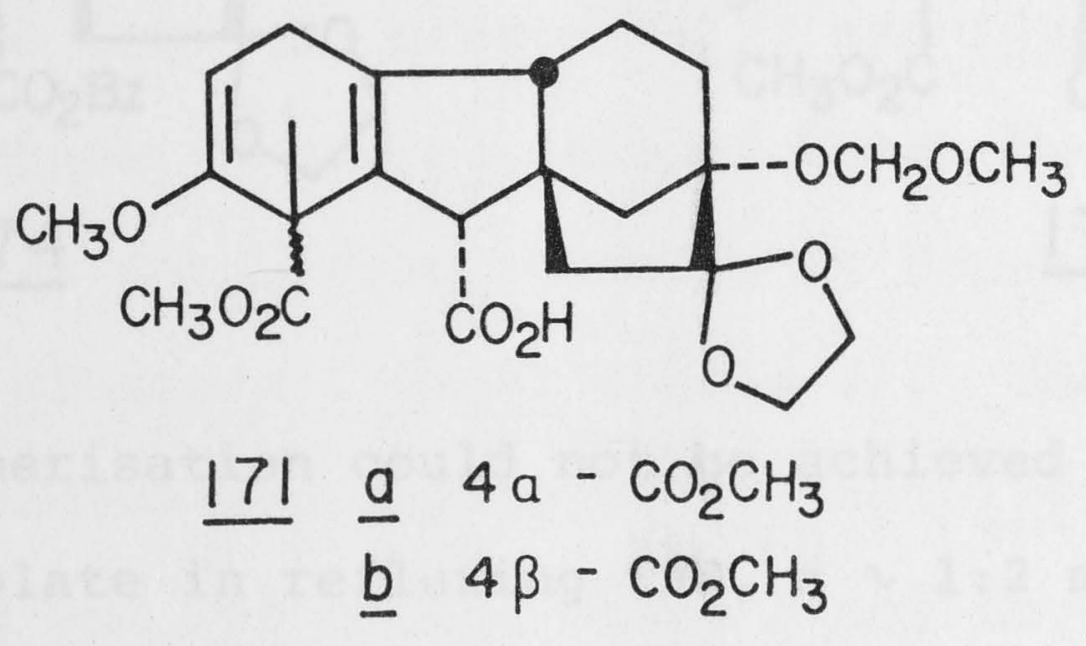

Since reductive methylation of the $\mathrm{C} 6$ *-epimeric aromatic ester acid 172 could help resolve the stereochemical ambiguity at $\mathrm{C} 4$ in isomer 171 , diester 170 was treated with potassium hydroxide in methanol/water. Unfortunately, a selective hydrolysis could not be achieved and diacid 173 was the sole product.

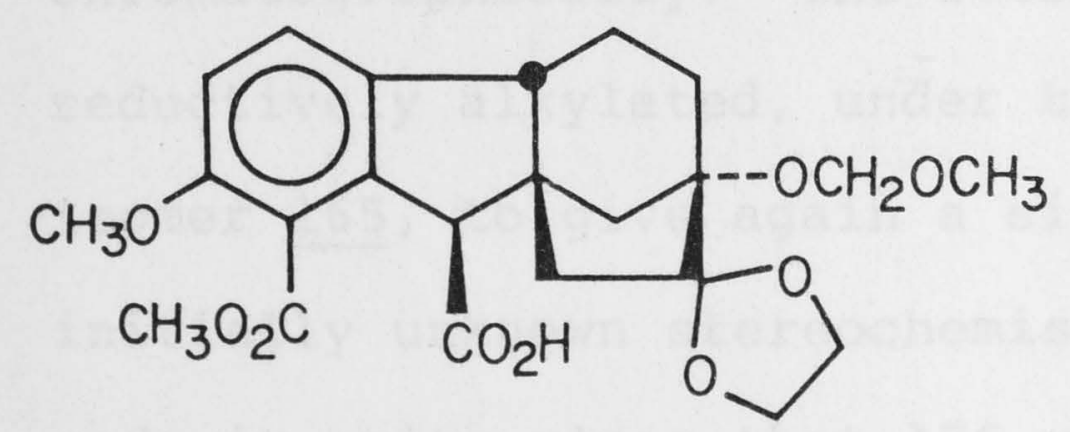

172

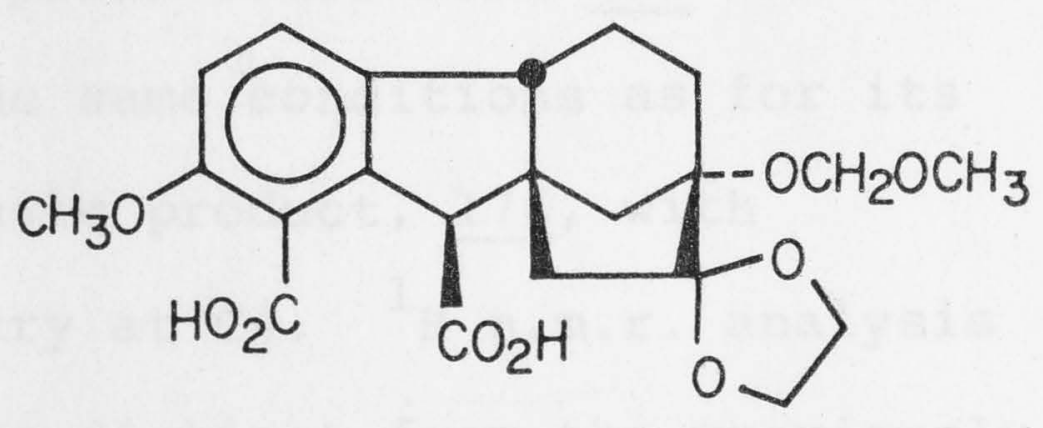

173

It seemed that intramolecular participation of the $6 * \beta$-carboxylate anion greatly accelerated the hydrolysis of 
the aromatic ester. Obviously, the $6 *$-carboxyl group had to be transformed into a functionality which allowed epimerisation at $\mathrm{C} 6$ *, separation of the isomers, and reconstitution of the acid function under non-basic conditions. These considerations led to the preparation of benzyl ester 174 from acid 165 by treatment with benzyl bromide and potassium carbonate in DMF. 114

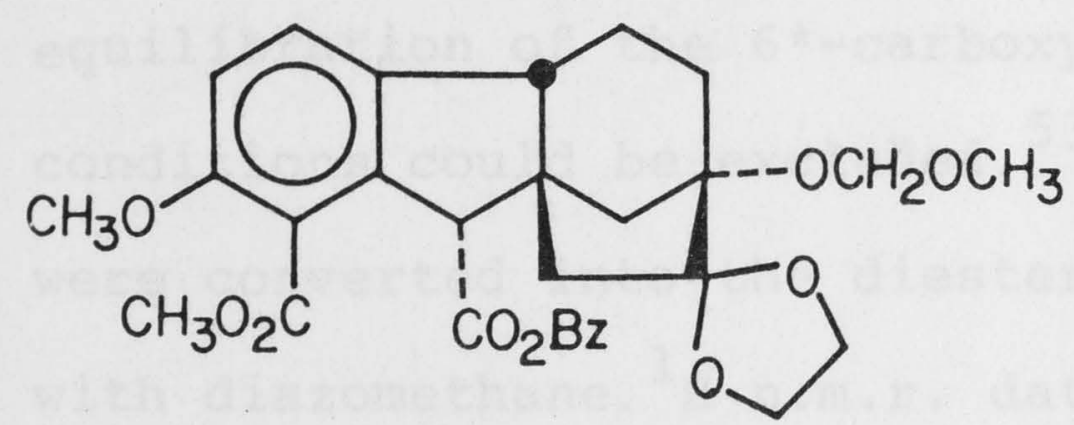

$\underline{174}$

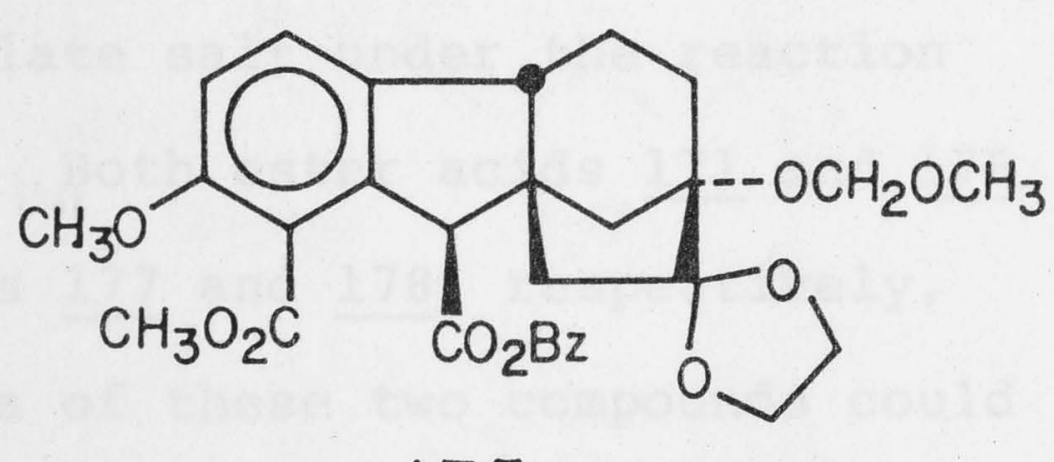

175

Although epimerisation could not be achieved with sodium benzyl alcoholate in refluxing THF, a $\sim 1: 2$ mixture of benzyl esters $\underline{174}$ and $\underline{175}$ was produced on treatment of 174 with 1,5-diazabicyclo|4.3.0|non-5-ene (DBN) at room temperature. Separation of the two isomers could not be accomplished by crystallisation or by liquid chromatography, but after hydrogenolysis over a palladium catalyst, the derived mixture of ester acids 165 and 172 could be resolved chromatographically. The less polar ester acid 172 was reductively alkylated, under the same conditions as for its isomer 165 , to give again a single product, 176 , with initially unknown stereochemistry at $\mathrm{C} 4 .{ }^{1} \mathrm{H}$ n.m.r. analysis made it quite clear that 176 was distinct from the previously obtained isomer 171; the shift of the quakternary methyl in 176 was $1.46 \mathrm{ppm}$ compared to 1.39 in 171 . 


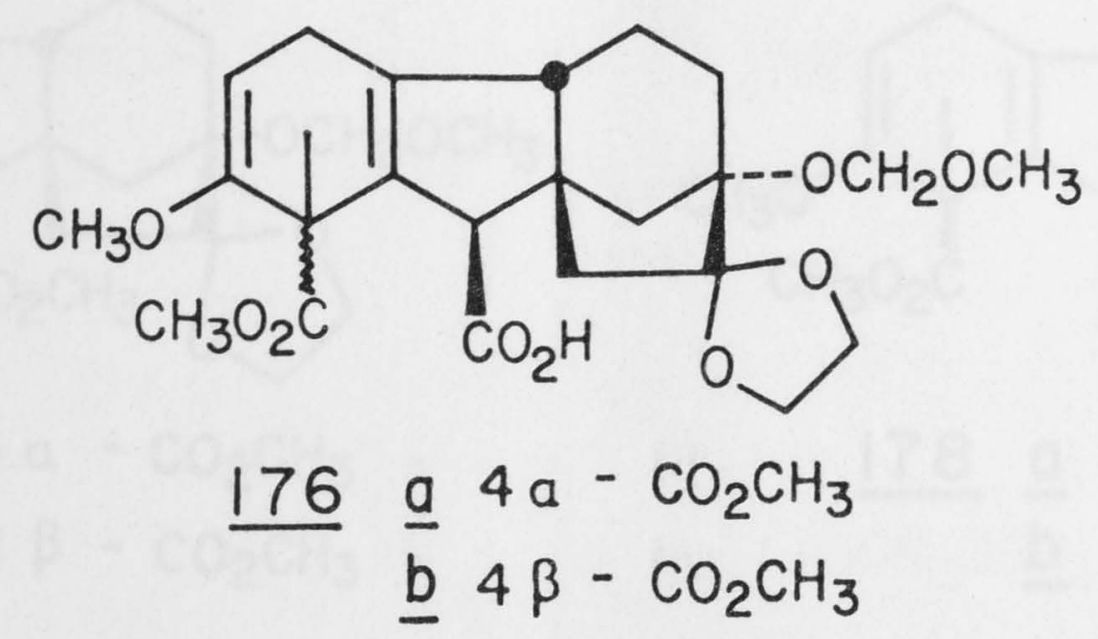

The formation of two isomers had been expected, as an equilibration of the 6 *-carboxylate salt under the reaction conditions could be excluded. 53 Both ester acids 171 and 176 were converted into the diesters 177 and 178 , respectively, with diazomethane. ${ }^{1} \mathrm{H}$ n.m.r. data of these two compounds could now be compared with those reported by House et al. ${ }^{56}$ for the fluorene diesters 179-181 (table 2). The good agreement between the indicative shifts of 177 and 179 on the one hand, and $\underline{178}$ and $\underline{180}$ on the other hand, suggested strongly that the same relative C4-chirality had been obtained in the gibbane series as in the fluorene models. Thus, the structures of the two diesters were provisionally assigned to be $177 \mathrm{a}$ and $178 \mathrm{~b}$. 


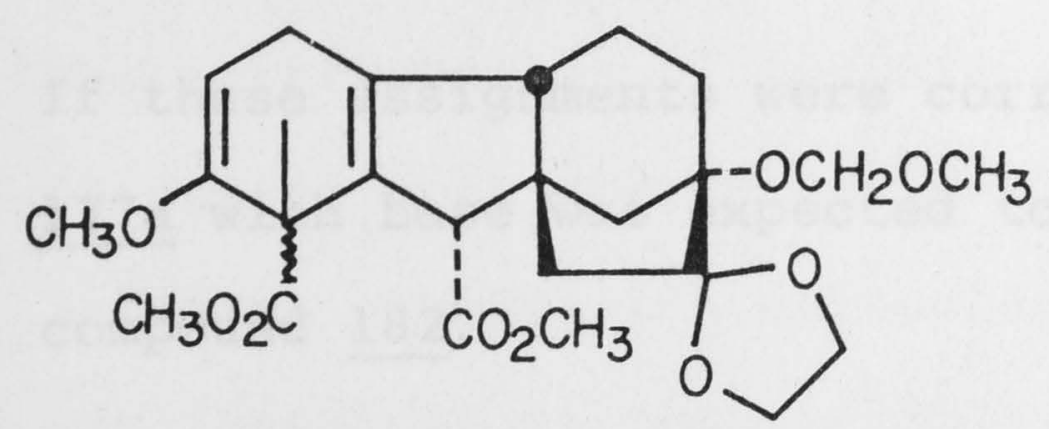

$$
177 \underline{a} \begin{array}{r}
4 \mathrm{a}-\mathrm{CO}_{2} \mathrm{CH}_{3} \\
\underline{b} 4 \beta-\mathrm{CO}_{2} \mathrm{CH}_{3}
\end{array}
$$<smiles>COC(=O)C1C(OC)=CCC2=C1[C@]1(C(C)=O)C=C2C2CCCCC21</smiles>

179

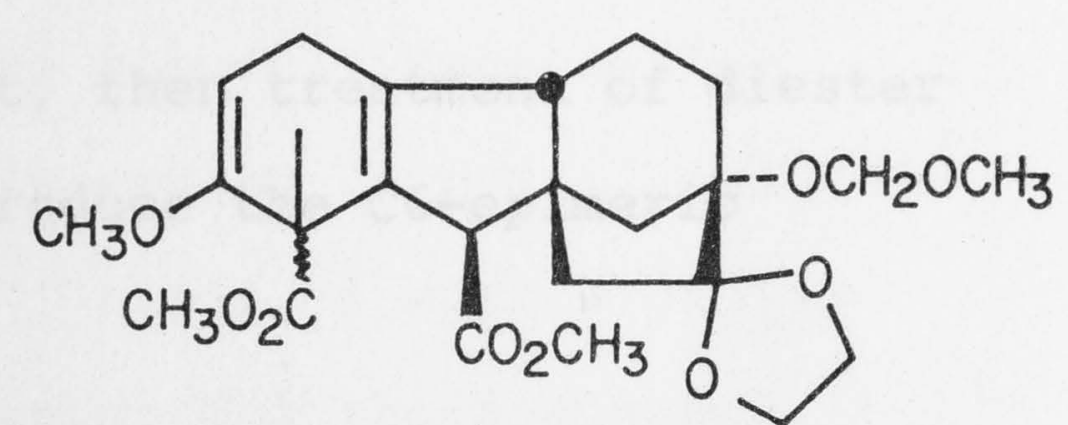

178 a $4 \mathrm{a}-\mathrm{CO}_{2} \mathrm{CH}_{3}$ b $4 \beta-\mathrm{CO}_{2} \mathrm{CH}_{3}$

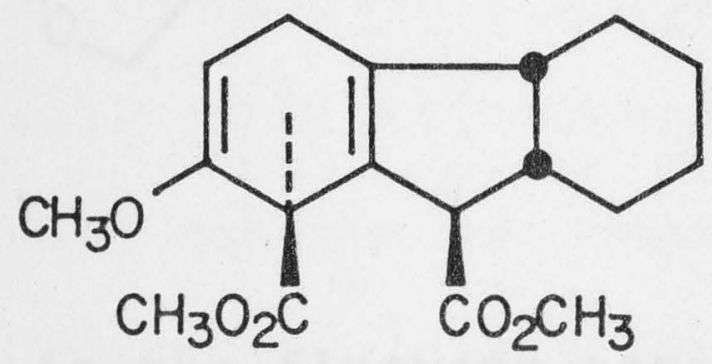

180<smiles>COC1=CCC2=C(C1C(C)=O)[C@]1(C(C)=O)C=C2[C@@H]2CCCC[C@H]21</smiles>

181

Table 2: ${ }^{1} \mathrm{H}$ n.m.r. data $\left(\delta, \mathrm{CDCl}_{3}, 100 \mathrm{MHz} \underline{177}, \underline{178}\right.$;

$60 \mathrm{MHz}$ 179-181)

Compound

$4-\mathrm{CH}_{3}$

4 - and $6-\mathrm{CO}_{2} \mathrm{CH}_{3}$

H6

177

1.36

$3.66 / 3.64$

$3.66(\mathrm{~s})$

179

1.39

$3.66 / 3.63$

$3.4-3.7 \quad(\mathrm{~m})$

178

1.46

$3.63 / 3.59$

3.35 (s)

180

1.47

$3.63 / 3.60$

$3.1-3.3(\mathrm{~m})$

$\underline{181}$

1.32

$3.69 / 3.66$

$<3.2(\mathrm{~m})$ 
If these assignments were correct, then treatment of diester $177 \mathrm{a}$ with base was expected to produce the c6-epimeric compound $\underline{182}$.

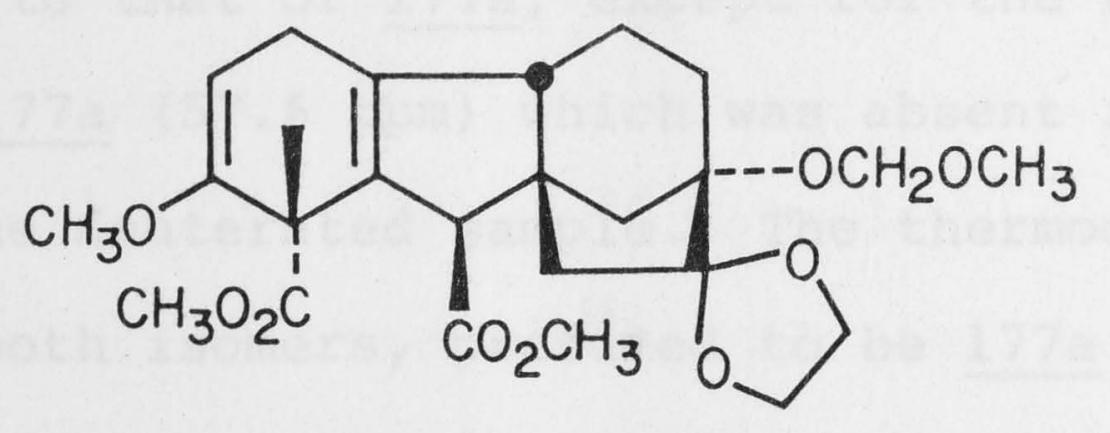

182

Diester 182 , corresponding to $\underline{181}$ in the fluorene series, bears the 6 -ester group in the $\beta$-position which, in similar systems, is known to be thermodynamically favoured (vide supra). However, if according to Loewenthal's observation, 109 diester $177 \mathrm{~b}$ had been obtained, then epimerisation at $\mathrm{C} 6$ should give rise to $178 \mathrm{~b}$. Unfortunately, diester $177 \mathrm{a}$ was recovered unchanged after treatment with sodium methoxide in boiling methanol. Exposure of the other isomer $178 \mathrm{~b}$ to the same conditions did not affect its stereochemistry either. To ensure that proton abstraction from the hindered c6-position had occurred under these conditions, the attempted equilibrations of $\underline{177 \mathrm{a}}$ and $\underline{178 \mathrm{~b}}$ were repeated in $\mathrm{d}_{1}$-methanol. Deuterium incorporation indeed took place and the two esters 183 and 184 were obtained from two separate exchange reactions.

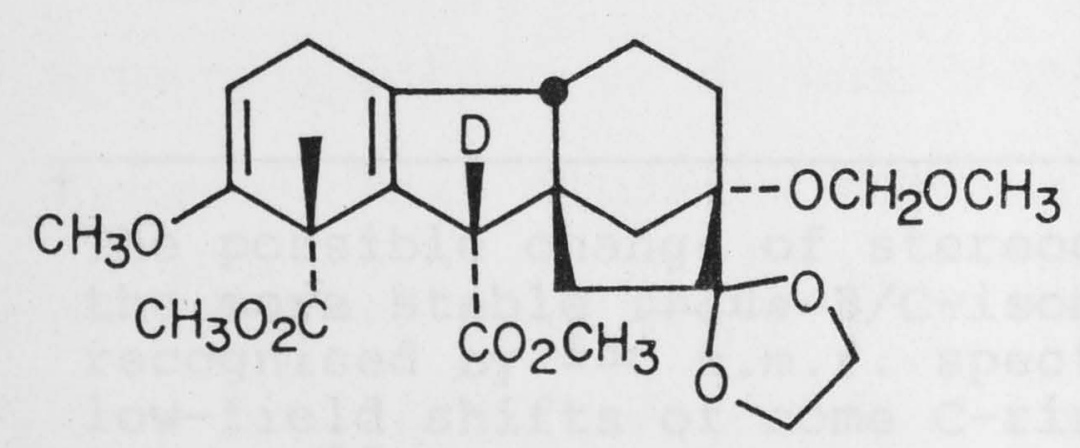

183

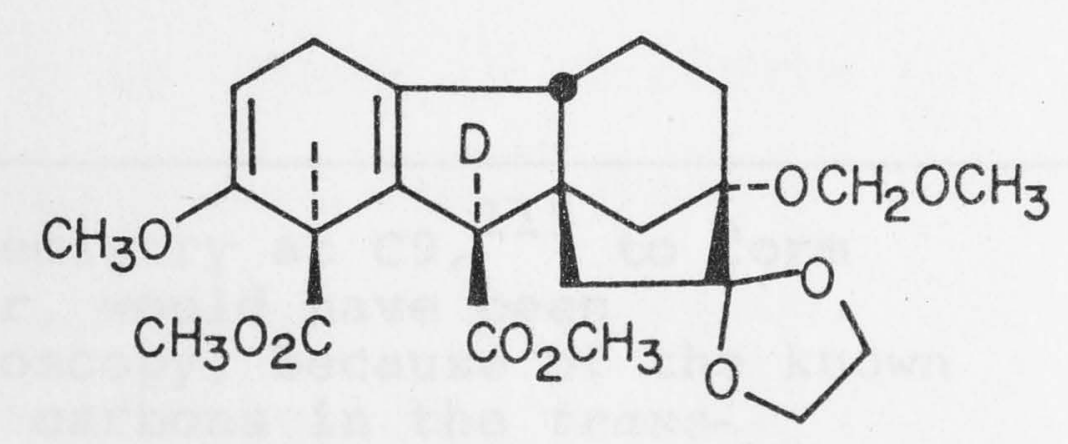

184 
The incorporation of deuterium was the only detectable change in both compounds, as indicated by ${ }^{1} \mathrm{H}$ n.m.r. and mass spectra. The proton decoupled ${ }^{13} \mathrm{C}$ n.m.r. spectrum of 183 was identical to that of $177 \mathrm{a}$, except for the resonance due to $\mathrm{C} 6$ in $177 \mathrm{a}(57.6 \mathrm{ppm})$ which was absent in the spectrum of the deuterated sample. The thermodynamic stability of both isomers, presumed to be $177 \mathrm{a}$ and 178b, indicated they differed at $\mathrm{C} 4$ as well as at $\mathrm{C} 6$, because neither of the previously established centres was expected to have been affected during the reductive alkylation. ${ }^{\dagger}$ Hence, the only remaining alternative to the assignment of structures $177 \mathrm{a}$ and $178 \mathrm{~b}$ would require entry of the methyl group on the same side as the 6-carboxyl functionality, leading to isomers $\underline{177 b}$ and $\underline{178 \mathrm{a}}$ respectively. This possibility, however, seems to be ruled out by the discrepancy between the ${ }^{1} \mathrm{H}$ n.m.r. data of 178 and 181 (cf. table 2). Clearly, the shielding of the methyl group by the 6 *-ester group in 181 is completely missing in compound 178 , indicating a trans-relationship between these two groups. With all the evidence favouring the initial assignments, it was decided to continue the synthesis from the acid presumed to be 17la which has all the correct gibberellin stereochemistry. Moreover, the conversion of 171 into compounds such as 24 or $25(\mathrm{R}=\mathrm{OH})$, both intermediates in a contemporaneous

The possible change of stereochemistry at C9, 115 to form the more stable trans-B/C-isomer, would have been recognised by $13 \mathrm{C}$ n.m.r. spectroscopy, because of the known low-field shifts of some c-ring carbons in the transisomer. 89 
synthesis of gibberellic acid, 33,34 would also establish the stereochemistry of 171 unequivocally.

The formation of the lactone bridge had previously been elaborated in different model compounds (cf. Scheme 16, 20). 1,57 In view of the difficulties encountered earlier in this work with the oxidation of 1,4-reduced benzoic acid derivatives, it seemed advisable to remove the enol ether prior to the liberation of the C4-acid functionality. Hydrolysis of the enol ether in ester 171 a with mineral acid ${ }^{51}$ was of course impractical because of the protecting groups in the C/D-portion. Enol ethers, however, can be hydrolysed with weak acids, such as acetic acid 116,117 and formic acid 117 which were not expected to affect either the methoxymethyl ether or the ketal functions. Nevertheless, the enol ether in acid 17la was recovered unchanged from treatment with organic acids such as acetic acid, formic acid, chloroacetic acid, and even oxalic acid in THF or acetone/water mixtures. Dichloroacetic acid and dilute hydrochloric acid not only hydrolysed the enol ether, but, as feared, also brought about partial cleavage of the methoxymethyl ether and the ketal group. ${ }^{118}$ Kresge and Chiang had observed that the rate of hydrolysis of enol ethers not only depended on the acidity of the catalyst, but that electrostatic effects played a considerable role. ${ }^{19}$ Thus, the negatively charged hydrogensulfate anion was found to be almost as effective for the enol ether cleavage, as the hydroxonium ion, although its $\mathrm{pk}_{\mathrm{a}}$-value is about four units higher. Unfortunately, even prolonged treatment of the enol ether in $171 \mathrm{a}$ with 
sodium hydrogensulfate did not result in any reaction. In the hydrolysis of enol ethers, unlike most other acid catalysed reactions, protonation is the rate determining step. 117 This suggested that a more powerful electrophile than the proton might induce the hydrolysis. The mercury (II) cation, a good electrophile, had been used to effect transetherification of enol ethers. ${ }^{120}$ Mercuric acetate had also been added to catalyse the hydrolysis of a dienol ether which could not be cleaved with formic acid. ${ }^{121}$ This reagent, however, just extended the list of reagents found to be ineffective in the hydrolysis of enol ether $171 \mathrm{a}$. Barton and coworkers, however, used a catalytic amount of mercuric nitrate instead of the acetate in order to realise complete hydrolysis of an enol ether. ${ }^{122}$ This reagent (0.33 equivalent), applied in a mixture of acetonitrile and water (5:1), selectively cleaved the enol ether in 171a. The ketone 185, isolated in 77\% yield, was pure and byproducts arising from hydrolysis of the methoxymethyl ether or the ketal could not be detected.

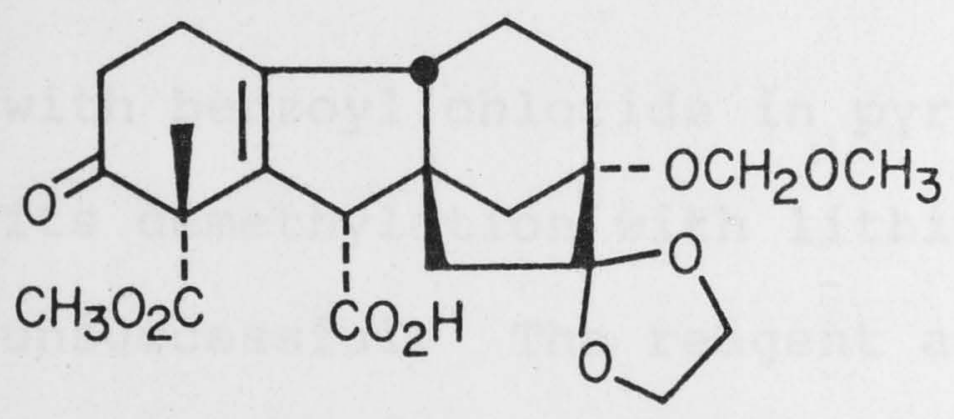

185

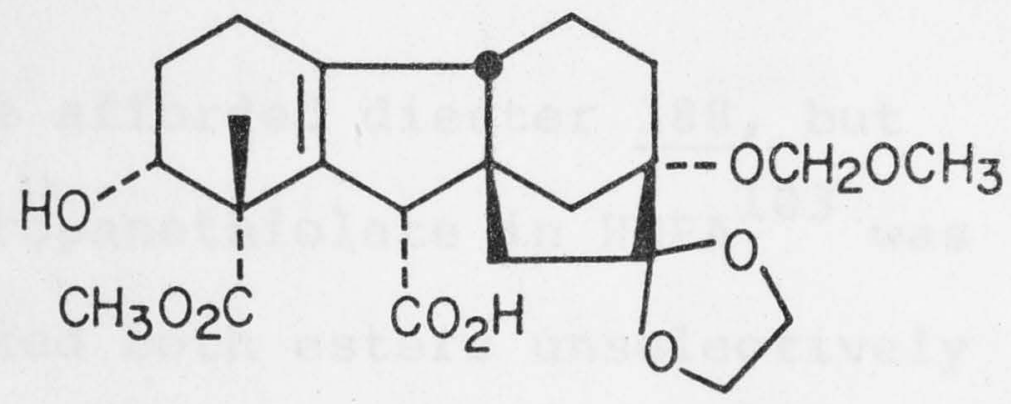

186

Reduction of the ketone 185 with sodium borohydride in ethanol at $0^{\circ}$ gave the alcohol 186 . It seemed that the $\alpha$-alcohol was produced largely, if not exclusively, as was expected from previous work. ${ }^{51}$ The hydroxyl group had 
then to be protected, so as to prevent the cleavage of the C3-C4 bond through a retro-aldol process ${ }^{36}$ during the forthcoming reactions involving basic conditions. The benzoyl group seemed adequate for this task, since it would survive all planned transformations and could be removed under mild conditions. $^{34}$ To facilitate separation of the protected product from the benzoic acid (generated from the hydrolysis of excessive benzoyl chloride), acid 186 was esterified with diazomethane prior to the protection of the hydroxyl group. The presence of this second ester group should be of no concern since, in the demethylation to follow, the less hindered B-ring methyl carboxylate was expected to react more rapidly than the quaternary A-ring ester. Treatment of the hydroxy diester 187

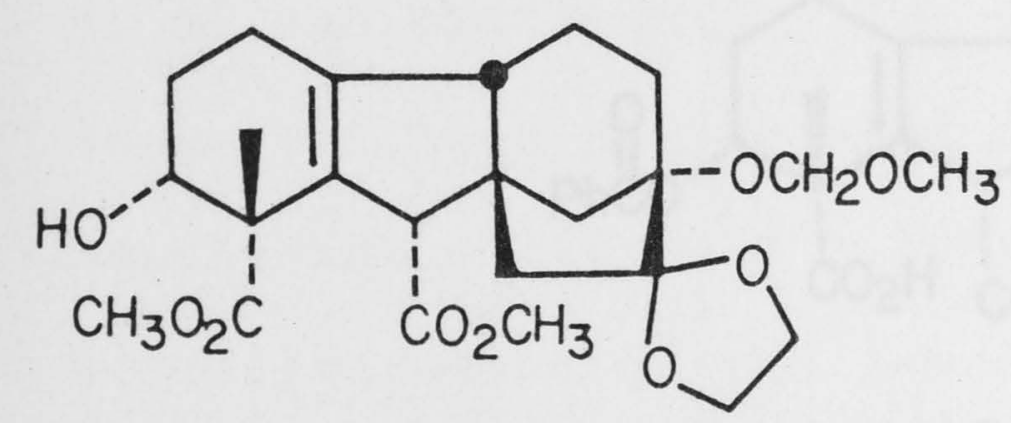

187

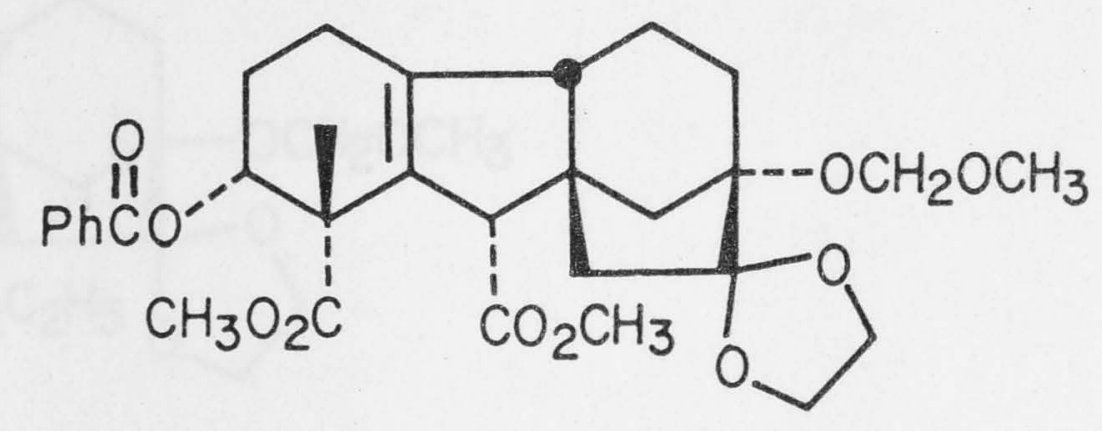

188

with benzoyl chloride in pyridine afforded diester 188 , but its demethylation with lithium propanethiolate in $\mathrm{HMPA}^{103}$ was unsuccessful. The reagent attacked both esters unselectively at a reasonable rate, but once a mono-carboxylate salt had formed, alkyl-oxygen fission of the second ester seemed virtually to cease. Prolongation of treatment or elevated temperatures were impractical because the compound did not 
withstand these harsher conditions. Considering that $\mathrm{S}_{\mathrm{N}}{ }^{2-\mathrm{cle}}$ eavages proceed more slowly on ethyl esters, ${ }^{123}$ the ester acid 186 was, accordingly, treated with diazoethane. ${ }^{124}$ The hydroxyl group of the resulting diester 189 was then protected as the benzoate, yielding the ethyl methyl ester 190 .

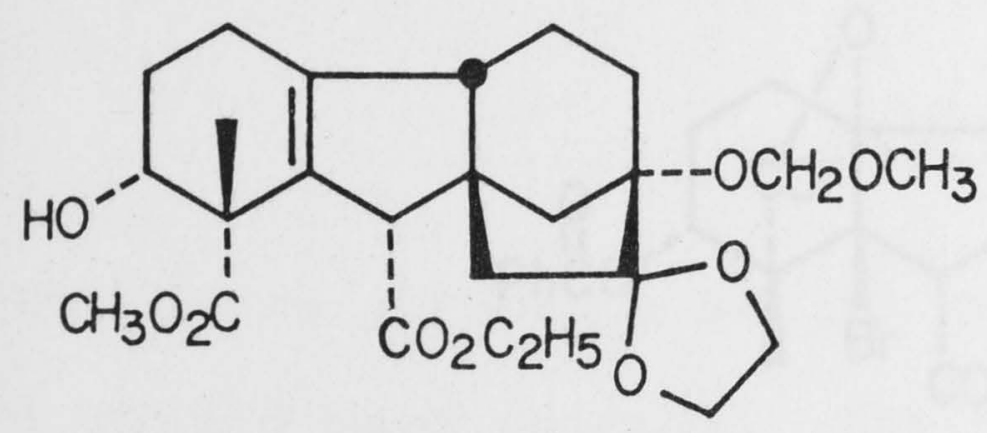

189

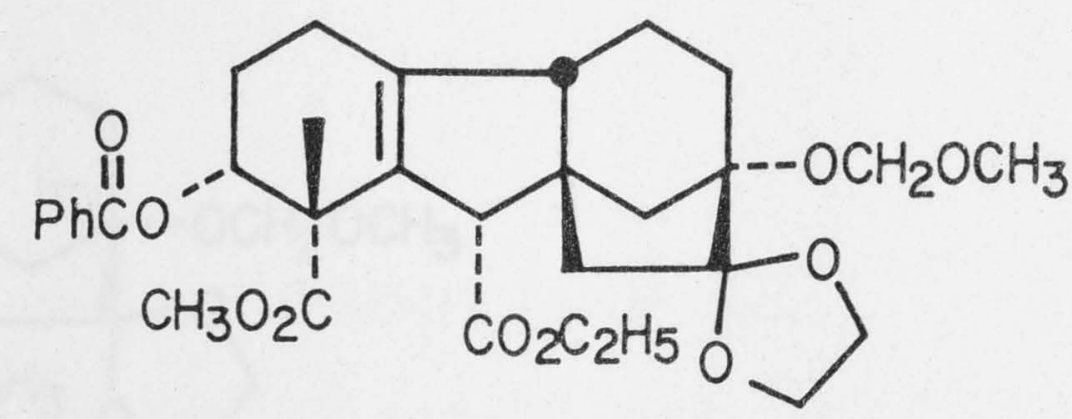

190

When this compound was subjected to the Johnson-Bartlett demethylation procedure, 103 the ester acid 191 was obtained in good yield.

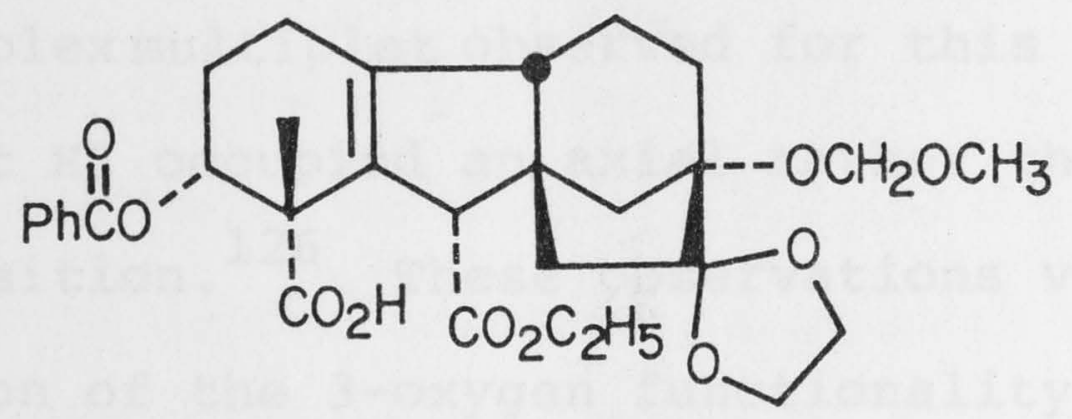

$\underline{191}$

The first attempts to induce halolactonisation were based on the conditions used by Loewenthal's group in the decalin model. 51 Treatment of acid 191 with potassium triiodide and potassium hydrogencarbonate in aqueous THF did not effect any lactonisation. Other unfruitful attempts to obtain a lactone from acid 191 included reagents such as the highly electrophilic mercuric trifluoroacetate ${ }^{125}$ in THF, and bromine on the preformed acid salt in DMF. When potassium tribromide was added to a solution of acid 191 in aqueous potassium hydrogencarbonate and THF at $0^{\circ}, 57$ however, 
the starting material was converted into a much less polar product within 1 hr (t.l.c. analysis). Since the i.r. spectrum of this compound clearly indicated that lactone formation had occurred $\left(\nu_{\max }\left(\mathrm{CH}_{2} \mathrm{Cl}_{2}\right) 1792 \mathrm{~cm}^{-1}\right)$, it was formulated as the bromo lactone 192 .

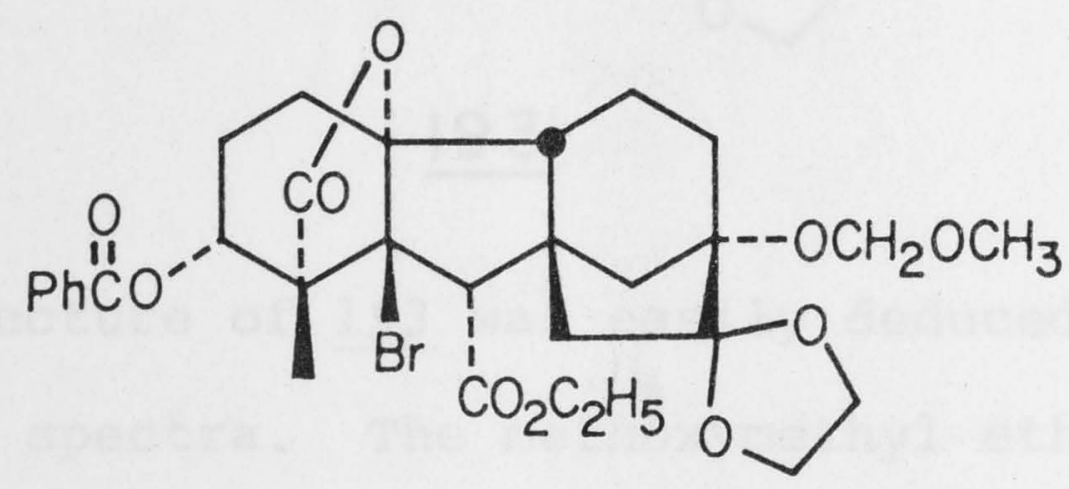

192

The ${ }^{l_{H}}$ n.m.r. spectrum of 192 showed a large downfield shift for H3 (0.65 ppm from 191), thus indicating a cisrelationship between $\mathrm{H3}$ and the axial bromide at $\mathrm{C} 5$. The broad and complexmultiplet observed for this proton also suggested that $\mathrm{H} 3$ occupied an axial rather than an equatorial position. ${ }^{126}$ These observations verified the $\alpha$-configuration of the 3-oxygen functionality. When the lactone formation was performed at $25^{\circ}$ a second compound was obtained (i.r. analysis, additional $\nu_{\max }\left(\mathrm{CH}_{2} \mathrm{Cl}_{2}\right)$ $1775 \mathrm{~cm}^{-1}$ ), but its structure was not investigated. Debromination of the bromo lactone 192 was first attempted with tribulyltin hydride 127 at $50^{\circ}$ in benzene in the presence of a radical initiator. 57 A complex mixture of products was obtained (t.l.c. analysis) which was not further analysed. However, chromium(II) acetate 128 effected debromination of the lactone 192 in dimethylsulfoxide (DMSO) in the presence of propanethiol at room temperature. 129 Isolation gave a lactone, assumed to be 
193, in 50\% yield from the acid 191.

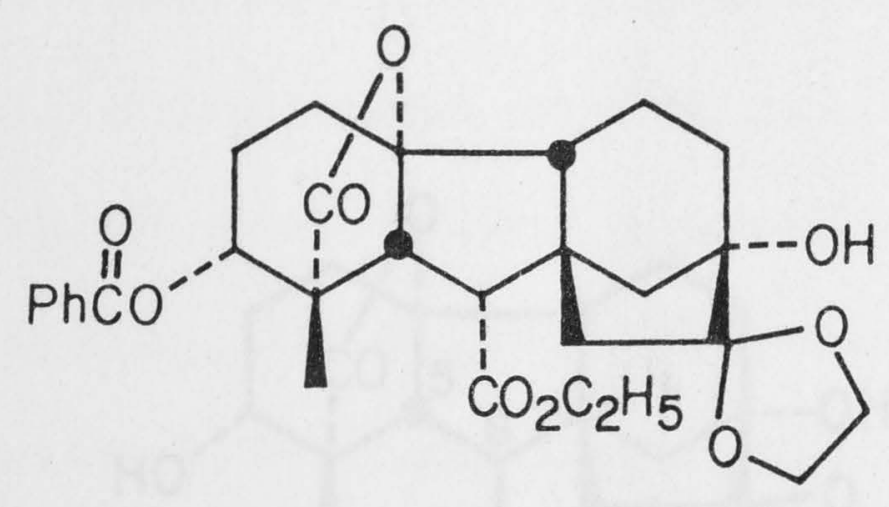

193

The gross structure of 193 was easily deduced from its i.r. and mass spectra. The methoxymethyl ether had, surprisingly, been hydrolysed completely during the debromination reaction. The stereochemistry at C6 was expected to have remained intact, since a base of the strength required to abstract $\mathrm{H} 6$ had never been present. Thus, it only remained to establish, whether the debromination had occurred stereospecifically and if so, in which way. The sharp melting point of lactone 193, its homogeneity by

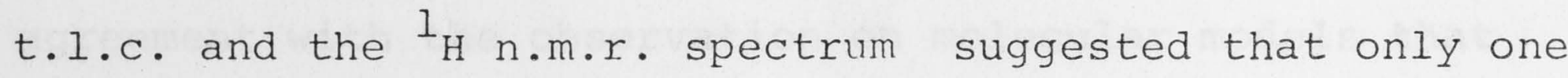
isomer had been obtained. The formation of 193 was strongly favoured on the grounds that a large amount of strain would be introduced by inverting the stereochemistry at C5. It is virtually impossible to assemble a Dreiding model of the gibberellin molecule with $5 \alpha$-stereochemistry. More evidence for the $\beta$-configuration of 193 was gained from its ${ }^{1}$ H n.m.r. spectrum: the protons at $\mathrm{C} 5$ and $\mathrm{C} 6$ gave rise to an $\mathrm{AB}$-quartet, with doublets at 3.05 (H6) and $2.44 \mathrm{ppm}$ (H5), and a coupling constant of $11 \mathrm{~Hz}$. The corresponding values for the lactone $\underline{194}^{33,130}$ possessing a gibberellin-like 
B-ring, were 2.67 (H6) and 2.48 (H5) with a vicinal coupling of $10 \mathrm{~Hz}$.

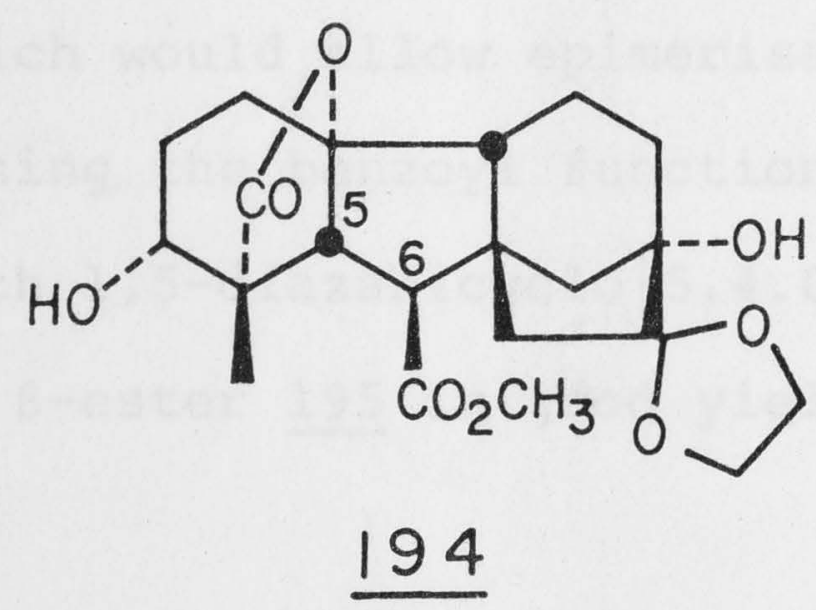

The assignment of the chemical shifts (H5, H6) in 194 were made on the basis of deuterium incorporation at $\mathrm{C}^{\dagger}$ under basic conditions, verifying Hanson's earlier assignments. ${ }^{131}$ The difference in the shifts of H6 in 193 (3.05) and $194(2.67)$ is understandable in terms of the shielding exerted by the lactone on the $6 \alpha$-hydrogen of 194. The slightly smaller coupling constant in $194(10 \mathrm{~Hz})$ is in agreement with the observation on molecular models that the dihedral angle $(\mathrm{H}-\mathrm{C} 5-\mathrm{C} 6-\mathrm{H})$ in $\underline{194}$ is not as close to $180^{\circ}$ as the angle in 193 is to $0^{\circ} .132$

The conversion of the ethyl ester 193 to the envisaged methyl ester 194 was first attempted in one step: it was hoped that sodium methoxide in refluent methanol would effect concomitant cleavage of the benzoate, ester alkoxy exchange, and epimerisation of the ester group. During the prolonged treatment which was necessary to obtain inversion

† The labelling experiment was performed on 13-deoxy-194. ${ }^{130}$ 
at 66 decomposition of the compounds occurred. This was probably due to the retro-aldol process undergone by the free c3-alcohol under these conditions. ${ }^{36}$ Thus, a method was required which would allow epimerisation of the ester without hydrolysing the benzoyl functionality. Treatment of ester 193 with 1,5-diazabicyclo|5.4.0|undec-5-ene in DMF at $90^{\circ}$ gave the $\beta$-ester $\underline{195}$ in good yield.

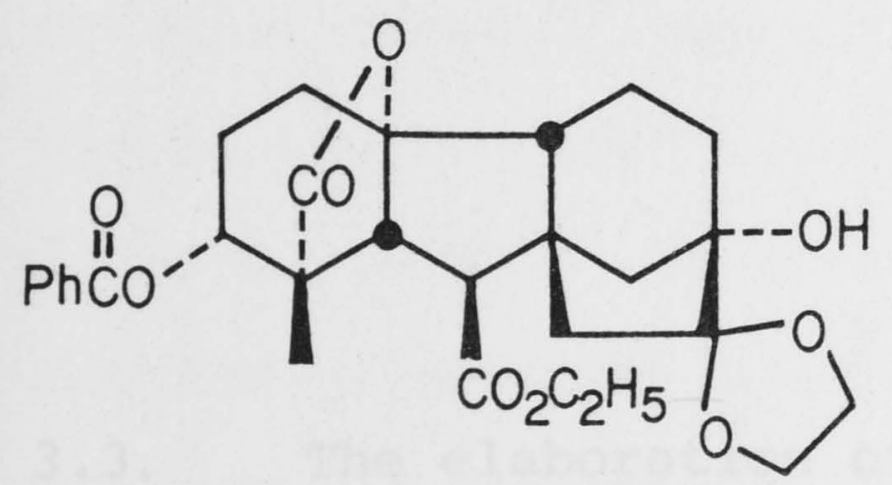

195

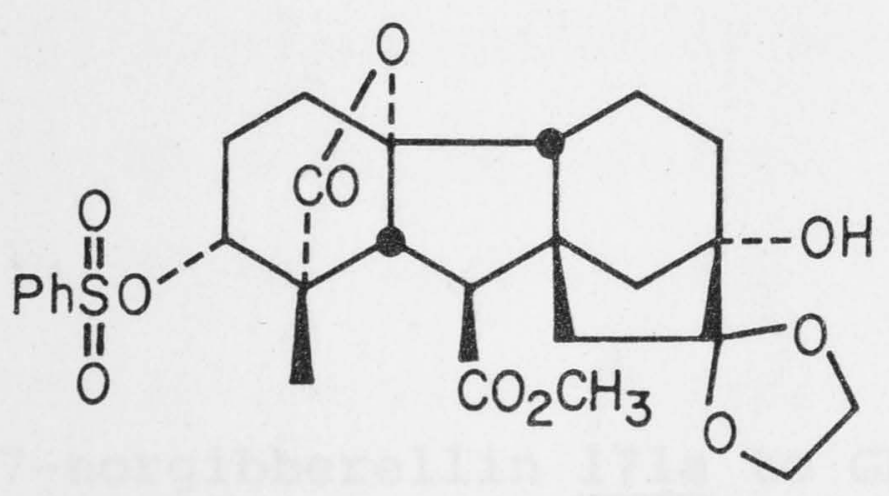

196

Although the outcome of this reaction was predictable, the $I_{\mathrm{H}}$ n.m.r. spectrum of 195 included a surprise: the chemical shifts of $\mathrm{H} 5$ and $\mathrm{H} 6$ coincided and appeared as a sharp singlet ( $\delta 2.68 \mathrm{ppm}$ ). A similar feature was later observed in the ${ }^{1}$ n.m.r. of sulfonate 196.130 The removal of the benzoyl group and hydrolysis of the ethyl ester in 195 were achieved with $1 \%$ sodium hydroxide at room temperature. Methylation of the crude product with ethereal diazomethane and purification by chromatography gave the desired ester 194, identical in all aspects to synthetic material obtained through a different route. 33 The successful synthesis of 194, confirmed the stereochemistry assigned to C3, C4, C5, C6 and C9 on spectroscopic evidence during the course of the synthesis. 
It also constitutes a formal total synthesis of gibberellic acid $\underline{2}$ and gibberellin $A_{8} 197$ since these have been prepared from ester 194 in our laboratories (cf. Scheme 9). 34,133

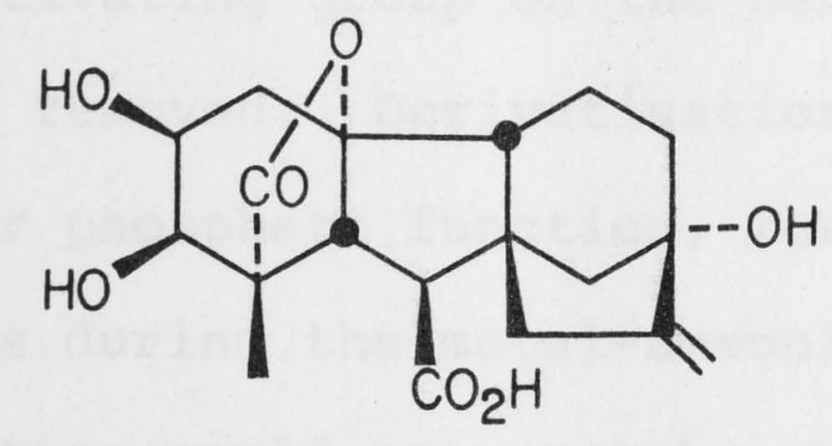

197

3.3. The elaboration of the 17-norgibberellin 17la to $\mathrm{GA}_{3}$ clearly can be made shorter and more efficient than has been described in this thesis. Thus, olefin 26, an intermediate in the transformation of ester $\underline{194}$ to gibberellic acid $\underline{2}$ should be accessible through the following route: protection of the hydroxyl group in diester 189 as the benzenesulfonate (rather than the benzoate), (ii) lactone formation as described above, and (iii) elimination of the sulfonate, epimerisation of the C6-carboxyl function and ester alkoxy exchange. The lack of time and material, however, prevented an investigation of this attractive sequence.

It seems unfortunate that the final stage of this $\mathrm{GA}_{3}$ synthesis required elimination of the 3 -oxygen function, 34 when such care was needed in both preserving, and then hydrolysing, the enol ether group. Reductive methylation of a simple benzoyl synthon would provide the desired olefin 
directly, but the required fluorenone starting material cannot be made simply because of insufficient activation in the cyclodehydration step. Clearly, the solution lies in using an activating group on the benzoyl synthon which may be readily removed. Derivatisation of the c3-substituent as sulfonate or phosphate function, for example, would ensure its loss during the metal-ammonia reduction. ${ }^{34}$ This sort of activation would not even be necessary for a cl-substituent, ${ }^{73}$ but unfortunately the cyclisation of acid 146 to the required fluorenone 104 could not be achieved in good yield. 66 If these aspects can be resolved, the problem of ensuring specific lactonisation onto the tetrasubstituted olefinic bond still remains. A lactonisation in this sense has been obtained by Loewenthal's group on a decalin model. 51 These considerations provide the potential for a saving of up to six steps, but there has been insufficient time to pursue them.

The significance of the present work remains, nevertheless, in the demonstration that gibberellins can be prepared by this general strategy with complete stereochemical control, and with relative efficiency and reliability. Moreover it brings to a climax two decades of widespread investigations by many groups on model studies and innumerable approaches based on precursors with benzenoid A-rings. The synthesis takes only 13 steps (from 2,5-dimethoxybenzoic acid) to establish a 17-norgibberellin structure with the correct relative stereochemistry at the key C4, C8 and C9 centres (or any other variation) and a set of functionalities 
suitable for the final elaboration. With some fine tuning, therefore, it should be possible to make any of the natural gibberellins or their analogues with an acceptable investment of effort and resources. 
EXPERIMENTAL 


\section{General Topics}

(i) Melting points were determined with a Reichert hotstage apparatus. Melting points (m.p.) and boiling points (b.p.) are uncorrected.

(ii) ${ }^{1}$ H n.m.r. spectra were recorded using a Joel Minimar 100 spectrometer operating at $100 \mathrm{MHz}$. The spectra were measured in deuterochloroform, unless otherwise stated, using tetramethylsilane (TMS) as an internal standard ( $\delta 0.00 \mathrm{ppm})$. Data are given in the following order: chemical shift $\delta$ relative to TMS (ppm); multiplicity; coupling constant ( $\mathrm{Hz})$; intensity as number of protons; assignment. The following abbreviations are used: s, singlet;

d, doublet; $t$, triptlet; $q$, quartet; dd, doublet of doublets; m, multiplet; e, envelope.

(iii) ${ }^{13} \mathrm{C}$ n.m.r. spectra were recorded using a Joel FX 60 spectrometer operating at $15.04 \mathrm{MHz}$. The spectra were measured using deuterochloroform as a solvent. The data are given in the following order: chemical shifts $\delta\left({ }^{13} \mathrm{C}\right)$ relative to TMS (ppm); multiplicity (when known); assignment (if possible). Both

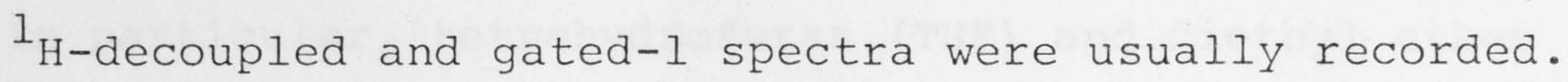

(iv) Infra-red spectra were recorded with a Jasco IRA-I or on a Perkin Elmer 457 spectrometer $\left(\nu_{\max }\right)$. Nujol mulls were used unless otherwise indicated.

(v) The mass spectra were recorded on an AEI MS 902 double-focussing mass spectrometer. The data are presented in the following order: $\mathrm{m} / \mathrm{z}$ value; 
relative intensity as a percentage of the base peak .

(vi) Ultra-violet spectra were recorded with a Unicam S.P. Ultra-violet spectrophotometer, using spectroscopic ethanol as a solvent.

(vii) Microanalyses were performed by the Australian National University Analytical Services Unit, Canberra.

(viii) Column chromatography was carried out using Merck Kieselgel 60 as the absorbent. Preparative thick layer chromatography (p.I.c.) was carried out on glass-backed plates $(20 \times 20 \mathrm{~cm}, 20 \times 40 \mathrm{~cm} ; 0.5 \mathrm{~mm}-$ $2 \mathrm{~mm}$ thick) coated with Merck Kieselgel KGF $254^{\text {. }}$ Analytical t.l.c. was performed on micro-slides coated with a layer of Merck Kieselgel $\mathrm{KGF}_{254^{\circ}}$ The microslides were visualised using first an ultraviolet light and then by spraying with a solution of 5\% (w/v) vanillin in concentrated sulfuric acid and heating at $180^{\circ}$.

(ix) Reactions were run in an atmosphere of nitrogen. The solvents used were dried over molecular sieves. 135 In particular, tetrahydrofuran (THF) and diethyl ether (ether) were distilled from the ketyl formed by the reaction of sodium with benzophenone. Petroleum ether refers to the fraction which boils between $40^{\circ}$ and $60^{\circ}$.

(x) Organic extracts were dried over magnesium sulfate unless otherwise indicated. After filtration the solvent was evaporated on a Büchi rotary evaporator 
(water aspirator pressure) and the last traces removed on a vacuum pump (ca. 0.1 Torr).

(xi) The concentration of sulfuric acid is given in $\%(w / w)$. $\mathrm{PPA}^{136}$ was prepared by adding phosphorфus pentoxide $(500 \mathrm{~g})$ to $85 \%$ orthophosphoric acid $(375 \mathrm{~g})$ at such a rate to maintain the internal temperature at $90^{\circ}$. After heating at $120^{\circ}$ for an additional 3 hr the resultant colourless syrup was stored in a desiccator.

(xii) Ethereal diazomethane was prepared from $N$-nitroso-Nmethyl urea (small amounts) or p-toluenesulfonylmethylnitrosoamide (Diazald, large scale). 137 For the preparation of diazoketones it was dried over potassium hydroxide pellets ( $3 \mathrm{hr}$ ) before use.

\section{General Procedure}

Reductive alkylation of 2,5-dimethoxybenzoic acid 74 : Lithium metal ( 12.5 mmol) was added piecewise to a stirred suspension of the acid 74 ( $5 \mathrm{mmol}$ ) in liquid ammonia ( $100 \mathrm{ml}$ ) and THF (10 ml) at $-33^{\circ}$ until a deep blue colour persisted. After $20 \mathrm{~min}$. a solution of the alkylating agent ( $6.0 \mathrm{mmol})$ in THF ( $5 \mathrm{ml}$ ) was added dropwise over 5 min., stirring was continued for an additional $60 \mathrm{~min}$, and the ammonia was allowed to evaporate. The residue obtained was dissovled in water $(\sim 50 \mathrm{ml})$ and extracted with ethyl acetate $(2 \times 50 \mathrm{ml})$ to remove unwanted neutral by-products. The basic aqueous phase was cooled to $0^{\circ}$, layered with fresh ethyl acetate $(100 \mathrm{ml})$ and acidified to $\mathrm{pH} 5$ with sodium dihydrogenphosphate. The layers were separated, and the aqueous phase extracted 
further with ethyl acetate $(2 \times 50 \mathrm{ml})$. The extracts were washed with brine $(50 \mathrm{ml})$ and dried. Removal of the solvent gave the crystalline alkylated acid in a high state of purity.

\section{Notes on Nomenclature}

Compounds described in the Experimental have been named, where appropriate, as derivatives of the following:<smiles>O=CC12C=CC=CC=C1c1ccccc1C=C2</smiles>
1H-2, 10a-Ethanophenanthrene (ref.138)

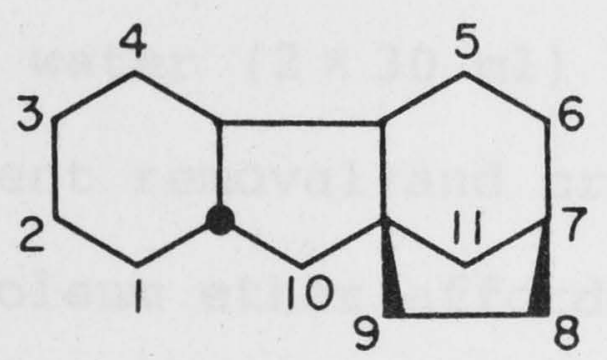


Chapter 1<smiles>COc1cc(CO)cc(OC)c1</smiles>

$\underline{85}$<smiles>COc1cc(CBr)c(Br)c(OC)c1</smiles>

84

2-Bromo-3,5-dimethoxybenzyl bromide 84 was prepared by the route previously described: ${ }^{74}$ to a stirred solution of $3,5-$ dimethoxybenzyl alcohol ${ }^{140}(1.68 \mathrm{~g}, 10 \mathrm{mmol})$ in a chloroform/ carbon tetrachloride solution $(1: 1,10 \mathrm{ml})$ at $-10^{\circ}$ and in the absence of light was added $\mathrm{N}$-bromosuccinimide (1.78 $\mathrm{g}, 10 \mathrm{mmol}$ ) in one portion. The cooling bath was removed after $1 \mathrm{hr}$ and the reaction mixture was stirred for a further $4 \mathrm{hr}$. The mixture was diluted with chloroform $(50 \mathrm{ml})$ and extracted with water $(2 \times 30 \mathrm{ml})$ and once with saturated brine. Drying, solvent removal and crystallisation from dichloromethanepetroleum ether afforded 2-bromo-3,5-dimethoxybenzyl alcohol $(1.85 \mathrm{~g}, 75 \%)$.

M.p. $106-108^{\circ}$ (1it. $\left.{ }^{74} 108-109^{\circ}\right)$. Freshly distilled phosphorous tribromide (0.32 ml, 3.7 mmol) in anhydrous ether ( $1 \mathrm{ml}$ ) was added dropwise to a stirred solution of 2-bromo-3,5-dimethoxybenzyl alcohol (1.8 g, 7.3 mmol) in anydrous ether $(5 \mathrm{ml})$. The reaction mixture was boiled under reflux for $3 \mathrm{hr}$, cooled and diluted with water $(10 \mathrm{ml})$. The organic portion was separated, washed twice with water, once with saturated brine and dried. The solvent was removed and the crude product crystallised from dichloromethane-petroleum ether to afford 2-bromo-3,5dimethyoxybenzyl bromide $84(2.10 \mathrm{~g}, 93 \%)$ as colourless 
needles.

M.p. $103-105^{\circ}$ (1it. $\left.{ }^{76} 101-102^{\circ}\right)$.<smiles>COc1cc(CBr)c(Br)c(OC)c1</smiles>

84

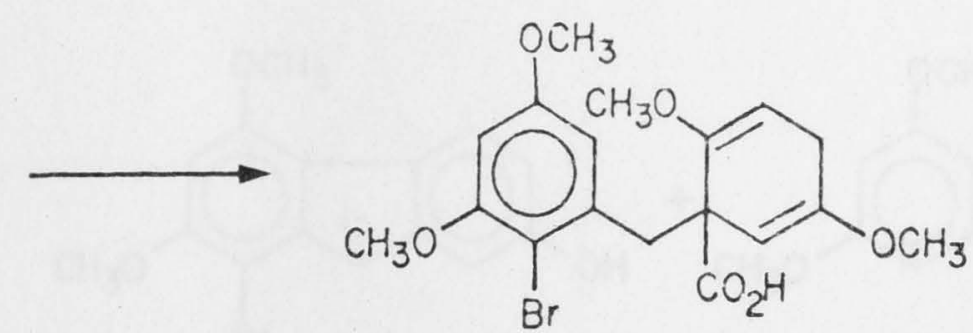

$\underline{86}$

The dianion $\underline{75}$ (from acid $\underline{74 ;} 0.91 \mathrm{~g}, 5 \mathrm{mmol}$ ) was alkylated with bromide $84(1.86 \mathrm{~g}, 6 \mathrm{mmol})$ to provide

\section{1 - [(2-bromo-3,5-dimethoxypheny 1$)$ methyl $]-2,5$-dimethoxy-2,5-} cyclohexadiene-1-carboxylic acid 86 (1.59 $\mathrm{g}, 77 \%$ ) as a white crystalline solid.

M.p. $125-129^{\circ} \quad\left(\mathrm{CCl}_{4}\right)$.

$\delta 6.30(\mathrm{~s}, 2 \mathrm{H}, \mathrm{ArH}), 4.72(\mathrm{t}, \mathrm{J}=4 \mathrm{~Hz}, 1 \mathrm{H}, \mathrm{H} 3), 4.70(\mathrm{~s}, 1 \mathrm{H}, \mathrm{H} 6)$,

$3.78\left(\mathrm{~s}, 3 \mathrm{H}, \mathrm{ArOCH}_{3}\right), 3.68\left(\mathrm{~s}, 3 \mathrm{H}, \mathrm{ArOCH}_{3}\right), 3.60\left(\mathrm{~s}, 3 \mathrm{H}, \mathrm{C}=\mathrm{COCH}_{3}\right)$,

$3.48\left(\mathrm{~s}, 3 \mathrm{H}, \mathrm{C}=\mathrm{COCH}_{3}\right), 3.45$ and $3.36\left(\mathrm{ABq}, \mathrm{J}_{\mathrm{AB}}=15 \mathrm{~Hz}, 2 \mathrm{H}, \mathrm{ArCH}_{2}\right)$,

$2.64\left(\mathrm{dd}, \mathrm{J}_{1}=20 \mathrm{~Hz}, \mathrm{~J}_{2}=4 \mathrm{~Hz}, 1 \mathrm{H}, \mathrm{H} 4\right), 2.40 \quad\left(\mathrm{dd}, \mathrm{J}_{1}=2 \mathrm{OHz}, \mathrm{J}_{2}=4 \mathrm{~Hz}, 1 \mathrm{H}, \mathrm{H} 4\right)$. $\nu_{\max } 1700,1690,1660,1600,1580 \mathrm{~cm}^{-1}$.

$\mathrm{m} / \mathrm{z} \quad 414 / 412\left(6 \%, \mathrm{M}^{+}\right), 370 / 368(12), 368 / 366(20), 333$ (20), $289(21), 257(57), 157(59), 139(100)$.

$\mathrm{C}_{18} \mathrm{H}_{21} \mathrm{BrO}_{6} \quad$ H.r.m.s. Calcd: 362.1418 .

Found: $\quad 362.1422$. 
<smiles></smiles>

The acid $86(100 \mathrm{mg}, 0.24 \mathrm{mmol})$ was added to vigorously stirred $60 \% \mathrm{H}_{2} \mathrm{SO}_{4}\left(2 \mathrm{ml}\right.$, degassed with $\left.\mathrm{N}_{2}, 20 \mathrm{~min}\right)$ at room temperature. The acid dissolved with gas evolution and after $30 \mathrm{~min}$. the dark green solution was poured onto ice $(15 \mathrm{~g})$. The organic extracts (dichloromethane $2 \times 20 \mathrm{ml}$ ) were washed with water $(2 \times 20 \mathrm{ml})$, brine $(20 \mathrm{ml})$, and dried. Removal of the solvent left a black oil (60 mg). Chromatography (p.l.c., 4\% methanol-dichloromethane) afforded

(i) a mixture (11 mg) of 8-bromo-5,7-dimethoxy-3,4dihydrofluoren-2(1H)-one 83 and $\underline{5,7-d i m e t h o x y-3,4-}$ dihydrofluoren-2(1H)-one 87 ( $1: 2$ ).

$\delta \quad 6.60(\mathrm{~d}, \mathrm{~J}=2 \mathrm{~Hz}, \sim 0.67 \mathrm{H}, \mathrm{H} 8, \underline{87}), 6.42(\mathrm{~s}, \sim 0.33 \mathrm{H}, \mathrm{H} 6,83), 6.36$ $(\mathrm{d}, \mathrm{J}=2 \mathrm{~Hz}, \sim 0.67 \mathrm{H}, \mathrm{H} 6, \underline{87}), 3.78\left(\mathrm{~s}, \sim 2 \mathrm{H}, 2 \times \mathrm{ArOCH}_{3}, \underline{83}\right), 3.76(\mathrm{~s}, \sim 4 \mathrm{H}$ ， $\left.2 \times \mathrm{ArOCH}_{3}, \underline{87}\right), 3.76(\mathrm{e}, 4 \mathrm{H}, \mathrm{Hl}, \mathrm{H} 9), 3.10(\mathrm{~m}, 2 \mathrm{H}, \mathrm{H} 4), 2.56(t, \mathrm{~J}=8 \mathrm{~Hz}$, $2 \mathrm{H}, \mathrm{H} 3)$.

$\mathrm{m} / \mathrm{z} \quad 324 / 322\left(12 \%, \mathrm{M}^{+}, \underline{83}\right), 244\left(100 \%, \mathrm{M}^{+}, \underline{87}\right), 216(50), 202(30)$, $188(28)$.

(ii) a mixture (18 mg) of 8-bromo-5,7-dimethoxyfluoren-2-ol 88 and 5,7-dimethoxyfluoren-2-ol 89

$\delta 7.78(\mathrm{~d}, \mathrm{~J}=9 \mathrm{~Hz}, 1 \mathrm{H}, \mathrm{H} 5), 7.00-6.42(\mathrm{~m}, \sim 3.5 \mathrm{H}), 4.88(\mathrm{bs}, \mathrm{ArOH})$, $3.88(\mathrm{~s}, 3 \mathrm{H}), 3.85(\mathrm{~s}, 3 \mathrm{H}), 3.76(\mathrm{~m}, 2 \mathrm{H}, \mathrm{H} 9)$. 
$\mathrm{m} / \mathrm{z} \quad 322 / 320\left(48 \%, \mathrm{M}^{+}, \underline{88}\right), 307 / 305(22), 242\left(100, \mathrm{M}^{+}, \underline{89}\right)$, 227 (38).<smiles>COc1cc(COC(C)=O)cc(OC)c1</smiles>

91

$\underline{92}$

Phosphor 4 s oxychloride $(3.66 \mathrm{ml}, 40 \mathrm{mmol})$ was added dropwise to $\mathrm{DMF}(16 \mathrm{ml})$ at $0^{\circ}$. After ten minutes 3,5-dimethoxybenzyl acetate $^{91} \underline{1}^{1.41}(4.2 \mathrm{~g}, 20 \mathrm{mmol})$ in DMF $(13 \mathrm{ml})$ was added and the yellow reaction mixture was stirred for $4 \mathrm{hr}$ at $60^{\circ}$. The solution was cooled, poured onto an ice $(200 \mathrm{~g}) / \mathrm{sodium}$ acetate $(60 \mathrm{~g})$ mixture, and stirred for $4 \mathrm{hr}$, to give a precipitate. Extraction with dichloromethane $(3 \times 100 \mathrm{ml})$, which was washed with water $(50 \mathrm{ml}), 1 \mathrm{~N}$ sodium bicarbonate $(2 \times 50 \mathrm{ml})$, water $(50 \mathrm{ml})$, brine $(50 \mathrm{ml})$, gave after drying and solvent removal 2-acetoxymethyl-4,6-dimethoxybenzaldehyde 92 (4.52 9, 95\%) as a white solid (m.p. $\left.132-135^{\circ}\right)$. An analytical sample was obtained by recrystallisation from dichloromethane-petroleum ether.

M.p. $\quad 136-136 \cdot 5^{\circ}$.

$\delta 10.38(\mathrm{~s}, 1 \mathrm{H}, \mathrm{CHO}), 6.60(\mathrm{~d}, \mathrm{~J}=2 \mathrm{~Hz}, 1 \mathrm{H}), 6.38(\mathrm{~d}, \mathrm{~J}=2 \mathrm{~Hz}, 1 \mathrm{H})$, $5.48(\mathrm{~s}, 2 \mathrm{H}), 3.85(\mathrm{~s}, 6 \mathrm{H}), 2.17(\mathrm{~s}, 3 \mathrm{H})$.

$v_{\max } 1745,1675,1610,1580 \mathrm{~cm}^{-1}$.

$\mathrm{m} / \mathrm{z} 238\left(28 \%, \mathrm{M}^{+}\right), 196(35), 195(100), 178(74)$.

$\mathrm{C}_{12} \mathrm{H}_{14} \mathrm{O}_{5} \quad$ Calcd: C, 60.5; H, 5.9.

Found: $\mathrm{C}, 60.6 ; \mathrm{H}, 6.0 \%$ 
<smiles>COc1cc(COC(C)=O)c(C=O)c(OC)c1</smiles>

92<smiles>COc1cc(CO[C+](C)=O)c(C(=O)O)c(OC)c1</smiles>

93

Finely powdered aldehyde $\underline{92}(2.38 \mathrm{~g}, 10 \mathrm{mmol})$ was added with vigorous stirring to water $(25 \mathrm{ml})$ at $70^{\circ}$, followed by a solution of potassium permanganate $(2.21 \mathrm{~g}, 14 \mathrm{mmol})$ in water $(35 \mathrm{ml})$ in three portions over an hour. The temperature was maintained at 70-80 for another two hours, after which the purple colour had disappeared. Sodium bicarbonate was added to obtain $\mathrm{pH} 9$ and the hot solution was filtered. The manganese dioxide residue was washed with hot water $(2 \times 20$ ml). The combined aqueous layers were extracted with dichloromethane $(2 \times 50 \mathrm{ml})$, acidified to $\mathrm{pH} 1$ with $6 \mathrm{~N}$ hydrochloric acid at $0^{\circ}$ and extracted with fresh dichloromethane $(3 \times 50 \mathrm{ml})$ which was washed with water $(50 \mathrm{ml})$, brine (50 ml) and dried. Removal of solvent gave 2-acetoxymethyl-4,6dimethoxybenzoic acid $93(1.80 \mathrm{~g}, 71 \%)$ as a colourless solid. Recrystallisation from dichloromethane-petroleum ether gave the analytical sample.

M.p. $105-107^{\circ}$.

$\delta 10.60(\mathrm{bs}, 1 \mathrm{H}), 6.60(\mathrm{~d}, \mathrm{~J}=2 \mathrm{~Hz}, 1 \mathrm{H}), 6.44(\mathrm{~d}, \mathrm{~J}=2 \mathrm{~Hz}, 1 \mathrm{H})$,

$5.34(\mathrm{~s}, 2 \mathrm{H}), 3.91(\mathrm{~s}, 3 \mathrm{H}), 3.83(\mathrm{~s}, 3 \mathrm{H}), 2.12(\mathrm{~s}, 3 \mathrm{H})$.

$\nu_{\max } 1730,1715,1600,1580,1570 \mathrm{~cm}^{-1}$.

$\mathrm{m} / \mathrm{z} 254\left(18 \%, \mathrm{M}^{+}\right), 222(8), 221(7), 194(45), 193(100)$.

$\mathrm{C}_{12} \mathrm{H}_{14} \mathrm{O}_{6} \quad$ Calcd: C, 56.7; H, 5.6.

Found: C, 56.6; H, 5.5\%. 
<smiles>COC(=O)Cc1cc(OC)cc(OC)c1C(=O)O</smiles>

$\underline{93}$<smiles>COc1cc(COC(C)=O)c(OC)c(OC)c1</smiles>

$\underline{94}$

To acid $93(1.27 \mathrm{~g}, 5 \mathrm{mmol})$ in dichloromethane (10 $\mathrm{ml})$ was added diazomethane ( $7 \mathrm{mmol}$ ) in ether $(20 \mathrm{ml})$ at $0^{\circ}$.

Removal of excessive diazomethane and solvent afforded methyl 2-acetoxymethyl-4,6-dimethoxybenzoate 94 ( $1.27 \mathrm{~g}, 95 \%$ ) as a colourless oil.

$\delta \quad 6.50(\mathrm{~d}, \mathrm{~J}=2 \mathrm{~Hz}, 1 \mathrm{H}), 6.42(\mathrm{~d}, \mathrm{~J}=2 \mathrm{~Hz}, 1 \mathrm{H}), 5.07(\mathrm{~s}, 2 \mathrm{H}), 3.82$ $(\mathrm{s}, 3 \mathrm{H}), 3.75(\mathrm{~s}, 6 \mathrm{H}), 2.03(\mathrm{~s}, 3 \mathrm{H})$. $\nu_{\max }(\mathrm{film}) 1730-1720,1600,1580 \mathrm{~cm}^{-1}$. $\mathrm{m} / \mathrm{z} 268\left(18 \%, \mathrm{M}^{+}\right), 226(7), 195(31), 194(31), 193(100)$. $\mathrm{C}_{13} \mathrm{H}_{16}{ }^{\mathrm{O}} 6$ H.r.m.s. Calcd: 268.0947 . Found: 268.0939 .<smiles>COCc1cc(OC)cc(OC)c1C(C)(C)C</smiles>

$\underline{94}$<smiles>COc1cc2c(c(OC)c1)C(=O)OC2</smiles>

$\underline{95}$

(i) The ester $94(1.07 \mathrm{~g}, 4 \mathrm{mmol})$ and potassium carbonate $(1.10 \mathrm{~g}, 8 \mathrm{mmol})$ in THF $(20 \mathrm{ml})$, methanol $(30 \mathrm{ml})$ and water $(5 \mathrm{ml})$ were heated at reflux under nitrogen for $16 \mathrm{hr}$. The reaction mixture was cooled, the solvent evaporated and the residue partitioned between dichloromethane (100 ml) and water $(50 \mathrm{ml})$. The organic layer was washed once more with water $(30 \mathrm{ml})$, brine $(50 \mathrm{ml})$ and dried. After solvent removal 
5,7-dimethoxyphthalide $95(0.7149,92 \%)$ was obtained as a yellowish solid.

M.p. $151-152^{\circ}$ (needles from methanol) (lit. ${ }^{80} 151-153^{\circ}$ ). $\nu_{\max } 1750$ (lit. 801748 ) $\mathrm{cm}^{-1}$.

(ii) The ester $94(268 \mathrm{mg}, 1 \mathrm{mmol})$ and sodium hydroxide $(40 \mathrm{mg}, 1 \mathrm{mmol})$ in methanol $(20 \mathrm{ml})$ and water $(2 \mathrm{ml})$ were kept at $23^{\circ}$ for $1.5 \mathrm{hr}$. After work-up as described under (i) 5,7-dimethoxyphthalide 95 (165 mg, 85\%) was obtained. (iii) The acid $93(762 \mathrm{mg}, 3 \mathrm{mmol})$ was treated as described for ester 94 under (i). After solvent evaporation, the residue was dissolved in water $(30 \mathrm{ml})$. Acidification in a two-phase system (ethyl acetate, $30 \mathrm{ml}$ ) at $0^{\circ}$ with $2 \mathrm{~N}$ hydrochloric acid to $\mathrm{pH} 3$ gave after repeated extraction ( $2 \times 30 \mathrm{ml}$ ethyl acetate), washing of the organic solvent (brine $30 \mathrm{ml}$ ) drying and solvent removal 5,7-dimethoxyphthalide $95(498 \mathrm{mg}, 85 \%)$.<smiles>CC(=O)c1c(C)cc(Cl)cc1O</smiles>

Methyl 2,4-dihydroxy-6-methylbenzoate:

This compound was prepared from methyl crotonate and methyl acetoacetate in the same way as described for the corresponding ethyl ester, 84 except for the solvent (methanol) and the reaction time ( $36 \mathrm{hr}$ reflux) in the first condensation step. Debromination was achieved with nickel/aluminium alloy in alkaline solution ${ }^{142}$ ( $60 \%$ overall). 
M.p. 139-1410 (from dichloromethane-petroleum ether) (1it. $\left.143142^{\circ}\right)$.<smiles>COc1cc(C)c(C(C)=O)c(O)c1</smiles>

100

Methyl 2,4-dihydroxy-6-methylbenzoate (3.64 g, $20 \mathrm{mmol})$, sodium carbonate $(2.65 \mathrm{~g}, 25 \mathrm{mmol})$ and dimethyl sulfate $(2.37 \mathrm{ml}, 25 \mathrm{mmol})$ in acetone $(70 \mathrm{ml})$ were mechanically stirred and heated at reflux for $12 \mathrm{hr} . \quad 30 \%$ Aqueous ammonia solution $(10 \mathrm{ml})$ was added to the cooled reaction mixture and stirring was continued for one hour. The solvent was evaporated, the aqueous layer extracted with ether $(3 \times 100 \mathrm{ml})$ and the organic layer was washed with $1 \mathrm{~N}$ sodium carbonate (50 $\mathrm{ml}$, removes starting material), water $(50 \mathrm{ml})$ and brine $(50 \mathrm{ml})$. The oily residue was crystallised from ethanol to leave methyl 2-hydroxy-4-methoxy-6methylbenzoate $100(2.94 \mathrm{~g}, 75 \%)$. M.p. $62-64^{\circ}$ (lit. ${ }^{85} 60-62^{\circ} ;$ lit. $\left.{ }^{144} 63-65^{\circ}\right)$. $\nu_{\max } 3400,1650,1620,1575 \mathrm{~cm}^{-1}$. 
<smiles>COc1cc(C)c(C(C)=O)c(O)c1</smiles>

100<smiles>COc1cc(O)c(C(=O)O)c(CBr)c1</smiles>

101

To a solution of ester $100(1.96 \mathrm{~g}, 10 \mathrm{mmol})$ and $\alpha, \alpha^{i}$-azobis-isobutyronitrile (2 $\mathrm{mg})$ in carbon tetrachloride (30 ml), heated at reflux with a $500 \mathrm{~W}$ tungsten lamp, was added dropwise a solution of bromine $(0.51 \mathrm{ml}, 10 \mathrm{mmol})$ in carbon tetrachloride $(15 \mathrm{ml})$ over $15 \mathrm{~min}$. The solvent was removed and the solid (contained about 5\% starting material) recrystallised from petroleum ether $\left(60-80^{\circ}\right)$ to give methyl 2-bromomethyl-6-hydroxy-4-methoxybenzoate $101(2.39 \mathrm{~g}, 87 \%)$.

M.p. $113.5-115^{\circ}$ (cubes from carbon tetrachloride).

$\delta 11.64(\mathrm{~s}, 1 \mathrm{H}, \mathrm{ArOH}), 6.48(\mathrm{~d}, \mathrm{~J}=2 \mathrm{~Hz}, 1 \mathrm{H}), 6.42(\mathrm{~d}, \mathrm{~J}=2 \mathrm{~Hz}, 1 \mathrm{H})$,

$4.74\left(\mathrm{~s}, 2 \mathrm{H}, \mathrm{CH}_{2} \mathrm{Br}\right), 3.98\left(\mathrm{~s}, 3 \mathrm{H}, \mathrm{CO}_{2} \mathrm{CH}_{3}\right), 3.81$ (s, $\left.3 \mathrm{H}, \mathrm{ArOCH}_{3}\right)$. $\nu_{\max } 1650,1610,1590 \mathrm{~cm}^{-1}$.

$\mathrm{m} / \mathrm{z} 276 / 274\left(22 \%, \mathrm{M}^{+}\right), 244 / 242(54), 195$ (100), 163 (39), 135 (59).

$\mathrm{C}_{10} \mathrm{H}_{11} \mathrm{BrO}_{4} \quad$ Calcd: C, 43.7; H, 4.0; $\mathrm{Br}, 29.1$. Found: $\mathrm{C}, 43.7 ; \mathrm{H}, 4.1 ; \mathrm{Br}, 29.1 \%$<smiles>COc1cc(O)c(C(C)=O)c(CBr)c1</smiles>

101<smiles>COC(=O)c1c(CBr)cc(OC)cc1OC</smiles>

$\underline{90}$

Ester $101(2.2 \mathrm{~g}, 8 \mathrm{mmol})$ in ether/methanol (10:1, $80 \mathrm{ml})$ at $2^{\circ}$ was treated with diazomethane ( $\left.40 \mathrm{mmol}\right)$ in ether $(80 \mathrm{ml})$. 
After 5 days at $2^{\circ}$ the colourless solution was filtered and the solvent removed. The oily residue $(2.2 \mathrm{~g})$ which contained about $10 \%$ starting material, ${ }^{+}$was chromatographed on silica gel to afford methyl 2-bromomethyl-4,6-dimethoxybenzoate 90 ( $1.87 \mathrm{~g}, 81 \%$ ) which crystallised on standing.

M.p. $\quad 74-76^{\circ}$.

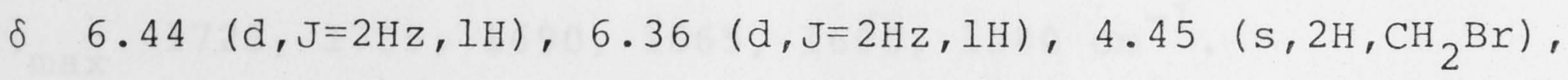
$3.87\left(\mathrm{~s}, 3 \mathrm{H}, \mathrm{CO}_{2} \mathrm{CH}_{3}\right), 3.76\left(\mathrm{~s}, 6 \mathrm{H}, 2 \times \mathrm{ArOCH}_{3}\right)$.

$\nu_{\max } 1720,1610,1590 \mathrm{~cm}^{-1}$.

$\mathrm{m} / \mathrm{z} 290 / 288\left(48 \%, \mathrm{M}^{+}\right), 259 / 257$ (16), 258/256 (14), 209 (100), $179(18), 178(20)$.

$\mathrm{C}_{11} \mathrm{H}_{13} \mathrm{BrO}_{4} \quad$ H.r.m.s. Calcd: 287.9998 .

Found: 287.9992 .<smiles>COc1cc(CBr)c(C(C)=O)c(OC)c1</smiles>

90<smiles>COC1=CC(Cc2cc(OC)cc(OC)c2C(C)=O)(C(=O)O)C(O)=CC1</smiles>

102

Dianion $\underline{75}$ (from acid $\underline{74}, 0.546 \mathrm{~g}, 3 \mathrm{mmol}$ ) was alkylated with bromide $\underline{90}(1.08 \mathrm{~g}, 3.75 \mathrm{mmol})$ to provide $1-[(3,5$-dimethoxy2-methoxycarbonylphenyl) methyl] -2,5-dimethoxy-2,5-cyclohexadiene-1-carboxylic acid $102(0.835 \mathrm{~g}, 71 \%)$ as yellowish powder.

tExtraction of the phenolic starting material from the mixture in ether with $2 \mathrm{~N}$ potassium carbonate and ice-cold $0.5 \mathrm{~N}$ potassium hydroxide was unsuccessful. 
M.p. 148-150 (from dichloromethane-petroleum ether).

$\delta 9.40(\mathrm{~b}, 1 \mathrm{H}), 7.23(\mathrm{~s}, 2 \mathrm{H}, \mathrm{ArH}), 4.70(t, \mathrm{~J}=4 \mathrm{~Hz}, 1 \mathrm{H}, \mathrm{H} 3)$,

$4.45(\mathrm{~s}, 1 \mathrm{H}, \mathrm{H} 6), 3.82\left(\mathrm{~s}, 3 \mathrm{H}, \mathrm{CO}_{2} \mathrm{CH}_{3}\right), 3.72\left(\mathrm{~s}, 3 \mathrm{H}, \mathrm{ArOCH}_{3}\right)$,

$3.70\left(\mathrm{~s}, 3 \mathrm{H}, \mathrm{ArOCH}_{3}\right), 3.56\left(\mathrm{~s}, 3 \mathrm{H}, \mathrm{C}=\mathrm{C}-\mathrm{OCH}_{3}\right), 3.50\left(\mathrm{~s}, 3 \mathrm{H}, \mathrm{C}=\mathrm{C}-\mathrm{OCH}_{3}\right)$,

3.34 and $3.00\left(\mathrm{ABq}, \mathrm{J}_{\mathrm{AB}}=14 \mathrm{~Hz}, 2 \mathrm{H}, \mathrm{ArCH}_{2}\right), 2.68\left(\mathrm{dd}, \mathrm{J}_{1}=19 \mathrm{~Hz}, \mathrm{~J}_{2}=\right.$ $4 \mathrm{~Hz}, 1 \mathrm{H}, \mathrm{H} 4), 2.43\left(\mathrm{dd}, \mathrm{J}_{1}=19 \mathrm{~Hz}, \mathrm{~J}_{2}=4 \mathrm{~Hz}, 1 \mathrm{H}, \mathrm{H} 4\right)$.

$\nu_{\max } 1725,1705,1690,1665,1600,1580 \mathrm{~cm}^{-1}$.

$\mathrm{m} / \mathrm{z} \quad 392\left(11 \%, \mathrm{M}^{+}\right), 361$ (7), $348(49), 315$ (13), 301 (16),

$285(15), 210(100), 179(37), 139(44)$.

$\mathrm{C}_{20} \mathrm{H}_{24} \mathrm{O}_{8} \quad \mathrm{Calcd}: \quad \mathrm{C}, 61.2 ; \mathrm{H}, 6.2$.

Found: $\mathrm{C}, 61.0 ; \mathrm{H}, 6.0 \%$

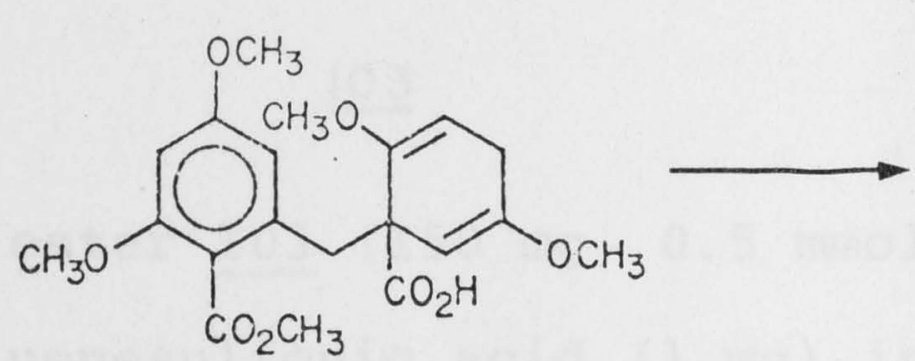

102<smiles>COc1cc(OC)c2c(c1C(C)=O)CC1=CC(=O)CCC12</smiles>

103

Polyphosphoric acid (PPA) $(10 \mathrm{ml})$ was heated to $100^{\circ}$ while being degassed with a nitrogen stream (30 min). After cooling to $25^{\circ}$ (PPA stays much less viscous than before heating), acid 102 ( $390 \mathrm{mg}, 1 \mathrm{mmol}$ ) was mixed vigorously with the PPA. Occasional mixing was maintained for $3 \mathrm{hr}$ at room temperature. The resulting dark brown syrup was poured onto ice $(50 \mathrm{~g})$ with stirring. Extraction with ethyl acetate $(3 \times 50 \mathrm{ml})$, washing of the organic layer (water $2 \times 20 \mathrm{ml}$, brine $30 \mathrm{ml}$ ), drying and solvent removal gave methyl 5,7-dimethoxy-2-oxo-2,3,4,4atetrahydrofluorene-8-carboxylate $103(232 \mathrm{mg}, 77 \%$ ) as a dark coloured oil. This compound rapidly decomposed and all attempts to obtain an analytical sample were unsuccessful. 
$\delta 6.28(\mathrm{~s}, 1 \mathrm{H}), 5.92(\mathrm{~m}, 1 \mathrm{H}, \mathrm{Hl}), 3.90$ and $3.73\left(\mathrm{ABq}, \mathrm{J}_{\mathrm{AB}}=19 \mathrm{~Hz}\right.$, $2 \mathrm{H}, \mathrm{H} 9), 3.77(\mathrm{~s}, 9 \mathrm{H}), 3.2-1.40(\mathrm{~m}, 5 \mathrm{H})$.

$\nu_{\max }\left(\mathrm{CH}_{2} \mathrm{Cl}_{2}\right) \quad 1720,1665,1590 \mathrm{~cm}^{-1}$.

$\mathrm{m} / \mathrm{z} 302\left(100 \%, \mathrm{M}^{+}\right), 274(23), 271(40), 260(23), 243$ (30),

$241(29), 228(28), 215$ (27).

$\lambda_{\max } 225$ (21140) nm.

$\mathrm{C}_{17} \mathrm{H}_{18} \mathrm{O}_{5} \quad$ H.r.m.s. Calcd: 302.1154 .

Found: $\quad 302.1150$.<smiles>COC(=O)c1c(OC)cc(OC)c2c1CC1=CC(=O)CCC1C21CC1</smiles>

$\underline{103}$

105

Keto ester $103(150 \mathrm{mg}, 0.5 \mathrm{mmol}), \operatorname{glycol}(0.2 \mathrm{ml})$ and

p-toluenesulfonic acid ( $1 \mathrm{mg}$ ) in 1,2 -dichloroethane (25 ml) were heated at reflux for $18 \mathrm{hr}$ with azeotropic removal of water (reverse Dean-Stark apparatus containing $4 \AA$ molecular sieves). The cooled solution was washed with water $(2 \times 10 \mathrm{ml})$ and brine $(20 \mathrm{ml})$. Reextraction of the aqueous layers, drying of the combined organic portions and removal of solvent gave methyl 2,2-ethylenedioxy-5,7-dimethoxy-1,2,3,4-tetrahydrofluorene-8-carboxylate $105(104 \mathrm{mg}, 60 \%)$ as a yellowish oil. This compound decomposed on heating and purification by chromatography.

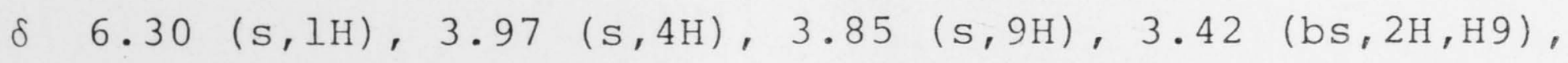
$3.00-2.70(\mathrm{~m}, 2 \mathrm{H}, \mathrm{Hl}), 2.60(\mathrm{~m}, 2 \mathrm{H}, \mathrm{H} 4), 1.88(\mathrm{t}, \mathrm{J}=6 \mathrm{~Hz}, 2 \mathrm{H}, \mathrm{H} 3)$. $\nu_{\max }\left(\mathrm{CH}_{2} \mathrm{Cl}_{2}\right) \quad 1720,1590 \mathrm{~cm}^{-1}$. 
$\mathrm{m} / \mathrm{z} 346\left(65 \%, \mathrm{M}^{+}\right), 315(12), 260(100), 228(52)$.

$\lambda_{\max } 272(14100), 248$ (14200) nm.

$\mathrm{C}_{19} \mathrm{H}_{22} \mathrm{O}_{6} \quad$ H.r.m.s. Calcd: 346.1416 .

Found: $\quad 346.1418$. 
Chapter 2

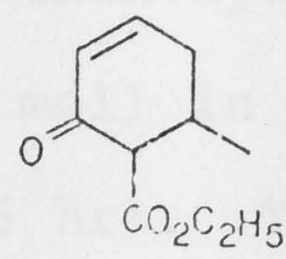

Ethyl 6-methyl-2-oxocyclohex-3-ene-1-carboxylate was prepared from crotonaldehyde and ethyl acetoacetate according to the method of Piskov ${ }^{145}$ in $50 \%$ yield.
B.p. $\quad 92^{\circ}-100^{\circ} / 0.5 \mathrm{~mm}$
(lit. 145
$\left.93^{\circ}-95^{\circ} / 0.8 \mathrm{~mm}\right)$<smiles>CCOC(=O)C1C(=O)C=CCC1C</smiles>

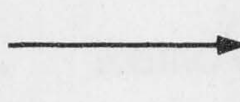<smiles>CCc1cccc(OC)c1CC</smiles>

116

(i) Ethyl 6-methyl-2-oxocyclohex-3-ene-1-carboxylate $136.4 \mathrm{~g}$, $0.20 \mathrm{~mol})$ was brominated using $\mathrm{N}$-bromosuccinimide $(42.7 \mathrm{~g}$, $0.24 \mathrm{~mol})$, dibenzoyl peroxide ( $1 \mathrm{mg}$ ) and light (500 W tungsten lamp) in refluxing carbon tetrachloride (500 ml). After $2 \mathrm{hr}$ the succinimide was removed by filtration and triethylamine 96 (42 $\mathrm{ml}, 0.3 \mathrm{~mol})$ was added to the filtrate. The reaction mixture was stirred at $40^{\circ}$ for $2 \mathrm{hr}$, water $(200$ ml) was added and the layers were separated. The organic portion was washed with $2 \mathrm{~N}$ hydrochloric acid $(2 \times 200 \mathrm{ml})$, water $(200 \mathrm{ml})$, brine $(200 \mathrm{ml})$ and dried. The brown oil $(38 \mathrm{~g}))^{\dagger}$ obtained after solvent removal was methylated with dimethylsulfate $(23.6 \mathrm{ml}, 0.25 \mathrm{~mol})$ and potassium carbonate $(38 \mathrm{~g}, 0.275 \mathrm{~mol})$ in refluxing acetone $(350 \mathrm{ml}, 18 \mathrm{hr})$.

\footnotetext{
${ }^{1} \mathrm{H}$ n.m.r. analysis indicated the presence of $\sim 15 \%$ brominated aromatic compound.
} 
The resulting ester was then hydrolysed with potassium hydroxide $(16.8 \mathrm{~g}, 0.30 \mathrm{~mol})$ in methanol $(300 \mathrm{ml})$ and water $(20 \mathrm{ml}$, reflux, $16 \mathrm{hr})$. The solvent was removed and the residue dissolved in $2 \mathrm{~N}$ sodium hydroxide $(200 \mathrm{ml})$ cooled to $0^{\circ}$ and nickel/aluminium alloy $(4 \mathrm{~g})$ was added in portions over 2 hr. ${ }^{142}$ The reaction mixture was filtered into concentrated hydrochloric acid (150 ml) at $0^{\circ}$. The aqueous layer was extracted with ether $(3 \times 400 \mathrm{ml})$, the organic portions washed sequentially with water $(2 \times 100 \mathrm{ml})$, brine $(200 \mathrm{ml})$ and dried. Removal of solvent gave a brown oil which crystallised from dichloromethane-petroleum ether to give 2-methoxy-6-methylbenzoic acid $116(24.8 \mathrm{~g}, 75 \%)$. M.p. 137-139 (Lit. ${ }^{\circ}$ 146 $140^{\circ}$ ).

(ii) To ethyl 6-methyl-2-oxocyclohex-3-ene-1-carboxylate $(3.6 \mathrm{~g}, 0.02 \mathrm{~mol})$ in dry acetic acid $(10 \mathrm{ml})$ was added bromine $(3.16 \mathrm{ml}, 0.062 \mathrm{~mol})$ in acetic acid $(6 \mathrm{ml})$ and the reaction mixture was heated to 55-60 for $20 \mathrm{hr}$. Evaporation of the solvent and addition of ice/water left a yellowish powder, which was filtered, washed with water $(2 \times 5 \mathrm{ml})$ and dried over phosphorłus pentoxide in vacuo $(6.45 \mathrm{~g}$, mainly dibrominated phenolic ester). The compound was treated as under (i) however $7.5 \mathrm{~g}$ nickel/aluminium alloy was used. Acid 116 was obtained in $68 \%$ yield $(2.26 \mathrm{~g})$.

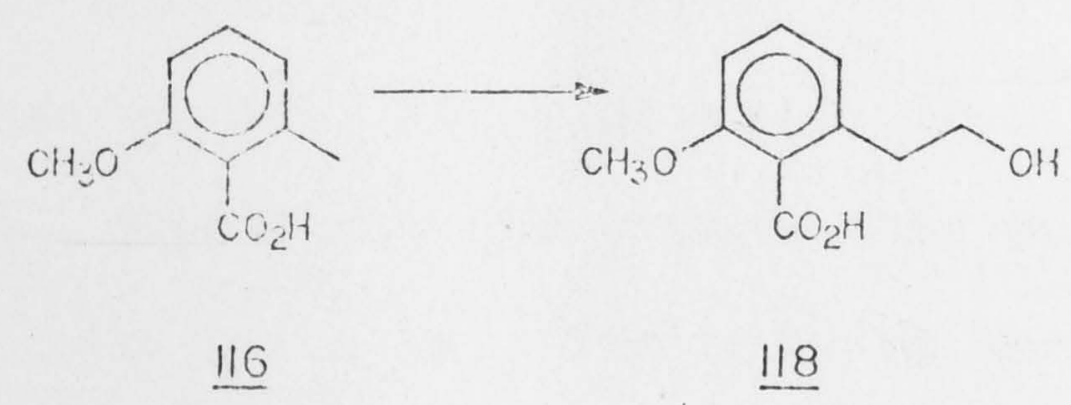


Butyllithium in hexane (1.6M, $206 \mathrm{ml}, 0.33 \mathrm{~mol})$ was added dropwise to a stirred solution of acid $116(24.9 \mathrm{~g}, 0.15 \mathrm{~mol})$ in THF $(500 \mathrm{ml})$ at $-20^{\circ} .97$ stirring was continued for 30 min. at $-20^{\circ}$, dry paraformaldehyde $(27 \mathrm{~g})$ was added to the bright red solution, and the mixture was allowed to warm to room temperature overnight. The resultant solution was concentrated, the residue dissolved in water (400 ml) and extracted with ether $(2 \times 200 \mathrm{ml})$ to remove unwanted neutral material. The basic phase was cooled to $0^{\circ}$, layered with dichloromethane $(300 \mathrm{ml})$, and acidified to $\mathrm{pH} 1$ with $6 \mathrm{~N}$ hydrochloric acid. Further extraction with dichloromethane $(2 \times 200 \mathrm{ml})$, washing of the organic layers (water $200 \mathrm{ml}$, brine $200 \mathrm{ml}$ ), drying and solvent removal gave after trituration of the residue with boiling chloroform 2-(2-hydroxyethyl)-6-methoxybenzoic acid $118(18.23 \mathrm{~g}, 62 \%)$ as colourless crystals.

M.p. $107-109^{\circ}$.

$\delta\left(\mathrm{CDCl}_{3} / \mathrm{CD}_{3} \mathrm{COCD}_{3}\right) 7.30(\mathrm{t}, \mathrm{J}=8 \mathrm{~Hz}, 1 \mathrm{H}, \mathrm{H} 4), 6.92(\mathrm{~d}, \mathrm{~J}=8 \mathrm{~Hz}, 1 \mathrm{H}, \mathrm{H} 3)$, $6.83(\mathrm{~d}, \mathrm{~J}=8 \mathrm{~Hz}, 1 \mathrm{H}, \mathrm{H} 5), 3.80\left(\mathrm{~s}, 3 \mathrm{H}, \mathrm{ArOCH}_{3}\right), 3.74(t, \mathrm{~J}=7.5 \mathrm{~Hz}, 2 \mathrm{H}$, $\left.\mathrm{CH}_{2} \mathrm{OH}\right), 2.85\left(t, \mathrm{~J}=7.5 \mathrm{~Hz}, 2 \mathrm{H}, \mathrm{ArCH}_{2}\right)$.

$\nu_{\max } 3270,1690 \mathrm{~cm}^{-1}$.

$\mathrm{m} / \mathrm{z} 196\left(3 \%, \mathrm{M}^{+}\right), 178(100), 166(12), 148(68)$.

$\mathrm{C}_{10} \mathrm{H}_{12} \mathrm{O}_{4} \quad$ Calcd: C, 61.2; H, 6.2.

Found: $\mathrm{C}, 61.0 ; \mathrm{H}, 6.0 \%$ 
<smiles>COc1cccc(CCO)c1C(=O)O</smiles>

118

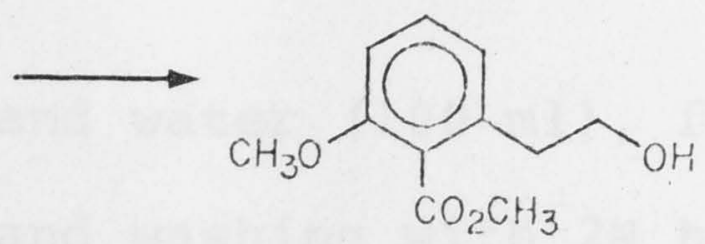

119

The hydroxy acid $118(8.8 \mathrm{~g}, 50 \mathrm{mmol})$ in THF (150 $\mathrm{ml}$ ) at $0^{\circ}$ was treated with a slight excess of diazomethane ( 55 mmol) in ether $(100 \mathrm{ml})$. After $10 \mathrm{~min}$ at $0^{\circ}$, the excess diazomethane was removed with a stream of nitrogen. The solution was concentrated at $20^{\circ}$ to afford methyl 2-(2-hydroxyethyl)6-methoxybenzoate $119(10.5 \mathrm{~g}, 100 \%)$ as a yellowish oil which lactonised on standing or heating.

$\delta 7.30(t, J=8 \mathrm{~Hz}, 1 \mathrm{H}), 6.84(\mathrm{~d}, \mathrm{~J}=8 \mathrm{~Hz}, 1 \mathrm{H}), 6.78(\mathrm{~d}, \mathrm{~J}=8 \mathrm{~Hz}, 1 \mathrm{H})$, $3.87\left(\mathrm{~s}, 3 \mathrm{H}, \mathrm{CO}_{2} \mathrm{CH}_{3}\right), 3.80(\mathrm{~s}, 3 \mathrm{H}), 3.78(\mathrm{t}, \mathrm{J}=7 \mathrm{~Hz}, 2 \mathrm{H}), 2.77$ $(t, \mathrm{~J}=7 \mathrm{~Hz}, 2 \mathrm{H})$. $\nu_{\max }(\mathrm{film}) \quad 3370,1725 \mathrm{~cm}^{-1}$. $\mathrm{m} / \mathrm{z} 210\left(13 \%, \mathrm{M}^{+}\right), 192(22), 180(40), 178(58), 148(100)$. $\mathrm{C}_{11} \mathrm{H}_{14} \mathrm{O}_{4} \quad$ H.r.m.s. Calcd: 210.0892 . Found: 210.0890 .<smiles>COC(=O)c1c(CCO)cccc1OC</smiles>

119<smiles>COC(=O)c1c(CCI)cccc1OC</smiles>

109

Hydroxy ester $119(10.5 \mathrm{~g}, 50 \mathrm{mmol})$ was dissolved in pyridine $(50 \mathrm{ml})$ and $p$-toluenesulfonyl chloride $(19 \mathrm{~g}, 100 \mathrm{mmol})$ was added portionwise at $0^{\circ}$. After stirring for $16 \mathrm{hr}$ at $5^{\circ}$, water $(16 \mathrm{ml})$ was added and the homogeneous solution was kept at room temperature for $1 \mathrm{hr}$. The mixture was partitioned 
between ether $(200 \mathrm{ml})$ and water $(100 \mathrm{ml})$, further extraction with ether $(2 \times 100 \mathrm{ml})$ and washing with $2 \mathrm{~N}$ hydrochloric acid $(2 \times 100 \mathrm{ml}), 1 \mathrm{~N}$ sodium bicarbonate $(100 \mathrm{ml})$, water $(100 \mathrm{ml})$ and brine $(100 \mathrm{ml})$, drying and solvent removal gave the tosylate ester $(14.6 \mathrm{~g})$.

$\delta 7.70(\mathrm{~d}, \mathrm{~J}=8 \mathrm{~Hz}, 2 \mathrm{H}), 7.26(\mathrm{~d}, \mathrm{~J}=8 \mathrm{~Hz}, 2 \mathrm{H}), 7.2 \mathrm{l}(\mathrm{t}, \mathrm{J}=7.5 \mathrm{~Hz}, 1 \mathrm{H})$, $6.77(\mathrm{~d}, \mathrm{~J}=7.5 \mathrm{~Hz}, 1 \mathrm{H}), 6.74(\mathrm{~d}, \mathrm{~J}=7.5 \mathrm{~Hz}, 1 \mathrm{H}), 4.14(\mathrm{t}, \mathrm{J}=7.5 \mathrm{~Hz}, 2 \mathrm{H}$, $\left.\mathrm{CH}_{2} \mathrm{OTs}\right), 3.78(\mathrm{~s}, 3 \mathrm{H}), 3.72(\mathrm{~s}, 3 \mathrm{H}), 2.86(t, \mathrm{~J}=7.5 \mathrm{~Hz}, 2 \mathrm{H}), 2.3 \mathrm{I}$ $\left(\mathrm{s}, 3 \mathrm{H}, \mathrm{ArCH}_{3}\right)$.

The crude tosylate $(14.6 \mathrm{~g}, 40 \mathrm{mmol})$ in acetone $(100 \mathrm{ml}$ ) was added slowly to a solution of sodium iodide $(30 \mathrm{~g}, 200 \mathrm{mmol})$ in acetone $(250 \mathrm{ml})$ and the mixture stirred for $16 \mathrm{hr}$ at room temperature. The resulting precipitate was filtered off, the filtrate concentrated and the residue partitioned between ether $(200 \mathrm{ml})$ and water $(200 \mathrm{ml})$. The aqueous layer was reextracted with ether $(2 \times 100 \mathrm{ml})$, the organic part washed with water $(50 \mathrm{ml})$, brine $(100 \mathrm{ml})$ and dried. Removal of the solvent gave methyl 2-(2-iodoethyl)-6-methoxybenzoate 109 (12.5 g, 78\% from acid 118 ) as an oil (homogenous by t.l.c.). $\delta 7.35(t, J=8.5 \mathrm{~Hz}, 1 \mathrm{H}, \mathrm{H} 4), 6.87(\mathrm{~d}, \mathrm{~J}=8.5 \mathrm{~Hz}, 2 \mathrm{H}, \mathrm{H} 3, \mathrm{H} 5), 3.89$ $\left(\mathrm{s}, 3 \mathrm{H}, \mathrm{CO}_{2} \mathrm{CH}_{3}\right), 3.79\left(\mathrm{~s}, 3 \mathrm{H}, \mathrm{ArOCH}_{3}\right), 3.50-2.91(\mathrm{~m}, 4 \mathrm{H})$. $\nu_{\max }(\mathrm{film}) \quad 1725,1580 \mathrm{~cm}^{-1}$. $\mathrm{m} / \mathrm{z} 320\left(12 \%, \mathrm{M}^{+}\right), 289(15), 193(47), 161$ (100). $\mathrm{C}_{11} \mathrm{H}_{13} \mathrm{IO}_{3} \quad$ H.r.m.s. Calcd: 319.9911 . Found: 319.9913 . 


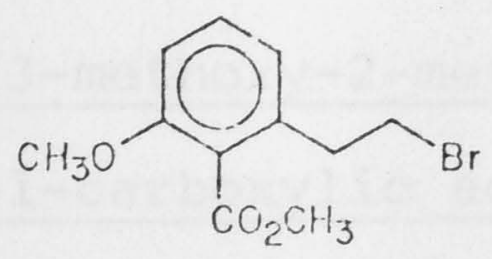

122

The tosylate ester (from hydroxy ester $119,210 \mathrm{mg}, 1$ mmol), lithium bromide (870 $\mathrm{mg}, 10 \mathrm{mmol}$ ) and sodium iodide (15 mg, $0.1 \mathrm{mmol})$ in dry acetone $(20 \mathrm{ml})$ were heated under reflux for $40 \mathrm{hr}$. The solvent was evaporated and the residue partitioned between ether $(20 \mathrm{ml})$ and water $(10 \mathrm{ml})$. Further extraction with ether $(2 \times 20 \mathrm{ml})$, washing (water $10 \mathrm{ml}$, brine $20 \mathrm{ml})$, drying and solvent removal afforded a yellow oil (250 mg). Methyl 2-(2-bromoethyl)-6-methoxybenzoate 122 $(180 \mathrm{mg}, 66 \%)$ was obtained after purification (p.1.c., 3\% methanol-dichloromethane) and crystallisation on standing. M.p. $\quad 51-53^{\circ}$.

$\delta \quad 7.35(t, J=8.5 \mathrm{~Hz}, 1 \mathrm{H}, \mathrm{H} 4), 6.85(\mathrm{~d}, \mathrm{~J}=8.5 \mathrm{~Hz}, 2 \mathrm{H}), 3.94\left(\mathrm{~s}, 3 \mathrm{H}, \mathrm{CO}_{2}\right.$ $\left.\mathrm{CH}_{3}\right), 3.80\left(\mathrm{~s}, 3 \mathrm{H}, \mathrm{ArOCH}_{3}\right), 3.78-2.92(\mathrm{~m}, 4 \mathrm{H})$.

$\nu_{\max } 1725,1580 \mathrm{~cm}^{-1}$.

$\mathrm{m} / \mathrm{z} 274 / 272\left(6 \%, \mathrm{M}^{+}\right), 243 / 241$ (12), 193 (29), 161 (100).

$\mathrm{C}_{11} \mathrm{H}_{13} \mathrm{BrO}_{3} \quad$ H.r.m.s. Calcd: 272.0048 .

Found: 272.0049 .<smiles>COC1=CC(CCc2cccc(OC)c2C(=O)O)(C(=O)O)C=CC1</smiles>

Dianion $\underline{75}$ (from acid $74,6.37 \mathrm{~g}, 35 \mathrm{mmol}$ ) was alkylated with iodoester $109(12.32 \mathrm{~g}, 38.5 \mathrm{mmol})$. 
2,5-dimethoxy-1-[2-(3-methoxy-2-methoxycarbonylphenyl) ethyl] -2,5-cyclohexadiene-1-carboxylic acid 110 was obtained as a greyish powder $(6.85 \mathrm{~g}, 50 \%)$.

M.p. 158-160 (acetone-ether).

$\delta 7.30(t, J=8 \mathrm{~Hz}, 1 \mathrm{H}, \mathrm{ArH}), 6.80(\mathrm{~d}, \mathrm{~J}=8 \mathrm{~Hz}, 1 \mathrm{H}, \mathrm{ArH}), 6.76(\mathrm{~d}, \mathrm{~J}=8 \mathrm{~Hz}$ ， $1 \mathrm{H}, \mathrm{ArH}), 4.82(t, \mathrm{~J}=4 \mathrm{~Hz}, 1 \mathrm{H}, \mathrm{H} 3), 4.43(\mathrm{~s}, 1 \mathrm{H}, \mathrm{H} 6), 3.83(\mathrm{~s}, 3 \mathrm{H}$, $\left.\mathrm{CO}_{2} \mathrm{CH}_{3}\right), 3.77\left(\mathrm{~s}, 3 \mathrm{H}, \mathrm{ArOCH}_{3}\right), 3.54\left(\mathrm{~s}, 6 \mathrm{H}, \mathrm{C}=\mathrm{C}-\mathrm{OCH}_{3}\right), 2.90$ (d, $\mathrm{J}=4 \mathrm{~Hz}, 2 \mathrm{H}, \mathrm{H} 4), 2.4-1.8(\mathrm{~m}, 4 \mathrm{H})$.

$\nu_{\max } 1730,1700,1690,1660 \mathrm{~cm}^{-1}$.

$\mathrm{m} / \mathrm{z} \quad 376\left(4 \%, \mathrm{M}^{+}\right), 332(84), 330(62), 299(26), 285$ (18), $157(100), 153(92)$.

$\mathrm{C}_{20} \mathrm{H}_{24} \mathrm{O}_{7} \quad$ Calcd: C, 63.8; H, 6.4 . Found: $\mathrm{C}, 63.6 ; \mathrm{H}, 6.4 \%$

Further acidification of the aqueous layer to $\mathrm{pH} 2$ in a two phase system (ethyl acetate) at $0^{\circ}$, gave after the usual work-up 2,5-dimethoxy-1,4-dihydrobenzoic acid $120^{147}$ $(2.70 \mathrm{~g}, 42 \%)$ as an unstable oil.

$\delta 10.68\left(\mathrm{bs}, 1 \mathrm{H}, \mathrm{CO}_{2} \mathrm{H}\right), 4.74(t, \mathrm{~J}=4 \mathrm{~Hz}, 1 \mathrm{H}, \mathrm{H} 3), 3.63(\mathrm{~d}, \mathrm{~J}=4 \mathrm{~Hz}$, $1 \mathrm{H}, \mathrm{H} 6), 3.79(\mathrm{~m}, 1 \mathrm{H}, \mathrm{Hl}), 3.50\left(\mathrm{~s}, 6 \mathrm{H}, 2 \times \mathrm{OCH}_{3}\right), 2.88(\mathrm{~m}, 2 \mathrm{H}, \mathrm{H} 4)$. The neutral organic extracts gave after evaporation of the solvent and purification by chromatography methyl 1-methoxy-6-vinylbenzoate 121 ( $3.21 \mathrm{~g}, 16.8 \mathrm{mmol})$. B.p. $90 \% / 0.01 \mathrm{~mm}$.

$\delta 7.28(\mathrm{~d}, \mathrm{~J}=8 \mathrm{~Hz}, 1 \mathrm{H}, \mathrm{H} 5), 7.12(\mathrm{t}, \mathrm{J}=8 \mathrm{~Hz}, 1 \mathrm{H}, \mathrm{H} 4), 6.76(\mathrm{~d}, \mathrm{~J}=8 \mathrm{~Hz}$ ， $1 \mathrm{H}, \mathrm{H} 3), 6.61\left(\mathrm{dd}, \mathrm{J}_{1}=17 \mathrm{~Hz}, \mathrm{~J}_{2}=11 \mathrm{~Hz}, 1 \mathrm{H}, \mathrm{CH}=\mathrm{C}\right), 5.68(\mathrm{~d}, \mathrm{~J}=17 \mathrm{~Hz}, 1 \mathrm{H}$, $\left.\mathrm{C}=\mathrm{CH}_{2}\right), 5.27\left(\mathrm{~d}, \mathrm{~J}=11 \mathrm{~Hz}, 1 \mathrm{H}, \mathrm{C}=\mathrm{CH}_{2}\right), 3.84\left(\mathrm{~s}, 3 \mathrm{H}, \mathrm{CO}_{2} \mathrm{CH}_{3}\right), 3.78$ $\left(\mathrm{s}, 3 \mathrm{H}, \mathrm{ArOCH}_{3}\right)$. $\nu_{\max } 1730,1595,1575 \mathrm{~cm}^{-1}$. 
$\mathrm{m} / \mathrm{z} \quad 192\left(79 \%, \mathrm{M}^{+}\right), 177(13), 162(39), 161$ (100).

$\lambda_{\max } 250(\mathrm{sh}, 7450), 295$ (2290) nm.

$\mathrm{C}_{11} \mathrm{H}_{12} \mathrm{O}_{3} \quad$ Calcd: C, 68.7; H, 6.3.

Found: $\mathrm{C}, 68.3 ; \mathrm{H}, 6.1 \%$

Alkylation of dianion 75 with phenethyl bromide 122 led predominantly (> 90\%) to formation of 2,5-dimethoxy-1,4dihydrobenzoic acid $\underline{120}$ and styrene 121.<smiles>COC1=CC(CCc2cccc(OC)c2C(C)=O)(C(=O)O)C=CC1</smiles>

110

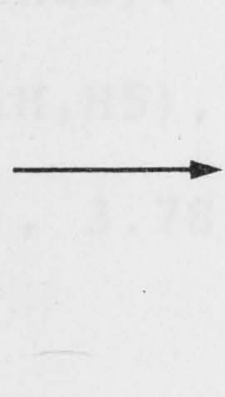

$\sqrt{2}$<smiles>COC(=O)c1c(OC)ccc2c1CCC1=C2CCC(=O)C1</smiles>

106<smiles>COc1ccc2c(c1C(C)=O)CCC1=CC(=O)CCC12</smiles>

124

Acid 110 ( $376 \mathrm{mg}, 1 \mathrm{mmol}$ ) was added portionwise as quick as possible (gas evolution!) to vigorously stirred PPA (4 ml) at $45^{\circ}$. Stirring was continued for $0.5 \mathrm{hr}$, then the reaction was slowly poured onto ice $(20 \mathrm{~g})$ with stirring. Extraction with dichloromethane $(3 \times 20 \mathrm{ml})$, washing of the organic layers with water $(2 \times 10 \mathrm{ml})$, brine $(20 \mathrm{ml})$ afforded, after drying and solvent removal, a brownish foam (270 mg). Chromatography (p.l.c., 4\% methanol-dichloromethane) gave

(i) methyl 7-methoxy-2-oxo-1,2,3,4,9,10-hexahydrophenanthrene8-carboxylate $106(63 \mathrm{mg}, 22 \%)$.

M.p. $117-119^{\circ}$ (ether).

$\delta 7.17(\mathrm{~d}, \mathrm{~J}=9 \mathrm{~Hz}, 1 \mathrm{H}, \mathrm{H} 5), 6.76(\mathrm{~d}, \mathrm{~J}=9 \mathrm{~Hz}, 1 \mathrm{H}, \mathrm{H} 6), 3.88(\mathrm{~s}, 3 \mathrm{H}$, $\left.\mathrm{CO}_{2} \mathrm{CH}_{3}\right), 3.79\left(\mathrm{~s}, 3 \mathrm{H}, \mathrm{ArOCH}_{3}\right), 3.00(\mathrm{~s}, 2 \mathrm{H}, \mathrm{Hl}), 2.90-2.46(\mathrm{~m}, 6 \mathrm{H})$, $2.15(t, \mathrm{~J}=8 \mathrm{~Hz}, 2 \mathrm{H})$. 
$\nu_{\max } 1725,1590,1575 \mathrm{~cm}^{-1}$.

$\mathrm{m} / \mathrm{z} 286\left(100 \%, \mathrm{M}^{+}\right), 284(79), 255(30), 253(30), 251$ (44),

$244(28), 212(39)$.

$\lambda_{\max } 272(16300) \mathrm{nm}$.

$\mathrm{C}_{17} \mathrm{H}_{18} \mathrm{O}_{4} \quad \mathrm{Calcd}: \quad \mathrm{C}, 71.3 ; \mathrm{H}, 6.3$.

Found: $\mathrm{C}, 71.4 ; \mathrm{H}, 6.6 \%$

(ii) methyl 7-methoxy-2-oxo-2,3,4,4a,9,10-hexahydrophenanthrene-

8-carboxylate $124(134 \mathrm{mg}, 47 \%)$.

M.p. $\quad 137-141^{\circ}$ (ether).

$\delta 7.25(\mathrm{~d}, \mathrm{~J}=9 \mathrm{~Hz}, 1 \mathrm{H}, \mathrm{H} 5), 6.84(\mathrm{~d}, \mathrm{~J}=9 \mathrm{~Hz}, 1 \mathrm{H}, \mathrm{H} 6), 5.95(\mathrm{~m}, 1 \mathrm{H}, \mathrm{H} \mathrm{l})$,

$3.86\left(\mathrm{~s}, 3 \mathrm{H}, \mathrm{CO}_{2} \mathrm{CH}_{3}\right), 3.78\left(\mathrm{~s}, 3 \mathrm{H}, \mathrm{ArOCH}_{3}\right), 3.67(\mathrm{~m}, 1 \mathrm{H}, \mathrm{H} 4 \mathrm{a})$ ，

$3.00-1.60(\mathrm{~m}, 8 \mathrm{H})$.

$\nu_{\max } 1715,1670,1625,1590,1580 \mathrm{~cm}^{-1}$.

$\mathrm{m} / \mathrm{z} 286\left(100 \%, \mathrm{M}^{+}\right), 284$ (12), 255 (21), 254 (20), 244 (24).

$\lambda_{\max } 233$ (21700) $\mathrm{nm}$.

$\mathrm{C}_{17} \mathrm{H}_{18} \mathrm{O}_{4} \quad \mathrm{Calcd}: \quad \mathrm{C}, 71.3 ; \mathrm{H}, 6.3$.

Found: $\mathrm{C}, 70.9 ; \mathrm{H}, 6.6 \%$

(iii) methyl 2,7-dimethoxy-9,10-dihydrophenanthrene-1-

carboxylate 125 ( $12 \mathrm{mg}, 4 \%)$.

M.p. $152-153^{\circ}$.

$\delta 7.65(\mathrm{~d}, \mathrm{~J}=8 \mathrm{~Hz}, 1 \mathrm{H}, \mathrm{H} 4), 7.58(\mathrm{~d}, \mathrm{~J}=8 \mathrm{~Hz}, 1 \mathrm{H}, \mathrm{H} 3), 6.90-6.73(\mathrm{~m}, 3 \mathrm{H})$,

$3.90\left(\mathrm{~s}, 3 \mathrm{H}, \mathrm{CO}_{2} \mathrm{CH}_{3}\right), 3.82\left(\mathrm{~s}, 3 \mathrm{H}, \mathrm{ArOCH}_{3}\right), 3.78\left(\mathrm{~s}, 3 \mathrm{H}, \mathrm{ArOCH}_{3}\right)$,

$2.76(\mathrm{~s}, 4 \mathrm{H})$.

$\nu_{\max } 1730,1600,1585 \mathrm{~cm}^{-1}$.

$\mathrm{m} / \mathrm{z} 298\left(100 \%, \mathrm{M}^{+}\right), 267$ (13), $265(20)$.

$\mathrm{C}_{18} \mathrm{H}_{18} \mathrm{O}_{4} \quad$ H.r.m.s. Calcd: 298.1205 .

Found: 298.1209 .

In the large scale preparation (5.64 $\mathrm{g}, 15 \mathrm{mmol})$ the brownish foam $(3.86 \mathrm{~g}, \approx 90 \%)$ was used without further purification 
in the next step. ${ }^{1} \mathrm{H}$ n.m.r. and t.l.c. analysis indicated that the foam consisted almost exclusively of ketones 106 and 124 .<smiles></smiles>

$\underline{106 / 124}$<smiles>COc1ccc2c(c1C(C)=O)CCC1=C2CCC(O)(C#N)C1</smiles>

$\underline{126}$

The mixture of phenanthrenones $\underline{106 / 124}(3.86 \mathrm{~g}, 13.5 \mathrm{mmol})$ was dissolved in THF $(75 \mathrm{ml})$, ether $(25 \mathrm{ml})$ and water (100 ml) were added, and the two-phase system was purged of oxygen with a stream of nitrogen for $2 \mathrm{hr}$. Sodium cyanide $15.28 \mathrm{~g}$, 108 mmol) was added, followed by dropwise addition of $4 \mathrm{~N}$ hydrochloric acid (27 ml, $108 \mathrm{mmol}$ ) over $4 \mathrm{hr}$ (Caution! HCN evolution). After the addition was completed (t.l.c. analysis), the excessive hydrogen cyanide was removed by bubbling nitrogen through the solution during $12 \mathrm{hr}$ (aqueous permanganate trap). Ethyl acetate $(100 \mathrm{ml})$ was added and the layers separated, followed by further extraction $(2 \times 100 \mathrm{ml})$. The organic layers were washed with water $(2 \times 100 \mathrm{ml})$, brine $(100 \mathrm{ml})$ and dried. Removal of the solvent gave methyl 2-cyano-2-hydroxy-7-methoxy-1,2,3,4, 9,10-hexahydrophenanthrene-8-carboxylate 126 (3.9 g) as an oil, which was used in the next step without purification. A small sample was purified by chromatography (p.l.c.) but a satisfactory analysis could not be obtained (decomposition on 


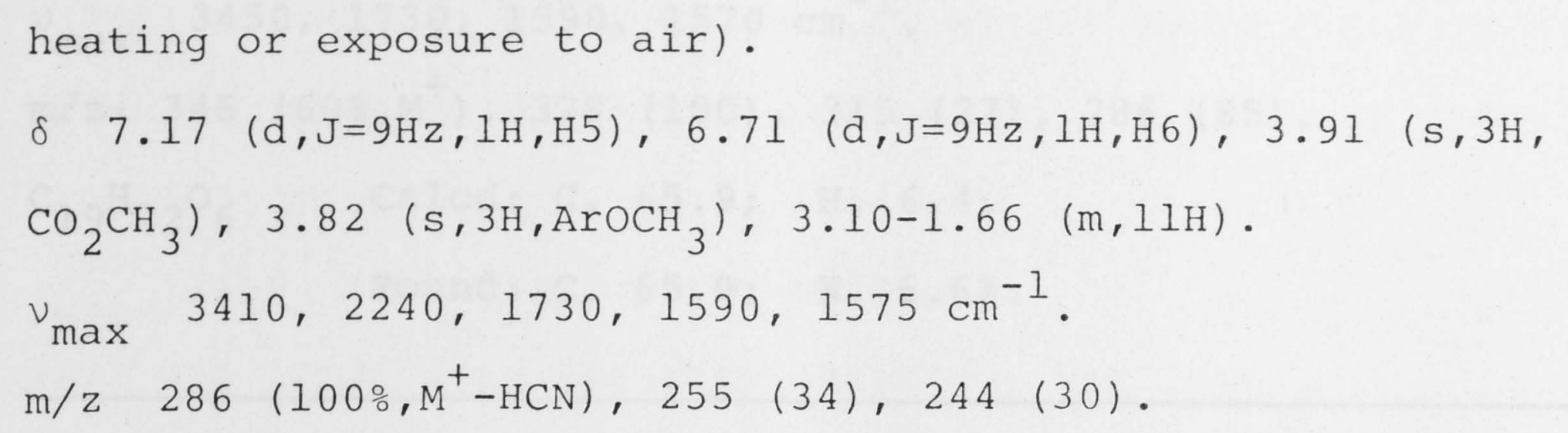<smiles>COc1ccc2c(c1C(C)=O)CCC1=C2CCC(O)(C#N)C1</smiles>

126

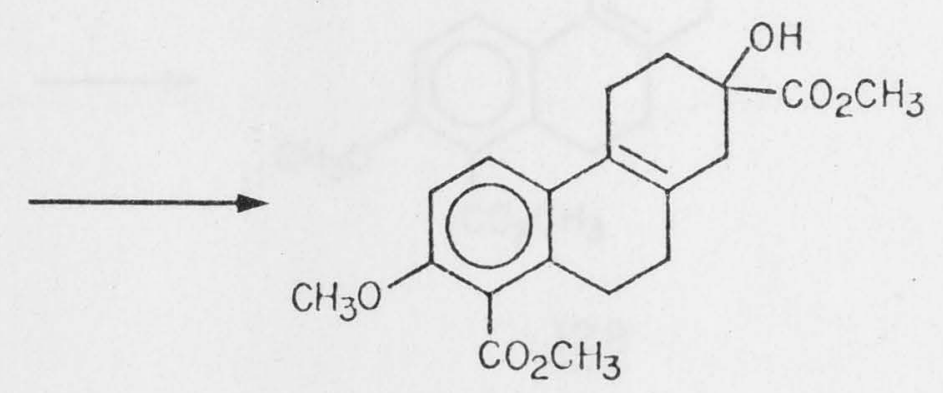

127

A stirred solution of cyanohydrin $\underline{126}$ (3.9 g) in dry methanol $(30 \mathrm{ml})$ at $0^{\circ}$ was saturated with hydrogen chloride resulting in a dark brown solution. The flask was stoppered and the reaction allowed to warm to room temperature over night. The excess hydrogen chloride was allowed to evaporate and the reaction mixture poured onto ice $(60 \mathrm{~g})$ and stirred for $1 \mathrm{hr}$ at $0^{\circ}$. Extraction with dichloromethane $(3 \times 60 \mathrm{ml})$ gave, after washing (water $2 \times 30 \mathrm{ml}$, brine $60 \mathrm{ml}$ ), drying and solvent removal, a dark brown oil (3.36 g) which was chromatographed on silica gel (chloroform) to give dimethyl 2-hydroxy-7-methoxy-1,2,3,4,9,10-hexahydrophenanthrene-2,8dicarboxylate 127 (2.52 $9,49 \%$ from acid 110).

M.p. 134-136 (dichloromethane-petroleum ether). $\delta 7.17(\mathrm{~d}, \mathrm{~J}=9 \mathrm{~Hz}, 1 \mathrm{H}, \mathrm{H} 5), 6.71(\mathrm{~d}, \mathrm{~J}=9 \mathrm{~Hz}, 1 \mathrm{H}, \mathrm{H} 6), 3.90(\mathrm{~s}, 3 \mathrm{H}$, $\left.\mathrm{ArCO}_{2} \mathrm{CH}_{3}\right), 3.82(\mathrm{~s}, 6 \mathrm{H}), 3.36(\mathrm{bs}, 1 \mathrm{H}, \mathrm{OH}), 3.15-1.66(\mathrm{~m}, 1 \mathrm{OH})$. 


$$
\begin{aligned}
& \nu_{\max } 3450,1730,1590,1570 \mathrm{~cm}^{-1} . \\
& \mathrm{m} / \mathrm{z} 346\left(60 \%, \mathrm{M}^{+}\right), 328(100), 315(27), 286 \quad(85) . \\
& \mathrm{C}_{19}{ }^{\mathrm{H}} 22^{\mathrm{O}} 6 \quad \text { Calcd: } \mathrm{C}, 65.9 ; \mathrm{H}, 6.4 . \\
& \text { Found: } \mathrm{C}, 65.9 ; \mathrm{H}, 6.6 \%
\end{aligned}
$$<smiles>COc1ccc2c(c1C(C)=O)CCC1=C2CCC(O)(C(C)=O)C1</smiles>

127

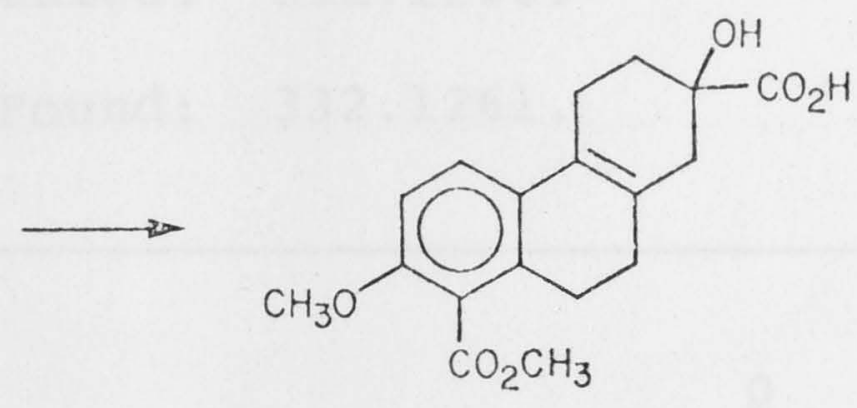

$\underline{128}$

Hydroxy ester $127(2.42 \mathrm{~g}, 7.0 \mathrm{mmol})$ was dissolved in methanol $(80 \mathrm{ml})$ and water $(5 \mathrm{ml})$ and the solution purged of oxygen with a stream of nitrogen ( $1 \mathrm{hr}$ ). The solution was cooled to $0^{\circ}$, potassium hydroxide pellets $(1.57 \mathrm{~g}, 28 \mathrm{mmol})$ added and the mixture stirred for 2 hr at $25^{\circ}$. The solution was concentrated in vacuo at $25^{\circ}$, the residue dissolved in water $(20 \mathrm{ml})$ and extracted with ethyl acetate $(2 \times 15 \mathrm{ml})$. The basic aqueous phase was then cooled to $0^{\circ}$, acidified to $\mathrm{pH} I$ with $6 \mathrm{~N}$ hydrochloric acid, the precipitate collected by filtration and dried (phosphorous pentoxide in vacuo at $25^{\circ}$ ) to give 2-hydroxy-7-methoxy-8-methoxycarbonyl-1, 2, 3,4,9,10hexahydrophenanthrene-2-carboxylic acid $128(2.06 \mathrm{~g}, 89 \%)$ as a yellowish solid, m.p. 202-207\%. An analytical sample could not be obtained, even after several recrystallisations and drying at higher temperatures. M.p. $208-212^{\circ}$ (acetone-ether). 


$$
\begin{aligned}
& \delta\left(\mathrm{CDCl}_{3} / \mathrm{d}_{6}-\mathrm{DMSO}\right) 7.15(\mathrm{~d}, \mathrm{~J}=9 \mathrm{~Hz}, 1 \mathrm{H}, \mathrm{H} 5), 6.78(\mathrm{~d}, \mathrm{~J}=9 \mathrm{~Hz}, 1 \mathrm{H}, \mathrm{H} 4), \\
& 6.20\left(\mathrm{bs}, 2 \mathrm{H}, \mathrm{OH}, \mathrm{CO}_{2} \mathrm{H}\right), 3.90\left(\mathrm{~s}, 3 \mathrm{H}, \mathrm{CO}_{2} \mathrm{CH}_{3}\right), 3.84\left(\mathrm{~s}, 3 \mathrm{H}, \mathrm{ArOCH}_{3}\right), \\
& 2.85-1.70(\mathrm{~m}, 10 \mathrm{H}) . \\
& \nu_{\max } 3400,1735-1720,1595,1575 \mathrm{~cm}^{-1} . \\
& \mathrm{m} / \mathrm{z} 332\left(100 \%, \mathrm{M}^{+}\right), 314(71), 301(40), 384(68) . \\
& \mathrm{C}_{18} \mathrm{H}_{20} \mathrm{O}_{6} \mathrm{H} . \mathrm{r} . \mathrm{m} . \mathrm{s} . \quad \text { Calcd: } 332.1260 . \\
& \text { Found: } 332.1261 .
\end{aligned}
$$

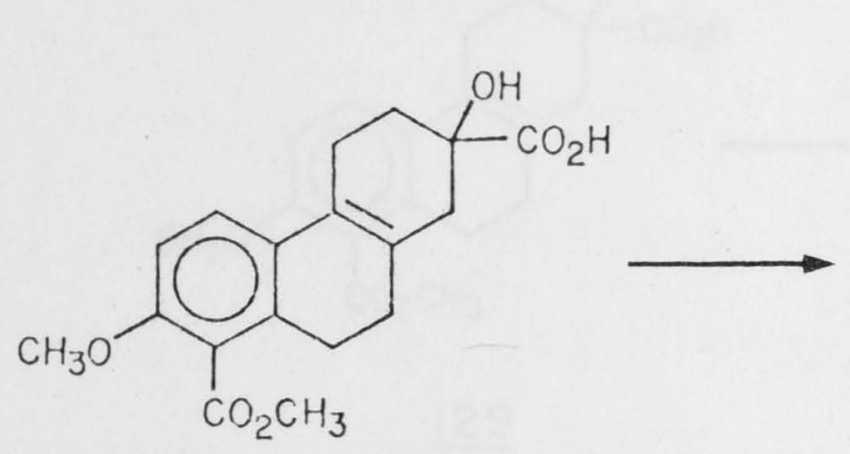

128<smiles>COc1ccc2c(c1C(C)=O)CCC1=C2CCC(OC(C)=O)(OC(C)=O)C1</smiles>

123

Hydroxy acid $128(2.05 \mathrm{~g}, 6.2 \mathrm{mmol})$ and dichloroacetyl chloride (1.49 $\mathrm{ml}, 15.5 \mathrm{mmol})$ in 1,2 -dichloroethane were heated under reflux for $5 \mathrm{hr}$. The solvent was evaporated, the residue dissolved in acetone $(25 \mathrm{ml})$ and water $(5 \mathrm{ml})$, and stirring was continued at $25^{\circ}$ for $16 \mathrm{hr}$. The acetone was removed in vacuo and the aqueous portion extracted with dichloromethane $(3 \times 25 \mathrm{ml})$ which was washed with water $(2 \times 10 \mathrm{ml})$, brine $(25 \mathrm{ml})$ and dried. Solvent removal gave 2-dichloroacetoxy-7-methoxy8-methoxycarbonyl-1,2,3,4,9,10-hexahydrophenanthrene-2carboxylic acid $\underline{129}(2.47 \mathrm{~g}, 90 \%)$ as a yellow foam (homogeneous by t.l.c.) which could not be induced to crystallise. 
$\delta \quad 10.95,\left(\mathrm{bs}, 1 \mathrm{H}, \mathrm{CO}_{2} \mathrm{H}\right), 7.15(\mathrm{~d}, \mathrm{~J}=9 \mathrm{~Hz}, 1 \mathrm{H}, \mathrm{H} 5), 6.78(\mathrm{~d}, \mathrm{~J}=9 \mathrm{~Hz}$, $1 \mathrm{H}, \mathrm{H} 4), 5.98\left(\mathrm{~s}, 1 \mathrm{H}, \mathrm{COCHCl}_{2}\right), 3.91\left(\mathrm{~s}, 3 \mathrm{H}, \mathrm{CO}_{2} \mathrm{CH}_{3}\right), 3.82(\mathrm{~s}, 3 \mathrm{H}$, $\left.\mathrm{ArOCH}_{3}\right), 3.05-1.80(\mathrm{~m}, 10 \mathrm{H})$. $v_{\max } 1765,1730,1595,1580 \mathrm{~cm}^{-1}$.

$\mathrm{m} / \mathrm{z} 444(0.6 \%), 442\left(1, \mathrm{M}^{+}\right), 426$ (I), 424 (1.5), 408 (I), $406(3), 372(10), 314(100)$.

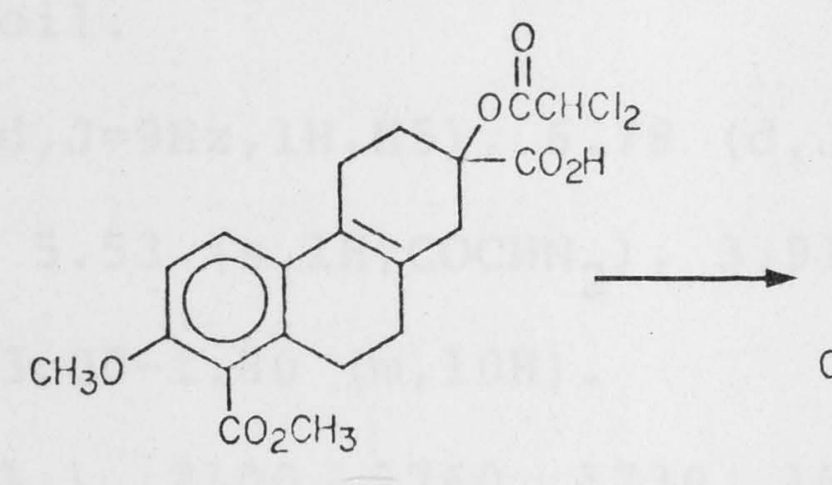

129<smiles></smiles>

132

Dimethylformamide $(0.042 \mathrm{ml}, 0.55 \mathrm{mmol})$ was added to a suspension of acid $\underline{129}(2.44 \mathrm{~g}, 5.5 \mathrm{mmol})$ and oxalyl chloride (1.4 $\mathrm{ml}, 16.5 \mathrm{mmol})$ in dichloromethane $(30 \mathrm{ml})$ at $0^{\circ}$, resulting in gas evolution. The reaction mixture was allowed to warm to room temperature and stirred for $18 \mathrm{hr}$. The volatiles were removed and the residue dissolved in dry benzene $(10 \mathrm{ml})$, filtered, and the precipitate washed with cold benzene $(2 \times 3 \mathrm{ml})$. The filtrate was concentrated and remaining traces of hydrogen chloride removed under high vacuum ( $4 \mathrm{hr}$ ) to give acid chloride 130 as a brown oil (2.49 g). $\nu_{\max }\left(\mathrm{CH}_{2} \mathrm{Cl}_{2}\right) \quad 1790,1765,1730,1595,1585 \mathrm{~cm}^{-1}$.

A solution of the crude acid chloride $130(2.49 \mathrm{~g})$ in dichloromethane $(20 \mathrm{ml})$ was added dropwise over $15 \mathrm{~min}$. to diazomethane $(40 \mathrm{mmol})$ in ether $(100 \mathrm{ml})$ at $-25^{\circ}$. The reaction mixture was allowed to warm to $0^{\circ}$ ( $1 \mathrm{hr}$ ) at which time the reaction was complete (t.1.c. analysis). The excess 
of diazomethane was evaporated with a stream of nitrogen and the solution concentrated to give the crude diazoketone 131 as a brown gum $(2.40 \mathrm{~g})$.

A small sample (100 mg) was purified by p.1.c. (2\% methanol-dichloromethane) to give methyl 2-diazoacetyl-2dichloroacetoxy-7-methoxy-1, 2, 3,4,9,10-hexahydrophenanthrene8-carboxylate 131 ( $57 \mathrm{mg}, 55 \%$ from acid 129) as a yellowish unstable oil.

$\delta 7.15(\mathrm{~d}, \mathrm{~J}=9 \mathrm{~Hz}, 1 \mathrm{H}, \mathrm{H} 5), 6.78(\mathrm{~d}, \mathrm{~J}=9 \mathrm{~Hz}, 1 \mathrm{H}, \mathrm{H} 6), 5.94(\mathrm{~s}, 1 \mathrm{H}$, $\left.\mathrm{COCHCl}_{2}\right), 5.53\left(\mathrm{~s}, 1 \mathrm{H}, \mathrm{COCHN}_{2}\right), 3.91\left(\mathrm{~s}, 3 \mathrm{H}, \mathrm{CO}_{2} \mathrm{CH}_{3}\right), 3.82(\mathrm{~s}, 3 \mathrm{H}$, $\left.\mathrm{ArOCH}_{3}\right), 3.00-1.80(\mathrm{~m}, 10 \mathrm{H})$. $\nu_{\max }\left(\mathrm{CH}_{2} \mathrm{Cl}_{2}\right) \quad 2100,1760,1730,1640,1595,1585 \mathrm{~cm}^{-1}$. $\mathrm{m} / \mathrm{z} 468(3 \%), 466\left(4, \mathrm{M}^{+}\right), 442(6), 440(38), 438$ (59), $310(100)$.

A solution of crude diazoketone $131(2.40 \mathrm{~g})$ in dichloromethane $(25 \mathrm{ml})$ was added dropwise over $10 \mathrm{~min}$. to a mixture of trifluoroacetic acid $(50 \mathrm{ml})$ and dichloromethane (25 $\mathrm{ml})$ at $-20^{\circ}$. After an additional $10 \mathrm{~min}$. at $-20^{\circ}$, dichloromethane $(50 \mathrm{ml})$ and water $(50 \mathrm{ml})$ were added and the layers separated. The organic phase was washed with water $(2 \times 30 \mathrm{ml})$, brine $(50 \mathrm{ml})$, and dried. Evaporation of the solvent left a brown gum $(2.08 \mathrm{~g})$ which was chromatographed rapidly ${ }^{148}$ on silica (Merck silica gel $\mathrm{H}, 40 \mathrm{~g}$, chloroform) to give methyl 2-dichloroacetoxy-7-methoxy-12-oxo-2, 3,9,10-tetrahydro-1H2,10a-ethanophenanthrene-8-carboxylate 132 ( $1.35 \mathrm{~g}, 56 \%$ from acid 129).

M.p. $190-194^{\circ}$.

$\delta 7.56(d, J=9 \mathrm{~Hz}, 1 \mathrm{H}, \mathrm{H} 5), 6.74(\mathrm{~d}, \mathrm{~J}=9 \mathrm{~Hz}, 1 \mathrm{H}, \mathrm{H} 6), 6.05 \quad(t, \mathrm{~J}=4 \mathrm{~Hz}$ ， $1 \mathrm{H}, \mathrm{H} 4), 5.97\left(\mathrm{~s}, 1 \mathrm{H}, \mathrm{COCHCl}_{2}\right), 3.91\left(\mathrm{~s}, 3 \mathrm{H}, \mathrm{CO}_{2} \mathrm{CH}_{3}\right), 3.80(\mathrm{~s}, 3 \mathrm{H}$, 
$\left.\mathrm{ArOCH}_{3}\right), 3.15-1.65(\mathrm{~m}, 1 \mathrm{OH})$.

$\nu_{\max } 1770,1755,1720,1595,1580 \mathrm{~cm}^{-1}$.

$\mathrm{m} / \mathrm{z} 442(5 \%), 440(27), 438\left(41, \mathrm{M}^{+}\right), 368(21), 310(100)$.

$\mathrm{C}_{21} \mathrm{H}_{20} \mathrm{Cl}_{2} \mathrm{O}_{6} \quad$ H.r.m.s. Calcd: 438.0637 .

Found: 438.0633 .

$\delta\left({ }^{13} \mathrm{C}\right) 209.9(\mathrm{~s}, \mathrm{Cl} 2), 168.4\left(\mathrm{~s}, \underline{\mathrm{CO}}_{2} \mathrm{CH}_{3}\right), 163.2\left(\mathrm{~s}, \mathrm{OCOCHCl}_{2}\right)$,

$155.7(\mathrm{~s}, \mathrm{C} 7), 140.2(\mathrm{~s}, \mathrm{C} 4 \mathrm{a}), 134.8(\mathrm{~s}, \mathrm{C} 8 \mathrm{a}), 126.2(\mathrm{~d}, \mathrm{C} 5)$,

$124.4(\mathrm{~s}, \mathrm{c} 4 \mathrm{~b}), 123.2(\mathrm{~s}, \mathrm{c} 8), 114.1(\mathrm{~d}, \mathrm{c} 4), 109.9(\mathrm{~d}, \mathrm{c} 6)$,

$86.3(\mathrm{~s}, \mathrm{C} 2), 64.1\left(\mathrm{~d}, \mathrm{COCHCl}_{2}\right), 56.0\left(\mathrm{q}, \mathrm{ArOCH}_{3}\right), 52.4(\mathrm{q}$ ， $\left.\mathrm{CO}_{2} \mathrm{CH}_{3}\right), 50.3(t, \mathrm{Cl}), 42.5(t, \mathrm{Cl}), 39.4(\mathrm{~s}, \mathrm{ClOa}), 36.9(t, \mathrm{C} 3)$, $32.7(t, \mathrm{Cl} 0), 24.6(t, \mathrm{C} 9)$.

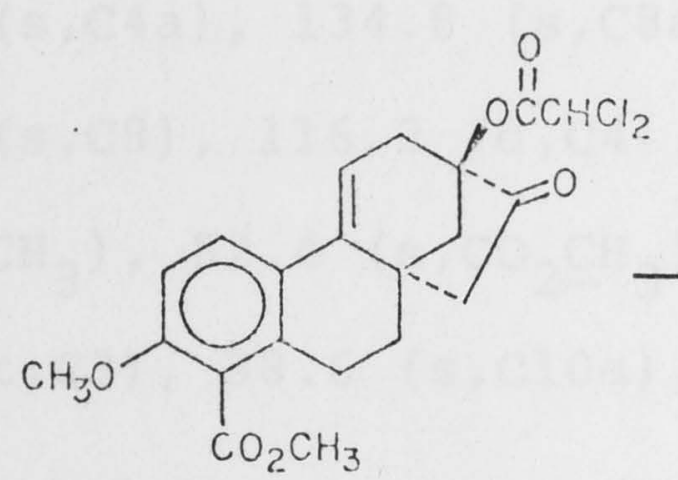

132

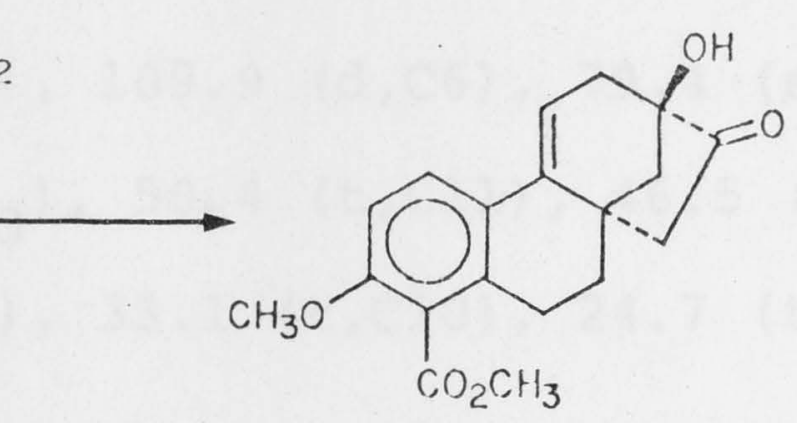

13.3

Dichloroacetoxy ketone $132(1.32 \mathrm{~g}, 3 \mathrm{mmol})$ was dissolved in a mixture of THF-methanol (l:l, $50 \mathrm{ml})$ and water ( $1 \mathrm{ml}$ ) and the solution deoxygenated with a stream of nitrogen. Sodium bicarbonate $(504 \mathrm{mg}, 6 \mathrm{mmol})$ was added and the suspension stirred for $1 \mathrm{hr}$. The solution was neutralised with sodium dihydrogenphosphate and the solvent evaporated. The residue was partitioned between dichloromethane $(30 \mathrm{ml})$ and water $(20 \mathrm{ml})$. The organic layer was washed with water $(20 \mathrm{ml})$ and brine $(30 \mathrm{ml})$ and dried. Removal of the solvent and crystallisation (dichloromethane-petroleum ether) gave 
methyl 2-hydroxy-7-methoxy-12-oxo-2,3,9,10-tetrahydro-1H-2,10aethanophenanthrene-8-carboxylate 133 (895 mg, 91\%) as slightly yellowish crystals. M.p. 196-198 (acetone-ether-petroleum ether). $\delta 7.66(\mathrm{~d}, \mathrm{~J}=9 \mathrm{~Hz}, 1 \mathrm{H}, \mathrm{H} 5), 6.87(\mathrm{~d}, \mathrm{~J}=9 \mathrm{~Hz}, 1 \mathrm{H}, \mathrm{H} 6), 6.12(t, \mathrm{~J}=4 \mathrm{~Hz}$, $1 \mathrm{H}, \mathrm{H} 4), 3.94\left(\mathrm{~s}, 3 \mathrm{H}, \mathrm{CO}_{2} \mathrm{CH}_{3}\right), 3.85\left(\mathrm{~s}, 3 \mathrm{H}, \mathrm{ArOCH}_{3}\right), 3.10-1.68(\mathrm{~m}$, $11 \mathrm{H})$.

$\nu_{\max } 3420,1735,1725,1590,1575 \mathrm{~cm}^{-1}$.

$\mathrm{m} / \mathrm{z} \quad 328\left(100 \%, \mathrm{M}^{+}\right), 297(16), 286(10)$.

$\mathrm{C}_{19} \mathrm{H}_{20} \mathrm{O}_{5} \quad \mathrm{Calcd}: \quad \mathrm{C}, 69.5 ; \mathrm{H}, 6.1$.

Found: $\quad$ C, 69.5; H, 6.0\%.

$\delta\left({ }^{13} \mathrm{C}\right) 218.7(\mathrm{~s}, \mathrm{Cl} 2), 168.7\left(\mathrm{~s}, \mathrm{CO}_{2} \mathrm{CH}_{3}\right), 155.4(\mathrm{~s}, \mathrm{C} 7)$, $139.8(\mathrm{~s}, \mathrm{C} 4 \mathrm{a}), 134.8(\mathrm{~s}, \mathrm{C} 8 \mathrm{a}), 126.0(\mathrm{~d}, \mathrm{C} 5), 125.0(\mathrm{~s}, \mathrm{C} 4 \mathrm{~b})$, $123.1(\mathrm{~s}, \mathrm{c} 8), 116.2(\mathrm{~d}, \mathrm{c} 4), 109.9(\mathrm{~d}, \mathrm{c} 6), 79.4(\mathrm{~s}, \mathrm{c} 2), 56.0$ $\left(\mathrm{q}, \mathrm{ArOCH}_{3}\right), 52.4\left(\mathrm{~s}, \mathrm{CO}_{2} \mathrm{CH}_{3}\right), 50.4(t, \mathrm{Cll}), 46.5$ (t, Cl), $39.8(t, \mathrm{C} 3), 38.6(\mathrm{~s}, \mathrm{Cl0a}), 33.1(t, \mathrm{Cl0}), 24.7(t, \mathrm{C} 9)$.<smiles>COC(=O)c1c(OC)ccc2c1CCC13CC(=O)C(O)(CC=C21)C3</smiles>

133<smiles></smiles>

134

The hydroxy ketone $133(885 \mathrm{mg}, 2.7 \mathrm{mmol})$, ethylene glycol (1.5 ml, $27 \mathrm{mmol}), p$-toluenesulfonic acid (l $\mathrm{mg})$ and 1,2dichloroethane $(75 \mathrm{ml})$ were heated under reflux with azeotropic removal of water (reverse Dean-stark apparatus containing $4 \AA$ molecular sieves) for $40 \mathrm{hr}$. The cooled solution was washed with water $(2 \times 20 \mathrm{ml}), 1 \mathrm{~N}$ sodium bicarbonate $(30 \mathrm{ml})$ 
and brine $(50 \mathrm{ml})$. Drying and solvent removal gave methyl 12,12 -ethylenedioxy-2-hydroxy-7-methoxy-2,3,9,10-tetrahydro$\underline{1 H-2,10 a-e t h a n o p h e n a n t h r e n e-8 \text {-carboxylate } 134}$ (964 mg, 96\%) as a crystalline white solid.

M.p. 154-157\% (dichloromethane-petroleum ether). $\delta 7.66(\mathrm{~d}, \mathrm{~J}=9 \mathrm{~Hz}, 1 \mathrm{H}, \mathrm{H} 5), 6.78(\mathrm{~d}, \mathrm{~J}=9 \mathrm{~Hz}, 1 \mathrm{H}, \mathrm{H} 6), 6.12(t, \mathrm{~J}=4 \mathrm{~Hz}$, $1 \mathrm{H}, \mathrm{H} 4), 3.98\left(\mathrm{~s}, 4 \mathrm{H}, \mathrm{OCH}_{2} \mathrm{CH}_{2} \mathrm{O}\right), 3.91\left(\mathrm{~s}, 3 \mathrm{H}, \mathrm{CO}_{2} \mathrm{CH}_{3}\right), 3.84(\mathrm{~s}, 3 \mathrm{H}$, $\left.\mathrm{ArOCH}_{3}\right), 3.08-1.60(\mathrm{~m}, 11 \mathrm{H})$. $\nu_{\max } 3520,1730,1595,1580 \mathrm{~cm}^{-1}$.

$\mathrm{m} / \mathrm{z} \quad 372\left(100 \%, \mathrm{M}^{+}\right), 354(18), 341(32), 310(95), 286(64)$. $\mathrm{C}_{21} \mathrm{H}_{24} \mathrm{O}_{6} \quad$ Calcd: C, 67.7; H, 6.5. Found: $\mathrm{C}, 67.8 ; \mathrm{H}, 6.7 \%$

$\delta\left({ }^{13} \mathrm{C}\right) 168.6\left(\mathrm{~s}, \mathrm{CO}_{2} \mathrm{CH}_{3}\right), 154.8(\mathrm{~s}, \mathrm{C} 7), 139.5(\mathrm{~s}, \mathrm{C} 4 \mathrm{a}), 134.7$ $(\mathrm{s}, \mathrm{C} 8 \mathrm{a}), 125.8(\mathrm{~d}, \mathrm{C} 5), 125.7(\mathrm{~s}, \mathrm{C} 4 \mathrm{~b}), 122.6(\mathrm{~s}, \mathrm{c} 8), 116.9(\mathrm{~d}, \mathrm{c} 4)$, $114.8(\mathrm{~s}, \mathrm{C} 12), 109.5(\mathrm{~s}, \mathrm{C} 6), 78.3(\mathrm{~s}, \mathrm{C} 2), 65.7$ and 64.8 $\left(2 \times t, \mathrm{OCH}_{2} \mathrm{CH}_{2} \mathrm{O}\right), 55.8\left(q, \mathrm{ArOCH}_{3}\right), 52.2\left(q, \mathrm{CO}_{2} \mathrm{CH}_{3}\right), 50.6(t, \mathrm{Cll})$, $48.4(t, \mathrm{Cl}), 38.6(\mathrm{~s}, \mathrm{Cl0a}), 35.8(t, \mathrm{C} 3), 33.5(t, \mathrm{Cl0})$, 24.5 (C9).

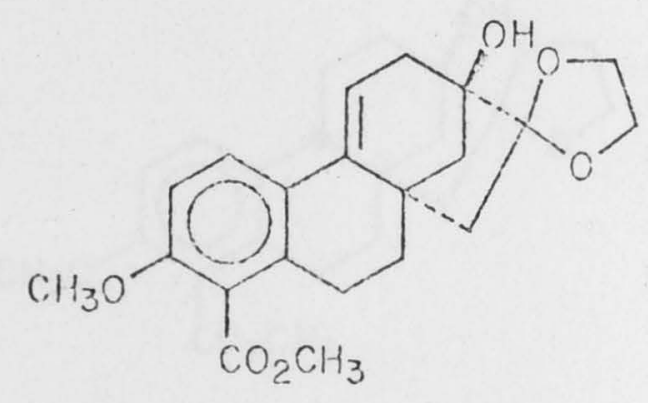

134

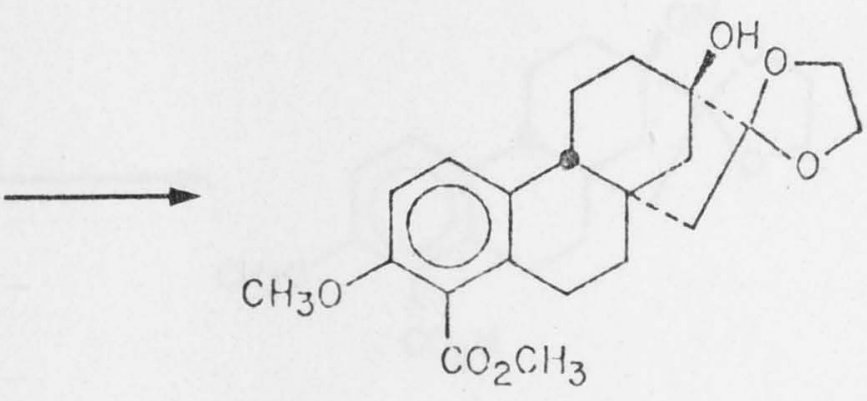

135

The unsaturated ketal $134(930 \mathrm{mg}, 2.5 \mathrm{mmol})$ in ethyl acetate $(60 \mathrm{ml})$ was hydrogenated at atmospheric pressure over palladium on carbon catalyst $(10 \%, 60 \mathrm{mg})$ for $2 \mathrm{hr}$ at $25^{\circ}$. The reaction mixture was filtered through celite and 
concentrated to leave white crystalline $\underline{( \pm)(2 \alpha, 4 a \alpha, 10 a \beta)}$ methyl 12,12-ethylenedioxy-2-hydroxy-7-methoxy-2,3,4,4a, 9, 10hexahydro-1H-2,10a-ethanophenanthrene-8-carboxylate 135 (916 mg, 98\%).

M.p. 178-180 (dichloromethane-petroleum ether). $\delta 7.22(\mathrm{~d}, \mathrm{~J}=9 \mathrm{~Hz}, 1 \mathrm{H}, \mathrm{H} 5), 6.77(\mathrm{~d}, \mathrm{~J}=9 \mathrm{~Hz}, 1 \mathrm{H}, \mathrm{H} 6), 3.96(\mathrm{~s}, 4 \mathrm{H}$, $\left.\mathrm{OCH}_{2} \mathrm{CH}_{2} \mathrm{O}\right), 3.88\left(\mathrm{~s}, 3 \mathrm{H}, \mathrm{CO}_{2} \mathrm{CH}_{3}\right), 3.80\left(\mathrm{~s}, 3 \mathrm{H}, \mathrm{ArOCH}_{3}\right), 2.70-2.20$ $(\mathrm{m}, 4 \mathrm{H}, \mathrm{H} 4 \mathrm{a}, \mathrm{H} 9, \mathrm{OH}), 2.08-1.40(\mathrm{~m}, 10 \mathrm{H})$. $\nu_{\max } 3370,1725,1595,1585 \mathrm{~cm}^{-1}$. $\mathrm{m} / \mathrm{z} 374\left(100 \%, \mathrm{M}^{+}\right), 345(15), 343(20)$.

$\mathrm{C}_{21} \mathrm{H}_{26}{ }^{\mathrm{O}} 6 \quad$ Calcd: C, 67.4; H, 7.0. Found: $\mathrm{C}, 67.3 ; \mathrm{H}, 7.0 \%$

$\delta\left({ }^{13} \mathrm{C}\right) 169.0\left(\mathrm{~s}, \underline{\mathrm{CO}}_{2} \mathrm{CH}_{3}\right), 153.9(\mathrm{~s}, \mathrm{C} 7), 133.9(\mathrm{~s}, \mathrm{C} 8 \mathrm{a})$, $131.5(\mathrm{~s}, \mathrm{C} 4 \mathrm{~b}), 129.0(\mathrm{~d}, \mathrm{C} 5), 122.7(\mathrm{~s}, \mathrm{C} 8), 114.0(\mathrm{~s}, \mathrm{Cl} 2)$, $109.1(\mathrm{~d}, \mathrm{c} 6), 78.6(\mathrm{~s}, \mathrm{C} 2), 65.5$ and $64.5\left(2 \times t, \mathrm{OCH}_{2} \mathrm{CH}_{2} \mathrm{O}\right)$, $55.8\left(q, \mathrm{ArOCH}_{3}\right), 52.1\left(q, \mathrm{CO}_{2} \mathrm{CH}_{3}\right), 51.0(t, \mathrm{Cll}), 43.5(\mathrm{~d}, \mathrm{C} 4 \mathrm{a})$, $42.3((t, \mathrm{Cl}), 37.4(\mathrm{~s}, \mathrm{ClOa}), 34.3(t, \mathrm{C} 3), 33.0(t, \mathrm{Cl} 0)$, $24.0(t, c 9)$.

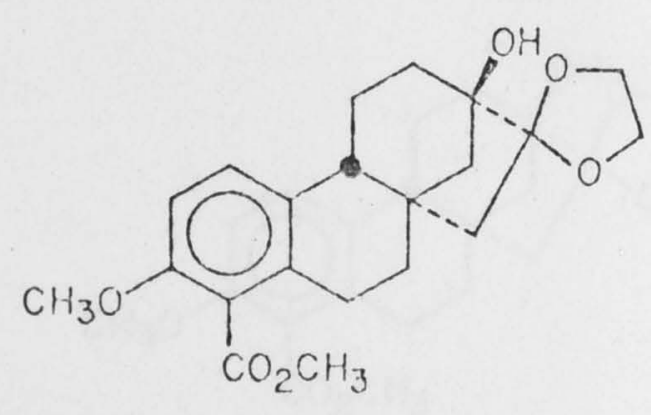

135

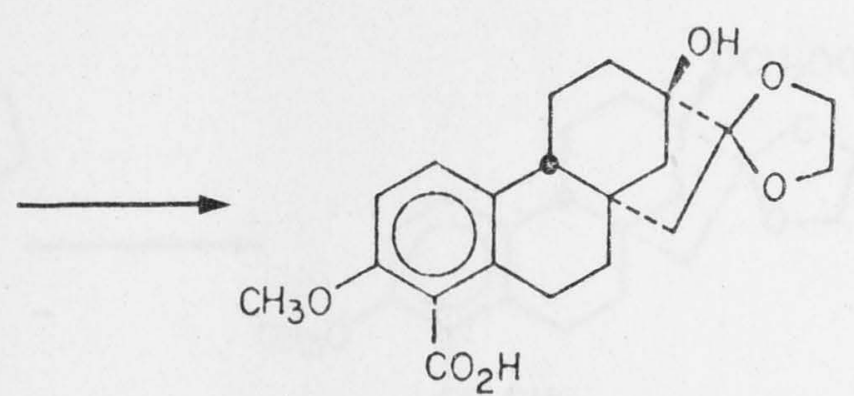

136

The ester $135(75 \mathrm{mg}, 0.2 \mathrm{mmol})$ was added to lithium propanethiolate in $\mathrm{HMPA}^{103}(0.5 \mathrm{M}, 2.4 \mathrm{mI})$ and the solution stirred for $2.5 \mathrm{hr}$. Ice $(6 \mathrm{~g})$ and $1 \mathrm{~N}$ sodium bicarbonate $(5 \mathrm{ml})$ were added, and the aqueous layer washed with 
chloroform $(3 \times 5 \mathrm{ml})$ which was reextracted with $0.5 \mathrm{~N}$ sodium bicarbonate $(5 \mathrm{ml})$. The combined aqueous layers were cooled to $0^{\circ}$, layered with ehtyl acetate $(15 \mathrm{ml})$, and acidified to $\mathrm{pH} 1$ with $6 \mathrm{~N}$ hydrochloric acid. Reextraction of the aqueous portion (ethyl acetate, $2 \times 10 \mathrm{ml}$ ), washing of the organic layers with water $(10 \mathrm{ml})$ and brine $(20 \mathrm{ml})$ gave, after drying and solvent removal ( \pm ) $(2 \alpha, 4 a \alpha, 10 a \beta) 12,12-$ ethylenedioxy-2-hydroxy-7-methoxy-2, 3,4,4a, 9, 10-hexahydro$\underline{1 H-2,10 a-e t h a n o p h e n a n t h r e n e-8-c a r b o x y l i c ~ a c i d} 136(65 \mathrm{mg}$, 91\%) as a white solid.

M.p. $\quad 255-258^{\circ}$.

$\delta\left(\mathrm{CDCl}_{3} / \mathrm{d}_{6}-\mathrm{DMSO}\right) \quad 7.22(\mathrm{~d}, \mathrm{~J}=9 \mathrm{~Hz}, 1 \mathrm{H}, \mathrm{H} 5), 6.80(\mathrm{~d}, \mathrm{~J}=9 \mathrm{~Hz}, 1 \mathrm{H}, \mathrm{H} 6)$, $4.00\left(\mathrm{~s}, 4 \mathrm{H}, \mathrm{OCH}_{2} \mathrm{CH}_{2} \mathrm{O}\right), 3.86\left(\mathrm{~s}, 3 \mathrm{H}, \mathrm{ArOCH}_{3}\right), 2.80-2.20(\mathrm{~m}, 3 \mathrm{H}$, $\mathrm{H} 4 \mathrm{a}, \mathrm{H} 9), 2.04-1.36(\mathrm{~m}, 10 \mathrm{H})$.

$\nu_{\max } 3360,1705,1595,1580 \mathrm{~cm}^{-1}$.

$\mathrm{m} / \mathrm{z} 360\left(100 \%, \mathrm{M}^{+}\right), 331(26)$.

$\mathrm{C}_{20} \mathrm{H}_{24} \mathrm{O}_{6} \quad$ Calcd: C, 66.7; H, 6.7.

Found: $\mathrm{C}, 66.3 ; \mathrm{H}, 6.9 \%$.

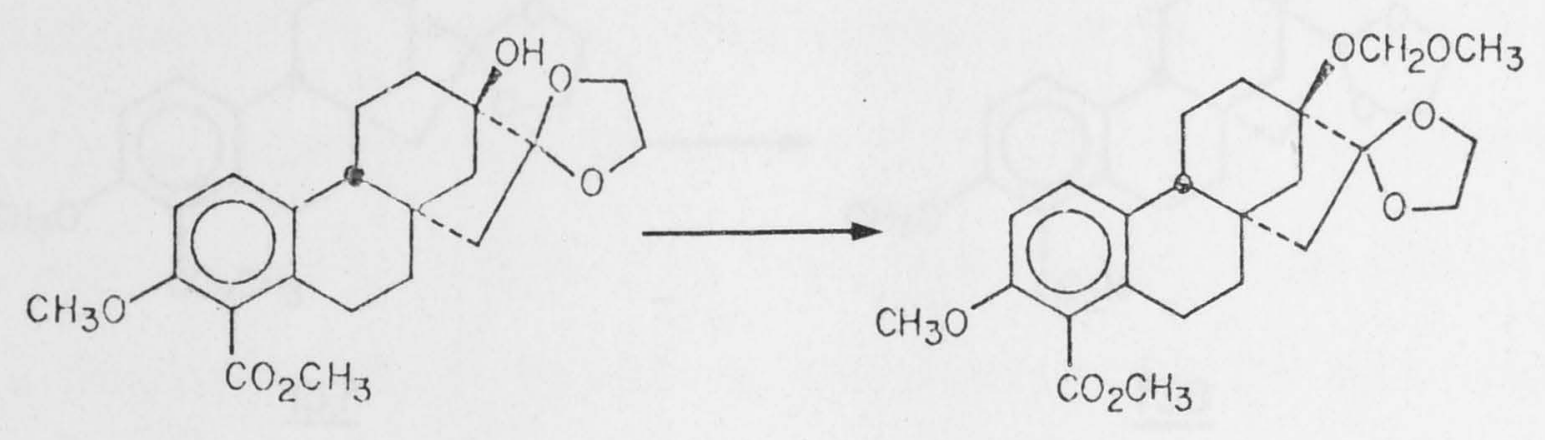

135

137

To hydroxy ester $135(823 \mathrm{mg}, 2.2 \mathrm{mmol})$ and $\mathrm{N}$-ethyl-Ndiisopropylamine $(7.66 \mathrm{ml}, 44 \mathrm{mmol})$ in dichloromethane $(7.66 \mathrm{ml})$ at $0^{\circ}$ was added dropwise chloromethyl methyl ether (1.68 ml, $22 \mathrm{mmol})$. After stirring for $16 \mathrm{hr}$ at $25^{\circ}$, 
ether $(50 \mathrm{ml})$ and water $(30 \mathrm{ml})$ were added and the layers separated. The organic layer was washed with IN acetic acid $(2 \times 25 \mathrm{ml})$, water $(25 \mathrm{ml})$, brine $(50 \mathrm{ml})$ and dried. Evaporation of the solvent, followed by crystallisation (dichloromethane-ether) gave $( \pm)(2 \alpha, 4 a \alpha, 10 a \beta)$ methyl 12,12ethylenedioxy-7-methoxy-2-methoxymethyloxy-2, 3,4,4a, 9, 10hexahydro-1H-2,10a-ethanophenanthrene-8-carboxylate 137 $(735 \mathrm{mg}, 80 \%)$ as a colourless solid.

M.p. $146-150^{\circ}$.

$\delta 7.22(\mathrm{~d}, \mathrm{~J}=9 \mathrm{~Hz}, 1 \mathrm{H}, \mathrm{H} 5), 6.78(\mathrm{~d}, \mathrm{~J}=9 \mathrm{~Hz}, 1 \mathrm{H}, \mathrm{H} 6), 4.98$ and $4.72\left(\mathrm{ABq}, \mathrm{J}_{\mathrm{AB}}=7 \mathrm{~Hz}, 2 \mathrm{H}, \mathrm{OCH}_{2} \mathrm{O}\right), 3.97\left(\mathrm{bs}, 4 \mathrm{H}, \mathrm{OCH}_{2} \mathrm{CH}_{2} \mathrm{O}\right), 3.88$ $\left(\mathrm{s}, 3 \mathrm{H}, \mathrm{CO}_{2} \mathrm{CH}_{3}\right), 3.79\left(\mathrm{~s}, 3 \mathrm{H}, \mathrm{ArOCH}_{3}\right), 3.40\left(\mathrm{~s}, 3 \mathrm{H}, \mathrm{CH}_{2} \mathrm{OCH}_{3}\right)$, $2.80-1.42(\mathrm{~m}, 13 \mathrm{H})$. $\nu_{\max } 1730,1595,1585 \mathrm{~cm}^{-1}$. $\mathrm{m} / \mathrm{z} \quad 418\left(40 \%, \mathrm{M}^{+}\right), 387(15), 374(16), 373(100)$. $\mathrm{C}_{23} \mathrm{H}_{30} \mathrm{O}_{7} \quad$ H.r.m.s. Calcd: 418.1991 . Found: 418.1995 .<smiles>CCOC1(CC23CCc4c(ccc(OC)c4C(C)=O)C2CCC(OC)(OC)C3)CCO1</smiles>

137

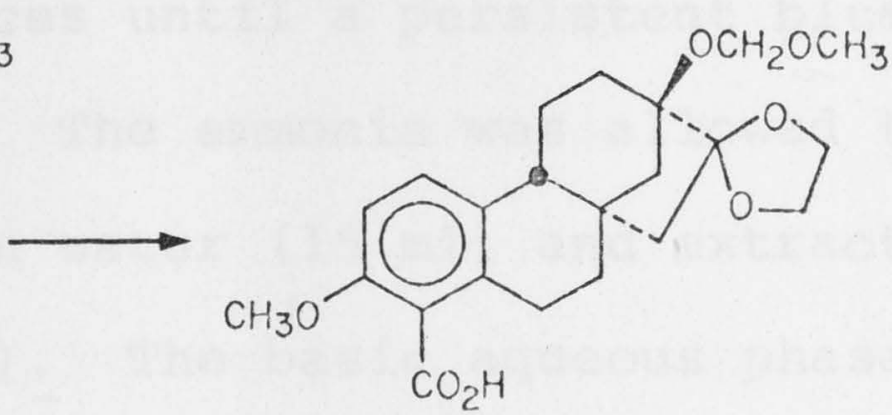

138

The ester $137(418 \mathrm{mg}, 1 \mathrm{mmol})$ was demethylated in the same way as described for ester $\underline{135}$ to give ( \pm$)(2 \alpha, 4 \mathrm{a} \alpha, 10 \mathrm{a} \beta)$ 12,12-ethylenedioxy-7-methoxy-2-methoxymethyloxy-2, 3,4,4a, 9 , 10-hexahydro-1H-2-10a-ethanophenanthrene-8-carboxylic acid 138 $(340 \mathrm{mg}, 84 \%)$ as a white powder. 
M.p. $\quad 194-197^{\circ}$.

$\delta\left(\mathrm{CDCl}_{3} / \mathrm{d}_{6}-\mathrm{DMSO}\right) \quad 8.50\left(\mathrm{bs}, 1 \mathrm{H}, \mathrm{CO}_{2} \mathrm{H}\right), 7.20(\mathrm{~d}, \mathrm{~J}=9 \mathrm{~Hz}, 1 \mathrm{H}, \mathrm{H} 5)$,

$6.76(\mathrm{~d}, \mathrm{~J}=9 \mathrm{~Hz}, 1 \mathrm{H}, \mathrm{H} 6), 4.95$ and $4.70\left(\mathrm{ABq}, \mathrm{J}_{\mathrm{AB}}=7 \mathrm{~Hz}, 2 \mathrm{H}, \mathrm{OCH}_{2} \mathrm{O}\right)$

$3.95\left(\mathrm{bs}, 4 \mathrm{H}, \mathrm{OCH}_{2} \mathrm{CH}_{2} \mathrm{O}\right), 3.80\left(\mathrm{~s}, 3 \mathrm{H}, \mathrm{ArOCH}_{3}\right), 3.38(\mathrm{~s}, 3 \mathrm{H}$,

$\left.\mathrm{CH}_{2} \mathrm{OCH}_{3}\right), 2.96-1.40(\mathrm{~m}, 13 \mathrm{H})$.

$\nu_{\max } 1730,1585 \mathrm{~cm}^{-1}$.

$\mathrm{m} / \mathrm{z} \quad 404\left(44 \%, \mathrm{M}^{+}\right), 359(100)$.

$\mathrm{C}_{22} \mathrm{H}_{28} \mathrm{O}_{7} \quad$ Calcd: C, 65.3; $\mathrm{H}, 7.0$.

Found: $\mathrm{C}, 65.2 ; \mathrm{H}, 6.9 \%$

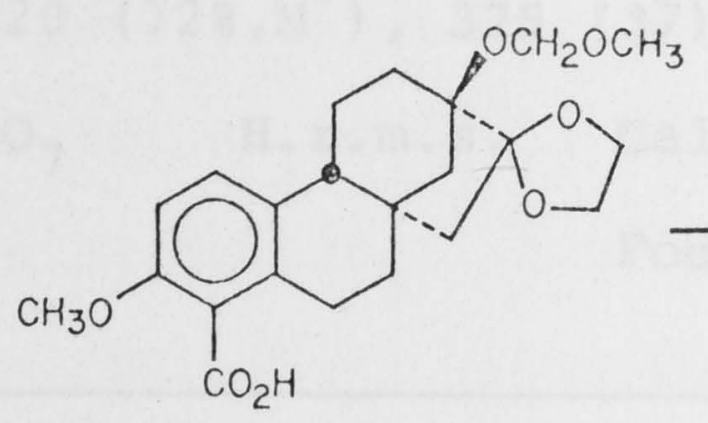

138<smiles>COC1=CCC2=C(CCC34CC5(OCCO5)[C@@](OC)(CCC23)C4)C1C(C)=O</smiles>

140

I'o acid 138 ( $100 \mathrm{mg}, 0.25 \mathrm{mmol}$ ) and potassium $t$-butoxide $(28 \mathrm{mg}, 0.25 \mathrm{mmol})$ in $\operatorname{THF}(2.5 \mathrm{ml})$, methanol $(0.1 \mathrm{ml}, 2.5$ mmol) and ammonia $(25 \mathrm{ml})$ at $-78^{\circ}$ was added sodium ( $15 \mathrm{mg}$, $0.63 \mathrm{mmol}$ ) in small pieces until a persistent blue colour was obtained (15 min.). The ammonia was allowed to evaporate, the residue dissolved in water $(15 \mathrm{ml})$ and extracted with ethyl acetate $(2 \times 10 \mathrm{ml})$. The basic aqueous phase was cooled to $0^{\circ}$, layered with fresh ethyl acetate $(20 \mathrm{ml})$ and saturated with sodium dihydrogenphosphate ( $\mathrm{pH}$ 5). The layers were separated and the aqueous phase reextracted with ethyl acetate $(2 \times 15 \mathrm{ml})$. The organic layers were washed with brine $(20 \mathrm{ml})$ and treated with ethereal diazomethane ( $~ 0.5 \mathrm{mmol}$ ). Drying and removal of the volatiles gave 


\section{( \pm ) $(2 \alpha, 4 a \alpha, 8 \xi, 10 a \beta)$ methyl 12,12-ethylenedioxy-7-methoxy-}

\section{2-methoxymethyloxy-2, 3,4,4a,5,8,9,10-octahydro- $1 \mathrm{H}-2,10 \mathrm{a}-$}

\section{ethanophenanthrene-8-carboxylate $140(93 \mathrm{mg}, 89 \%$ ) as a}

yellowish oil (homogeneous by t.l.c., 4\% methanol-

dichloromethane) which decomposed on heating.

$\delta \quad 4.95$ and $4.68\left(\mathrm{ABq}, \mathrm{J}_{\mathrm{AB}}=8 \mathrm{~Hz}, 2 \mathrm{H}, \mathrm{OCH}_{2} \mathrm{O}\right), 4.84 \quad(\mathrm{t}, \mathrm{J}=4 \mathrm{~Hz}, 1 \mathrm{H}, \mathrm{H} 6)$,

$4.00\left(\mathrm{~m}, 5 \mathrm{H}, \mathrm{OCH}_{2} \mathrm{CH}_{2} \mathrm{O}, \mathrm{H} 8\right), 3.70\left(\mathrm{~s}, 3 \mathrm{H}, \mathrm{CO}_{2} \mathrm{CH}_{3}\right), 3.56(\mathrm{~s}, 3 \mathrm{H}$,

$\left.\mathrm{C}=\mathrm{COCH}_{3}\right), 3.38\left(\mathrm{~s}, 3 \mathrm{H}, \mathrm{CH}_{2} \mathrm{OCH}_{3}\right), 2.92$ and $2.52\left(\mathrm{ABq}, \mathrm{J}_{\mathrm{AB}}=12 \mathrm{~Hz}\right.$, $2 \mathrm{H}, \mathrm{H} 5), 2.20-1.32(\mathrm{~m}, 13 \mathrm{H})$.

$\nu_{\max }\left(\mathrm{CHCl}_{3}\right) 1730,1700 \mathrm{~cm}^{-1}$.

$\mathrm{m} / \mathrm{z} \quad 420\left(72 \%, \mathrm{M}^{+}\right), 375(37), 361(100)$.

$\mathrm{C}_{23} \mathrm{H}_{32} \mathrm{O}_{7} \quad$ H.r.m.s. Calcd: 420.2148 .

Found: 420.2149 .

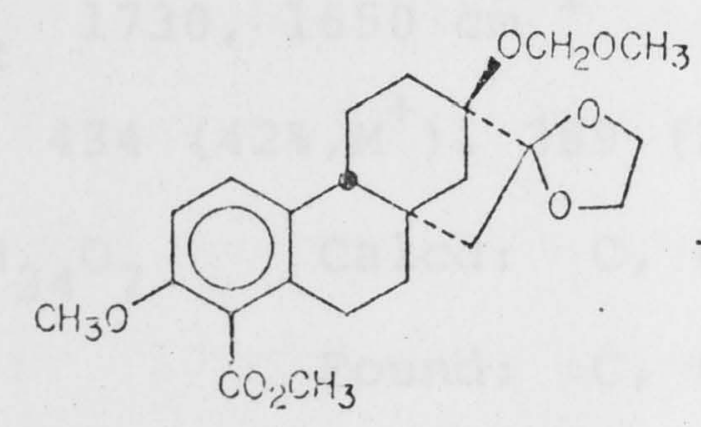

137

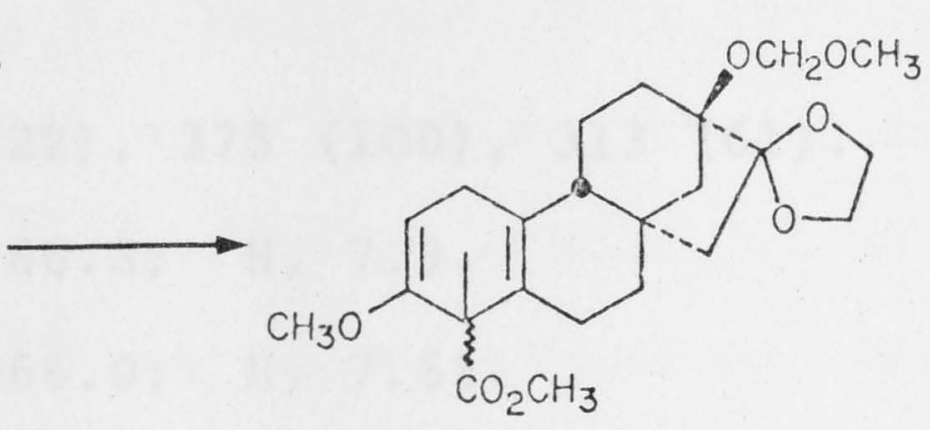

139

Potassium ( $24 \mathrm{mg}, 0.63 \mathrm{mmol}$ ) was added in small pieces to a solution of ester 137 (105 $\mathrm{mg}, 0.25 \mathrm{mmol}$ ) and $t$-butyl alcohol $(0.023 \mathrm{ml}, 0.25 \mathrm{mmol})$ in freshly distilled ammonia (from sodium amide, $50 \mathrm{ml}$ ) and $\mathrm{THF}(5 \mathrm{ml})$ at $-78^{\circ}$, until a persistent blue colour was obtained. After 10 min. methyl iodide $(0.156 \mathrm{ml}, 2.5 \mathrm{mmol})$ was added dropwise and the temperature was allowed to reach $-33^{\circ}$ followed by addition of ammonium chloride (265 mg, $5 \mathrm{mmol}$ ) and evaporation of the ammonia. 
The residue was partitioned between water (10 $\mathrm{ml}$ ) and dichloromethane $(20 \mathrm{ml})$. Further extraction with dichloromethane $(2 \times 15 \mathrm{ml})$, washing of the organic layers (water $10 \mathrm{ml}$, brine $20 \mathrm{ml}$ ), drying, and removal of the solvent gave a yellow oil ( $88 \mathrm{mg})$. Crystallisation from ether-petroleum ether afforded $( \pm)(2 \alpha, 4 a \alpha, 8 \xi, 10 a \beta)$ methyl 12,12-ethylenedioxy-7-methoxy-2-methoxymethyloxy-8-methyl$2,3,4,4 a, 5,8,9,10$-octahydro-1H-2,10a-ethanophenanthrene-8carboxylate $139(77 \mathrm{mg}, 71 \%)$ as colourless crystals. M.p. $\quad 106-110^{\circ}$.

$\delta 4.94$ and $4.68\left(\mathrm{ABq}, \mathrm{J}_{\mathrm{AB}}=7.5 \mathrm{~Hz}, 2 \mathrm{H}, \mathrm{OCH}_{2} \mathrm{O}\right), 4.76(t, \mathrm{~J}=4 \mathrm{~Hz}, 1 \mathrm{H}, \mathrm{H} 6)$, $3.98\left(\mathrm{~m}, 4 \mathrm{H}, \mathrm{OCH}_{2} \mathrm{CH}_{2} \mathrm{O}\right), 3.66\left(\mathrm{~s}, 3 \mathrm{H}, \mathrm{CO}_{2} \mathrm{CH}_{3}\right), 3.53\left(\mathrm{~s}, 3 \mathrm{H}, \mathrm{C}=\mathrm{COCH}_{3}\right)$, $3.38\left(\mathrm{~s}, 3 \mathrm{H}, \mathrm{CH}_{2} \mathrm{OCH}_{-3}\right), 2.92$ and $2.58\left(\mathrm{ABq}, \mathrm{J}_{\mathrm{AB}}=12 \mathrm{~Hz}, 2 \mathrm{H}, \mathrm{H} 5\right), 2.24-$ $1.36(\mathrm{~m}, 13 \mathrm{H}), 1.42\left(\mathrm{~s}, 3 \mathrm{H}, \mathrm{CH}_{3}\right)$.

$\nu_{\max } 1730,1650 \mathrm{~cm}^{-1}$. $\mathrm{m} / \mathrm{z} \quad 434\left(42 \%, \mathrm{M}^{+}\right), 389(22), 375(100), 313$ (61).

$\mathrm{C}_{24} \mathrm{H}_{34} \mathrm{O}_{7} \quad$ Calcd: C, 66.3; H, 7.9. Found: $\mathrm{C}, 66.0 ; \mathrm{H}, 7.6 \%$.<smiles>COC1=CCC2=C(CCC34CC[C@@](OC)(CC23)C2(C4)OCCO2)C1C(C)=O</smiles>

140<smiles>CCOC1(C2(OCC)COCCO2)CCC2=C3CC=C(OC)C(C(C)=O)(CC3)C2CC1</smiles>

139

(i) To ester $140(84 \mathrm{mg}, 0.20 \mathrm{mmol})$ in freshly distilled HMPA ( $3 \mathrm{ml})$ at $0^{\circ}$ was added methyl iodide $(0.25 \mathrm{ml}, 4 \mathrm{mmol})$ followed by potassium hydride (160 $\mathrm{mg}, 4 \mathrm{mmol}$ ) in six 
portions over $4 \mathrm{hr}$. The addition of methyl iodide $(0.25 \mathrm{ml})$ and potassium hydride $(160 \mathrm{mg})$ was repeated in the same fashion and the reaction mixture stirred for an additional $14 \mathrm{hr}$ at $25^{\circ}$. Ether $(30 \mathrm{ml})$ and water (20 $\mathrm{ml}$, careful!) were added and the layers separated. Further extraction (ether $2 \times 30 \mathrm{ml}$ ), sequential washing of the organic layers (water $3 \times 20 \mathrm{ml}$, brine $30 \mathrm{ml}$ ), drying, and solvent removal left a yellowish oil (78 mg), homogeneous by t.l.c. (4\% methanol-dichloromethane). ${ }^{1} \mathrm{H}$ n.m.r. analysis indicated the presence of $139(\sim 70 \%)$ and $137(\sim 30 \%)$.

(ii) Ester $140(42 \mathrm{mg}, 0.10 \mathrm{mmol})$ in THF $(0.5 \mathrm{ml})$ was added to lithium disopropylamide (from disopropylamine, $0.021 \mathrm{ml}, 0.15 \mathrm{mmol}$ and butyl lithium, $1.75 \mathrm{M}$ in hexane, $0.085 \mathrm{ml})$ in THF (l $\mathrm{ml})$ at $-78^{\circ} .149$ After $30 \mathrm{~min}$. methyl iodide $(0.125 \mathrm{ml}, 2.0 \mathrm{mmol})$ and $\mathrm{HMPA}(0.025 \mathrm{ml}$, $0.14 \mathrm{mmol})$ in THF $(0.5 \mathrm{ml})$ were added and the solution was allowed to warm to room temperature. Ether $(20 \mathrm{ml})$ and water $(10 \mathrm{ml})$ were added, the layers separated, and the aqueous phase reextracted with ether $(2 \times 10 \mathrm{ml})$. After washing (water $2 \times 10 \mathrm{ml}$, brine $20 \mathrm{ml}$ ), the dried solvents were evaporated to leave an oil (33 $\mathrm{mg})$ which was mainly ( 90\%) starting material $140\left({ }^{1} \mathrm{H}\right.$ n.m.r. and t.l.c. analysis). When the temperature during the proton abstraction was raised to (a) $-40^{\circ}(30 \mathrm{~min})$ and (b) $0^{\circ}(1 \mathrm{hr})$, then a mixture of 140 and aromatic ester $137[(a) \sim 3: 2$; (b) $\sim 1: 2]$ was obtained $\left({ }^{1} \mathrm{H}\right.$ n.m.r. analysis). 


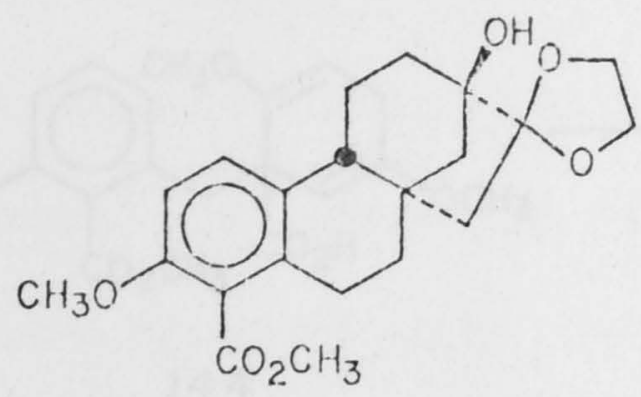

$\underline{135}$

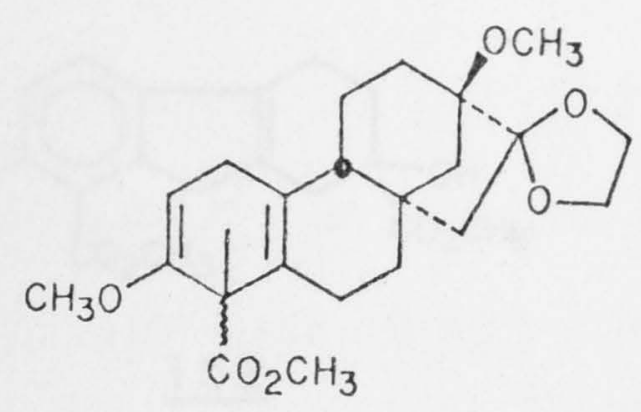

142

Potassium ( $\sim 98 \mathrm{mg}, 0.25 \mathrm{mmol}$ ) was added in small pieces to a solution of ester $135(37 \mathrm{mg}, 0.10 \mathrm{mmol})$ in freshly distilled ammonia $(20 \mathrm{ml})$ and THF $(2 \mathrm{ml})$ at $-78^{\circ}$ until a persistent blue colour was obtained. After 10 min. methyl iodide $(0.062 \mathrm{ml}, 1 \mathrm{mmol})$ was added dropwise and the reaction mixture treated as described for the methylation of 137 to give $( \pm)(2 \alpha, 4 a \alpha, 8 \xi, 10 a \beta)$ methyl 12,12 -ethylenedioxy-2,7dimethoxy-8-methyl-2,3,4,4a,5,8,9,10-octahydro-1H-2,10aethanophenanthrene-8-carboxylate 142 ( $31 \mathrm{mg}, 86 \%$ ) as a yellowish oil (homogeneous by t.l.c.).

$\delta \quad 4.76(t, J=4 \mathrm{~Hz}, 1 \mathrm{H}, \mathrm{H} 6), 4.00\left(\mathrm{~m}, 4 \mathrm{H}, \mathrm{OCH}_{2} \mathrm{CH}_{2} \mathrm{O}\right), 3.68(\mathrm{~s}, 3 \mathrm{H}$, $\left.\mathrm{CO}_{2} \mathrm{CH}_{3}\right), 3.55\left(\mathrm{~s}, 3 \mathrm{H}, \mathrm{C}=\mathrm{COCH}_{3}\right), 3.38\left(\mathrm{~s}, 3 \mathrm{H}, \mathrm{OCH}_{3}\right), 2.92$ and $2.58\left(\mathrm{ABq}, \mathrm{J}_{\mathrm{AB}}=12 \mathrm{~Hz}, 2 \mathrm{H}, \mathrm{H} 5\right), 2.40-1.40(\mathrm{~m}, 13 \mathrm{H}), 1.44\left(\mathrm{~s}, 3 \mathrm{H}, \mathrm{CH}_{3}\right)$. $\nu_{\max } 1735,1700 \mathrm{~cm}^{-1}$.

$\mathrm{m} / \mathrm{z} \quad 404\left(57 \%, \mathrm{M}^{+}\right), 345(100), 313(69)$.

$\mathrm{C}_{23} \mathrm{H}_{32} \mathrm{O}_{6} \quad$ H.r.m.s. Calcd: 404.2198 .

Found: 404.2196. 
Chapter 3<smiles>COC1=CC(Cc2cccc(OC)c2C(=O)O)(C(=O)O)C(O)=CC1</smiles>

144

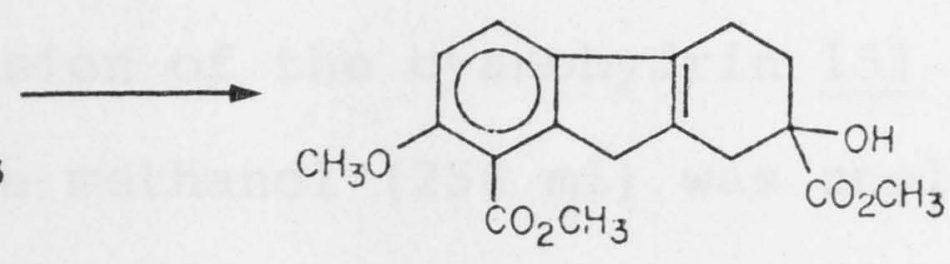

152

The preparation of hydroxy ester $\underline{152}$ is an adaptation of the previously described procedure. 66

Finely powdered acid $144^{66,150}$ (18.1 $\mathrm{g}, 50 \mathrm{mmol}$ ) was added to mechanically stirred PPA $(500 \mathrm{~g}$, pre-degassed with a stream of nitrogen, $30 \mathrm{min.}$ ) at $60^{\circ}$ as quick as possible (foams). The solution was stirred rapidly for another $30 \mathrm{~min}$. at this temperature, cooled and poured onto ice $(1000 \mathrm{~g})$ in five portions with vigorous stirring. The yellow precipitate was extracted into ethyl acetate $(3 \times 500 \mathrm{ml})$, the extracts were washed with water (500 ml), IN aqueous sodium bicarbonate $(500 \mathrm{ml})$, brine $(500 \mathrm{ml})$ and dried. Removal of the solvent gave a yellow solid $(13.0 \mathrm{~g})$ which was a 4:1 mixture of fluorenones 71 and $\underline{145}\left({ }^{1} \mathrm{H}\right.$ n.m.r. analysis $)$. The crude mixture of $\underline{71}$ and $\underline{145}(13.0 \mathrm{~g}, 47.8 \mathrm{mmol})$ was dissolved in THF $(400 \mathrm{ml})$, water $(250 \mathrm{ml})$ was added and the system purged of oxygen with a stream of nitrogen for 1 hr. Sodium cyanide $(14.0 \mathrm{~g}, 287 \mathrm{mmol})$ was added, followed by the dropwise addition of $4 \mathrm{~N}$ hydrochloric acid $(72 \mathrm{ml}$ ) over $2 \mathrm{hr}$ (Caution! HCN evolution). After the addition was completed (t.l.c. showed a single spot), the excess of hydrogen cyanide was driven off with a nitrogen stream (14 hr, aqueous permanganate trap). Ethyl acetate $(200 \mathrm{ml})$ was added and the layers separated. The organic phase was washed with water $(3 \times 100 \mathrm{ml})$, brine $(200 \mathrm{ml})$ and dried. Removal of the solvent gave the cyanohydrin 151 (14.0 g) as 
a brown foam.

A stirred suspension of the cyanohydrin 151 (14.0 g, $46.8 \mathrm{mmol})$ in absolute methanol (250 ml) was cooled to $0^{\circ}$ and then treated with hydrogen chloride gas until the methanol was saturated. The flask was then stoppered securely and the solution allowed to warm to room temperature overnight. The resultant dark solution was concentrated to about half the volume and then poured onto ice $(250 \mathrm{~g})$ with stirring. After $1 \mathrm{hr}$, the precipitate that had formed was extracted into ethyl acetate $(3 \times 200 \mathrm{ml})$. The ethyl acetate extracts were washed with water $(100 \mathrm{ml}), 1 \mathrm{~N}$ aqueous bicarbonate solution (100 ml), brine $(200 \mathrm{ml})$ and dried. Removal of the solvent gave a dark brown oil (12.1 g) which was chromatographed on silica gel (360 g, chloroform) to give dimethyl 2-hydroxy-7-methoxy-1,2,3,4-tetrahydrofluorene-2,8-dicarboxylate $152(8.3 \mathrm{~g}, 50 \%)$ as colourless crystals.

M.p. $116-120^{\circ} \quad\left(1\right.$ it. $\left.{ }^{66} 118-120^{\circ}\right)$.<smiles>COc1ccc2c(c1C(C)=O)CC1=C2CCC(O)(C(=O)O)C1</smiles>

$\underline{153}$<smiles>COc1ccc2c(c1C(C)=O)CC1=C(CCC(OC(=O)O)(C(=O)O)C1)C2</smiles>

154

A suspension of hydroxy acid $153^{66}(7.95 \mathrm{~g}, 25 \mathrm{mmol})$ and chloroacetic anhydride $(12.83 \mathrm{~g}, 75 \mathrm{mmol})$ in 1,2-dichloroethane $(250 \mathrm{ml})$ was heated at reflux for $3 \mathrm{hr}$, resulting in a homogeneous solution. The cold solution was washed with water $(2 \times 100 \mathrm{ml})$, brine $(150 \mathrm{ml})$ and dried. Removal of the 
solvent gave a crystalline residue, which was washed with cold ether $(3 \times 20 \mathrm{ml})$ to leave 2-chloroacetoxy-7-methoxy-8methoxycarbonyl-1,2,3,4-tetrahydrofluorene-2-carboxylic acid $154(8.86 \mathrm{~g}, 90 \%)$ as colourless crystals. M.p. $\quad 183-185^{\circ}$.

$\delta\left(\mathrm{CDCl}_{3} / \mathrm{d}_{6}-\mathrm{DMSO}\right) \quad 8.45(\mathrm{~b}, 1 \mathrm{H}), 7.17(\mathrm{~d}, \mathrm{~J}=8 \mathrm{~Hz}, 1 \mathrm{H}, \mathrm{H} 5)$, $6.87(\mathrm{~d}, \mathrm{~J}=8 \mathrm{~Hz}, 1 \mathrm{H}, \mathrm{H} 6), 4.04\left(\mathrm{~s}, 2 \mathrm{H}, \mathrm{COCH}_{2} \mathrm{Cl}\right), 3.91(\mathrm{~s}, 3 \mathrm{H}$ ， $\left.\mathrm{CO}_{2} \mathrm{CH}_{3}\right), 3.87\left(\mathrm{~s}, 3 \mathrm{H}, \mathrm{ArOCH}_{3}\right), 3.4 \mathrm{l}(\mathrm{bs}, 2 \mathrm{H}, \mathrm{H} 9), 3.03(\mathrm{~m}, 2 \mathrm{H}, \mathrm{HI})$, $2.65-2.14(\mathrm{~m}, 4 \mathrm{H}, \mathrm{H} 3, \mathrm{H} 4)$.

$\nu_{\max } 1745,1720,1700,1580 \mathrm{~cm}^{-1}$.

$\mathrm{m} / \mathrm{z} 396(1 \%), 394\left(3, \mathrm{M}^{+}\right), 378(1.5), 376(4), 358(31)$, $300(100), 272(22), 268$ (29).

$\mathrm{C}_{19} \mathrm{H}_{19} \mathrm{ClO}_{7} \quad$ H.r.m.s. Calcd: 394.0819 . Found: 394.0823 .<smiles>COC(=O)c1c(OC)ccc2c1CC1=C2CCC(C(=O)O)(C(=O)O)C1</smiles>

154<smiles>COc1ccc2c(c1C(=O)O)C[C@]13CC(=O)[C@](OC(=O)CCl)(CC=C21)C3</smiles>

157

Dry DMF (0.03 ml, $0.4 \mathrm{mmol})$ was added to a stirred suspension of acid $\underline{154}(7.88 \mathrm{~g}, 20 \mathrm{mmol})$ and oxalyl chloride (5.15 $\mathrm{ml}$, $60 \mathrm{mmol})$ in dichloromethane $(100 \mathrm{ml})$ at $0^{\circ}$. When the gas evolution had ceased, DMF $(0.03 \mathrm{ml})$ was added again and the homogeneous mixture was allowed to reach room temperature. The addition of DMF was repeated in $1 \mathrm{hr}$ intervals until t.1.c. analysis (4\% methanol-dichloromethane) indicated complete conversion. The volatiles were removed in vacuo and the resulting precipitate, acid chloride 155 (8.1 g) was freed from residual hydrogen chloride at an oil pump. 
$\nu_{\max }\left(\mathrm{CH}_{2} \mathrm{Cl}_{2}\right) \quad 1790,1755,1720,1580 \mathrm{~cm}^{-1}$.

A solution of the acid chloride 155 ( $8.1 \mathrm{~g}$ ) in dichloromethane $(100 \mathrm{ml})$ was added to diazomethane ( $120 \mathrm{mmol})$ in ether $(250 \mathrm{ml})$ at $-20^{\circ}$ and allowed to warm to room temperature. Filtration and removal of the solvent gave methyl 2-chloroacetoxy-2-diazoacetyl-7-methoxy-1,2,3,4tetrahydrofluorene-8-carboxylate $156(8.0 \mathrm{~g})$ as a yellow solid. A small sample was purified by chromatography (p.1.c., 4\% methanol-dichloromethane) but no satisfactory analysis could be obtained.

M.p. $\quad 147-150^{\circ}$.

$\delta \quad 7.24(\mathrm{~d}, \mathrm{~J}=8 \mathrm{~Hz}, 1 \mathrm{H}, \mathrm{H} 5), 6.92(\mathrm{~d}, \mathrm{~J}=8 \mathrm{~Hz}, 1 \mathrm{H}, \mathrm{H} 6), 5.57(\mathrm{~s}, 1 \mathrm{H}$, $\left.\mathrm{COCHN}_{2}\right), 4.05\left(\mathrm{~s}, 2 \mathrm{H}, \mathrm{COCH}_{2} \mathrm{Cl}\right), 3.93\left(\mathrm{~s}, 3 \mathrm{H}, \mathrm{CO}_{2} \mathrm{CH}_{3}\right), 3.87(\mathrm{~s}, 3 \mathrm{H}$, $\left.\mathrm{ArOCH}_{3}\right), 3.44(\mathrm{bs}, 2 \mathrm{H}, \mathrm{H} 9), 3.14$ and $2.88\left(\mathrm{ABq}, \mathrm{J}_{\mathrm{AB}}=18 \mathrm{~Hz}, 2 \mathrm{H}, \mathrm{Hl}\right)$, $2.52(\mathrm{e}, 2 \mathrm{H}, \mathrm{H} 4), 2.46-2.00(\mathrm{~m}, 2 \mathrm{H}, \mathrm{H} 3)$.

$\nu_{\max } 2100,1745,1715,1635,1580 \mathrm{~cm}^{-1}$.

$\mathrm{m} / \mathrm{z} \quad 420(1.5), 418\left(4, \mathrm{M}^{+}\right), 392(12), 390(34), 324(100)$, $314(26), 262(82), 272(40), 236(59), 225$ (51), 178 (41), 165 (43).

A solution of the crude diazoketone $(8.0 \mathrm{~g})$ in dichloromethane $(100 \mathrm{ml})$ was added over $15 \mathrm{~min}$. to a stirred mixture of trifluoracetic acid $(200 \mathrm{ml})$ and dichloromethane (100 ml) at $-20^{\circ}$. After a further $10 \mathrm{~min}$. ice and water (total $300 \mathrm{~g}$ ) were added, and the layers separated. Reextraction of the aqueous layers (dichloromethane $2 \times 100 \mathrm{ml}$ ), washing of the organic phase (water $2 \times 100 \mathrm{ml}$, brine $100 \mathrm{ml}$ ) gave after drying and solvent removal a brown oil (7.3 g). Chromatography 
on silica gel (140 g, chloroform) afforded $( \pm)$ methyl 7dichloroacetoxy-2-methoxy-8-oxogibba-1,3,4a(10a), 4b-tetraene1-carboxylate $157 \quad(5.54 \mathrm{~g}, 71 \%)$ as yellowish crystals. M.p. $133-135^{\circ}$ (plates from dichloromethane-petroleum ether).

$\delta 7.34(\mathrm{~d}, \mathrm{~J}=8 \mathrm{~Hz}, 1 \mathrm{H}, \mathrm{H} 4), 6.82(\mathrm{~d}, \mathrm{~J}=8 \mathrm{~Hz}, 1 \mathrm{H}, \mathrm{H} 3), 5.68 \quad(t$ ， $\mathrm{J}=3.5 \mathrm{~Hz}, 1 \mathrm{H}, \mathrm{H} 5), 4.07\left(\mathrm{~s}, 2 \mathrm{H}, \mathrm{COCH}_{2} \mathrm{Cl}\right), 3.87\left(\mathrm{~s}, 3 \mathrm{H}, \mathrm{CO}_{2} \mathrm{CH}_{3}\right)$,

$3.83\left(\mathrm{~s}, 3 \mathrm{H}, \mathrm{ArOCH}_{3}\right), 3.40-2.08(\mathrm{~m}, 8 \mathrm{H})$.

$\nu_{\max } 1755,1730,1720,1600,1590 \mathrm{~cm}^{-1}$.

$\mathrm{m} / \mathrm{z} 390(13 \%), 388\left(35, \mathrm{M}^{+}\right), 361(5), 359(16), 296$ (74),

$264(100), 211(35)$.

$\mathrm{C}_{20} \mathrm{H}_{19} \mathrm{ClO}_{6} \quad$ Calcd: C, 61.5; H, 4.9; Cl, 9.1.

Found: $\mathrm{C}, 61.3 ; \mathrm{H}, 4.9 ; \mathrm{Cl}, 9.2 \%$.

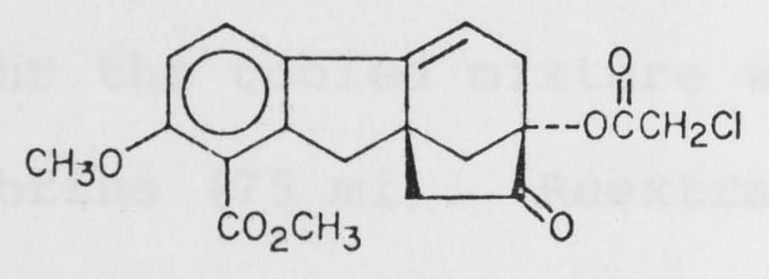

157

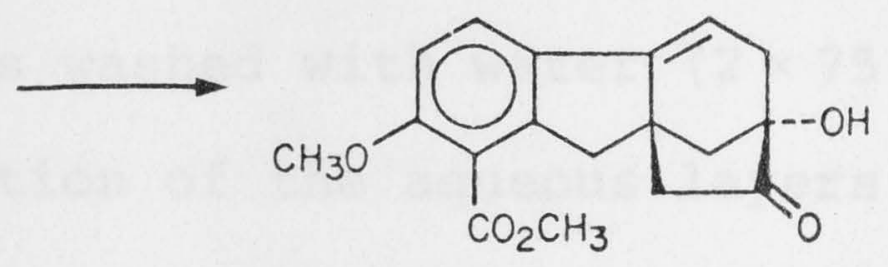

159

Ester $157(5.46 \mathrm{~g}, 14 \mathrm{mmol})$ in $\operatorname{THF}(40 \mathrm{ml})$, methanol (90 ml) and water $(10 \mathrm{ml})$ was heated at reflux for $1 \mathrm{hr}$ in a nitrogen atmosphere. The solution was cooled to $0^{\circ}$, potassium carbonate $(7.73 \mathrm{~g}, 56 \mathrm{mmol})$ and potassium bicarbonate (0.56 $\mathrm{g}, 5.6 \mathrm{mmol})$ added, and stirring continued for $1.5 \mathrm{hr}$ at $22^{\circ}$. The solvents were removed in vacuo at $20^{\circ}$, and dichloromethane $(100 \mathrm{ml})$ and water $(50 \mathrm{ml})$ added. The organic layer was washed with water $(50 \mathrm{ml}), 1 \mathrm{~N}$ acetic acid $(50 \mathrm{ml})$, water $(50 \mathrm{ml})$ and brine $(50 \mathrm{ml})$. After drying, solvent removal and recrystallisation from dichloromethane- 
ether $( \pm)$ methyl 7-hydroxy-2-methoxy-8-oxogibba-1,3,4a (10a),4b-tetraene-1-carboxylate $159(3.91 \mathrm{~g}, 89 \%$ ) was obtained as colourless crystals.

M.p. $149-152^{\circ}$ (lit. ${ }^{6}$ 150-152 ${ }^{\circ}$ ).<smiles>COc1ccc2c(c1C(C)=O)CC1(CC(=O)C3(O)CC=C1C3)C2</smiles>

$\underline{159}$

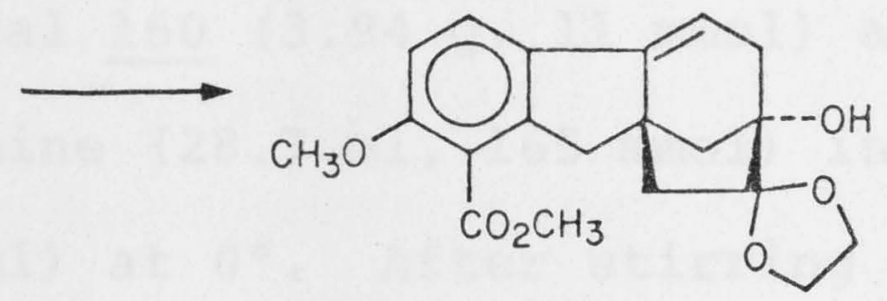

160

The a-hydroxy ketone $159(3.77 \mathrm{~g}, 12 \mathrm{mmol})$, ethylene glycol $(6.7 \mathrm{ml}, 120 \mathrm{mmol}), p$-toluenesulfonic acid (l $\mathrm{mg}$ ) and 1,2-dichloroethane (150 ml) were combined and heated at reflux with azeotropic removal of water (reverse DeanStark apparatus containing $4 \AA$ molecular sieves). After 16 hr the cooled mixture was washed with water $(2 \times 75 \mathrm{ml})$ and brine $(75 \mathrm{ml})$. Reextraction of the aqueous layers (dichloromethane, $2 \times 100 \mathrm{ml})$, drying of the combined organic extracts, and solvent removal afforded $( \pm)$ methyl 8,8ethylenedioxy-7-hydroxy-2-methoxygibba-1,3,4a(10a), 4btetraene-1-carboxylate $160(4.08 \mathrm{~g}, 95 \%)$ as a white solid. M.p. $160-163^{\circ}$ (Lit. ${ }^{66} 162-165^{\circ}$ ). 


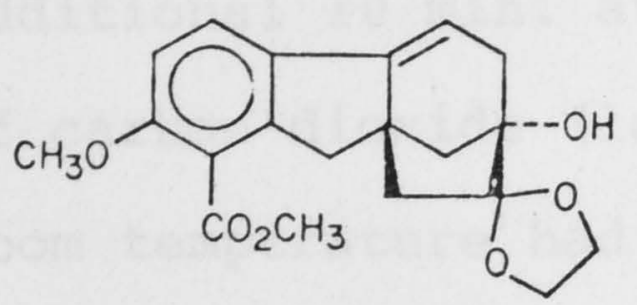

160

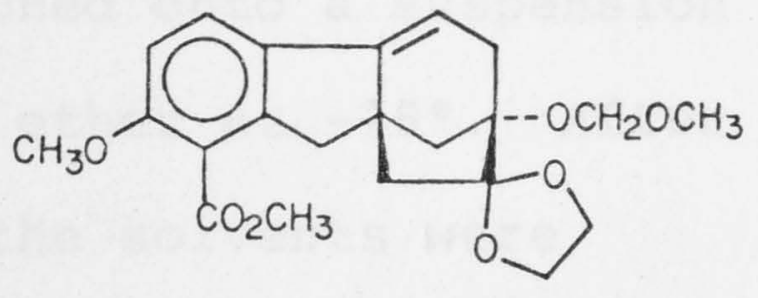

161

Chloromethyl methyl ether $(8.40 \mathrm{ml}, 110 \mathrm{mmol})$ was added dropwise to hydroxy ketal 160 (3.94 g, $11 \mathrm{mmol})$ and $\mathrm{N}$-ethyl-N-diisopropylamine $(28.7 \mathrm{ml}, 165 \mathrm{mmol})$ in dichloromethane $(28.7 \mathrm{ml})$ at $0^{\circ}$. After stirring for $18 \mathrm{hr}$ at $25^{\circ}$, ice $(50 \mathrm{~g})$ and dichloromethane $(100 \mathrm{ml})$ were added to the red solution. The organic phase was washed with water $(50 \mathrm{ml})$, ice-cold $1 \mathrm{~N}$ hydrochloric acid $(2 \times 50 \mathrm{ml})$, water $(50 \mathrm{ml})$ and brine $(100 \mathrm{ml})$. Reextraction (dichloromethane, $2 \times 100 \mathrm{ml}$ ), drying of the organic layer, and solvent removal gave a red oil (4.0 g) which after chromatography on silica gel (20 g, chloroform) afforded

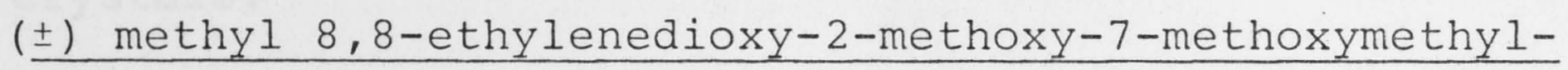
oxygibba-1,3,4a(10a),4b-tetraene-1-carboxylate 161 (3.40 g, $77 \%$ ) as a crystalline solid.

M.p. $122-125^{\circ}$ (1it. $\left.{ }^{66} \quad 122-125^{\circ}\right)$.<smiles>CCOC12CC=C3c4ccc(OC)c(C(C)=O)c4CC3(C1)C1(C2)OCCO1</smiles>

$\underline{161}$

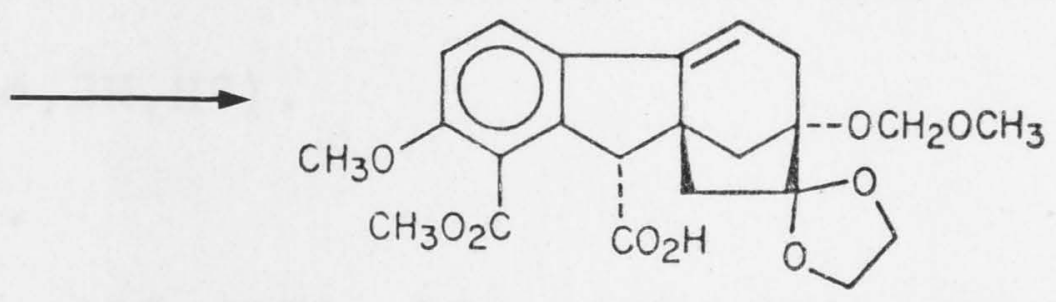

162

To ester 161 ( $3.22 \mathrm{~g}, 8 \mathrm{mmol}$ ) and $\mathrm{HMPA}$ ( $1.54 \mathrm{ml}, 8.8 \mathrm{mmol}$ ) in THF $(40 \mathrm{ml})$ at $-20^{\circ}$ was added dropwise lithium $t$-butylcyclohexylamide in benzene-hexane $(0.5 \mathrm{M}, 24 \mathrm{ml})$ over, $10 \mathrm{~min} .^{53}$ The purple solution was stirred for an 
additional $10 \mathrm{~min}$. at $-20^{\circ}$ and siphoned onto a suspension of carbon dioxide (large excess) in ether at $-78^{\circ}$. After room temperature had been reached, the solvents were evaporated and the residue dissolved in water $(100 \mathrm{ml})$. The aqueous layer was extracted with chloroform $(3 \times 20 \mathrm{ml})$ which in turn was backwashed with $1 \mathrm{~N}$ potassium carbonate $(2 \times 20 \mathrm{ml})$. The combined aqueous layers were acidified to $\mathrm{pH}$ l with $6 \mathrm{~N}$ hydrochloric acid in a two-phase system (ethyl acetate, $100 \mathrm{ml}$ ) at $0^{\circ}$. The saturated aqueous layer (sodium chloride) was reextracted (ethyl acetate, $2 \times 50 \mathrm{ml}$ ) and the organic layer washed with water $(50 \mathrm{ml})$, brine $(100 \mathrm{ml})$ and dried. Removal of the solvent gave after crystallisation from dichloromethane-ether $( \pm)(10 \alpha)$ 8,8-ethylenedioxy-2-methoxy1-methoxycarbonyl-7-methoxymethyloxygibba-1,3,4a (10a), 4btetraene-1-carboxylic acid $162(3.17 \mathrm{~g}, 89 \%)$ as colourless crystals.

M.p. $\quad 173-175^{\circ}$.

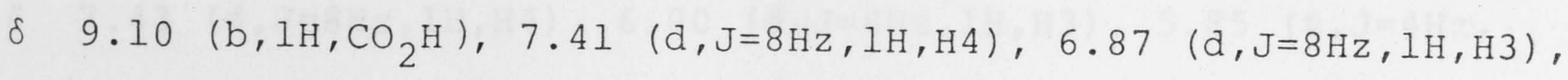
$5.84(t, \mathrm{~J}=3.5 \mathrm{~Hz}, 1 \mathrm{H}, \mathrm{H} 5), 4.95$ and $4.68\left(\mathrm{ABq}, \mathrm{J}=7 \mathrm{~Hz}, 2 \mathrm{H}, \mathrm{OCH}_{2} \mathrm{O}\right)$, $3.92\left(\mathrm{~m}, 5 \mathrm{H}, \mathrm{OCH}_{2} \mathrm{CH}_{2} \mathrm{O}, \mathrm{HlO}\right), 3.79\left(\mathrm{~s}, 3 \mathrm{H}, \mathrm{ArOCH}_{3}\right), 3.76(\mathrm{~s}, 3 \mathrm{H}$, $\left.\mathrm{CO}_{2} \mathrm{CH}_{3}\right), 3.31\left(\mathrm{~s}, 3 \mathrm{H}, \mathrm{CH}_{2} \mathrm{OCH}_{3}\right), 2.65(\mathrm{~m}, 2 \mathrm{H}, \mathrm{H} 6), 2.50$ and 2.00 $(\mathrm{ABq}, \mathrm{J}=11 \mathrm{~Hz}, 2 \mathrm{H}, \mathrm{H} l 1), 2.14(\mathrm{e}, 2 \mathrm{H}, \mathrm{H} 9)$. $\nu_{\max } 1730,1695,1585 \mathrm{~cm}^{-1}$. $\mathrm{m} / \mathrm{z} 446\left(23 \%, \mathrm{M}^{+}\right), 414(42), 401(20), 239(61), 211$ (40), $87(100), 45(95)$. $\begin{aligned} & \mathrm{C}_{23} \mathrm{H}_{26} \mathrm{O}_{9} \text { Calcd: } \mathrm{C}, 61.9 ; \mathrm{H}, 5.9 . \\ & \text { Found: } \mathrm{C}, 61.5 ; \mathrm{H}, 6.2 \%\end{aligned}$ $\delta\left({ }^{13} \mathrm{C}\right) 176.2\left(\mathrm{~s}, \mathrm{CO}_{2} \mathrm{H}\right), 166.1\left(\mathrm{~s}, \mathrm{CO}_{2} \mathrm{CH}_{3}\right), 158.8(\mathrm{~s}, \mathrm{C} 2)$, 
$146.2(\mathrm{~s}, \mathrm{C} 4 \mathrm{~b}), 142.5(\mathrm{~s}, \mathrm{C} 10 \mathrm{a}), 131.9(\mathrm{~s}, \mathrm{C} 4 \mathrm{a}), 125.2(\mathrm{~d}, \mathrm{C} 4)$, $118.4(\mathrm{~s}, \mathrm{Cl}), 114.9(\mathrm{~s}, \mathrm{C} 8), 112.7(2 \times \mathrm{d}, \mathrm{C} 3, \mathrm{C} 11), 92.5$ (t, $\left.\mathrm{OCH}_{2} \mathrm{O}\right), 85.1(\mathrm{~s}, \mathrm{C} 7), 65.7$ and $64.9\left(t, \mathrm{OCH}_{2} \mathrm{CH}_{2} \mathrm{O}\right), 57.0(\mathrm{~d}, \mathrm{Cl} 0)$, $56.5\left(q, \mathrm{ArOCH}_{3}\right), 55.3\left(q, \mathrm{CH}_{2} \mathrm{OCH}_{3}\right), 52.9(t, \mathrm{C} 9), 51.8(q$, $\left.\mathrm{CO}_{2} \mathrm{CH}_{3}\right), 49.2(\mathrm{~s}, \mathrm{C} 9 \mathrm{a}), 38.7(t, \mathrm{Cll}), 35.3(t, \mathrm{C} 6)$.

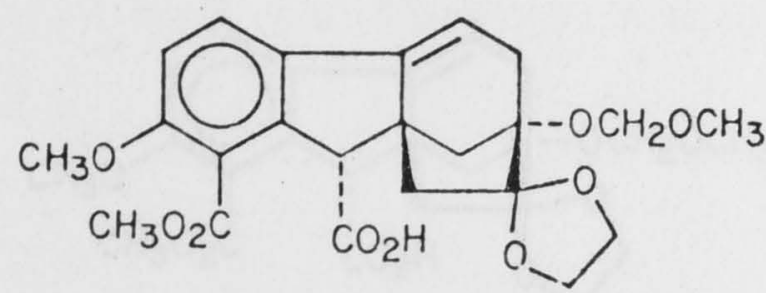

162

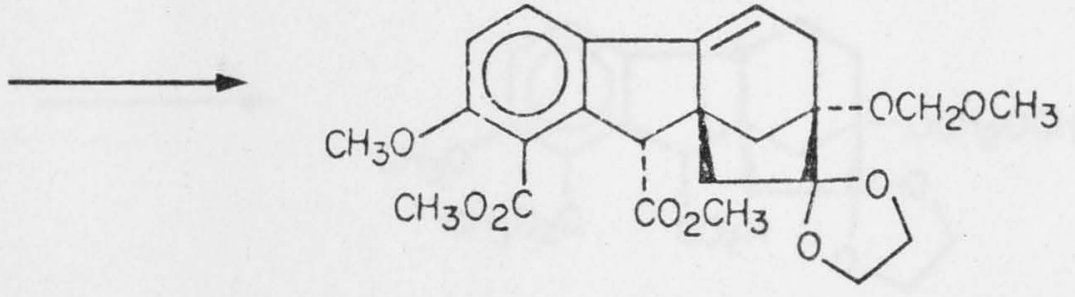

$\underline{163}$

Acid $\underline{162}(223 \mathrm{mg}, 0.5 \mathrm{mmol})$ in dichloromethane $(10 \mathrm{ml})$ at $0^{\circ}$ was treated with diazomethane ( $0.75 \mathrm{mmol})$ in ether $(3 \mathrm{ml})$. The solution was allowed to warm to room temperature and the volatiles were removed to give $( \pm)(10 \alpha)$ dimethyl 8,8ethylenedioxy-2-methoxy-7-methoxymethyloxygibba-1,3,4a (10a), $\underline{4 b-t e t r a e n e-1,10-d i c a r b o x y l a t e} 163(223 \mathrm{mg}, 97 \%)$ as a colourless oil.

$\delta 7.43(\mathrm{~d}, \mathrm{~J}=8 \mathrm{~Hz}, 1 \mathrm{H}, \mathrm{H} 4), 6.90(\mathrm{~d}, \mathrm{~J}=8 \mathrm{~Hz}, 1 \mathrm{H}, \mathrm{H} 3), 5.85 \quad(t, \mathrm{~J}=4 \mathrm{~Hz}$, $1 \mathrm{H}, \mathrm{H} 5), 4.96$ and $4.68\left(\mathrm{ABq}, \mathrm{J}_{\mathrm{AB}}=7 \mathrm{~Hz}, 2 \mathrm{H}, \mathrm{OCH}_{2} \mathrm{O}\right), 3.95\left(\mathrm{~m} 5 \mathrm{H}, \mathrm{OCH}_{2}\right.$ $\left.\mathrm{CH}_{2} \mathrm{O}, \mathrm{HIO}\right), 3.83\left(\mathrm{~s}, 3 \mathrm{H}, \mathrm{ArOCH}_{3}\right), 3.81\left(\mathrm{~s}, 3 \mathrm{H}, \mathrm{ArCO}_{2} \mathrm{CH}_{3}\right), 3.64$ (s, $\left.3 \mathrm{H}, \mathrm{CO}_{2} \mathrm{CH}_{3}\right), 3.35\left(\mathrm{~s}, 3 \mathrm{H}, \mathrm{CH}_{2} \mathrm{OCH}_{3}\right), 2.67(\mathrm{~m}, 2 \mathrm{H}, \mathrm{H} 6), 2.42$ and $1.90(\mathrm{ABq}, \mathrm{J}=11 \mathrm{~Hz}, 2 \mathrm{H}, \mathrm{H} 11), 2.14(\mathrm{e}, 2 \mathrm{H}, \mathrm{H} 9)$. $\nu_{\max }(\mathrm{film}) 1730-1710,1600,1590 \mathrm{~cm}^{-1}$. $\mathrm{m} / \mathrm{z} \quad 460\left(25 \%, \mathrm{M}^{+}\right), 428(51), 415(18), 401$ (13), 341 (30), $313(33), 297$ (39), $296(22), 269$ (59), 87 (100), 45 (57). $\mathrm{C}_{24} \mathrm{H}_{28}{ }^{\mathrm{O}} 9$ H.r.m.s. Calcd: 460.1733 . Found: 460.1733 .

$\delta\left({ }^{13} \mathrm{C}\right) \quad 171.9\left(\mathrm{~s}, \underline{\mathrm{CO}}_{2} \mathrm{CH}_{3}\right), 166.2\left(\mathrm{~s}, \operatorname{ArCO}_{2} \mathrm{CH}_{3}\right), 158.7(\mathrm{~s}, \mathrm{C} 2)$, 
$164.5(\mathrm{~s}, \mathrm{C} 4 \mathrm{~b}), 142.6(\mathrm{~s}, \mathrm{C} 10 \mathrm{a}), 131.8(\mathrm{~s}, \mathrm{C} 4 \mathrm{a}), 124.9(\mathrm{~d}, \mathrm{C} 4)$, $118.4(\mathrm{~s}, \mathrm{C} 1), 114.8(\mathrm{~s}, \mathrm{C} 8), 112.6(2 \times \mathrm{d}, \mathrm{C} 3, \mathrm{Cl} 1), 92.5$ $\left(t, \mathrm{OCH}_{2} \mathrm{O}\right), 84.9(\mathrm{~s}, \mathrm{C} 7), 65.6$ and $64.8\left(t, \mathrm{OCH}_{2} \mathrm{CH}_{2} \mathrm{O}\right), 57.1$ $(d, \mathrm{ClO}), 56.5\left(\mathrm{q}, \mathrm{ArOCH}_{3}\right), 55.2\left(\mathrm{q}, \mathrm{CH}_{2} \mathrm{OCH}_{3}\right), 52.7$ (t, C9), $51.8\left(2 \times \mathrm{q}_{2}, \mathrm{CO}_{2} \mathrm{CH}_{3}\right), 49.1(\mathrm{~s}, \mathrm{C} 9 \mathrm{a}), 38.7(t, \mathrm{Cll}), 35.2(t, \mathrm{C} 6)$.

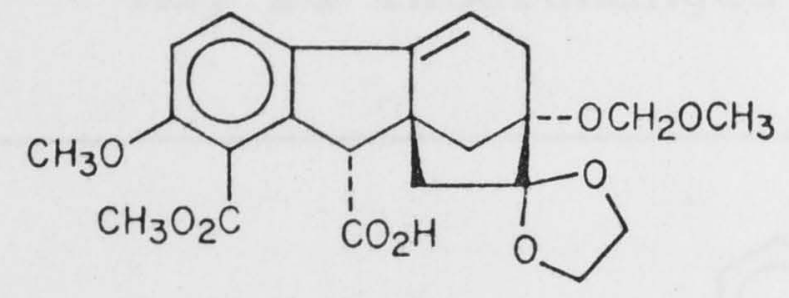

162

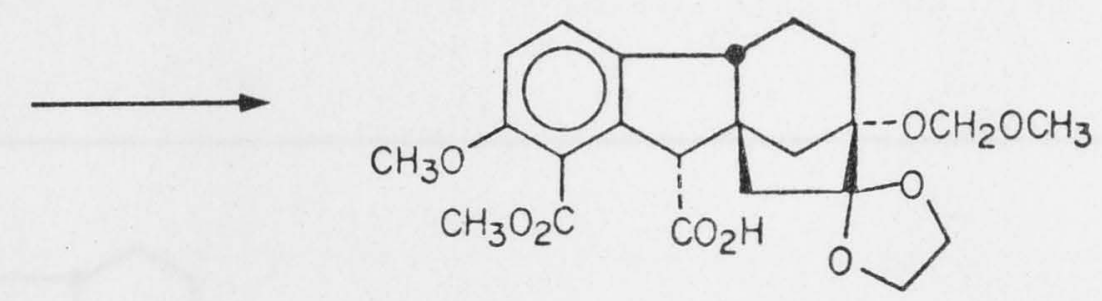

165

The acid $162(2.68 \mathrm{~g}, 6 \mathrm{mmol})$ in methanol (13 $\mathrm{ml}$ ) and ethyl acetate $(13 \mathrm{ml})$ was hydrogenated at atmospheric pressure over palladium on charcoal (10\%, $25 \mathrm{mg})$. After $16 \mathrm{hr}$ at room temperature the mixture was filtered through celite and the solvents removed. ( \pm$)(4 \mathrm{~b} \beta, 10 \alpha) 8,8$-ethylenedioxy2-methoxy-1-methoxycarbonyl-7-methoxymethyloxygibba-1,3, $\underline{4 a(10 a)-t r i e n e-10-c a r b o x y l i c ~ a c i d ~} 165(2.44 \mathrm{~g}, 91 \%)$ was obtained as a white powder.

M.p. $215^{\circ}$ (extensive sweating).

$\delta 8.68\left(\mathrm{bs}, 1 \mathrm{H}, \mathrm{CO}_{2} \mathrm{H}\right), 7.15(\mathrm{~d}, \mathrm{~J}=8 \mathrm{~Hz}, 1 \mathrm{H}, \mathrm{H} 4), 6.85(\mathrm{~d}, \mathrm{~J}=8 \mathrm{~Hz}, 1 \mathrm{H}$, $\mathrm{H} 3), 4.79$ and $4.61\left(\mathrm{ABq}, \mathrm{J}_{\mathrm{AB}}=7 \mathrm{~Hz}, 2 \mathrm{H}, \mathrm{OCH}_{2} \mathrm{CH}_{2} \mathrm{O}\right), 4.16(\mathrm{~s}, 1 \mathrm{H}, \mathrm{H} 10)$, $4.00\left(\mathrm{~s}, 4 \mathrm{H}, \mathrm{OCH}_{2} \mathrm{CH}_{2} \mathrm{O}\right), 3.82\left(\mathrm{~s}, 3 \mathrm{H}, \mathrm{ArOCH}_{3}\right), 3.80\left(\mathrm{~s}, 3 \mathrm{H}, \mathrm{ArCO}_{2} \mathrm{CH}_{3}\right)$, $3.27\left(\mathrm{~s}, 3 \mathrm{H}, \mathrm{CH}_{2} \mathrm{OCH}_{3}\right), 2.96(\mathrm{~m}, 1 \mathrm{H}, \mathrm{H} 4 \mathrm{~b}), 2.68(\mathrm{~d}, \mathrm{~J}=14 \mathrm{~Hz}, 1 \mathrm{H}, \mathrm{HIl})$, $2.53-1.65(\mathrm{~m}, 7 \mathrm{H})$.

$\nu_{\max } 1715-1690,1580 \mathrm{~cm}^{-1}$.

$\mathrm{m} / \mathrm{z} 448\left(3 \%, \mathrm{M}^{+}\right), 447(4), 417(8), 416(6), 404$ (12), 403 (58), $87(43), 73(33), 45(100)$.

$\mathrm{C}_{23} \mathrm{H}_{28} \mathrm{O}_{9} \quad \mathrm{Calcd}: \quad \mathrm{C}, 61.6 ; \mathrm{H}, 6.3$. Found: $\mathrm{C}, 61.5 ; \mathrm{H}, 6.2 \%$. 
$\delta\left({ }^{13} \mathrm{C}\right) 175.3\left(\mathrm{~s}, \mathrm{CO}_{2} \mathrm{H}\right), 167.0\left(\mathrm{~s}, \mathrm{CO}_{2} \mathrm{CH}_{3}\right), 157.3(\mathrm{~s}, \mathrm{C} 2)$, $140.9(\mathrm{~s}, \mathrm{ClOa}), 138.7(\mathrm{~s}, \mathrm{C} 4 \mathrm{a}), 125.4(\mathrm{~d}, \mathrm{C} 4), 119.3(\mathrm{~s}, \mathrm{Cl})$, $115.1(\mathrm{~s}, \mathrm{C} 8), 111.3(\mathrm{~d}, \mathrm{C} 3), 92.3\left(t, \mathrm{OCH}_{2} \mathrm{O}\right), 84.2(\mathrm{~s}, \mathrm{C} 7)$, 65.3 and $64.9\left(t, \mathrm{OCH}_{2} \mathrm{CH}_{2} \mathrm{O}\right), 57.4(\mathrm{~d}, \mathrm{ClO}), 56.5\left(\mathrm{q}, \mathrm{ArOCH}_{3}\right)$, $54.9\left(\mathrm{q}, \mathrm{CH}_{2} \mathrm{OCH}_{3}\right), 51.6\left(\mathrm{q}, \mathrm{CO}_{2} \mathrm{CH}_{3}\right), 51.0$ (C8)*, 50.6 (C9a) *, $45.7(t, C 9), 34.9(t, C 11), 30.3(t, C 6), 21.8(t, C 5)$.

* May be interchanged

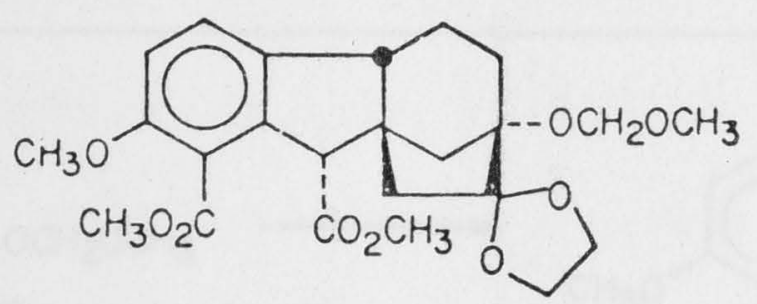

$\underline{166}$

(i) Ester $163(200 \mathrm{mg}, 0.43 \mathrm{mmol})$ was hydrogenated under the same conditiors as acid 162 to afford $( \pm)(4 \mathrm{~b} \beta, 10 \alpha)$ dimethyl 8,8-ethylenedioxy-2-methoxy-7-methoxymethyloxygibba$\underline{1,3,4 a(10 a)-t r i e n e-1,10-d i c a r b o x y l a t e ~} 166$ (199 mg, 99\%) as a colourless oil.

$\delta 7.08(\mathrm{~d}, \mathrm{~J}=8 \mathrm{~Hz}, 1 \mathrm{H}, \mathrm{H} 4), 6.80(\mathrm{~d}, \mathrm{~J}=8 \mathrm{~Hz}, 1 \mathrm{H}, \mathrm{H} 3), 4.70$ and 4.56 $\left(\mathrm{ABq}, \mathrm{J}_{\mathrm{AB}}=7 \mathrm{~Hz}, 2 \mathrm{H}, \mathrm{OCH}_{2} \mathrm{O}\right), 4.10(\mathrm{~s}, 1 \mathrm{H}, \mathrm{H} 6), 3.96\left(\mathrm{~s}, 4 \mathrm{H}, \mathrm{OCH}_{2} \mathrm{CH}_{2} \mathrm{O}\right)$, $3.81\left(\mathrm{~s}, 3 \mathrm{H}, \mathrm{ArOCH}_{3}\right), 3.72\left(\mathrm{~s}, 3 \mathrm{H}, \mathrm{ArCO}_{2} \mathrm{CH}_{3}\right), 3.67\left(\mathrm{~s}, 3 \mathrm{H}, \mathrm{CO}_{2} \mathrm{CH}_{3}\right)$, $3.25\left(\mathrm{~s}, 3 \mathrm{H}, \mathrm{CH}_{2} \mathrm{OCH}_{3}\right), 2.94(\mathrm{~m}, \mathrm{lH}, \mathrm{H} 4 \mathrm{~b}), 2.58(\mathrm{~d}, \mathrm{~J}=\mathrm{I} 4 \mathrm{~Hz}, 1 \mathrm{H}, \mathrm{HIl})$, $2.36-1.30(\mathrm{~m}, 7 \mathrm{H})$.

$v_{\max }(\mathrm{film}) \quad 1730-1710,1590 \mathrm{~cm}^{-1}$.

$\mathrm{m} / \mathrm{z} \quad 462\left(13 \%, \mathrm{M}^{+}\right), 417(100), 357(49), 87(33), 45$ (58).

$\mathrm{C}_{24} \mathrm{H}_{30} \mathrm{O}_{9} \quad$ H.r.m.s. Calcd: 462.1889 .

Found: 462.1884 .

$\delta\left({ }^{13} \mathrm{C}\right) \quad 171.0\left(\mathrm{~s}, \underline{\mathrm{CO}}_{2} \mathrm{CH}_{3}\right), 166.5\left(\mathrm{~s}, \mathrm{ArCO}_{2} \mathrm{CH}_{3}\right), 157.3(\mathrm{~s}, \mathrm{C} 2)$, $140.5(\mathrm{~s}, \mathrm{Cl} 0 \mathrm{a}), 138.6(\mathrm{~s}, \mathrm{C} 4 \mathrm{a}), 125.6(\mathrm{~d}, \mathrm{C} 4), 119.2(\mathrm{~s}, \mathrm{Cl})$, 
$114.9(\mathrm{~s}, \mathrm{C} 8), 92.3\left(t, \mathrm{OCH}_{2} \mathrm{O}\right), 84.0(\mathrm{~s}, \mathrm{C} 7), 65.2\left(2 \times t, \mathrm{OCH}_{2} \mathrm{CH}_{2} \mathrm{O}\right)$, $57.3(\mathrm{~d}, \mathrm{ClO}), 56.5\left(\mathrm{q}, \mathrm{ArOCH}_{3}\right), 55.1\left(\mathrm{q}, \mathrm{CH}_{2} \mathrm{OCH}_{-3}\right), 51.4(2 \times \mathrm{q}$, $\left.\mathrm{CO}_{2} \mathrm{CH}_{3}\right), 50.5(\mathrm{C} 8, \mathrm{C} 9 \mathrm{a}), 46.0(t, \mathrm{C} 9), 35.5(t, \mathrm{C} 11), 29.9(t, \mathrm{C} 6)$, $21.8(t, C 5)$.

(ii) To acid $165(20 \mathrm{mg})$ in dichloromethane $(3 \mathrm{ml})$ was added diazomethane (excess) in ether. Evaporation of the solvent gave diester 166 in quantitative yield (t.1.c. and $l_{\text {H n.m.r. analysis). }}$.

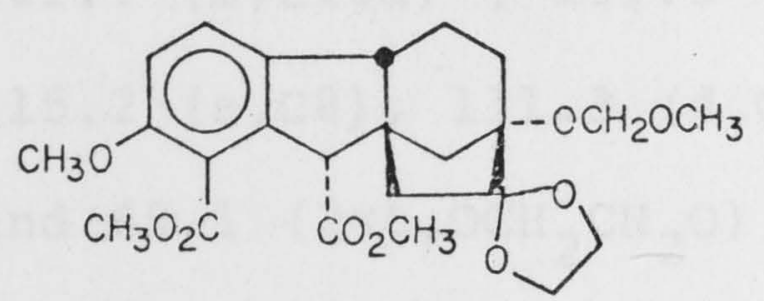

166

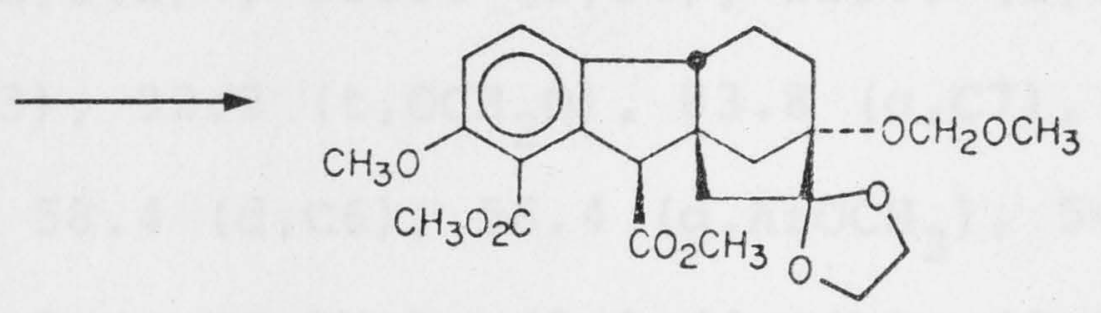

170

Diester 166 (116 $\mathrm{mg}, 0.25 \mathrm{mmol}$ ) in methanol (2 $\mathrm{ml}$ ) was added to a solution of sodium methoxide (from $100 \mathrm{mg}$ sodium) in methanol $(3 \mathrm{ml})$ and the resulting mixture heated at reflux for $16 \mathrm{hr}$. The solvent was removed, saturated aqueous sodium dihydrogenphosphate $(10 \mathrm{ml})$ and dichloromethane $(30 \mathrm{ml})$ added and the layers separated. The organic portion was washed with brine $(20 \mathrm{ml})$, dried and treated with an excess of ethereal diazomethane. Removal of the solvent gave an oil $(103 \mathrm{mg}$ ) which was a 2:1 mixture of diesters 170 and 166 ( ${ }^{1} \mathrm{H}$ n.m.r. analysis). Chromatography (p.l.c., 2\% methanoldichloromethane) afforded starting material 166 (26 mg, 22\%) and $( \pm)(4 \mathrm{~b} \beta, 10 \beta)$ dimethyl 8,8-ethylenedioxy-2-methoxy-7methoxymethyloxygibba-1,3,4a(10a)-triene-1,10-dicarboxylate $170(47 \mathrm{mg}, 41 \%)$ as a colourless oil. 
$\delta .7 .16(\mathrm{~d}, \mathrm{~J}=9 \mathrm{~Hz}, 1 \mathrm{H}, \mathrm{H} 4), 6.82(\mathrm{~d}, \mathrm{~J}=9 \mathrm{~Hz}, 1 \mathrm{H}, \mathrm{H} 3), 4.82$ and 4.56 $\left(\mathrm{ABq}, \mathrm{J}_{\mathrm{AB}}=7 \mathrm{~Hz}, 2 \mathrm{H}, \mathrm{OCH}_{2} \mathrm{O}\right), 3.98\left(\mathrm{bs}, 4 \mathrm{H}, \mathrm{OCH}_{2} \mathrm{CH}_{2} \mathrm{O}\right), 3.85(\mathrm{~s}, 6 \mathrm{H}$, $\left.\mathrm{ArCO}_{2} \mathrm{CH}_{3}, \mathrm{ArOCH}_{3}\right), 3.78(\mathrm{~s}, 1 \mathrm{H}, \mathrm{H} 6), 3.64\left(\mathrm{~s}, 3 \mathrm{H}, \mathrm{CO}_{2} \mathrm{CH}_{3}\right), 3.37$ $(\mathrm{m}, 1 \mathrm{H}, \mathrm{H} 4 \mathrm{~b}), 3.29\left(\mathrm{~s}, 3 \mathrm{H}, \mathrm{CH}_{2} \mathrm{OCH}_{3}\right), 2.56-1.36(\mathrm{~m}, 8 \mathrm{H})$. $\nu_{\max }\left(\mathrm{CH}_{2} \mathrm{Cl}_{2}\right) \quad 1730-1710,1580 \mathrm{~cm}^{-1}$. $\mathrm{m} / \mathrm{z} \quad 462\left(13 \%, \mathrm{M}^{+}\right), 417(100), 357(15)$.

$\mathrm{C}_{24} \mathrm{H}_{30} \mathrm{O}_{9} \quad$ H.r.m.s. Calcd: 462.1889 .

Found: 462.1884 .

$\delta\left({ }^{13} \mathrm{C}\right) \quad 171.7\left(\mathrm{~s}, \underline{\mathrm{CO}}_{2} \mathrm{CH}_{3}\right), 166.4\left(\mathrm{~s}, \mathrm{ArCO}_{2} \mathrm{CH}_{3}\right), 157.0(\mathrm{~s}, \mathrm{C} 2)$, $141.7(\mathrm{~s}, \mathrm{ClOa})^{*}, 139.5(\mathrm{~s}, \mathrm{C} 4 \mathrm{a})^{*}, 126.0(\mathrm{~d}, \mathrm{C} 4), 119.0(\mathrm{~s}, \mathrm{Cl})$, $115.2(\mathrm{~s}, \mathrm{C} 8), 111.3(\mathrm{~d}, \mathrm{C} 3), 92.2\left(\mathrm{t}, \mathrm{OCH}_{2} \mathrm{O}\right), 83.8(\mathrm{q}, \mathrm{C} 7), 65.5$ and $65.1\left(2 \times t, \mathrm{OCH}_{2} \mathrm{CH}_{2} \mathrm{O}\right), 58.4(\mathrm{~d}, \mathrm{C} 6), 56.4\left(\mathrm{q}, \mathrm{ArOCH}_{3}\right), 54.9$ $\left(\mathrm{q}, \mathrm{CH}_{2} \mathrm{OCH}_{3}\right), 51.7$ and $51.2\left(\mathrm{q}, \mathrm{CO}_{2} \mathrm{CH}_{3}\right), 48.0(\mathrm{~d}, \mathrm{C} 4 \mathrm{~b}), 43.8$ $(t, C 9), 41.3(t, C 11), 31.2(t, C 6), 20.8(t, C 5)$.

* May be interchanged.

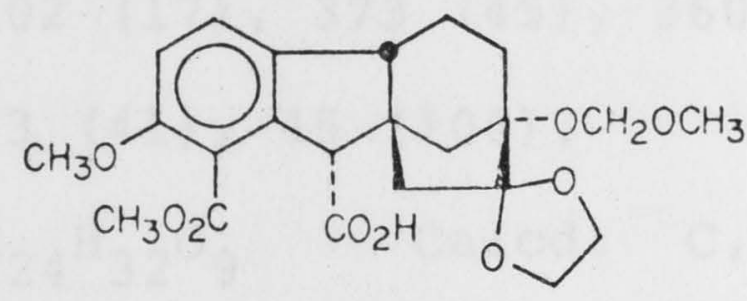

$\underline{165}$

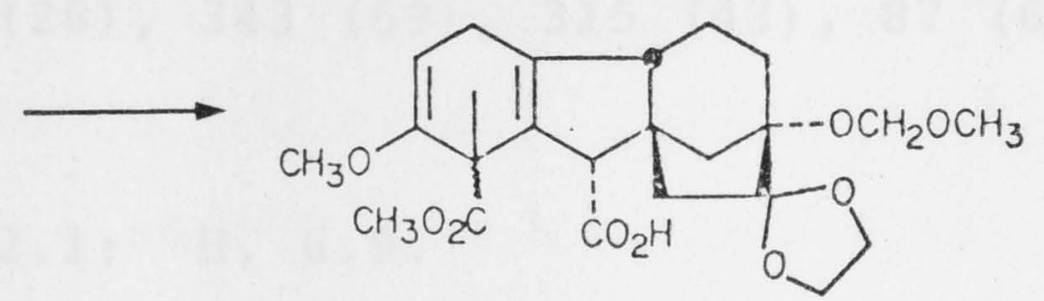

$\underline{171} \cong 4 \mathrm{a}-\mathrm{CO}_{2} \mathrm{CH}_{3}$

To the ester $165(896 \mathrm{mg}, 2 \mathrm{mmol})$ in THF $(40 \mathrm{ml})$ at $20^{\circ}$ was added potassium $t$-butoxide $(224 \mathrm{mg}, 2 \mathrm{mmol})$. After $30 \mathrm{~min}$. ammonia (distilled off sodium amide, $400 \mathrm{ml}$ ) was condensed into the reaction flask. To the resulting solution at $-78^{\circ}$ was added potassium ( $195 \mathrm{mg}, 5 \mathrm{mmol}$ ) in small pieces until a persistent blue colour was obtained (20 min). Methyl iodide $(1.25 \mathrm{ml}, 20 \mathrm{mmol})$ was introduced over $3 \mathrm{~min}$. and the mixture allowed to reach $-33^{\circ}$. After addition of 
ammonium chloride ( $\sim \mathrm{l} g$ ) the ammonia was evaporated with a stream of nitrogen. Water $(50 \mathrm{ml})$ was added, extracted with ether $(2 \times 50 \mathrm{ml})$ and saturated with sodium dihydrogenphosphate $(\mathrm{pH} 5)$. Extraction with dichloromethane $(3 \times 50 \mathrm{ml})$, drying of the organic portion and solvent removal afforded ( \pm ) $(1 \alpha, 4 \mathrm{~b} \beta, 10 \alpha) 8,8$-ethylenedioxy-2-methoxy-1-methoxycarbonyl7-methoxymethyloxy-1-methylgibba-2,4a(10a)-diene-10-carboxylic acid $171 \mathrm{a}(780 \mathrm{mg}, 84 \%)$ as white crystals.

M.p. $170-172^{\circ}$ (dichloromethane-ether).

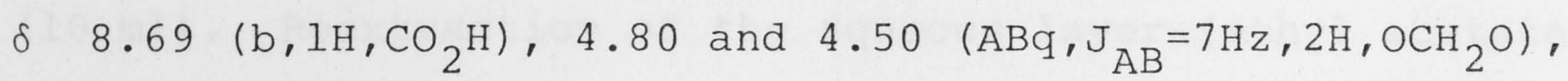

$4.76(t, \mathrm{~J}=4 \mathrm{~Hz}, 1 \mathrm{H}, \mathrm{H} 3), 3.97\left(\mathrm{bs}, 4 \mathrm{H}, \mathrm{OCH}_{2} \mathrm{CH}_{2} \mathrm{O}\right), 3.66(\mathrm{~s}, 1 \mathrm{H}, \mathrm{HlO})$,

$3.64\left(\mathrm{~s}, 3 \mathrm{H}, \mathrm{CO}_{2} \mathrm{CH}_{3}\right), 3.52\left(\mathrm{~s}, 3 \mathrm{H}, \mathrm{C}=\mathrm{COCH}_{3}\right), 3.33\left(\mathrm{~s}, 3 \mathrm{H}, \mathrm{CH}_{2} \mathrm{OCH}_{3}\right)$,

2.91 and $2.62\left(\mathrm{ABq}, \mathrm{J}_{\mathrm{AB}}=16 \mathrm{~Hz}, 2 \mathrm{H}, \mathrm{H} 4\right), 2.56-1.28(\mathrm{~m}, 9 \mathrm{H}), 1.39$ $\left(\mathrm{s}, 3 \mathrm{H}, \mathrm{CH}_{3}\right)$.

$\nu_{\max } 1725,1710,1685,1650 \mathrm{~cm}^{-1}$.

$\mathrm{m} / \mathrm{z} \quad 464\left(18 \%, \mathrm{M}^{+}\right), 463(4), 433(7), 432(8), 419(40), 405$ (19), $402(17), 373(45), 360(28), 343(69), 315(43), 87$ (60), $73(41), 45(100)$.

$\mathrm{C}_{24} \mathrm{H}_{32} \mathrm{O}_{9} \quad$ Calcd: C,62.1; H, 6.9. Found: $\mathrm{C}, 62.0 ; \mathrm{H}, 6.9 \%$.

$\delta\left({ }^{13} \mathrm{C}\right) 174.5\left(\mathrm{~s}, \mathrm{CO}_{2} \mathrm{H}\right){ }^{*}, 173.6\left(\mathrm{~s}, \mathrm{CO}_{2} \mathrm{CH}_{3}\right)^{*}, 156.2(\mathrm{~s}, \mathrm{C} 2)$, $139.9(\mathrm{~s}, \mathrm{C} 4 \mathrm{a}), 129.7(\mathrm{~s}, \mathrm{ClOa}), 115.2(\mathrm{~s}, \mathrm{C} 8), 92.6\left(\mathrm{t}, \mathrm{OCH}_{2} \mathrm{O}\right)$, $90.6(d, C 3), 84.4(s, C 7), 65.1\left(2 \times t, \mathrm{OCH}_{2} \mathrm{CH}_{2} \mathrm{O}\right), 57.0(\mathrm{~d}, \mathrm{ClO})$, $55.2\left(\mathrm{q}, \mathrm{C}=\mathrm{COCH}_{3}\right), 54.8\left(\mathrm{q}, \mathrm{CH}_{2} \mathrm{OCH}_{3}\right), 52.5\left(\mathrm{q}, \mathrm{CO}_{2} \mathrm{CH}_{3}\right), 48.8$ (s, $\mathrm{C} 9 \mathrm{a}$ and/or Cl) $48.6(\mathrm{C} 4 \mathrm{~b})^{* *}, 46.6(\mathrm{C} 9)^{* *}, 33.9(\mathrm{t}, \mathrm{Cll}), 29.1$ $(t, \mathrm{C} 6), 24.2(t, \mathrm{Cl}), 21.9(t, \mathrm{C} 5), 20.5\left(\mathrm{q}, \mathrm{CH}_{3}\right)$. 


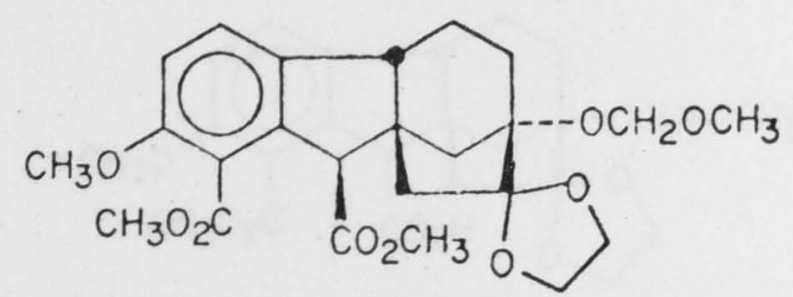

170

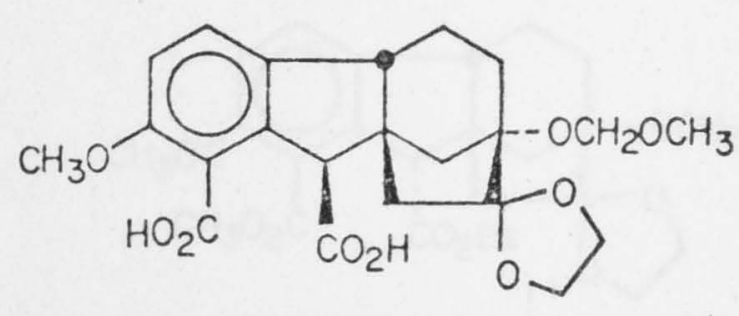

173

(i) Diester $170(46 \mathrm{mg}, 0.1 \mathrm{mmol})$ and potassium hydroxide (56 $\mathrm{mg}, 1 \mathrm{mmol}$ ) in THF (2 ml), methanol (l $\mathrm{ml}$ ) and water $(0.3 \mathrm{ml})$ were heated at reflux for $1.5 \mathrm{hr}$. The solvent was removed and the residue partitioned between saturated aqueous sodium dihydrogenphosphate $(5 \mathrm{ml})$ and ethyl acetate $(10 \mathrm{ml})$. Reextraction of the aqueous layer (ethyl acetate $2 \times 10 \mathrm{ml})$, drying of the combined organic portion and solvent removal gave after crystallisation $( \pm)(4 \mathrm{~b} B, 10 \beta) 8,8$-ethylenedioxy-2-methoxy-7-methoxymethyloxygibba-1,3,4a (10a)-triene1,10-dicarboxylic acid $173(29 \mathrm{mg}, 67 \%)$ as a white solid. M.p. $226-227.5^{\circ}$ (THF-ether).

$\delta\left(\mathrm{CDCl}_{3} / \mathrm{d}_{6}-\mathrm{DMSO}\right) \quad 8.00\left(\mathrm{~b}, 2 \mathrm{H}, \mathrm{CO}_{2} \mathrm{H}\right), 7.18(\mathrm{~d}, \mathrm{~J}=9 \mathrm{~Hz}, 1 \mathrm{H}, \mathrm{H} 4)$, $6.92(\mathrm{~d}, \mathrm{~J}=9 \mathrm{~Hz}, 1 \mathrm{H}, \mathrm{H} 3), 4.81$ and $4.59\left(\mathrm{ABq}, \mathrm{J}_{\mathrm{AB}}=7 \mathrm{~Hz}, 2 \mathrm{H}, \mathrm{OCH}_{2} \mathrm{O}\right)$, $4.04\left(\mathrm{~s}, 4 \mathrm{H}, \mathrm{OCH}_{2} \mathrm{CH}_{2} \mathrm{O}\right), 4.01\left(\mathrm{~s}, 3 \mathrm{H}, \mathrm{ArOCH}_{3}\right), 3.72$ ( $\left., 1 \mathrm{H}, \mathrm{H} 10\right)$, $3.37(\mathrm{~m}, 1 \mathrm{H}, \mathrm{H} 4 \mathrm{~b}), 3.28\left(\mathrm{~s}, 3 \mathrm{H}, \mathrm{CH}_{2} \mathrm{OCH}_{-3}\right), 2.58-1.28(\mathrm{~m}, 8 \mathrm{H})$. $\nu_{\max } 3200,1725,1700,1585 \mathrm{~cm}^{-1}$. $\mathrm{m} / \mathrm{z} \quad 434\left(26 \%, \mathrm{M}^{+}\right), 433(88), 390(26), 389(100), 372(26)$, $371(54), 344(49)$.
$\mathrm{C}_{22}{ }^{\mathrm{H}} 26^{\mathrm{O}} 9$
Calcd: C, 60.8; H, 6.0.
Found: $\mathrm{C}, 60.5 ; \mathrm{H}, 6.0 \%$

(ii) Ester $170(23 \mathrm{mg}, 0.05 \mathrm{mmol})$ was treated in the same way as above for $40 \mathrm{hr}$ at $20^{\circ}$. Diacid 173 (12 $\mathrm{mg}, 55 \%$ ) was again the major product. 


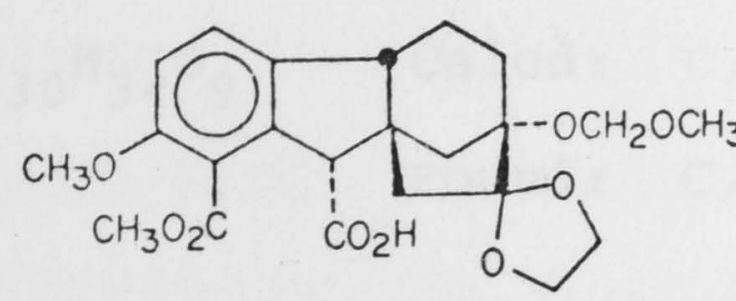

$\underline{165}$

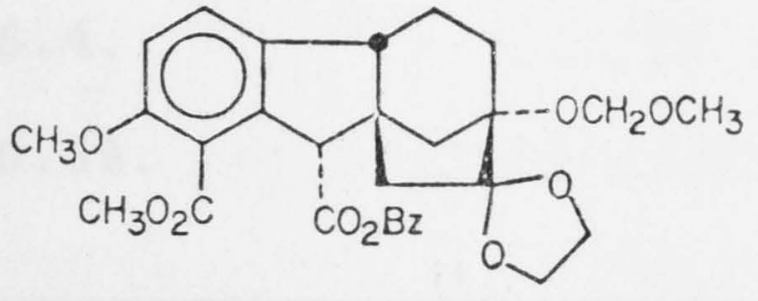

$\underline{174}$

Benzyl bromide $(0.18 \mathrm{ml}, 1.5 \mathrm{mmol})$ was added to a mixture of acid $\underline{165}(224 \mathrm{mg}, 0.5 \mathrm{mmol})$ and potassium carbonate $(207 \mathrm{mg}, 1.5 \mathrm{mmol})$ in $\operatorname{DMF}(0.5 \mathrm{ml})$. Stirring at room temperature was continued for $16 \mathrm{hr}$, triethylamine $(0.21 \mathrm{ml}$, 1.5 mmol) was added (to destroy the excess benzyl bromide), and the mixture stirred for another $2 \mathrm{hr}$. Water (20 ml) and ether $(30 \mathrm{ml})$ were added and the layers separated. The aqueous phase was reextracted (ether, $2 \times 20 \mathrm{ml}$ ) and the organic portions washed with cold $0.5 \mathrm{~N}$ hydrochloric acid $(2 \times 20 \mathrm{ml})$, water $(2 \times 10 \mathrm{ml})$ and brine $(20 \mathrm{ml})$. The solvent was evaporated and the crude product crystallised (from dichloromethane-petroleum ether) to leave $( \pm)(4 \mathrm{~b} \beta, 10 \alpha)$ benzyl 8,8-ethylenedioxy-2-methoxy-1-methoxycarbonyl-7methoxymethyloxygibba-1,3,4a(10a)-triene-10-carboxylate 174 $(227 \mathrm{mg}, 86 \%)$ as colourless crystals.

M.p. $\quad 127-129^{\circ}$.

$\delta 7.35(\mathrm{~m}, 5 \mathrm{H}, \mathrm{ArH}), 7.14(\mathrm{~d}, \mathrm{~J}=8 \mathrm{~Hz}, 1 \mathrm{H}, \mathrm{H} 4), 6.86(\mathrm{~d}, \mathrm{~J}=8 \mathrm{~Hz}, 1 \mathrm{H}$, $\mathrm{H} 3), 5.19$ and $5.12\left(\mathrm{ABq}, \mathrm{J}_{\mathrm{AB}}=12 \mathrm{~Hz}, 2 \mathrm{H}, \mathrm{CO}_{2} \mathrm{CH}_{2} \mathrm{Ph}\right), 4.63$ and 4.55 $\left(\mathrm{ABq}, \mathrm{J}_{\mathrm{AB}}=7 \mathrm{~Hz}, 2 \mathrm{H}, \mathrm{OCH}_{2} \mathrm{O}\right), 4.18(\mathrm{~s}, 1 \mathrm{H}, \mathrm{HIO}), 3.96\left(\mathrm{~m}, 4 \mathrm{H}, \mathrm{OCH}_{2} \mathrm{CH}_{2} \mathrm{O}\right)$, $3.83\left(\mathrm{~s}, 3 \mathrm{H}, \mathrm{ArOCH}_{3}\right), 3.68\left(\mathrm{~s}, 3 \mathrm{H}, \mathrm{CO}_{2} \mathrm{CH}_{3}\right), 3.23\left(\mathrm{~s}, 3 \mathrm{H}, \mathrm{CH}_{2} \mathrm{OCH}_{3}\right)$, $2.89(\mathrm{~m}, 1 \mathrm{H}, 4 \mathrm{Hb}), 2.63(\mathrm{~d}, \mathrm{~J}=14 \mathrm{~Hz}, 1 \mathrm{H}, \mathrm{Hll}), 2.46-1.28(\mathrm{~m}, 7 \mathrm{H})$. $\nu_{\max } 1725,1700,1595,1585 \mathrm{~cm}^{-1}$. $\mathrm{m} / \mathrm{z}$ (base peak 91; > $91 \mathrm{rel}$. 493) $538\left(12 \%, \mathrm{M}^{+}\right), 494$ (30), 493. (100), $357(32)$. 


$$
\begin{array}{lll}
\mathrm{C}_{30} \mathrm{H}_{34} \mathrm{O}_{9} & \text { Calcd: } & \mathrm{C}, 66.9 ; \mathrm{H}, 6.4 . \\
& \text { Found: } \mathrm{C}, 67.0 ; \mathrm{H}, 6.3 \%
\end{array}
$$

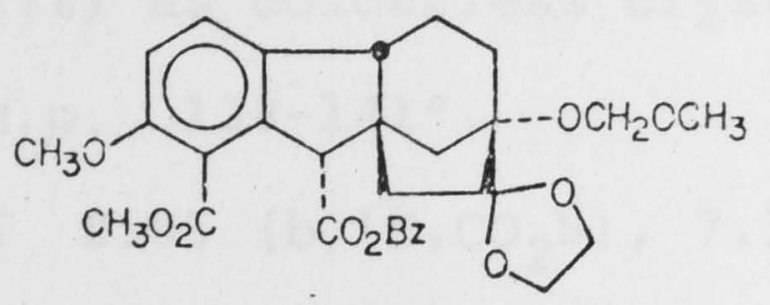

174

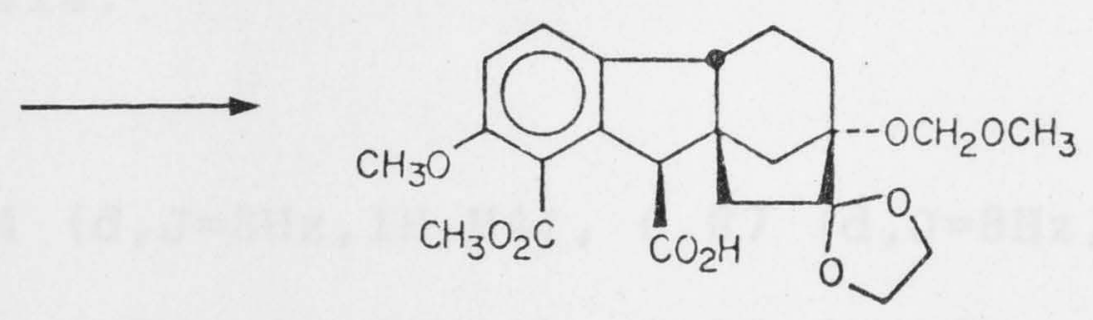

172

Ester $174(200 \mathrm{mg}, 0.37 \mathrm{mmol})$ was dissolved in 1,5-diazabicyclo |4.3.0|non-5-ene $(1 \mathrm{ml})$. After standing at room temperature for $16 \mathrm{hr}$, a 2:1 equilibrium mixture of $\beta$-ester 175 and ester 174 was reached (same ratio after additional $24 \mathrm{hr}$ ). Water $(10 \mathrm{ml})$ and dichloromethane $(10 \mathrm{ml})$ were added, the layers separated and the aqueous portion reextracted (dichloromethane, $2 \times 10 \mathrm{ml}$ ). The organic layers were washed with cold $0.5 \mathrm{~N}$ hydrochloric acid $(10 \mathrm{ml})$, water (10 ml), brine $(10 \mathrm{ml})$ and dried. Evaporation of the solvent left a yellowish oil (174 mg, 87\%) which was homogeneous by t.l.c. (2\% methanol-dichloromethane; 50\% ethyl acetate-ether). The $l_{H}$ n.m.r. spectrum of the mixture had the following peaks in addition to those from 174: $\delta 7.30$ ( $\mathrm{s}, \mathrm{ArH}), 7.19(\mathrm{~d}, \mathrm{~J}=8 \mathrm{~Hz}$, $\mathrm{HI}), 5.08\left(\mathrm{~s}, \mathrm{CO}_{2} \mathrm{CH}_{2} \mathrm{Ph}\right), 4.84$ and $4.53\left(\mathrm{ABq}, \mathrm{J}_{\mathrm{AB}}=7 \mathrm{~Hz}, \mathrm{OCH}_{2} \mathrm{O}\right)$, $3.66\left(\mathrm{~s}, \mathrm{CO}_{2} \mathrm{CH}_{3}\right), 3.35(\mathrm{~m}, \mathrm{H} 4 \mathrm{~b}), 3.26\left(\mathrm{~s}, \mathrm{CH}_{2} \mathrm{O} \mathrm{CH}_{3}\right)$. The mixture of esters 174 and $\underline{175}(174 \mathrm{mg}, 0.32 \mathrm{mmol})$ in methyl acetate $(4 \mathrm{ml})$ and methanol (4 ml) was hydrogenated over palladium on charcoal (10\%, $5 \mathrm{mg}$ ) at atmospheric pressure. After $16 \mathrm{hr}$ at room temperature the mixture was filtered (Celite) and the solvents removed. Chromatography (p.I.c., 7\% methanol-dichloromethane) of the resulting 
mixture (160 mg) gave acid 165 (30 $\mathrm{mg}, 21 \%)$ and $( \pm)(4 \mathrm{~b} \beta, 10 \beta)$ 8,8-ethylenedioxy-2-methoxy-1-methoxycarbonyl-7-methoxymethyloxygibba-1,3,4a(10a)-triene-10-carboxylic acid 172 (67 mg, 47\%) as colourless crystals.

M.p. $\quad 138-141^{\circ}$.

$\delta \quad 8.85\left(\mathrm{~b}, 1 \mathrm{H}, \mathrm{CO}_{2} \mathrm{H}\right), 7.14(\mathrm{~d}, \mathrm{~J}=8 \mathrm{~Hz}, 1 \mathrm{H}, \mathrm{H} 4), 6.87(\mathrm{~d}, \mathrm{~J}=8 \mathrm{~Hz}, 1 \mathrm{H}$, $\mathrm{H} 3), 4.85$ and $4.57\left(\mathrm{ABq}, \mathrm{J}_{\mathrm{AB}}=7 \mathrm{~Hz}, 2 \mathrm{H}, \mathrm{OCH}_{2} \mathrm{O}\right), 3.98$ (bs, $4 \mathrm{H}$, $\left.\mathrm{OCH}_{2} \mathrm{CH}_{2} \mathrm{O}\right), 3.85\left(\mathrm{~s}, 6 \mathrm{H}, \mathrm{ArCO}_{2} \mathrm{CH}_{3}, \mathrm{ArOCH}_{3}\right), 3.73(\mathrm{~s}, 1 \mathrm{H}, \mathrm{HlO})$, $3.35(\mathrm{~m}, \mathrm{lH}, \mathrm{H} 4 \mathrm{~b}), 3.29\left(\mathrm{~s}, 3 \mathrm{H}, \mathrm{CH}_{2} \mathrm{OCH}_{3}\right), 2.46(\mathrm{~d}, \mathrm{~J}=14 \mathrm{~Hz}, 1 \mathrm{H}, \mathrm{Hll})$, $2.40-1.45(\mathrm{~m}, 7 \mathrm{H})$.

$\nu_{\max } 1725,1590 \mathrm{~cm}^{-1}$.

$\mathrm{m} / \mathrm{z} \quad 448\left(15 \%, \mathrm{M}^{+}\right), 447(16), 417(8), 403(67), 372(28)$, $371(100), 343(37), 241(60)$.

$\mathrm{C}_{23} \mathrm{H}_{28}{ }^{\mathrm{O}} 9 \quad$ H.r.m.s. Cacld: 448.1733 .

Found: $\quad 448.1726$.

$\delta\left({ }^{13} \mathrm{C}\right) 175.6\left(\mathrm{~s}, \mathrm{CO}_{2} \mathrm{H}\right), 166.9\left(\mathrm{~s}, \underline{\mathrm{CO}}_{2} \mathrm{CH}_{3}\right), 157.4(\mathrm{~s}, \mathrm{C} 2)$, $141.8(\mathrm{~s}, \mathrm{Cl0a}), 139.7(\mathrm{~s}, \mathrm{C} 4 \mathrm{a}), 126.4(\mathrm{~d}, \mathrm{C} 4), 119.0(\mathrm{~s}, \mathrm{Cl})$, $115.3(\mathrm{~s}, \mathrm{C} 8), 111.8(\mathrm{~d}, \mathrm{C} 3), 92.2\left(t, \mathrm{OCH}_{2} \mathrm{O}\right), 65.5$ and 65.1 ( $t$, $\left.\mathrm{OCH}_{2} \mathrm{CH}_{2} \mathrm{O}\right), 58.4(\mathrm{~d}, \mathrm{C} 6), 56.5\left(\mathrm{q}, \mathrm{ArOCH}_{3}\right), 55.1\left(\mathrm{q}, \mathrm{CH}_{2} \mathrm{OCH}_{3}\right)$, $51.9\left(\mathrm{q}, \mathrm{CO}_{2} \mathrm{CH}_{3}\right), 51.6(\mathrm{~s}, \mathrm{C} 9 \mathrm{a}), 47.9(\mathrm{~d}, \mathrm{C} 4 \mathrm{~b}), 43.9(\mathrm{t}, \mathrm{C} 9)$, $41.6(t, \mathrm{Cl}), 31.3(t, \mathrm{C} 6), 20.9(t, \mathrm{C} 5)$.

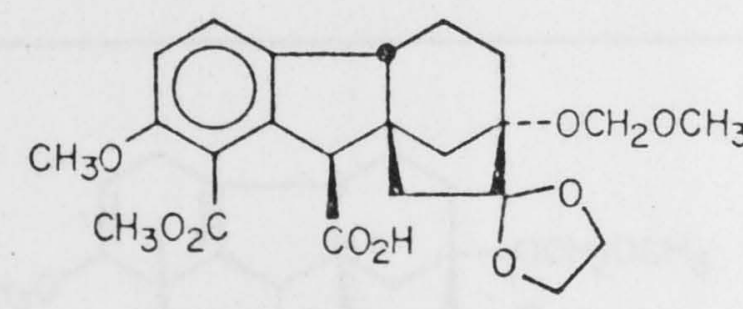

172
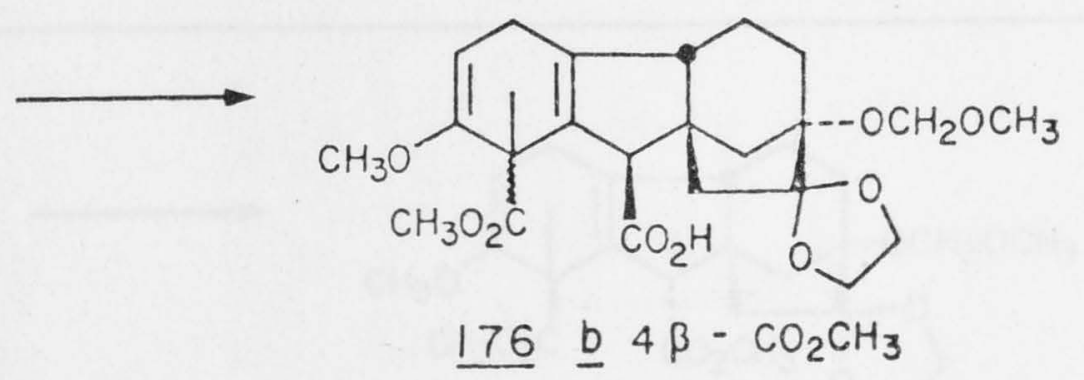

Ester acid $172(45 \mathrm{mg}, 0.1 \mathrm{mmol})$ was reduced and methylated 
as described for ester acid $\underline{165}$ to give ( \pm ) $(1 \beta, 4 b \beta, 10 \beta)$ 8,8-ethylenedioxy-2-methoxy-1-methoxycarbonyl-7-

methoxymethyloxy-1-methylgibba-2,4a(10a)-diene-10-carboxylic acid $176 \mathrm{~b} \quad(35 \mathrm{mg}, 75 \%$ ) after crystallisation from dichloromethane-petroleum ether.

M.p. $\quad 142-144^{\circ}$.

$\delta 9.30\left(\mathrm{~b}, 1 \mathrm{H}, \mathrm{CO}_{2} \mathrm{H}\right), 4.78$ and $4.61\left(\mathrm{ABq}, \mathrm{J}_{\mathrm{AB}}=7 \mathrm{~Hz}, 2 \mathrm{H}, \mathrm{OCH}_{2} \mathrm{O}\right)$, $4.76(t, J=4 \mathrm{~Hz}, 1 \mathrm{H}, \mathrm{H} 3), 3.97\left(\mathrm{bs}, 4 \mathrm{H}, \mathrm{OCH}_{2} \mathrm{CH}_{2} \mathrm{O}\right), 3.54(\mathrm{~s}, 6 \mathrm{H}$, $\left.\mathrm{CO}_{2} \mathrm{CH}_{3}, \mathrm{C}=\mathrm{COCH}_{3}\right), 3.34\left(\mathrm{~s}, 3 \mathrm{H}, \mathrm{CH}_{2} \mathrm{OCH}_{3}\right), 3.28(\mathrm{~s}, 1 \mathrm{H}, \mathrm{H} 10)$, $2.79(\mathrm{e}, 2 \mathrm{H}, \mathrm{H} 4), 2.58-1.10(\mathrm{~m}, 9 \mathrm{H}), 1.46\left(\mathrm{~s}, 3 \mathrm{H}, \mathrm{CH}_{3}\right)$. $\nu_{\max } 1730,1700,1690,1650 \mathrm{~cm}^{-1}$. $\mathrm{m} / \mathrm{z} \quad 464\left(65 \%, \mathrm{M}^{+}\right), 434$ (11), $419(35), 405$ (42), 373 (34), $359(81), 343(100), 331(88), 301(96), 227$ (81).

$\mathrm{C}_{24} \mathrm{H}_{32} \mathrm{O}_{9} \quad$ H.r.m.s. Calcd: 464.2046 . Found: 464.2035 .

$\delta\left({ }^{13} \mathrm{C}\right) \quad 173.5\left(2 \times \mathrm{s}, \mathrm{CO}_{2} \mathrm{H}, \underline{\mathrm{CO}}_{2} \mathrm{CH}_{3}\right), 155.7(\mathrm{~s}, \mathrm{C} 2), 141.5(\mathrm{~s}, \mathrm{C} 4 \mathrm{a})$, $131.8(\mathrm{~s}, \mathrm{ClOa}), 115.4(\mathrm{~s}, \mathrm{C} 8), 92.5\left(t, \mathrm{OCH}_{2} \mathrm{O}\right), 91.6(\mathrm{~d}, \mathrm{C} 3)$, $83.6(\mathrm{~s}, \mathrm{C} 7), 65.3$ and $65.1\left(t, \mathrm{OCH}_{2} \mathrm{CH}_{2} \mathrm{O}\right), 55.2\left(\mathrm{q}, \mathrm{C}=\mathrm{COCH}_{3}\right)$, $54.9\left(\mathrm{q}, \mathrm{CH}_{2} \mathrm{OCH}_{3}\right), 53.1(\mathrm{~d}, \mathrm{ClO}), 52.3\left(\mathrm{q}, \mathrm{CO}_{2} \mathrm{CH}_{3}\right), 48.8$ $(\mathrm{s}, \mathrm{C} 9 \mathrm{a})^{*}, 48.3(\mathrm{~s}, \mathrm{Cl})^{*}, 44.8(t, \mathrm{C} 9), 39.2(t, \mathrm{Cll}), 30.3(t$, $\mathrm{Cl} 2), 24.5(\mathrm{t}, \mathrm{C} 4), 21.4\left(\mathrm{q}+\mathrm{t}, \mathrm{CH}_{3}, \mathrm{C} 5\right)$.

* May be interchanged.

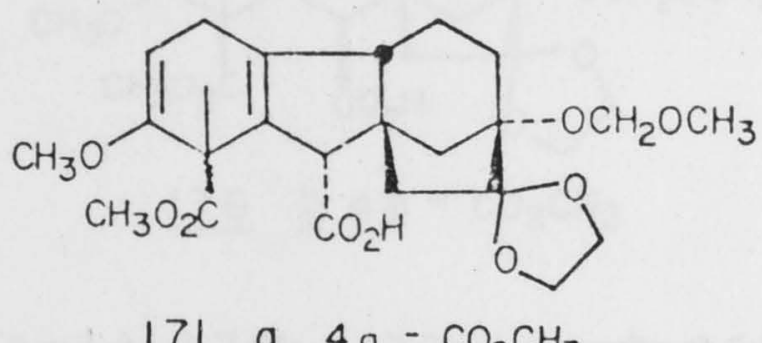

$\underline{171}$ a $4 \mathrm{a}-\mathrm{CO}_{2} \mathrm{CH}_{3}$

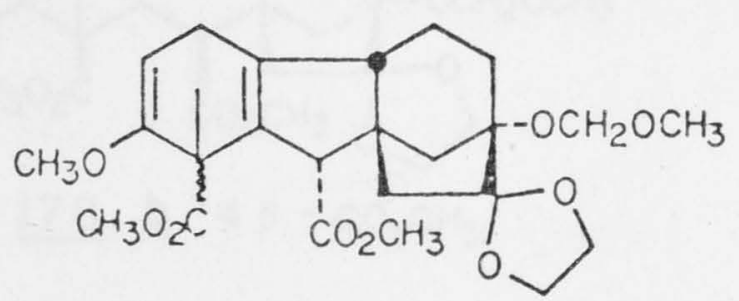

$177 \cong 4 \mathrm{a}-\mathrm{CO}_{2} \mathrm{CH}_{3}$ 
To acid 17la (100 mg, $0.24 \mathrm{mmol})$ in dichloromethane (5 ml) at $0^{\circ}$ was added diazomethane ( $\left.0.5 \mathrm{mmol}\right)$ in ether $(3 \mathrm{ml})$. After standing $1 \mathrm{hr}$ at room temperature the solvents were removed to leave $( \pm)(1 \alpha, 4 \mathrm{~b} \beta, 10 \alpha)$ dimethyl 8,8-ethylenedioxy-2methoxy-7-methoxymethyloxy-1-methylgibba-2,4a(10a)-diene-1,10dicarboxylate $177 \mathrm{a}$ (100 mg, 97\%) as a colourless oil.

$\delta \quad 4.80$ and $4.67\left(\mathrm{ABq}, \mathrm{J}_{\mathrm{AB}}=7 \mathrm{~Hz}, 2 \mathrm{H}, \mathrm{OCH}_{2} \mathrm{O}\right), 4.76(t, \mathrm{~J}=4 \mathrm{~Hz}, 1 \mathrm{H}, \mathrm{H} 3)$, $3.98\left(\mathrm{bs}, 4 \mathrm{H}, \mathrm{OCH}_{2} \mathrm{CH}_{2} \mathrm{O}\right), 3.66\left(\mathrm{~s}, 4 \mathrm{H}, \mathrm{HIO}, \mathrm{CO}_{2} \mathrm{CH}_{3}\right), 3.64(\mathrm{~s}, 3 \mathrm{H}$, $\left.\mathrm{CO}_{2} \mathrm{CH}_{3}\right), 3.51\left(\mathrm{~s}, 3 \mathrm{H}, \mathrm{C}=\mathrm{COCH}_{3}\right), 3.34\left(\mathrm{~s}, 3 \mathrm{H}, \mathrm{CH}_{2} \mathrm{OCH}_{3}\right), 2.92$ and $2.62\left(\mathrm{ABq}, \mathrm{J}_{\mathrm{AB}}=16 \mathrm{~Hz}, 2 \mathrm{H}, \mathrm{H} 4\right), 2.53-1.23(\mathrm{~m}, 9 \mathrm{H}), 1.36\left(\mathrm{~s}, 3 \mathrm{H}, \mathrm{CH}_{3}\right)$. $\nu_{\max }\left(\mathrm{CH}_{2} \mathrm{Cl}_{2}\right) 1740,1695,1660 \mathrm{~cm}^{-1}$. $\mathrm{m} / \mathrm{z} \quad 478\left(24 \%, \mathrm{M}^{+}\right), 447(19), 434(28), 433(100), 419$ (46), $387(64), 373(60), 357(82)$.

$\mathrm{C}_{25} \mathrm{H}_{34} \mathrm{O}_{9} \quad$ H.r.m.s. Calcd: 478.2202 .

Found: 478.2202 .

$\delta\left({ }^{13} \mathrm{C}\right) 171.8\left(2 \times \mathrm{s}, \underline{\mathrm{CO}}_{2} \mathrm{CH}_{3}\right), 156.2(\mathrm{~s}, \mathrm{C} 2), 139.7(\mathrm{~s}, \mathrm{C} 4 \mathrm{a})$, $129.9(\mathrm{~s}, \mathrm{ClOa}), 115.3(\mathrm{~s}, \mathrm{C} 8), 92.8\left(t, \mathrm{OCH}_{2} \mathrm{O}\right), 91.0(\mathrm{~d}, \mathrm{C} 3)$, $84.5(\mathrm{~s}, \mathrm{C} 7), 65.1\left(2 \times t, \mathrm{OCH}_{2} \mathrm{CH}_{2} \mathrm{O}\right), 57.6(\mathrm{~d}, \mathrm{C} 6), 55.2(2 \times \mathrm{q}$, $\left.\mathrm{C}=\mathrm{COCH}_{3}, \mathrm{CH}_{2} \mathrm{OCH}_{3}\right), 52.4$ and $51.5\left(\mathrm{q}, \mathrm{CO}_{2} \mathrm{CH}_{3}\right), 49.0(t, \mathrm{C} 9)$, $46.9(\mathrm{~s}, \mathrm{C} 9 \mathrm{a}$ or $\mathrm{Cl}), 34.6(t, \mathrm{Cl} 1), 29.1(t, \mathrm{C} 6), 24.8(t, \mathrm{C} 4)$, $22.1(t, \mathrm{C} 5), 20.5\left(\mathrm{q}, \mathrm{CH}_{3}\right)$.
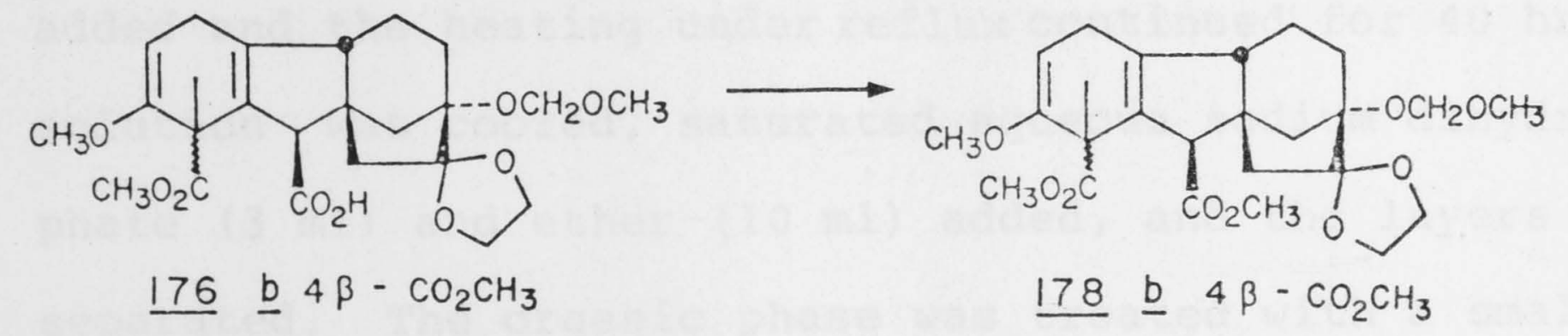

Acid $176 \mathrm{~b}(30 \mathrm{mg}, 0.065 \mathrm{mmol})$ was treated with diazomethane 
as described for acid $171 \mathrm{a}$ to give $( \pm)(1 \beta, 4 \mathrm{~b} \beta, 10 \beta)$ dimethy 8,8-ethylenedioxy-2-methoxy-7-methoxymethyloxy-1-methylgibba-

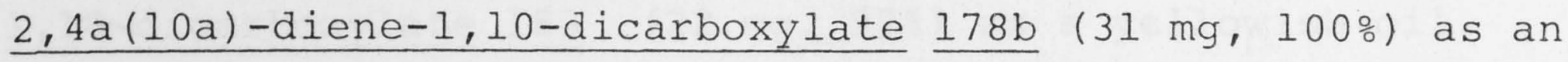
oil.

$\delta \quad 4.83$ and $4.65\left(\mathrm{ABq}, \mathrm{J}_{\mathrm{AB}}=7 \mathrm{~Hz}, 2 \mathrm{H}, \mathrm{OCH}_{2} \mathrm{O}\right), 4.81(t, \mathrm{~J}=4 \mathrm{~Hz}, 1 \mathrm{H}, \mathrm{H} 3)$, $3.99\left(\mathrm{bs}, 4 \mathrm{H}, \mathrm{OCH}_{2} \mathrm{CH}_{2} \mathrm{O}\right), 3.63\left(\mathrm{~s}, 3 \mathrm{H}, \mathrm{CO}_{2} \mathrm{CH}_{3}\right), 3.59$ ( $\left., 3,3 \mathrm{H}, \mathrm{CO}_{2} \mathrm{CH}_{3}\right)$, $3.55\left(\mathrm{~s}, 3 \mathrm{H}, \mathrm{C}=\mathrm{COCH}_{3}\right), 3.35\left(\mathrm{~s}, 4 \mathrm{H}, \mathrm{HlO}, \mathrm{CH}_{2} \mathrm{OCH}_{3}\right), 2.78(\mathrm{e}, 2 \mathrm{H}, \mathrm{H} 4)$, $2.65-1.40(\mathrm{~m}, 9 \mathrm{H}), 1.46\left(\mathrm{~s}, 3 \mathrm{H}, \mathrm{CH}_{3}\right)$.

$\nu_{\max }\left(\mathrm{CH}_{2} \mathrm{Cl}_{2}\right) \quad 1740-1720,1690,1655 \mathrm{~cm}^{-1}$. $\mathrm{m} / \mathrm{z} \quad 478\left(21 \%, \mathrm{M}^{+}\right), 447(13), 433(89), 419(84), 374$ (35), $373(100), 357(33)$.

$\mathrm{C}_{25} \mathrm{H}_{34} \mathrm{O}_{9} \quad$ H.r.m.s. Calcd: 478.2202 . Found: 478.2204 .

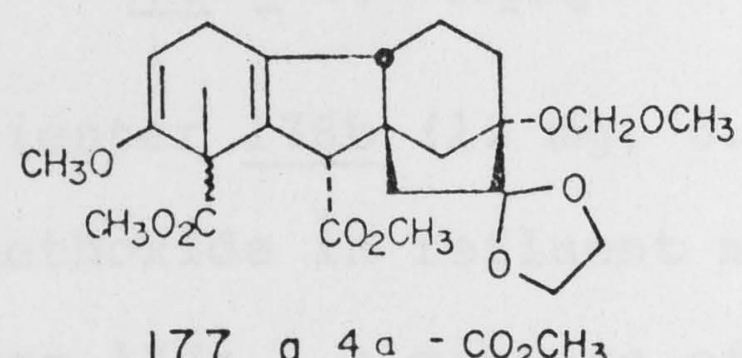

$177 \subseteq 4 a-\mathrm{CO}_{2} \mathrm{CH}_{3}$
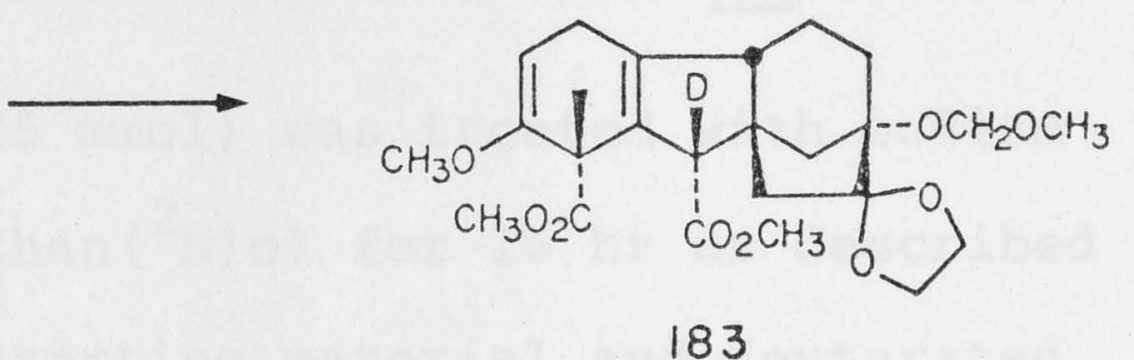

183

Sodium ( $11.5 \mathrm{mg}, 0.5 \mathrm{mmol})$ was added to methan $\left({ }^{2} \mathrm{H}\right) \mathrm{ol}(2 \mathrm{ml})$ at $0^{\circ}$ and the resulting solution heated at reflux for $1 \mathrm{hr}$ in a nitrogen atmosphere. Diester $177 \mathrm{a}$ (24 mg, $0.05 \mathrm{mmol}$ ) in methan $\left({ }^{2} \mathrm{H}\right)$ ol $(0.5 \mathrm{ml}$, also heated at reflux for $1 \mathrm{hr})$ was added and the heating under reflux continued for $40 \mathrm{hr}$. The solution was cooled, saturated aqueous sodium dihydrogenphosphate $(3 \mathrm{ml})$ and ether $(10 \mathrm{ml})$ added, and the layers separated. The organic phase was treated with a small amount of ethereal diazomethane, dried and the solvent evaporated to 
leave $( \pm)(1 \alpha, 4 b \beta, 10 \alpha)$ dimethyl 8,8-ethylenedioxy-2-methoxy7-methoxymethyloxy-l-methyl $\left(10-{ }^{2} \mathrm{H}\right)$ gibba-2, 4a (10a)-diene1,10-dicarboxylate $183(22 \mathrm{mg}, 92 \%)$ as a yellowish oil. $\delta$ identical to $177 \mathrm{a}$, except $3.66(\mathrm{~s}, 3 \mathrm{H})$.

$\nu_{\max }$ identical to $177 \mathrm{a}$.

$\mathrm{m} / \mathrm{z} \quad 479\left(20 \%, \mathrm{M}^{+}\right), 448(15), 435(30), 434(100), 420$ (42), $388(55), 374(52), 358(82)$.

$\mathrm{C}_{25} \mathrm{H}_{33} \mathrm{DO}_{9} \quad$ H.r.m.s. Calcd: 479.2265 .

Found: 479.2252 .

$\delta\left({ }^{13} \mathrm{C}\right)$ identical to $177 \mathrm{a}$, but 57.6 absent.

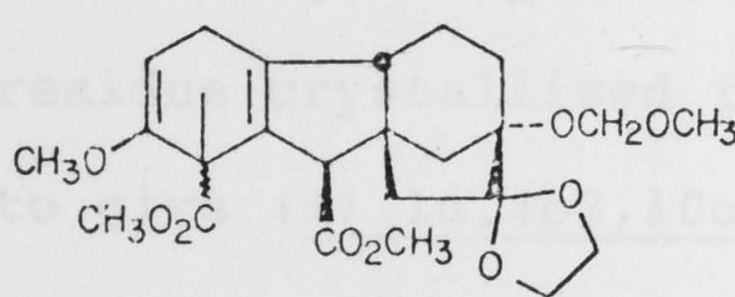

$178 \underline{b} 4 \beta-\mathrm{CO}_{2} \mathrm{CH}_{3}$

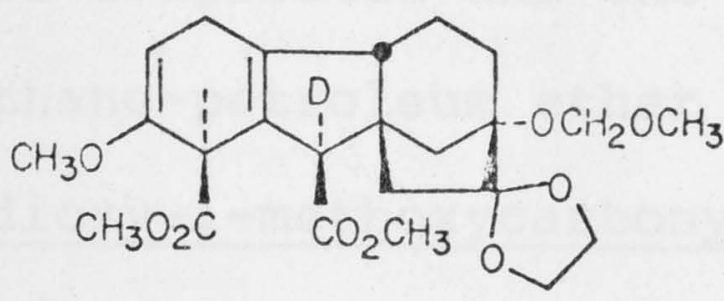

184

Diester $178 \mathrm{~b}(12 \mathrm{mg}, 0.025 \mathrm{mmol})$ was treated with sodium methoxide in refluent methan $\left({ }^{2} \mathrm{H}\right)$ ol for 16 hr as described for 177a. A mixture of starting material and deuterated ester 184 was obtained ( $8 \mathrm{mg})$. $\mathrm{m} / \mathrm{z} \quad 479\left(15 \%, \mathrm{M}^{+} \underline{184}\right), 478\left(16, \mathrm{M}^{+} \underline{178 \mathrm{~b}}\right), 434$ (91), 433 (69), $420(40), 419(67), 375(43), 374(100), 373(22), 358(40)$, $357(31)$

Both diesters $177 \mathrm{a}$ and $\underline{178 \mathrm{~b}}$ were recovered unchanged from treatment with sodium methoxide in boiling methanol (40 hr). 


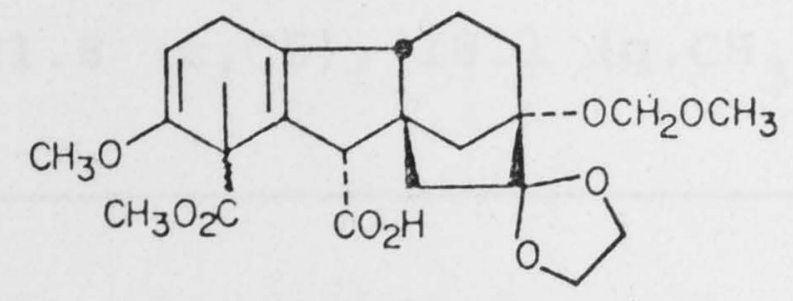

$\underline{171}$ a $4 \mathrm{a}-\mathrm{CO}_{2} \mathrm{CH}_{3}$

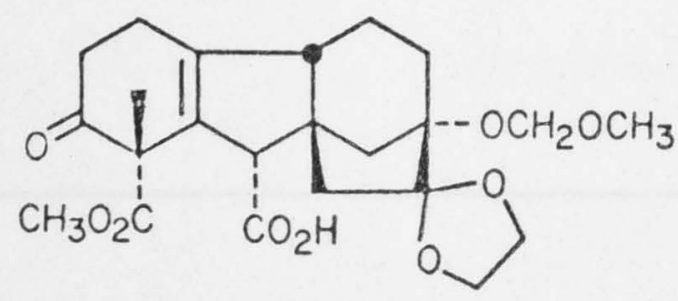

185

To ester acid 17la (650 mg, $1.4 \mathrm{mmol}$ ) in acetonitrile $(20 \mathrm{ml})$ and water $(4 \mathrm{ml})$ was added mercury(II) nitrate (137 $\mathrm{mg}, 0.42 \mathrm{mmol}$ ) and the reaction mixture stirred for $18 \mathrm{hr}$ at $22^{\circ}$. Water $(20 \mathrm{ml})$ and dichloromethane $(30 \mathrm{ml})$ were added, the layers separated and the aqueous portion reextracted with dichloromethane $(2 \times 20 \mathrm{ml})$. After drying of the organic portion the solvent was evaporated and the residue crystallised from dichloromethane-petroleum ether to give $( \pm)(1 \alpha, 4 \mathrm{~b} \beta, 10 \alpha)$ 8,8-ethylenedioxy-1-methoxycarbonyl7-methoxymethyloxy-1-methyl-2-oxogibb-4a(10a)-ene-10carboxylic acid $185 \quad(485 \mathrm{mg}, 77 \%)$ as colourless crystals. M.p. $\quad 139-140 \cdot 5^{\circ}$.

ઈ $7.32\left(\mathrm{~b}, 1 \mathrm{H}, \mathrm{CO}_{2} \mathrm{H}\right), 4.81$ and $4.65\left(\mathrm{ABq}, \mathrm{J}_{\mathrm{AB}}=7 \mathrm{~Hz}, 2 \mathrm{H}, \mathrm{OCH}_{2} \mathrm{O}\right)$, $3.98\left(\mathrm{~s}, 4 \mathrm{H}, \mathrm{OCH}_{2} \mathrm{CH}_{2} \mathrm{O}\right), 3.66\left(\mathrm{~s}, 3 \mathrm{H}, \mathrm{CO}_{2} \mathrm{CH}_{3}\right), 3.50(\mathrm{~s}, 1 \mathrm{H}, \mathrm{HlO})$, $3.34\left(\mathrm{~s}, 3 \mathrm{H}, \mathrm{CH}_{2} \mathrm{OCH}_{3}\right), 3.06-1.28(\mathrm{~m}, 13 \mathrm{H}), 1.33\left(\mathrm{~s}, 3 \mathrm{H}, \mathrm{CH}_{3}\right)$. $\nu_{\max } 1720,1705 \mathrm{~cm}^{-1}$.

$\mathrm{m} / \mathrm{z} \quad 450\left(12 \%, \mathrm{M}^{+}\right), 449(12), 419(20), 418(34), 405$ (100), $389(35), 388(82), 359(40), 344(55)$.

$\begin{array}{rll}\mathrm{C}_{23} \mathrm{H}_{30} \mathrm{O}_{9} & \text { Calcd: } & \mathrm{C}, 61.3 ; \mathrm{H}, 7.0 . \\ & \text { Found: } & \mathrm{C}, 61.2 ; \mathrm{H}, 6.9 \%\end{array}$ $\delta\left({ }^{13} \mathrm{C}\right) 207.7(\mathrm{~s}, \mathrm{C} 2), 175.2\left(\mathrm{~s}, \underline{\mathrm{CO}}_{2} \mathrm{CH}_{3}\right), 170.8\left(\mathrm{~s}, \mathrm{CO}_{2} \mathrm{H}\right)$, $143.1(\mathrm{~s}, \mathrm{C} 4 \mathrm{a}), 131.6(\mathrm{~s}, \mathrm{ClOa}), 115.3(\mathrm{~s}, \mathrm{C} 8), 92.8\left(\mathrm{t}, \mathrm{OCH}_{2} \mathrm{O}\right)$, $84.3(\mathrm{~s}, \mathrm{C} 7), 65.2\left(2 \times t, \mathrm{OCH}_{2} \mathrm{CH}_{2} \mathrm{O}\right), 57.2(\mathrm{~d}, \mathrm{Cl} 0), 55.2(\mathrm{q}$ ， $\left.\mathrm{CH}_{2} \mathrm{OCH}_{3}\right), 52.9\left(\mathrm{q}, \mathrm{CO}_{2} \mathrm{CH}_{3}\right), 48.3(\mathrm{~d}, \mathrm{C} 4 \mathrm{~b}), 47.2(t, \mathrm{C} 9)$, 


$$
\begin{aligned}
& 35.6(t, C 3), 33.9(t, C 11), 29.1(t, C 6), 23.3(t, C 4), \\
& 21.8(t, C 5), 18.1\left(q, \mathrm{CH}_{3}\right) .
\end{aligned}
$$

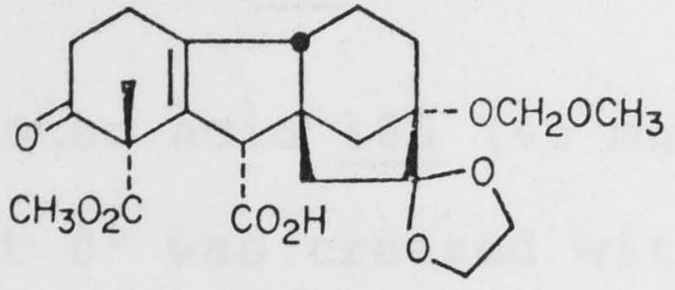

$\underline{185}$

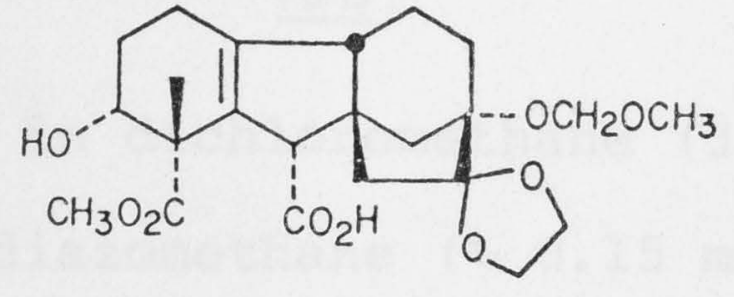

$\underline{186}$

Sodium borohydride (38 $\mathrm{mg}, 1 \mathrm{mmol}$ ) was added portionwise over $20 \mathrm{~min}$. to a stirred solution of keto ester 185 $(450 \mathrm{mg}, 1 \mathrm{mmol})$ in ethanol $(10 \mathrm{ml})$ at $0^{\circ}$. After a further $40 \mathrm{~min}$. at $0^{\circ}$, saturated aqueous sodium hydrogenphosphate $(5 \mathrm{ml})$ and ethyl acetate $(50 \mathrm{ml})$ were added. The organic layer was dried and the solvent removed to give after crystallisation from dichloromethane-petroleum ether

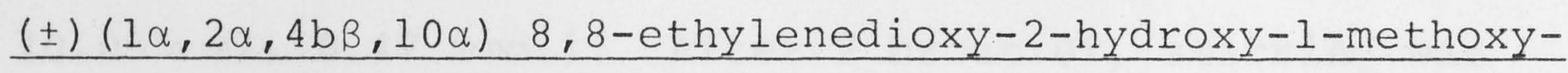
carbonyl-7-methoxymethyloxy-1-methylgibb-4a (10a)-ene-10carboxylic acid $186(407 \mathrm{mg}, 90 \%)$ as white crystals. M.p. $129-132^{\circ}$.

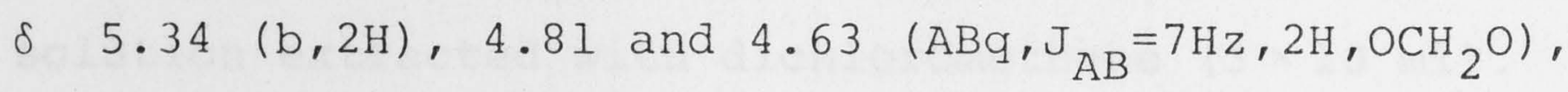
$3.96\left(\mathrm{bs}, 4 \mathrm{H}, \mathrm{OCH}_{2} \mathrm{CH}_{2} \mathrm{O}\right), 3.66\left(\mathrm{~s}, 3 \mathrm{H}, \mathrm{CO}_{2} \mathrm{CH}_{3}\right), 3.48(\mathrm{~m}, 2 \mathrm{H}, \mathrm{H} 2, \mathrm{HlO})$, $3.35\left(\mathrm{~s}, 3 \mathrm{H}, \mathrm{CH}_{2} \mathrm{OCH}_{3}\right), 2.60-1.26(\mathrm{~m}, 13 \mathrm{H}), 1.30\left(\mathrm{~s}, 3 \mathrm{H}, \mathrm{CH}_{3}\right)$. $\nu_{\max } 3400,3200,1730-1705 \mathrm{~cm}^{-1}$.

$\mathrm{m} / \mathrm{z} \quad 452\left(7 \%, \mathrm{M}^{+}\right), 434(9), 421(14), 420(28), 407$ (58), $390(100)$.

$\mathrm{C}_{23} \mathrm{H}_{32} \mathrm{O}_{9} \quad$ Calcd: $\quad 452.2046$. Found: $\quad 452.2035$. 


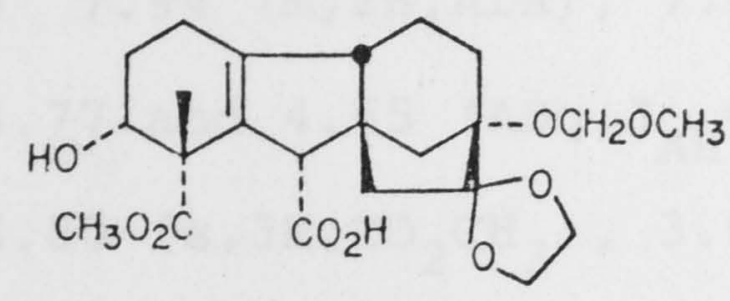

186

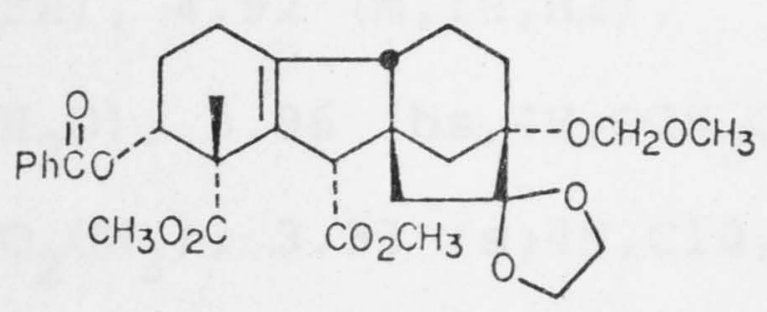

188

Ester acid $186(45 \mathrm{mg}, 0.1 \mathrm{mmol})$ in dichloromethane (3 ml) at $0^{\circ}$ was treated with ethereal diazomethane ( 0.15 mol) in ether $(3 \mathrm{ml})$ to leave, after removal of the volatiles, hydroxy diester 187 (44 mg).

$\delta \quad 4.76$ and $4.64\left(\mathrm{ABq}, \mathrm{J}_{\mathrm{AB}}=7 \mathrm{~Hz}, 2 \mathrm{H}, \mathrm{OCH}_{2} \mathrm{O}\right), 3.96\left(\mathrm{bs}, 4 \mathrm{H}, \mathrm{OCH}_{2} \mathrm{CH}_{2} \mathrm{O}\right)$, $3.69\left(\mathrm{~s}, 3 \mathrm{H}, \mathrm{CO}_{2} \mathrm{CH}_{3}\right), 3.64\left(\mathrm{~s}, 3 \mathrm{H}, \mathrm{CO}_{2} \mathrm{CH}_{3}\right), 3.48(\mathrm{~m}, 2 \mathrm{H}, \mathrm{H} 2, \mathrm{HlO})$, $3.37\left(\mathrm{~s}, 3 \mathrm{H}, \mathrm{CH}_{2} \mathrm{OCH}_{3}\right), 2.60-1.14(\mathrm{~m}, 13 \mathrm{H}), 1.26\left(\mathrm{~s}, 3 \mathrm{H}, \mathrm{CH}_{3}\right)$. $\nu_{\max }\left(\mathrm{CH}_{2} \mathrm{Cl}_{2}\right)$ 3600-3400, 1740-1710 $\mathrm{cm}^{-1}$.

To a solution of hydroxy diester $187(44 \mathrm{mg}, 0.094 \mathrm{mmol})$ in pyridine $(0.2 \mathrm{ml})$ at $0^{\circ}$ was added benzoyl chloride $(0.055 \mathrm{ml}, 0.47 \mathrm{mmol})$. After $2 \mathrm{hr}$ at $0^{\circ}$, stirring was continued at $25^{\circ}$ for $16 \mathrm{hr}$. The reaction mixture was cooled to $0^{\circ}, \operatorname{THF}(0.6 \mathrm{ml})$ and water $(0.2 \mathrm{ml})$ were added and stirring continued for $2 \mathrm{hr}$ at $25^{\circ}$. Water $(10 \mathrm{ml})$ was added and the solution extracted with dichloromethane $(3 \times 10 \mathrm{ml})$. The organic extracts were washed with water $(10 \mathrm{ml}), 2 \mathrm{~N}$ acetic acid $(10 \mathrm{ml}), I \mathrm{~N}$ sodium bicarbonate $(2 \times 10 \mathrm{ml})$, brine (10 ml) and dried. Evaporation of the solvent and purification by chromatography (p.1.c., 4\% methanol-dichloromethane) gave ( \pm ) $(1 \alpha, 2 \alpha, 4 \mathrm{~b} \beta, 10 \alpha)$ dimethyl 2-benzoyloxy-8,8-ethylenedioxy7-methoxymethyloxy-1-methylgibb-4a(10a)-ene-1,10-dicarboxylate $188(40 \mathrm{mg}, 75 \%)$ as colourless crystals.

M.p. $\quad 145-146.5^{\circ}$ (ether). 
ઈ $7.94(\mathrm{~m}, 2 \mathrm{H}, \mathrm{ArH}), 7.44(\mathrm{~m}, 3 \mathrm{H}, \mathrm{ArH}), 4.92(\mathrm{~m}, 1 \mathrm{H}, \mathrm{H} 2)$,

4.77 and $4.65\left(\mathrm{ABq}, \mathrm{J}_{\mathrm{AB}}=7 \mathrm{~Hz}, 2 \mathrm{H}, \mathrm{OCH}_{2} \mathrm{O}\right), 3.96\left(\mathrm{bs}, 4 \mathrm{H}, \mathrm{OCH}_{2} \mathrm{CH}_{2} \mathrm{O}\right)$,

$3.80\left(\mathrm{~s}, 3 \mathrm{H}, \mathrm{CO}_{2} \mathrm{CH}_{3}\right), 3.64\left(\mathrm{~s}, 3 \mathrm{H}, \mathrm{CO}_{2} \mathrm{CH}_{3}\right), 3.33(\mathrm{~s}, 4 \mathrm{H}, \mathrm{Cl} 0$,

$\left.\mathrm{CH}_{2} \mathrm{OCH}_{3}\right), 2.70-1.15(\mathrm{~m}, 13 \mathrm{H}), 1.22\left(\mathrm{~s}, 3 \mathrm{H}, \mathrm{CH}_{3}\right)$.

$\nu_{\max } 1735,1730,1710,1600,1580 \mathrm{~cm}^{-1}$.

$\mathrm{m} / \mathrm{z}$ (base peak 105; > $105 \mathrm{rel} .525), 570\left(16 \%, \mathrm{M}^{+}\right), 538$ (24), $525(100)$.

$\mathrm{C}_{31} \mathrm{H}_{38} \mathrm{O}_{10} \quad$ Calcd: C, 65.3; H, 6.7.

Found: $\mathrm{C}, 65.0 ; \mathrm{H}, 6.6 \%$

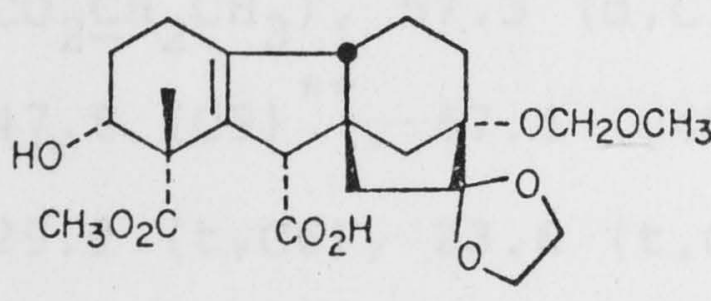

186

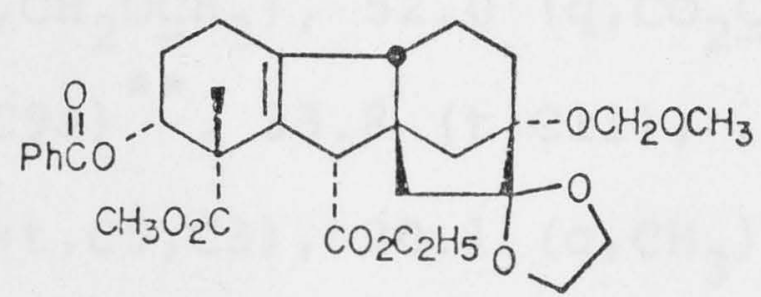

190

To ester acid 186 (100 mg, $0.22 \mathrm{mmol}$ ) in dichloromethane ( $3 \mathrm{ml}$ ) was added diazoethane $\mathrm{l}^{124}$ ( $0.4 \mathrm{mmol}$ ) in ether (2 $\mathrm{ml}$ ). After $30 \mathrm{~min}$. the excessive diazoethane was blown off with a stream of nitrogen and the volatiles removed, to leave hydroxy ethyl methyl ester 189 (104 mg), which was benzoylated in the same way as 187 to give $( \pm)(1 \alpha, 2 \alpha, 4 b \beta, 10 \alpha)$ ethyl 2-benzoyloxy-8,8-ethylenedioxy-1-methoxycarbonyl-7-

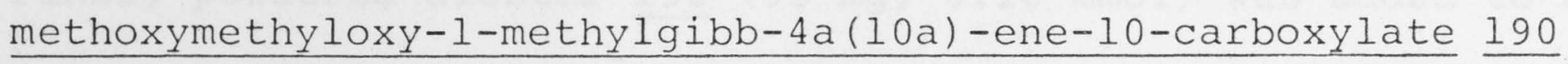
(101 mg, 79\% from $\underline{186}$ ) as slightly yellowish crystals. M.p. $133-135^{\circ}$ (ether-petroleum ether). $\delta 7.96(\mathrm{~m}, 2 \mathrm{H}, \mathrm{ArH}), 7.44(\mathrm{~m}, 3 \mathrm{H}, \mathrm{ArH}), 4.94(\mathrm{~m}, 1 \mathrm{H}, \mathrm{H} 2), 4.80$ and $4.68\left(\mathrm{ABq}, \mathrm{J}_{\mathrm{AB}}=7 \mathrm{~Hz}, 2 \mathrm{H}, \mathrm{OCH}_{2} \mathrm{O}\right), 4.18\left(\mathrm{bq}, \mathrm{J}=7 \mathrm{~Hz}, \mathrm{CO}_{2} \mathrm{CH}_{2} \mathrm{CH}_{3}\right)$, $4.00\left(\mathrm{~m}, 4 \mathrm{H}, \mathrm{OCH}_{2} \mathrm{CH}_{2} \mathrm{O}\right), 3.84\left(\mathrm{~s}, 3 \mathrm{H}, \mathrm{CO}_{2} \mathrm{CH}_{3}\right), 3.33(\mathrm{~s}, 4 \mathrm{H}, \mathrm{HlO}$, $\left.\mathrm{CH}_{2} \mathrm{OCH}_{3}\right), 2.71-1.20(\mathrm{~m}, 13 \mathrm{H}), 1.29\left(t, \mathrm{~J}=7 \mathrm{~Hz}, \mathrm{CO}_{2} \mathrm{CH}_{2} \mathrm{CH}_{3}\right)$, 
$1.23\left(\mathrm{~s}, 3 \mathrm{H}, \mathrm{CH}_{3}\right)$.

$\nu_{\max } 1735,1720,1600 \mathrm{~cm}^{-1}$.

$\mathrm{m} / \mathrm{z}$ (base peak 105; > $105 \mathrm{rel}$. 539) $584\left(15 \%, \mathrm{M}^{+}\right), 552$ (10),

$539(100), 523(15), 496(20), 357(40), 344$ (75).

$\mathrm{C}_{32} \mathrm{H}_{40} \mathrm{O}_{10} \quad$ Calcd: C, 65.7; H, 6.9.

Found: $\mathrm{C}, 65.6 ; \mathrm{H}, 6.9 \%$.

$\delta\left({ }^{13} \mathrm{C}\right) 172.7\left(\mathrm{~s}, \underline{\mathrm{CO}}_{2} \mathrm{C}_{2} \mathrm{H}_{5}\right)^{*}, 171.7\left(\mathrm{~s}, \underline{\mathrm{CO}}_{2} \mathrm{CH}_{3}\right)^{*}, 165.9$

$\left(\mathrm{s}, \mathrm{ArCO}_{2}\right), 142.6(\mathrm{~s}, \mathrm{C} 4 \mathrm{a}), 132.9(\mathrm{~d}, \mathrm{Ph}), 130.2$ (s,Cl0a and/or

$\mathrm{Ph}), 129.7(2 \times \mathrm{d}, \mathrm{Ph}), 128.4(2 \times \mathrm{d}, \mathrm{Ph}), 115.3(\mathrm{~s}, \mathrm{C} 8), 92.5\left(\mathrm{t}, \mathrm{OCH}_{2} \mathrm{O}\right)$,

$84.3(\mathrm{~s}, \mathrm{C} 7), 78.6(\mathrm{~d}, \mathrm{C} 2), 64.9\left(2 \mathrm{t}, \mathrm{OCH}_{2} \mathrm{CH}_{2} \mathrm{O}\right), 60.4(t$,

$\left.\mathrm{CO}_{2} \mathrm{CH}_{2} \mathrm{CH}_{3}\right), 57.3(\mathrm{~d}, \mathrm{ClO}), 55.0\left(\mathrm{q}, \mathrm{CH}_{2} \mathrm{OCH}_{3}\right), 52.0\left(\mathrm{q}, \mathrm{CO}_{2} \mathrm{CH}_{3}\right)$,

$47.8(\mathrm{C} 9)^{* *}, 47.4(\mathrm{C} 4 \mathrm{~b})^{* *}, 47.2(\mathrm{C} 9 \mathrm{a})^{* *}, 33.8(t, \mathrm{Cl} 1)$,

$29.1(t, \mathrm{C} 6), 23.6(t, \mathrm{C} 4), 22.2(2 \times t, \mathrm{C} 5, \mathrm{C} 3), 20.1\left(\mathrm{q}, \mathrm{CH}_{3}\right)$,

$14.2\left(\mathrm{q}, \mathrm{CO}_{2} \mathrm{CH}_{2} \mathrm{CH}_{3}\right)$.

*,** May be interchanged.

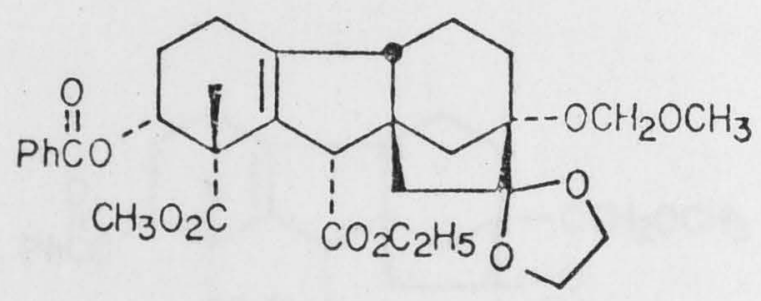

190

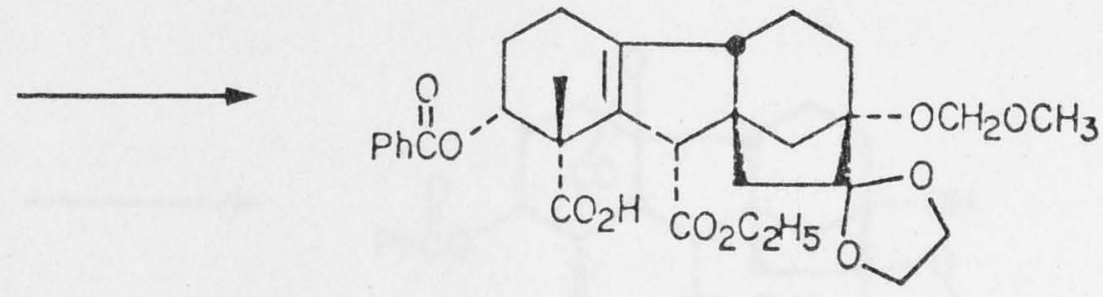

$\underline{191}$

Finely powdered diester $190(93 \mathrm{mg}, 0.16 \mathrm{mmol})$ was added to a solution of lithium propanethiolate in HMPA (0.5 M, $2 \mathrm{ml})$ and the solution stirred for $2 \mathrm{hr}$. Ether $(20 \mathrm{ml})$ and water $(10 \mathrm{ml})$ were added and the stirred two-phase system acidified to $\mathrm{pH} 2$ with $2 \mathrm{~N} \mathrm{HCl}$ at $0^{\circ}$. The layers were separated and the aqueous portion reextracted with ether $(2 \times 20 \mathrm{ml})$. The organic layers were sequentially washed with water $(3 \times 10 \mathrm{ml})$, 
brine $(10 \mathrm{ml})$ and dried. Removal of the solvent and crystallisation from dichloromethane-ether gave ( \pm ) $(1 \alpha, 2 \alpha, 4 \mathrm{~b} \beta, 10 \alpha)$ 2-benzoyloxy-10-ethoxycarbonyl-8,8ethylenedioxy-7-methoxymethyloxy - 1-methylgibb-4a(10a)-ene1-carboxylic acid $191(70.2 \mathrm{mg}, 77 \%)$ as a white powder. M.p. $\quad 178-182^{\circ}$ (dichloromethane-ether).

$\delta 8.60(\mathrm{~b}, 1 \mathrm{H}), 7.96(\mathrm{~m}, 2 \mathrm{H}, \mathrm{ArH}), 7.40(\mathrm{~m}, 3 \mathrm{H}, \mathrm{ArH}), 4.96(\mathrm{~m}, 1 \mathrm{H}$, $\mathrm{H} 2), 4.80$ and $4.68\left(\mathrm{ABq}, \mathrm{J}_{\mathrm{AB}}=7 \mathrm{~Hz}, 2 \mathrm{H}, \mathrm{OCH}_{2} \mathrm{O}\right), 4.16(\mathrm{~m}, 2 \mathrm{H}$, $\left.\mathrm{CO}_{2} \mathrm{CH}_{2} \mathrm{CH}_{3}\right), 4.00\left(\mathrm{~m}, 4 \mathrm{H}, \mathrm{OCH}_{2} \mathrm{CH}_{2} \mathrm{O}\right), 3.33\left(\mathrm{~s}, 4 \mathrm{H}, \mathrm{ClO}, \mathrm{CH}_{2} \mathrm{OCH}_{3}\right)$, $2.78-1.20(\mathrm{~m}, 13 \mathrm{H}), 1.29\left(\mathrm{t}, \mathrm{J}=7 \mathrm{~Hz}, 3 \mathrm{H}, \mathrm{CO}_{2} \mathrm{CH}_{2} \mathrm{CH}_{3}\right), 1.26(\mathrm{~s}, 3 \mathrm{H}$, $\left.\mathrm{CH}_{3}\right)$.

$\nu_{\max } 1725-1690,1595,1575 \mathrm{~cm}^{-1}$.

$\mathrm{m} / \mathrm{z}$ (base peak 105; > $105 \mathrm{rel} .525) 570\left(5 \%, \mathrm{M}^{+}\right), 539$ (7), $525(100), 508(71)$.
$\mathrm{C}_{31} \mathrm{H}_{38} \mathrm{O}_{10}$
Calcd:
C, 65.3; H, 6.7 .
Found:
C, $65.4 ; \mathrm{H}, 6.8 \%$

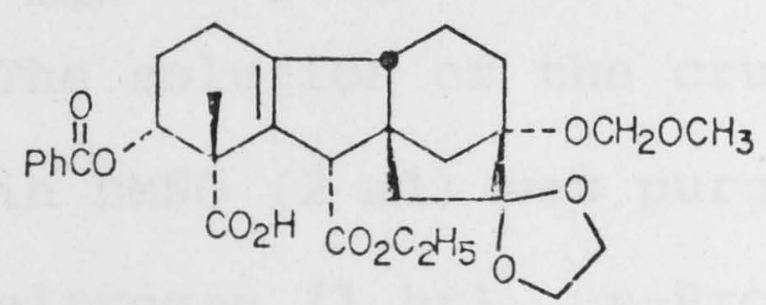

191

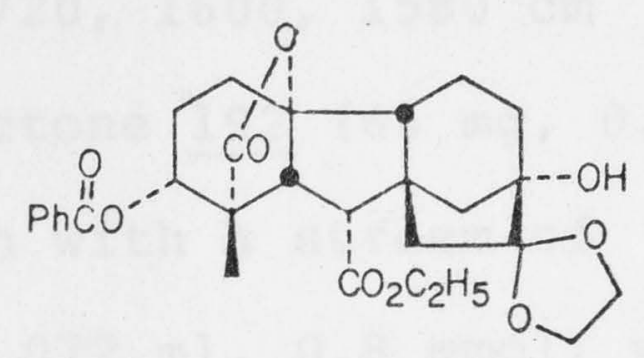

193

To a suspension of ester acid 191 ( $57 \mathrm{mg}, 0.1 \mathrm{mmol}$ ) in THF ( $1 \mathrm{ml}$ ) and $1 \mathrm{~N}$ aqueous potassium bicarbonate $\left(1.2 \mathrm{ml}\right.$ ) at $0^{\circ}$ was added $0.8 \mathrm{~N}$ aqueous potassium tribromide ( $1 \mathrm{ml}$ ) over 3 min. The mixture was stirred at $0^{\circ}$ for 1 hr resulting in a red solution, which contained no starting material 
(t.1.c., 2\% methanol-dichloromethane). Ether (20 ml) and IN aqueous sodium metabisulfite solution (to destroy excessive bromine) were added, the layers separated and the aqueous phase reextracted with ether $(2 \times 10 \mathrm{ml})$. The organic portion was washed with water $(10 \mathrm{ml})$, brine $(10 \mathrm{ml})$ and dried. Removal of solvent gave the bromo lactone 192 (65 mg) as a yellowish oil.

$\delta 8.12(\mathrm{~m}, 2 \mathrm{H}, \mathrm{ArH}), 7.51(\mathrm{~m}, 3 \mathrm{H}, \mathrm{ArH}), 5.61(\mathrm{~m}, 1 \mathrm{H}, \mathrm{H} 2), 4.79$ and $4.71\left(\mathrm{ABq}, \mathrm{J}_{\mathrm{AB}}=7 \mathrm{~Hz}, 2 \mathrm{H}, \mathrm{OCH}_{2} \mathrm{O}\right), 4.2 \mathrm{O}\left(\mathrm{q}, \mathrm{J}=7 \mathrm{~Hz}, 2 \mathrm{H}, \mathrm{CO}_{2} \mathrm{CH}_{2} \mathrm{CH}_{3}\right)$, $4.00\left(\mathrm{~m}, 4 \mathrm{H}, \mathrm{OCH}_{2} \mathrm{CH}_{2} \mathrm{O}\right), 3.88(\mathrm{~s}, 1 \mathrm{H}, \mathrm{HIO}), 3.33\left(\mathrm{~s}, 3 \mathrm{H}, \mathrm{CH}_{2} \mathrm{OCH}_{3}\right)$, $2.61-1.23(\mathrm{~m}, 12 \mathrm{H}), 1.31\left(\mathrm{t}, \mathrm{J}=7 \mathrm{~Hz}, 3 \mathrm{H}, \mathrm{CO}_{2} \mathrm{CH}_{2} \mathrm{CH}_{3}\right), 1.25\left(\mathrm{~s}, 3 \mathrm{H}, \mathrm{CH}_{3}\right)$. $\nu_{\max }\left(\mathrm{CH}_{2} \mathrm{Cl}_{2}\right) \quad 1792,1740,1720,1600,1580 \mathrm{~cm}^{-1}$. $\mathrm{m} / \mathrm{z}$ (base peak 105; > $105 \mathrm{rel} .525) 605 / 603\left(2 \%, \mathrm{M}^{+}-45\right)$, $569(3), 525(100), 403(19), 357(30)$.

When the bromo lactonisation was performed at $25^{\circ}$, a second product was obtained, but its structure was not investigated.

$\nu_{\max }\left(\mathrm{CH}_{2} \mathrm{Cl}_{2}\right) 1792,1775,1740,1720,1600,1580 \mathrm{~cm}^{-1}$. The solution of the crude bromo lactone 192 (65 $\mathrm{mg}, 0.1 \mathrm{mmol}$ ) in DMSO ( $2 \mathrm{ml}$ ) was purged of oxygen with a stream of nitrogen (l hr). n-Propylthiol (0.072 $\mathrm{ml}, 0.8 \mathrm{mmol})$ was added to the stirred solution, followed by chromium(II) acetate ( $250 \mathrm{mg}, 1.47 \mathrm{mmol}$ ) in 6 portions over $2 \mathrm{hr}$ at $25^{\circ}$ (the red colour obtained upon addition of chromium(II) acetate regularly disappeared slowly). The reaction mixture was poured onto ice $(15 \mathrm{~g})$ and extracted with ethyl acetate $(3 \times 15 \mathrm{ml})$. The organic layers were washed with water 
$(3 \times 10 \mathrm{ml})$, brine $(15 \mathrm{ml})$ and dried. The solvent was

evaporated and the residue chromatographically purified (p.l.c., 2\% methanol-dichloromethane) to give $( \pm)(1 \alpha, 2 \alpha, 4 \mathrm{a} \alpha$, $4 \mathrm{~b} \beta, 10 \alpha)$ 2-benzoyloxy-10-ethoxycarbonyl-8,8-ethylenedioxy7-hydroxy-1-methylgibbane-1,4a-carbolactone 193 (26 mg, 50\% from acid 191) as colourless crystals.

M.p. $208-210^{\circ}$ (dichloromethane-ether); $218-220^{\circ}$ (needles reformed above $210^{\circ}$ ).

$\delta 8.09(\mathrm{~m}, 2 \mathrm{H}, \mathrm{ArH}), 7.44(\mathrm{~m}, 3 \mathrm{H}, \mathrm{ArH}), 5.04(\mathrm{~m}, 1 \mathrm{H}, \mathrm{H} 2)$, $4.11\left(\mathrm{~m}, 2 \mathrm{H}, \mathrm{CO}_{2} \mathrm{CH}_{2} \mathrm{CH}_{3}\right), 3.96\left(\mathrm{~s}, 4 \mathrm{H}, \mathrm{OCH}_{2} \mathrm{CH}_{2} \mathrm{O}\right), 3.05(\mathrm{~d}, \mathrm{~J}=11 \mathrm{~Hz}$, $1 \mathrm{H}, \mathrm{HlO}), 2.44(\mathrm{~d}, \mathrm{~J}=11 \mathrm{~Hz}, 1 \mathrm{H}, \mathrm{HlOa}), 2.60-1.28(\mathrm{~m}, 14 \mathrm{H}), 1.29$ $\left(t, \mathrm{~J}=7 \mathrm{~Hz}, 3 \mathrm{H}, \mathrm{CO}_{2} \mathrm{CH}_{2} \mathrm{CH}_{3}\right), 1.17\left(\mathrm{~s}, 3 \mathrm{H}, \mathrm{CH}_{3}\right)$. $\nu_{\max } 3440,1775,1737,1715,1600,1585 \mathrm{~cm}^{-1}$. $\mathrm{m} / \mathrm{z}$ (base peak 105; > $105 \mathrm{rel}$. 480) $526\left(44 \%, \mathrm{M}^{+}\right), 508$ (21), $480(100), 360(68), 272(82)$.

$\mathrm{C}_{29} \mathrm{H}_{34}{ }^{\mathrm{O}} 9 \quad$ H.r.m.s. Calcd: 526.2203 . Found: 526.2213 .

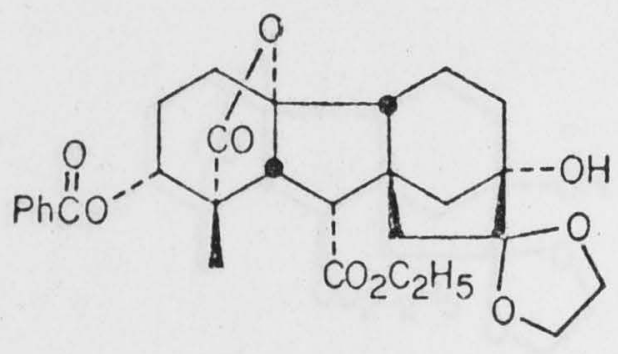

193

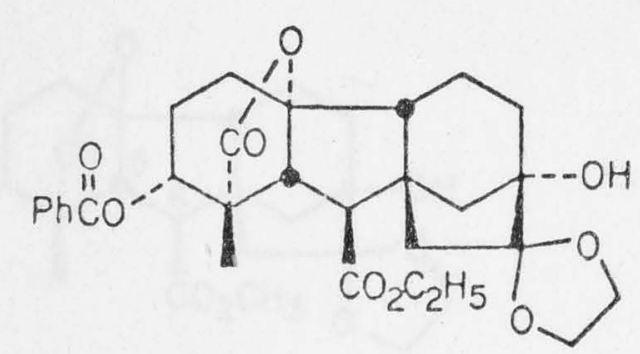

195

Lactone $193(15 \mathrm{mg}, 0.028 \mathrm{mmol})$ in DMF $(0.3 \mathrm{ml})$ containing 1,5 -diazabicyclo $5.4 .0 \mid$ undec-5-ene $(0.021 \mathrm{ml}, 0.14 \mathrm{mmol})$ was heated to $90^{\circ}$ for $17 \mathrm{hr}$. To the cooled solution was added dichloromethane $(10 \mathrm{ml})$ which was washed with cold $0.5 \mathrm{~N}$ hydrochloric acid $(2 \times 5 \mathrm{ml})$, water $(5 \mathrm{ml})$ and brine 
$(10 \mathrm{ml})$. The aqueous layer was reextracted with dichloromethane $(2 \times 10 \mathrm{ml})$, the organic portions washed, combined and dried. Removal of solvent and crystallisation from dichloromethane-ether-petroleum ether gave $( \pm)(1 \alpha, 2 \alpha, 4 a \alpha$, $\underline{4 b \beta, 10 \beta) 2-b e n z o y l o x y-10-e t h o x y c a r b o n y l-8,8-e t h y l e n e d i o x y-7-~}$ hydroxy-1-methylgibbane-1,4a-carbolactone 195 as colourless crystals.

M.p. 217-219० (dichloromethane-ether).

$\delta 8.02(\mathrm{~m}, 2 \mathrm{H}, \mathrm{ArH}), 7.47(\mathrm{~m}, 3 \mathrm{H}, \mathrm{ArH}), 5.18(\mathrm{~m}, 1 \mathrm{H}, \mathrm{H} 2), 4.19$ $\left(\mathrm{q}, \mathrm{J}=7 \mathrm{~Hz}, 2 \mathrm{H}, \mathrm{CO}_{2} \mathrm{CH}_{2} \mathrm{CH}_{3}\right), 3.95\left(\mathrm{bs}, 4 \mathrm{H}, \mathrm{OCH}_{2} \mathrm{CH}_{2} \mathrm{O}\right), 2.68(\mathrm{~s}, 2 \mathrm{H}$, $\mathrm{HlO}, \mathrm{HlOa}), 2.46(\mathrm{bs}, 1 \mathrm{H}, \mathrm{OH}), 2.50-1.32(\mathrm{~m}, 13 \mathrm{H}), 1.28$ (t, $\left.\mathrm{J}=7 \mathrm{~Hz}, 3 \mathrm{H}, \mathrm{CO}_{2} \mathrm{CH}_{2} \mathrm{CH}_{3}\right), 1.12\left(\mathrm{~s}, 3 \mathrm{H}, \mathrm{CH}_{3}\right)$. $\nu_{\max } 3520,1772,1735,1715,1600,1585 \mathrm{~cm}^{-1}$. $\mathrm{m} / \mathrm{z} 526\left(100 \%, \mathrm{M}^{+}\right), 481(18), 453(24), 438(36), 405$ (66), $492(15), 316(16), 272(24), 270$ (22), 105 (95).

$\mathrm{C}_{29} \mathrm{H}_{34} \mathrm{O}_{9} \quad \mathrm{Calcd}: \quad \mathrm{C}, 66.1 ; \mathrm{H}, 6.5$. Found: $\quad$ C, 65.9; H, 6.8\% .

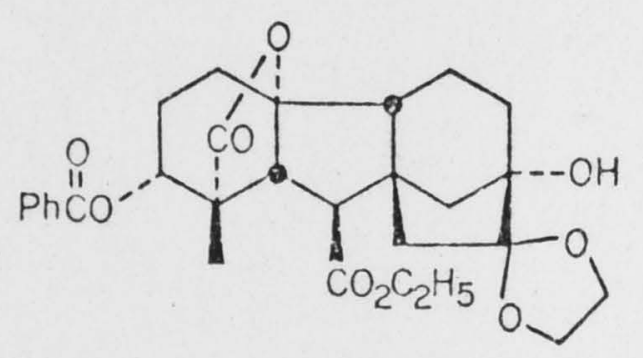

$\underline{195}$

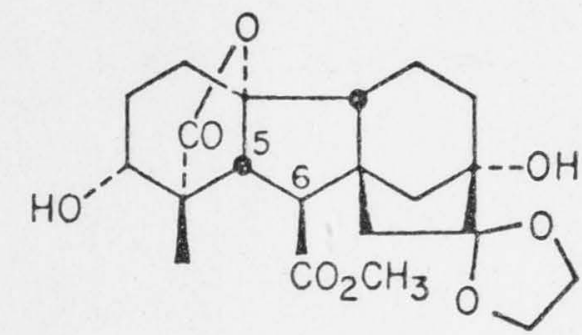

194

Lactone $195(10 \mathrm{mg}, 0.019 \mathrm{mmol})$ was dissolved in methanol $(1 \mathrm{ml}), 5 \%$ aqueous sodium hydroxide $(0.25 \mathrm{ml})$ added and the resulting solution kept at $25^{\circ}$ for $40 \mathrm{hr}$. Ethyl acetate ( $5 \mathrm{ml}$ ) and water $(8 \mathrm{ml})$ were added and the layers separated. The aqueous portion was acidified in a two-phase system 
(ethyl acetate, $10 \mathrm{ml}$ ) to $\mathrm{pH} 1$ with $6 \mathrm{~N}$ hydrochloric acid at $0^{\circ}$. Reextraction with ethyl acetate $(2 \times 10 \mathrm{ml})$, washing of the organic layers (water, $2 \times 10 \mathrm{ml}$, brine, $10 \mathrm{ml}$ ), drying and solvent removal afforded the acidic extract ( $4.0 \mathrm{mg}$ ) which was treated with ethereal diazomethane. Evaporation of the solvent gave after crystallisation from dichloromethane-ether $( \pm)(1 \alpha, 2 \alpha, 4 a \alpha, 4 b \beta, 10 \beta)$ 8,8-ethylenedioxy-2, 7dihydroxy-10-methoxycarbonyl-1-methylgibbane-1,4a-carbolactone $194(3.0 \mathrm{mg}, 40 \%)$ as colourless crystals. M.p. $272-274^{\circ} \quad\left(1\right.$ it. $\left.33275-277^{\circ}\right)$. $\delta^{\dagger}\left(\mathrm{CDCl}_{3} / \mathrm{CD}_{3} \mathrm{OD}\right) \quad 3.94\left(\mathrm{bs}, 4 \mathrm{H}, \mathrm{OCH}_{2} \mathrm{CH}_{2} \mathrm{O}\right), 3.73\left(\mathrm{~s}, 3 \mathrm{H}, \mathrm{CO}_{2} \mathrm{CH}_{3}\right)$, $2.66(\mathrm{~d}, \mathrm{~J}=10 \mathrm{~Hz}, 1 \mathrm{H}, \mathrm{HIO}), 2.48(\mathrm{~d}, \mathrm{~J}=10 \mathrm{~Hz}, 1 \mathrm{H}, \mathrm{HIOa}), 2.20-1.40$ $(\mathrm{m}, 16 \mathrm{H}), 1.13\left(\mathrm{~s}, 3 \mathrm{H}, \mathrm{CH}_{3}\right)$.

$\nu_{\max } 3525,3475,1752,1728 \mathrm{~cm}^{-1}$.

$\mathrm{m} / \mathrm{z} \quad 408\left(100 \%, \mathrm{M}^{+}\right), 391(13), 390(18), 377(21), 349$ (32), $320(60), 87(70)$.

$\mathrm{C}_{21} \mathrm{H}_{28} \mathrm{O}_{8} \quad$ H.r.m.s. Calcd: 408.1784 . Found: 408.1785 .

$t^{T}$ The spectrum has been recorded on a Varian CFT-20 operating at $80 \mathrm{MHz}$. 
REFERENCES 
1. L.G. Nickell, Chem. Eng. News, 56 (41), 18 (1978).

2. R.L. Wain, Chem. Soc. Rev., 261 (1977).

3. J.N. Turner, Outlook Agr., 7, 14 (1972).

4. J. MacMillan and V.M. Sponsel, Planta, 135, 129 (1977).

5. J.R. Rowe (ed.), "The Common and Systematic Nomenclature of Cyclic Diterpenes", 3rd. Rev., Forest Prod. Lab., U.S. Dept. Agric., Wisconsin, 1968.

6. S. Hori, Noji Shikenjo Seiseki, 12, 110 (1898); cf. ref. 13 .

7. E. Kurosawa, Trans. Nat. Hist. Soc. Formosa, 16, 213 (1926); cf. ref.13.

8. T. Yabuta and Y. Sumiki, J. Agr. Chem. Soc. Japan, I4, 1526 (1938); T. Yabuta, Y. Sumiki, K. Aso, T. Tamura, H. Igarashi and K. Tamari, ibid., 17, 721, 894, 975 (1941).

9. N. Takashi, H. Kitamura, A. Kawarada, T. Seta, M. Takai, S. Tamura and Y. Sumiki, Buzz. Agr. Chem. Soc. Japan, 19, 267 (1955).

10. B.E. Cross, J.F. Grove, J. Macmillan, J.S. Moffat, T.P.C. Mulholland, J.C. Seaton and N. Sheppard, Proc. Chem. Soc., 302 (1959).

11. F. McCapra, A.I. Scott, G. Sim and D.W. Young, Proc. Chem. Soc., 185 (1962).

12. J.A. Hartsuck and W.N. Lipscomb, J.Am. Chem. Soc., 85 , 3414 (1963).

13. K. Nakanishi, "Natural Products Chemistry", Vol.1, Academic Press, N.Y., 1974, pp.267-271.

14. A.J. Birch, R.W. Rickards, H. Smith, A. Harris and W.B. Whalley, Tetrahedron, ㄱ, 241 (1959). 
15. J.R. Hanson and A.F. White, J. Chem. Soc. (D), 1071 (1969).

16. B. Dockerill, R. Evans and J.R. Hanson, ibid., 919 (1977).

17. E. Fujita and M. Node, Heterocycles, 7, 709 (1977).

18. T.P.C. Mulholland and G. Ward, J. Chem. Soc., 4676 (1954).

19. H.J.E. Loewenthal, Proc. Chem. Soc., 355 (1960); Y. Kos and H.J.E. Loewenthal, J. Chem. Soc., 605 (1963).

20. U.R. Ghatak and P.C. Chakraborti, J. Org. Chem., 44, 4562 (1979).

21. H.J.E. Loewenthal and S.K. Malhotra, Proc. Chem. Soc., 230 (1962); H.J.E. Loewenthal and S.K. Malhotra, J. Chem. Soc., 990 (1965).

22. K. Mori, M. Matsui and Y. Sumiki, Agr. Biol. Chem., 26, 783 (1962); K. Mori, M. Matsui and Y. Sumiki, ibid., 27, $537(1963)$.

23. K. Mori, Tetrahedron, 27, 4907 (1971).

24. H.O. House, D.G. Melillo and F.J. Sauter, J. Org. Chem., 38, 741 (1973); H.O. House and D.G. Melillo, ibid, 38, $1398(1973)$.

25. M. Matsui, K. Mori and I. Takemoto, Tetrahedron, 32 , 1497 (1976).

26. Y. Hayase, S. Kamata, W. Nagata, M. Narisada and T. Wakabayashi, J. Am. Chem. Soc., 93, 5740 (1971).

27. E. Fujita, H. Hori and M. Node, J. Chem. Soc. Perkin I, 611 (1977).

28. K. Mori, M. Shiozaki, N. Itaya, M. Matsui and Y. Sumiki, Tetrahedron, 25, 1293 (1969).

29. J.F. Grove, J. Chem. Soc., 3545 (1961). 
30. B.E. Cross, R.H.B. Galt and J.R. Hanson, Tetrahedron, 18 , 451 (1962); B.E. Cross, R.H.B. Galt and J.R. Hanson, J. Chem. Soc., 295 (1964).

31. J.R. Hanson, Tetrahedron, 22, 701 (1966).

32. E.J. Corey, R.L. Danheiser, S. Chandrasekaran, G.E. Keck, B. Gopalan, S.D. Larsen, P. Siret and J.-L. Gras, J. Am. Chem. Soc., 100, 8034 (1978).

33. L. Lombardo and L.N. Mander, J. Am. Chem. Soc., 102, 0000 (1980) .

34. L. Lombardo, L.N. Mander and J.V. Turner, ibid., 102, 0000 (1980)

35. L. Lombardo and L.N. Mander, ibid., 102, 0000 (1980).

36. B.E. Cross, J.F. Grove and A. Morrison, J. Chem. Soc., 2498 (1961).

37. J.S. Moffat, ibid., 3045 (1960).

38. B.E. Cross, J.F. Grove, J. MacMillan, T.P.C. Mulholland and N. Sheppard, Proc. Chem. Soc., 221 (1958).

39. B.E. Cross, J. Chem. Soc., 4670 (1954).

40. E.J. Corey, Quart. Revs., 25, 455 (1971).

41. L.J. Dolby and C.N. Skold, J.Am. Chem. Soc., 96, 3276 (1974); L.J. Dolby and R.J. Milligan, ibid., 88, 4536 (1966).

42. G. Stork and J. Singh, ibid., 101, 7109 (1979).

43. L.N. Mander and S.G. Pyne, ibid., 101, 3373 (1979).

44. L.N. Mander and M. Woolias, unpublished results.

45. S.A. Monti and S.-C. Chen, J. Org. Chem., 44, 1170 (1979).

46. T. Hori and K. Nakanishi, J. Chem. Soc. Chem. Comm., 528 (1969). 
47. Y. Yamada, K. Hosaka, H. Nagaoka and K. Iguchi, ibid., $519(1974)$.

48. Y. Yamada and H. Nagaoka, Synthesis, 577 (1977).

49. E.J. Corey and R.L. Danheiser, Tetrahedron Lett., 4477 (1973) .

50. E.J. Corey, T.M. Brennan and R.L. Carney, J. Am. Chem. Soc., 93, 7316 (1971).

51. M.D. Bachi, J.W. Epstein, Y. Herberg-Minzly and H.J.E. Loewenthal, J. Org. Chem., 34, 126 (1969).

52. H.J.E. Loewenthal and S. Schatzmiller, J. Chem. Soc. Perkin I, 2149 (1975).

53. H.J.E. Loewenthal and S. Schatzmiller, ibid., 944 (1976).

54. A.J. Baker and A.C. Goudie, J. Chem. Soc. Chem. Comm., 951 (1972).

55. A.J. Baker and A.C. Goudie, ibid., 180 (1971).

56. H.O. House, R.C. Strickland and E.J. Zaiko, J. Org. Chem., 41, 2401 (1976).

57. H.O. House and E.J. Zaiko, ibid., 42, 3780 (1977).

58. E.J. Corey, R.L. Danheiser, S. Chandrasekaran, P. Siret, G.E. Keck and J.-L. Gras, J.Am. Chem. Soc., 100, 8031 (1978).

59. E.J. Corey and J.G. Smith, ibid., 101, 1038 (1979).

60. G. Stork, R.K. Boeckmann, Jr., D.F. Taber, W.C. Still and J. Singh, ibid., 101, 7107 (1979).

61. D.W. Johnson and L.N. Mander, Aust. J. Chem., 27, 1277 $(1974)$.

62. D.J. Beames, T.R. Klose and L.N. Mander, ib id., 27, 1269 (1974). 
63. D.J. Beames, L.N. Mander and J.V. Turner, ibid., 27 , 1977 (1974).

64. T.R. Klose and L.N. Mander, ibid., 27, 1287 (1974).

65. Y. Yamada, H. Nagaoka and M. Kimura, Synthesis, 581 (1977) .

66. J.M. Hook, Ph.D. Dissertation, Australian National University, Canberra, 1979.

67. E.J. Corey, R.A. Ellison, T. Hiraoka and M. Narisada, J. Am. Chem. Soc., 92, 396 (1970).

68. A.A. Ponaras, Tetrahedron Lett., 3105 (1976).

69. H.W. Thompson, J. Org. Chem., 36, 2577 (1971).

70. R.M. Lukes, G.I. Poos and L.H. Sarett, J. Am. Chem. Soc., 74, 1401 (1952).

71. J.W. Cook and C.L. Hewett, J. Chem. Soc., 62 (1936).

72. R.A. Barnes and M. Sedlak, J. Org. Chem., 27, 4562 (1962).

73. A.J. Birch and J. Slobbe, Aust. J. Chem., 30, 1045 (1977).

74. B.A.Ferguson, Ph.D. Dissertation, Australian National University, Canberra, 1977.

75. J.D. Billimoria and N.F. Maclagan, J. Chem. Soc., 3257 (1954) .

76. J.R. Cannon, T.M. Cresp, B.W. Metcalf, M.V. Sargent and J.A. Elix, J. Chem. Soc. (C), 3495 (1971).

77. A. Mathieu, Bulz. Soc. Chim. Fr., 1533 (1971).

78. R.L. Shriner and E.C. Kleiderer, "Organic Synthesis" Coll. Vol. II, ed. A.H. Blatt, John Wiley and Sons, Inc., N.Y., 1943, P.538.

79. T. Sala and M.V. Sargent, J. Chem. Soc. Chem. Comm., $253(1978)$. 
80. W.R. Allison and G.T. Newbold, J. Chem. Soc., 3335 (1959).

81. L.N. Mander, personal communication.

82. J.F.W. Mcomie, "Protective Groups in Organic Chemistry", Plenum Press, London, 1973, pp.98-114.

83. J.A. Elix and B.A.Ferguson, Aust. J. Chem., 31, 1041 (1978).

84. R.M. Anker and A.H. Cook, J. Chem. Soc., 311 (1945).

85. T.M. Harris and J.V. Hay, J. Am. Chem. Soc., 99, 1631 (1977) .

86. E. Müller and W. Rundel, Angew. Chem., 70, 105 (1958);

E. Müller, M. Bauer and W. Rundel, Z. Naturforschung, 14B, 209 (1959).

87. E. Müller, R. Heischkeil and M. Bauer, Ann., 677, 55 (1964).

88. C.D. Gutsche, Org. React., 8, 364 (1954).

89. A.L. Cossey and L.N. Mander, Tetrahedron Lett., 969 (1979).

90. L. Lombardo and L.N. Mander, Synthesis, in press.

91. R.H.B. Galt and J.R. Hanson, J. Chem. Soc., 1565 (1965).

92. P. Hedden, J. Macmillan and B.O. Phinney, J. Chem. Soc. Perkin I, 587 (1974).

93. M. Node, H. Hori and E. Fujita, ibid., 2144 (1976).

94. T.R. Klose, Ph.D. Dissertation, The University of Adelaide, 1971.

95. J. Libman, M. Sprecher and Y. Mazur, Tetrahedron, 25 , 1679 (1969).

96. L.K. Osanova and V.B. Piskov, Sintez Prirodn. Soedin., ikh Analogov i Fragmentov, Akad. Nauk SSSR, otd, Obshch. i Tekhn. Khim., 50 (1965); C.A., 65, 3782a (1966). 
97. F.M. Hauser and R. Rhee, Synthesis, 245 (1977).

98. D.J. Crispin, A.E. Vanstone and J.S. Whitehurst, J. Chem. Soc. (C), 10 (1970).

99, P.E. Pfeffer, L.S. Silbert and J.M. Chirinko, J. Org. Chem., 37, 451 (1972).

100. The syntheses of these and further hydrophenanthrenones have been published: J.M. Hook, L.N. Mander and R. Urech, Synthesis, 374 (1980).

101. A.J. Birch, P.L. Macdonald and V.H. Powell, J. Chem. Soc. (C), 1469 (1970).

102. I.A. Blair, A. Ellis, D.W. Johnson and L.N. Mander, Aust. J. Chem., 31, 405 (1978).

103. P.A. Bartlett and W.S. Johnson, Tetrahedron Lett., 4459 (1970).

104. L.N. Mander and M. Woolias, unpublished results.

105. A.F. Kluge, K.G. Untch and J.H. Fried, J.Am. Chem. Soc., 94, 7827 (1972).

106. E.J. Corey, J.-L. Gras and P. Ulrich, Tetrahedron Lett., $809(1976)$.

107. R. Scheffold, L. Révész, J. Aebersold and A. Schaltegger, Chimia, 30, 57 (1976).

108. M. Gunter, personal communication.

109. H.J.E. Loewenthal, letter to L.N. Mander.

110. A.J. Baker, letter to L.N. Mander.

111. D. Kelly, personal communication.

112. J.F. Grove and T.P.C. Mulholland, J. Chem. Soc., 3007 (1960). 
113. Cf. H.J.E. Loewenthal, "Guide for the Perplexed Organic Experimentalist", Heyden, London, 1978, pp.133-136.

114. S.G. Pyne, Ph.D. Dissertation, Australian National University, Canberra, 1979.

115. H.W. Thompson and T.E. Naipawer, J. Org. Chem., 37, 1307 (1972).

116. H.O. House, "Modern Synthetic Reactions", 2nd ed., Benjamin, Inc., London, 1972, pp.504-507.

117. A.J. Kresge, H.L. Chen, Y. Chiang, E.Murrill, M.A. Payne and D.S. Sagatys, J. Am. Chem. Soc., 93, 413 (1971).

118. Cf. ref. 113, pp.136-138.

119. A.J. Kresge and Y. Chiang, J. Am. Chem. Soc., 95, 803 (1973).

120. H. Yuki, K. Hatada and K. Nagata, Bull. Soc. Chem. Japan, 43, 1817 (1970).

121. W.G. Dauben, C.P. Baskin and H.C.H.A. van Riel, J. Org. Chem., 44, 1567 (1979).

122. M.J.V. de Oliveira Baptista, A.G.M. Barrett, D.H.R. Barton, M. Girijavallabhan, R.C. Jennings, J. Kelly, V.J. Papadimitriou, J.V. Turner and N.A. Usher, J. Chem. Soc. Perkin I, 1477 (1977).

123. C.A. Bunton "Nucleophilic Substitution at a Saturated Carbon Atom", Elsevier, Amsterdam, 1963, pp.25-31.

124. A.F. McKay, W.L. Ott, G.W. Taylor, M.N. Buchanan and J.F. Crooker, Can. J. Res. (Sec.B), 28, 683 (1950).

125. G. Massiot, H.-P. Husson and P. Potier, Synthesis, 722 $(1974)$. 
126. J.W. Emsley, J. Feeney and L.H. Sutcliff, "High Resolution Nuclear Magnetic Resonance Spectroscopy", Vol.2, Pergamon Press, Oxford, 1966, pp.700-710.

127. H.G. Kuivila, Synthesis, 499 (1970).

128. J.R. Hanson, ibid., 1 (1974).

129. D.H.R. Barton, N.K. Basu, R.H. Hesse, F.S. Morehouse, M.M. Pechet, J. Am. Chem. Soc., 88, 3016 (1966).

130. Compounds 194, 13-deoxy-194 and 196, al1 derived from natural gibberellins, were generously provided by

A. L. Cossey and L.N. Mander.

131. J.R. Hanson, J. Chem. Soc., 5036 (1965).

132. L.M. Jackmann and S. Sternhell, "Applications of Nuclear Magnetic Resonance spectroscopy in Organic Chemistry", 2nd ed., Pergamon Press, Oxford, 1969, p.164.

133. This total synthesis of gibberellic acid has been submitted for publication (J.M. Hook, L.N. Mander and R. Urech) as a communication to J. Am. Chem. Soc.

134. G.W. Kenner and N.R. Williams, J. Chem. Soc., 522 (1955).

135. D.R. Burfield, G.-H. Gan and R.H. Smithers, J. Appl. Chem. Biotechnol., 28, 23 (1978); D.R. Burfield and R.H. Smithers, J. Org. Chem., 43, 3966 (1978).

136. F. Uhlig and H.R. Snyder, "Advances in Organic Chemistry: Methods and Results", Vol. I, ed. R.A. Raphael et al., Interscience, Inc., N.Y., 1960, pp.35-81; F.D. Popp and W.E. McEwen, Chem. Rev., 58, 321 (1958).

137. L.F. Fieser and M. Fieser, "Reagent for organic Synthesis", Vol. 1, J. Wiley and Sons, Inc., N.Y., 1967, pp. 191-195. 
138. Chemical Abstracts, 9th Collective Index, (Chemical Substances) $\underline{76}-\underline{85}, 15738 \mathrm{CS}$ (1972-1976).

139. Chemical Abstracts, 9th Collective Index, (Chemical Substances) $\underline{76}-\underline{85}, 17235 \mathrm{CS}$ (1972-1976).

140. A. Bhati, Tetrahedron, 18, 1519 (1962).

14l. H.E. Zimmermann and V.R. Sandel, J.Am. Chem. Soc., 85, $915(1963)$.

142. J. Santesson, Acta Chem. Scand., 24, 3373 (1970).

143. "Dictionary of Organic Compounds", 4th ed., ed. H.M. Bunburry, Eyre and Spottiswoode Ltd., 1965, p.1113.

144. J. Herzig, F. Wenzel and P. Kurzweil, Monatsh. Chemie, 24, $898(1903)$.

145. V.B. Piskov, J. Org. Chem. U.S.S.R., I, 1254 (1965).

146. F. Grosser, Z. Naturf., 3B, 380 (1948).

147. O.L. Chapman and P. Fitton, J. Am. Chem. Soc., 85, 41 (1963).

148. W.C. Still, M. Kahn and A. Mitra, J. Org. Chem., 43 , $2923(1978)$.

149. R.J. Cregge, J.L. Hermann, C.S. Lee, J.E. Richman and R.H. Schlesinger, Tetrahedron Lett., 2425 (1973).

150. J.M. Hook and L.N. Mander, J. Org. Chem., 45, 1722 (1980). 